\title{
Large artery properties and cardiovascular risk : a population study
}

Citation for published version (APA):

van der Heijden-Spek, J. J. (2000). Large artery properties and cardiovascular risk : a population study. [Doctoral Thesis, Maastricht University]. Unigraphic. https://doi.org/10.26481/dis.20001116jh

Document status and date:

Published: 01/01/2000

DOI:

10.26481/dis.20001116jh

Document Version:

Publisher's PDF, also known as Version of record

\section{Please check the document version of this publication:}

- A submitted manuscript is the version of the article upon submission and before peer-review. There can be important differences between the submitted version and the official published version of record.

People interested in the research are advised to contact the author for the final version of the publication, or visit the DOI to the publisher's website.

- The final author version and the galley proof are versions of the publication after peer review.

- The final published version features the final layout of the paper including the volume, issue and page numbers.

Link to publication

\footnotetext{
General rights rights.

- You may freely distribute the URL identifying the publication in the public portal. please follow below link for the End User Agreement:

www.umlib.nl/taverne-license

Take down policy

If you believe that this document breaches copyright please contact us at:

repository@maastrichtuniversity.nl

providing details and we will investigate your claim.
}

Copyright and moral rights for the publications made accessible in the public portal are retained by the authors and/or other copyright owners and it is a condition of accessing publications that users recognise and abide by the legal requirements associated with these

- Users may download and print one copy of any publication from the public portal for the purpose of private study or research.

- You may not further distribute the material or use it for any profit-making activity or commercial gain

If the publication is distributed under the terms of Article $25 \mathrm{fa}$ of the Dutch Copyright Act, indicated by the "Taverne" license above, 
Large artery properties and cardiovascular risk:

a population study 
(C) Janneke van der Heijden-Spek, Maastricht 2000

ISBN 90-5681-083-9

Unigraphic, Maastricht 


\title{
Large artery properties and cardiovascular risk: a population study
}

\author{
PROEFSCHRIFT
}

ter verkrijging van de graad van doctor aan de Universiteit Maastricht,

op gezag van de Rector Magnificus,

Prof. Dr. A.C. Nieuwenhuijzen Kruseman, volgens het besluit van het College van Decanen, in het openbaar te verdedigen op donderdag 16 november 2000 om 14.00 uur

door

Jannie Jacoba van der Heijden-Spek

geboren op 21 juli 1967 te Schoonhoven 


\section{Promotores:}

Prof. dr. H.A.J. Struijker Boudier

Prof. dr. L.M.A.B. Van Bortel (Universiteit Gent, België)

\section{Co-promotor:}

Dr. J.A. Staessen (Universiteit Leuven, België)

\section{Beoordelingscommissie:}

Prof. dr. J.W. van Ree (voorzitter)

Prof. dr. K.M.L. Leunissen

Prof. dr. R.S. Reneman

Prof. dr. M. Safar (Service de Médecine Interne, Paris, France)

Dr. C.D.A. Stehouwer (Vrije Universiteit Amsterdam)

Publication of this thesis was financially supported by the Dr. Saal van Zwanenbergstichting, Astra Zeneca, Pie Medical Benelux and Servier Nederland.

Financial support by the Netherlands Heart Foundation for the publication of this thesis is greatfully acknowledged. 
Aan: mijn ouders

Harry en Floris 


\section{Abbreviations}

$\begin{array}{ll}\text { BA } & \text { brachial artery } \\ \text { BMI } & \text { body mass index } \\ \text { CC } & \text { cross-sectional compliance } \\ \text { CCA } & \text { common carotid artery } \\ \text { D } & \text { diameter } \\ \text { DBP } & \text { diastolic blood pressure } \\ \text { DC } & \text { distensibility coefficient } \\ \text { FA } & \text { femoral artery } \\ \text { IDDM } & \text { insulin-dependent diabetes mellitus } \\ \text { InsR } & \text { insulin resistance } \\ \text { MAP } & \text { mean arterial pressure } \\ \text { PWV } & \text { pulse wave velocity } \\ \text { SBP } & \text { systolic blood pressure }\end{array}$




\section{Contents}

Chapter 1 Introduction 9

$\begin{array}{lll}\text { Chapter } 2 & \text { Methods and subjects } & 41\end{array}$

Chapter 3 The effect of age on brachial artery wall properties differs from the aorta and is gender-dependent: a population study 49

Chapter 4 Disparate effects of age and gender on the wall properties of elastic and muscular large arteries: a population study

Chapter 5 Menopause and the characteristics of the large arteries in a population study

Chapter 6 Obesity, fat distribution and vessel wall properties

Chapter 7 Relation between insulin resistance and large artery properties

Chapter 8 The effect of insulin-dependent diabetes mellitus on large artery wall properties

Chapter 9 General discussion

Chapter 10 Summary

Chapter 11 Samenvatting

Dankwoord 



\title{
CHAPTER 1
}

\author{
Introduction
}


In Western countries cardiovascular disease remains the main cause of death in the population 1. Cardiovascular disease comprises several entities like myocardial infarction, heart failure, stroke and peripheral vascular disease. Several risk factors for the development of cardiovascular disease have been identified: age, male gender, blood pressure, hyperlipidemia, smoking, obesity and diabetes mellitus ${ }^{2}$. The precise role of these risk factors in atherogenesis and how and why plaques form are still not fully understood. Large artery properties might also play a role in this process.

\section{ATHEROSCLEROSIS}

The earliest lesions of the arterial wall which are thought to relate to atherosclerosis are the fatty streaks, seen in children from three years of age. At about twenty years fibro-fatty plaques appear, consisting of a core of lipid and cellular debris, surrounded by a fibromuscular plaque, containing proliferated smooth muscle and collagen and elastic tissue ${ }^{2}$. Later these plaques undergo progressive changes; hemorrhages and ulceration. These changes reduce the lumen size and predipose to thrombosis and plaque rupture, which may acutely occlude the arterial lumen.

Atherosclerosis mainly affects large arteries ${ }^{3}$ and is mostly located at branches or bifurcations. The cause of the development of atherosclerosis is unknown. One important theory is the response to injury theory; a disturbance in flow pattern causes chronic minimal injury to the endothelium, leading to the development of atherosclerosis ${ }^{2,4}$. Most studies on atherosclerosis focus on atherosis. Information on sclerosis, the stiffening of arteries, is more scarce ${ }^{5}$. According to a theory by O'Rourke, this stiffness can be caused by material fatigue of the arterial wall, caused by changes in arterial pressure during each heart cycle ${ }^{6}$.

\subsection{LARGE ARTERY WALL PROPERTIES}

\subsubsection{Arterial tree}

The arterial system is a complex network of elastic and muscular tubes, whose diameter varies with the pulsating pressure ${ }^{7}$. Large arteries have two special and specific functions; a conduit and a buffering function. The conduit function makes that blood from the heart is delivered from central to peripheral arteries with a minimal fall in mean arterial pressure. The conduit function is efficient because of wide arterial calibre and corresponding low resistance ${ }^{8}$. The buffering function dampens the pressure oscillations which are a consequence of the heart's intermittent action, making the flow to the tissues more continuous and less pulsatile. This latter function is a result of the visco-elastic properties of the arterial wall.

\subsubsection{Definitions}

Two important vessel wall properties are distensibility and compliance. In the literature the term arterial compliance often refers to compliance as well as distensibility. This confusion remained until a few years ago, since no good techniques were available to accurately measure both vessel wall properties separately. Compliance and distensibility are, however, quite different. Distensibility, defined as the relative change in volume per unit of pressure, reflects the strain on the arterial wall exerted by the stress ${ }^{9}$, while compliance, defined as the change in volume per unit of pressure, reflects the capacity to store volume ${ }^{7,10}$. Arterial compliance 
(C) is related to arterial distensibility (D) and arterial volume (V) by the formula $\mathrm{C}=\mathrm{DxV}^{7}$.

\subsubsection{Clinical importance}

Compliance reflects the buffering capacity of the artery ${ }^{11}$. Arterial compliance and total peripheral resistance are major determinants of cardiac afterload ${ }^{11}$. A decrease in compliance leads to an increase in pulse pressure (and systolic pressure) and contributes to a higher (mechanical) afterload of the heart ${ }^{12-14}$. An increase in pulse pressure has been shown to be associated with an increased cardiovascular morbidity ${ }^{15}$. An increase in cardiac afterload enhances the risk for cardiac hypertrophy and heart failure ${ }^{16}$. By increasing pulse pressure, a decrease in arterial compliance may also have deleterious effects on coronary dynamics. It will lower diastolic pressure, while it increases systolic pressure, having practically no effect on mean arterial pressure levels and cardiac output. This means that coronary driving pressure may fall although oxygen requirements remain the same or may even increase because of cardiac hypertrophy and increased systolic pressure ${ }^{17}$.

Distensibility is considered a determinant of pulsatile stress on the vessel wall. Pulsatile stress induces degeneration of vascular media ${ }^{18}$. It is also thought to be a significant risk factor for endothelial lesions and plaque rupture, important features in atherosclerotic disease ${ }^{19}$. Consequently preservation of vessel wall properties might be important in protecting the arterial wall at a particular arterial site ${ }^{20}$.

\subsubsection{Determinants of large artery properties}

Arterial distensibility has both structural and functional determinants: distensibility depends on the blood pressure level and on the intrinsic elastic properties of the material which composes the arterial wall and the amount of this material ${ }^{13}$. The arterial wall is divided into three layers: the tunica intima, tunica media and tunica adventitia. The intima may contribute to arterial wall stiffness by releasing vasoactive substances such as nitric oxide and endothelin, which have effects on smooth muscle (see later). The tunica media comprises the largest part of the wall and is the principal determinant of the vessel's mechanical properties ${ }^{7}$. Collagen and elastin are the predominantly elastic materials of the arterial wall. The arterial wall is regarded as a two phase structure: at low distending pressure the tension is borne by the relatively distensible elastin fibres, while at a high distending pressure the tension is mainly borne by the less extensible collagen fibres and the arterial wall becomes stiffer ${ }^{13,21}$. This means that the behaviour of arterial stiffness is non-linear and compliance and distensibility depend on the level of blood pressure, i.e. with an increase in blood pressure, the arterial wall becomes stiffer. The arterial tree is not a homogeneous system; the distribution of collagen and elastin differs between arteries. In the proximal aorta elastin is the dominant component, while towards the periphery collagen dominates ${ }^{7,22-24}$.

Another important constituent of the arterial wall is smooth muscle ${ }^{7}$. Although smooth muscle is largely responsible for viscosity of the arterial wall, it also contributes to its stiffness by modulating the tension of elastic fibres ${ }^{13,25}$ and by regulating arterial caliber and volume ${ }^{26}$. During contraction, the muscle transfers the circumferential tension from the collagen to itself and elastin, thereby increasing the extensibility of the vessel ${ }^{27}$. This effect is most marked in peripheral muscular arteries and least marked in the central elastic aorta ${ }^{10}$. The nonlinear elastic behaviour of the arterial wall, nonuniform elastic properties of different arteries, different effects of smooth muscle on arterial stiffness and diameter, and viscosity of 
the arterial wall makes it difficult to measure and interpret arterial wall properties. In the assessment of arterial wall properties important considerations are: which arterial territory was measured, at which pressure (isobaric) or pressure range (operating pressure) were the wall properties measured and has some medication, like vasodilatory drugs been used ?

\subsubsection{Techniques to measure large artery properties}

The first data on vessel wall properties were derived from isolated vessels ${ }^{28}$, later followed by animal experiments ${ }^{29-31}$. Since compliance in animals was estimated by invasive techniques and under anesthesia, these data cannot be fully extrapolated to the human, in vivo, situation. Nowadays different aspects of vessel wall properties can be measured in vivo using noninvasive techniques.

\section{Total/Systemic compliance}

Total or systemic arterial compliance $(C)$ is an estimate of compliance of the whole arterial tree. Three methods are known. Firstly it has been estimated from stroke volume (SV) and pulse pressure (PP) by the formula $\mathrm{PP}=\mathrm{SV} / \mathrm{C}^{32}$. This method, however, does not take into account the velocity of ejection of the blood from the heart and the reflected waves. Total arterial compliance is also estimated via simple models of the arterial circulation, using analysis of the blood pressure wave. During diastole the aortic valves are closed, as a result of which the diastolic waveform can be considered as a response of the arterial system to the pressure changes occurring in systole ${ }^{33}$. In this case the general shape of the pressure curve commonly assumes a simple monoexponential form. This monoexponential decline in pressure can be used to calculate arterial compliance, based on a "Windkessel model" ${ }^{33}$ (second method) or an analog model, the electrical RC model, associating in series a single capacitance $(\mathrm{C})$ and a single resistance (R) (third method) ${ }^{34}$. Arterial compliance is the ratio between the time constant of the diastolic decay and the calculated vascular resistance ${ }^{33-35}$. The limitations of these models are that pressure oscillations are considered to occur simultaneously in all parts of the arterial tree. However, pressure changes do not occur at the same time, since pulse wave velocity varies between arteries. In addition, in these models wave reflections in the arterial tree are overlooked ${ }^{36}$.

\section{Regional compliance}

Regional compliance describes compliance in an arterial segment. It can be calculated from arterial volume and distensibility. Regional distensibility can be assessed by measuring pulse wave velocity ${ }^{22}$. Distensibility (DC) and pulse wave velocity (PWV) are inversely related ${ }^{37}$ by the Moens-Korteweg equation: $P W V=\sqrt{ } 1 / \rho D C$, in which $\rho$ is the blood density ${ }^{38}$. Since diameter of an arterial segment is not constant, from PWV only regional distensibility and not regional compliance can be assessed accurately. Pulse wave velocity may be measured with transit time techniques. It is measured from the foot of pressure waves recorded at two points along the arterial tree and calculated as $\mathrm{L} / \mathrm{dt}$, where $\mathrm{L}$ is the distance between the two measuring sites and dt is the time delay ${ }^{7,39}$. The distance is mostly measured with a tape measurer, which is not very precise. The PWV method also does not distuingish the increased pulse wave velocity due to general or more localized stiffening, for instance caused by local plaque formation ${ }^{40}$. Pulse wave velocity is primarily determined by vascular elasticity, but the results are also affected by blood density, velocity of ejection, mean blood pressure and arterial wall 
thickness $^{41}$.

\section{Local compliance}

Noninvasive ultrasonic measurements of vessel diameter and diameter changes were first described by Arndt and coworkers, who used an A-mode technique ${ }^{42}$. Since this first publication several groups have developed different ultrasound techniques to measure local compliance non-invasively. These techniques were based on B-mode ${ }^{43}, \mathrm{M}$-mode ${ }^{44,45}$, continuous wave ${ }^{46}$, pulsed wave Doppler ${ }^{47,48}$ and multigate pulsed Doppler ${ }^{49,50}$. Most of these techniques are time-consuming, inaccurate and have several limitations ${ }^{40}$. In 1972, Hokanson developed a new method which accurately measured diameter changes during the heart cycle. This was possible by using the phase of the radiofrequency signal and positioning of windows at both arterial walls ${ }^{51,52}$. A few years later Hoeks and coworkers developed a system based on tracking the position of the vessel wall during the heart cycle, using this radiofrequency signal ${ }^{40,50}$. With this system diameter and stroke change in diameter of various large arteries can be measured accurately. Blood pressure is measured simultaneously. Assuming that during the heart cycle arteries predominantly change in diameter and not much in length, cross-sectional compliance, defined as arterial compliance per unit of length, can be used as an estimate of local compliance. From diameter, stroke change in diameter and pulse pressure cross-sectional compliance and distensibility coefficient can be calculated. Compared to other techniques, the advantage of this technique is that different vascular territories can be measured and both compliance and distensibility can be calculated.

Simultaneously Tardy and coworkers developed a new A-mode echo-tracking device to measure vessel wall properties of distal large arteries ${ }^{53}$. With this technique radial artery diameter and stroke change in diameter are measured together with blood pressure measurements at the finger with a Finapress device ${ }^{54,55}$. Lately, besides these ultrasound techniques, magnetic resonance imaging is also used to measure arterial dimensions ${ }^{56,57}$. This method however is very expensive and time-consuming.

The weakness of the echo-tracking techniques is the assessment of pulse pressure at the site of the measurement. However if a good relation between pulse pressure in target and surrogate arteries exists, the error may be proportional. Consequently if pulse pressure in target and surrogate arteries behave similarly, results of comparative studies may demonstrate quite accurately changes in vessel wall properties, despite the fact that absolute values of vessel wall properties may be incorrect ${ }^{20}$. Several studies described a good relation between carotid and brachial artery pulse pressure ${ }^{58,59}$. It is however known that pulse wave reflections may boost pulse pressure in the carotid artery, but not in the brachial artery ${ }^{10}$. This may disturb the relation between brachial and carotid artery pulse pressures. The relation between brachial and carotid pulse pressure is also not constant, for example the timing and magnitude of pulse wave reflections can be altered by vasodilatory drugs, ageing, mental stress etc, leading to a different relation between brachial and carotid pulse pressure.

Until now no accurate method exists to measure blood pressure non-invasively at the carotid or femoral artery. A non-invasive technique to measure local pulse pressure has been proposed: applanation tonometry ${ }^{60,61}$. Benetos and coworkers found a good correlation between brachial artery and femoral artery pulse pressure recorded with this technique ${ }^{24}$. This method however requires a lot of skill and cannot be applied in all subjects (for instance obese subjects) and for all arteries. At the moment attempts are made to measure local pulse pressure 
and diameter simultaneously with ultrasound techniques, but these methods still have to be evaluated ${ }^{9}$. Calculation of the pulse pressure of a central artery with the amplitude and contour of the pressure wave of a peripheral artery may also be promising ${ }^{62}$.

\subsubsection{Variability}

Blood pressure and heart rate vary over the day ${ }^{63}$. A similar diurnal pattern has been found for vessel wall properties of elastic and muscular large arteries. Distensibility appears to decrease during the night, while diameter increases, resulting in no change in compliance from day to night ${ }^{64}$. As a consequence in longitudinal studies, patients have to be measured at the same time of the day. This applies not only for local, but also for systemic and regional compliance. Apart from a day-night rhythm, also short-term variations in elastic properties have been reported ${ }^{65}$. These short-term variations, observed in the femoral artery, could be caused by changes in vascular tone ${ }^{65}$. Hayoz et al reported a vasomotion pattern in radial arteries of healthy volunteers; this fluctuation in diameter is flow-related ${ }^{66}$.

The effect of vascular smooth muscle tone on arterial wall properties is not clear. Sympathetic stimulation, using mental stress and cold pressure tests, was found to increase ${ }^{67}$ and decrease radial artery distensibility and compliance ${ }^{68}$. The increase could be caused by the decrease in diameter, which unloads collagen fibers in favor of elastin. Subjects using the vascoconstrictor ergotamine, showed a lower carotid distensibility compared to subjects not taking it ${ }^{69}$, while there was no difference in blood pressure or wall thickness. Smooth muscle relaxation with nitroglycerin increases brachial artery compliance, with no effect on brachial artery distensibility ${ }^{70}$. Pharmacological blockade of the brachial plexus also increased radial artery compliance ${ }^{71}$, with no effect on arterial diameter. Modulators of vascular muscle tone may thus influence large artery function. The effect may depend on the vascular territory ${ }^{20}$.

\subsection{RELATION AND INFLUENCE OF CARDIOVASCULAR RISK FACTORS}

This section describes not only the relation between vessel wall properties and well-known cardiovascular risk factors (hypertension, smoking, hyperlipidemia and diabetes mellitus), but also the relation with other factors that might directly or indirectly influence cardiovascular risk, such as age, gender and exercise.

\subsubsection{Age}

The effect of age on elastic properties of the arterial system was firstly investigated by Roy in $1880^{72}$. These studies were in vitro studies ${ }^{73-75}$, later followed by in vivo measurements using pulse wave velocity techniques ${ }^{22,41,76}$. In the past decade several ultrasound studies concerning this issue have been described. Most of these studies focused on proximal, elastic arteries, like the aorta and common carotid artery. The major changes described with ageing are arterial dilatation, increase in wall thickness and decrease in elasticity $22-24,41,49,73,76-83$. Aortic distensibility seems to reach its peak at about 10 years of age ${ }^{22}$, and starts to decrease in the 3rd age decade ${ }^{49,74}$.

The mechanism by which ageing can cause a decrease in distensibility is not fully clear. There are several possibilities: 
1. Degeneration of elastic fibers and a parallel increase in collagen: The cyclic stress on the elastic fibers can have a fatigueing effect ${ }^{10,84}$, which may result in fracturing of load-bearing elastic fibers with stretching and remodeling of the arterial wall ${ }^{10,84}$. This leads to a loss of elasticity and a parallel increase in collagen and mucopolysaccharide.

2. Increase in vascular muscle mass: With age vascular smooth muscle cells accumulate in the arterial wall, which may lead to a decrease in arterial distensibility.

3. Atherosclerosis: Development of atherosclerosis could play a role ${ }^{84,85}$. This is however contradicted by the fact that in a population without atherosclerosis (Chinese population) compliance also decreases with age ${ }^{41}$.

4. Early and advanced wave reflections: Early wave reflections can increase pulse pressure, which could lead to a lower distensibility ${ }^{86}$.

The stiffening of the aorta and its major branches with age leads to a widening of pulse pressure and a progressive increase in systolic pressure ${ }^{87}$, implicating a higher cardiovascular risk.

The arterial tree comprises also (predominantly) muscular arteries, like the brachial and femoral arteries. Some smaller studies reported conflicting results on the effect of ageing on muscular arteries $24,51,77,80,83,88$. For instance some authors reported an increase in femoral diameter with age ${ }^{51,80}$, while others found no relation between age and arterial diameter ${ }^{24,77}$. From these studies it appears that ageing might have different effects on proximal and distal arteries, although other reasons, like differences in (small) study populations cannot be excluded.

\subsubsection{Gender}

Male gender is a cardiovascular risk factor, even after controlling for other risk factors ${ }^{89}$. Large artery wall properties differ between men and women. Women have smaller diameters of all arteries ${ }^{23,24,75,77,90}$. One of the explanations is that arterial calibre is influenced by body size (height) ${ }^{78,91}$, and the size of women is relatively smaller than men. The influence of gender on arterial stiffness is inconsistent across the published reports $22,24,57,78,90,92$. Again, most studies focussed on elastic arteries, while the effect of gender on muscular arteries is ill defined 77,88 . An explanation for the differences in large artery properties between men and women might be the effect of estrogens (see 1.3.10). The gender difference in vessel wall properties might contribute to the difference in cardiovascular risk between men and women.

\subsubsection{Race}

Prevalence of hypertension and mortality from hypertension related diseases (stroke) is higher among Africans than Caucasians ${ }^{93}$. Whether this is caused by an increased stiffness was investigated in a small number of studies. Two studies described no difference in aortic distensibility between Asian and Caucasian or Nigerian and Caucasian subjects, both living in the same country ${ }^{94}$. However in a recent cross-sectional study, aortic stiffness was lower in normotensive blacks than normotensive whites ${ }^{95}$. In hypertensive subjects however, blacks exhibited a higher stiffness than their white counterparts. In the latter study, several explanations for this phenomenon were given: different composition of the wall, different genetic factors (e.g. renin-angiotensin system), differences in vasodilatory capacity or differences in salt-sensitivity. Since the number of studies is small and the results of the studies inconsistent, further studies are necessary. 


\subsubsection{Hypertension}

Hypertension, defined as a resting systolic blood pressure $\geq 140 \mathrm{mmHg}$ and a diastolic blood pressure $\geq 90 \mathrm{mmHg}^{96}$, is a powerful and independent cardiovascular risk factor ${ }^{97}$. Epidemiological studies have shown that mortality and morbidity caused by hypertension are better related with the systolic than with the diastolic blood pressure ${ }^{97,98}$. This suggests that pulsatile stress (pulse pressure) plays an important role in the ill effects of hypertension. As mentioned before, arterial compliance is an important determinant of pulsatile stress. Blood pressure is known to be a major determinant of arterial distensibility ${ }^{21}$. A high blood pressure by itself can decrease arterial distensibility ${ }^{10}$. This was first appreciated by Frank in $1905^{99,100}$. Since pathological arterial wall changes similar to those of ageing are seen in hypertensive subjects at an earlier age, hypertension is often considered to accelerate ageing of large arteries ${ }^{101}$. In general arterial distensibility and compliance of the elastic ${ }^{33,102-104}$ and muscular ${ }^{105,106}$ arteries, measured at operating pressure, are lower in hypertensive subjects. Arterial diameter increases in hypertension ${ }^{102,107}$, possibly to compensate for the loss in distensibility, to limit the decrease in compliance. Two different mechanisms for a decrease in distensibility have been suggested: 1 . structural changes due to arterial degeneration (primary defect) or 2 . functional changes due to the distending pressure per se ${ }^{101}$.

No decrease in vessel wall properties of elastic ${ }^{101,106}$ and muscular ${ }^{108-110}$ large arteries in hypertensive compared to normotensive subjects were shown, when the subjects had been studied at the same blood pressure (isobaric wall properties). This suggests that the decrease in wall properties seen in hypertensives could be explained by an increase in pressure per se and that mechanical alterations of conduit arteries are not causal in the development of hypertension. At the same mean arterial pressure, distensibility and compliance of the muscular radial artery in hypertensives were also equal or even higher compared to normotensives 111. The authors suggested this possible increase could be due to hypertension-related hypertrophy of vascular smooth muscle, which decreases the relative amount of collagen in the vessel wall ${ }^{111}$. Later the same group discriminated different hypertensive patients: subjects with hypertrophy and subjects with remodeling of the radial artery ${ }^{112}$. In the first group isobaric radial artery compliance was increased, while in the latter radial artery compliance was not different ${ }^{112}$, indicating that compliance depends on the hypertrophy or remodeling pattern. In contrast to these results another study showed lower isobaric compliance and distensibility of the femoral artery in hypertensive subjects ${ }^{106}$. The stiffening might thus not only be the result of pressure elevation, but can also be an intrinsic pressure-independent change of large artery properties caused by alterations of the vessel wall. These alterations could be functional or structural. Functional changes are increases in vasomotor tone, changes in endothelial function and activation of the renin-angiotensin system ${ }^{113}$. Structural changes include an increase in wall thickness ${ }^{113}$.

There also seems to be a difference between essential hypertensives and subjects with systolic hypertension, the first showing lower carotid artery wall properties and higher radial artery wall properties, while in the latter both are markedly reduced ${ }^{114}$.

The stiffening of the aorta and its major branches with hypertension has the same effect as the stiffening with age, namely a progressive increase in systolic pressure and widening of pulse pressure ${ }^{39}$, leading to an increase of the cardiovascular risk. A recent report of the ARIC study showed that a decrease in carotid artery stiffness is associated with a higher risk to develop hypertension, suggesting that lower arterial elasticity is related to the development of 
hypertension ${ }^{115}$.

Like in hypertension, also in borderline hypertension (blood pressure between 140/90 and $150 / 95 \mathrm{mmHg}$, subgroup of hypertension ${ }^{96}$ ), compliance and distensibility of large arteries are diminished. This has been described for elastic ${ }^{116-121}$ as well as for muscular ${ }^{121}$ large arteries. Hypertensive subjects can be divided in sodium-sensitive and sodium-resistant subjects, based on the effect of a sodium load on blood pressure ${ }^{122}$. Sodium-sensitive borderline hypertensive subjects have lower compliance and distensibility of the carotid, brachial and femoral arteries compared to sodium-resistant subjects, deviating more from normal controls ${ }^{121}$. The mechanisms underlying these findings are however not clear ${ }^{121}$.

The results considering arterial compliance in subjects with a family-history of hypertension, show some discrepancy, with some reporting lower arterial compliance ${ }^{123}$ and others with no difference compared to control subjects ${ }^{124}$. A lower arterial compliance in these subjects could be due to environmental or genetic effects. Evidence for the latter is given by a study from Benetos et al, showing that AT1 receptor polymorphism $(\mathrm{A} \rightarrow \mathrm{C}$ polymorphism) might be involved: aortic stiffness was higher in CC compared to AA subjects, while aortic stiffness of AC subjects was intermediate ${ }^{125}$.

Antihypertensive drugs have different effects on arterial compliance. Large artery compliance can be increased by calcium antagonists, angiotensin converting enzyme inhibitors, selective $\beta_{1}$-blocking agents with vasodilating properties, diuretics containing thiazides and nitrates ${ }^{126}$. This beneficial effect may, in part, be due to a decrease in blood pressure. The non-selective beta-blocker propranolol and the direct vasodilators of the hydralazine group and the centrally acting $\alpha 2$ - agonist clonidine however do not increase arterial compliance, despite a marked fall in blood pressure ${ }^{127}$. This suggests that these drugs might have a negative effect on large artery wall properties. Antihypertensive drugs might also have a direct positive action on the vessel wall. Evidence for this was given by a study showing a more pronounced increase in arterial compliance with the ACE inhibitor perindopril than with the combined diuretic amiloride-hydrochlorothiazide, with a similar decrease in blood pressure ${ }^{128}$.

The effect of antihypertensive agents may also depend on the vascular territory. For instance the diuretic amiloride-hydrochlorothiazide did not change wall properties of the carotid artery, but did increase brachial artery wall properties ${ }^{128}$. The effects of antihypertensive drugs on large artery properties also depend on the dose of the drug, the duration of treatment and the arterial state (age, coexistence of other diseases) ${ }^{20}$. In addition the effect of antihypertensive drugs on arterial compliance can be different because of different effects on diameter and distensibility.

\subsubsection{Heart rate}

Tachycardia is strongly related to cardiovascular death ${ }^{129}$. The number of studies on the relation between heart rate and arterial stiffness is small. Sa Cunha described a negative relation between heart rate and aortic stiffness and carotid and femoral distension, independent of age and blood pressure ${ }^{130}$. Two recent studies in humans showed, with atrial pacing, a decrease in aortic distensibility and total arterial compliance ${ }^{131,132}$. Part of this could have been explained by an increase in blood pressure. The relation between heart rate and vessel wall properties might be caused by a shortening of time available for recoil, resulting in arterial stiffening ${ }^{7,8}$. 


\subsubsection{Obesity}

Obesity is an independent risk factor for cardiovascular disease ${ }^{133,134}$. Overweight non-smoking subjects have mortality rates up to 4 times higher than those for non-smoking subjects who are at desirable weight ${ }^{135}$. Many studies have shown altered hemodynamics in obese subjects. Cardiac output, stroke volume and circulating blood volume increase with body weight ${ }^{136-138}$, while total peripheral resistance is often lower in obese subjects ${ }^{136}$. Many obese subjects also show an increase in arterial blood pressure ${ }^{136-138}$, because total peripheral resistance did not decrease (enough) to counteract the increase in cardiac output.

The effect of obesity on large artery properties is not clear, some investigators found no effect of obesity on large artery properties, while others found a decrease or increase in arterial distensibility or compliance in obese subjects (Table 1).

Table 1. Studies on the effect of obesity on large artery properties

\begin{tabular}{|c|c|c|c|c|c|}
\hline Author & Artery & Technique & D & DC & CC \\
\hline Mujais $^{57}$ & aorta & PWV & & $=$ & \\
\hline Kupari $^{139}$ & aorta & MRI & & $=$ & \\
\hline Toto-Moukouo $^{140}$ & BA & PWV & & $\downarrow$ & \\
\hline Mangoni $^{141}$ & RA & ultrasound & $\uparrow$ & & $\uparrow$ \\
\hline Oren $^{142}$ & SAC & PP/SV & & & $\uparrow$ \\
\hline Resnick $^{143}$ & aorta & MRI & & $=$ & \\
\hline
\end{tabular}

$\mathrm{D}$, diameter; DC, distensibility coefficient; $\mathrm{CC}$, cross-sectional compliance; BA, brachial artery; RA, radial artery; SAC systemic arterial compliance; PWV, pulse wave velocity; PP/SV pulse pressure divided by stroke volume; MRI, magnetic resonance imaging; =, no change; $\uparrow$, increase; $\downarrow$, decrease

In the study by Resnick, aortic distensibility was significantly and inversely related to abdominal visceral fat ${ }^{143}$. In two studies reduction in body weight led to an improvement of large artery properties ${ }^{140,144}$. Yamashita found an increase in systemic arterial compliance with weight reduction, probably caused by a decrease in blood pressure ${ }^{145}$. The reason for the inconsistency in the data is not known. The same holds for the possible cause of the changes in vessel wall properties in obese subjects. One explanation could be the coïncidence of hyperinsulinemia in obese subjects ${ }^{146}$, which seems to be related to arterial stiffness ${ }^{57,147,148}$.

\subsubsection{Hypercholesterolemia}

Hypercholesterolemia is a well established risk factor for atherosclerosis ${ }^{149}$. Different results on the relation between hypercholesterolemia and vessel wall properties were found, depending on the vascular territory (Table 2)

Table 2 shows there is a difference between mild hypercholesterolemia and familial hypercho- 
lesterolemia $(\mathrm{FH})$. The reduction in arterial diameter and compliance in $\mathrm{FH}$, which is not seen in non-familial hypercholesterolemia, could be due to a genetic mechanism or due to persistent very high cholesterol levels ${ }^{152}$. The effect of hypercholesterolemia might also be related to the duration of increased cholesterol levels.

Table 2 Effect of hypercholesterolemia on large artery wall properties

\begin{tabular}{|c|c|c|c|c|c|c|}
\hline Author & Artery & Technique & Severity & $\mathrm{D}$ & DC & $\mathrm{CC}$ \\
\hline Hayoz $^{150}$ & RA & ultrasound & mild & $=$ & $=$ & $=$ \\
\hline Kool $^{151}$ & $\begin{array}{c}\text { CCA } \\
\text { BA } \\
\text { FA }\end{array}$ & ultrasound & mild & $\begin{array}{l}= \\
= \\
=\end{array}$ & $\begin{array}{l}= \\
= \\
\downarrow\end{array}$ & $\begin{array}{l}= \\
= \\
=\end{array}$ \\
\hline Avolio ${ }^{41}$ & aorta & PWV & mild & & $=$ & \\
\hline $\begin{array}{c}\text { Giannattasio } \\
152,155\end{array}$ & RA & ultrasound & $\begin{array}{l}\text { mild } \\
\text { familial }\end{array}$ & $=$ & $\downarrow$ & $=$ \\
\hline Lehmann ${ }^{153}$ & aorta & PWV & $\begin{array}{l}\text { familial, young } \\
\text { familial, adults }\end{array}$ & & $\begin{array}{l}1 \\
1\end{array}$ & \\
\hline Iannuzzi ${ }^{154}$ & aorta & ultrasound & children & $=$ & $=$ & \\
\hline Toikka ${ }^{156}$ & aorta & ultrasound/MRI & familial & & $=$ & \\
\hline Tomochika ${ }^{157}$ & aorta & ultrasound & familial & $=$ & $\downarrow$ & \\
\hline Pitsavos ${ }^{158}$ & aorta & ultrasound & familial & $=$ & $\downarrow$ & \\
\hline
\end{tabular}

1 , increase; $\downarrow$, decrease; =, no change compared with normocholesterolemic subjects; BA, brachial artery; CCA, common carotid artery; FA, femoral artery; RA, radial artery; D, diameter; DC, distensibility coefficient; $\mathrm{CC}$, cross-sectional compliance; PWV, pulse wave velocity; MRI, magnetic resonance imaging

As can also be seen in Table 2, young subjects (4-20 years) with FH have significantly higher distensibility of the aorta ${ }^{153}$, while adult patients with $\mathrm{FH}$ have a significantly lower aortic distensibility than control subjects ${ }^{153}$. This could be due to the development of early stages of atherosclerosis in these patients, in which it has been suggested that possibly first an increase in distensibility is seen, followed by a decrease of distensibility later in the process ${ }^{159}$.

The change in vessel wall properties in subjects with FH is suggested to be caused by an (1) impaired function or secretion of endothelial relaxing factors, (2) an increased content of collagen and calcium subsequent to deposition of cholesterol in the vessel wall, (3) a potentiating effect of cholesterol on the responsiveness of vascular smooth muscle to sympathetic stimuli or (4) a toxic effect of oxidized lipoproteins ${ }^{155,160}$. The latter (oxidized LDL) is negatively associated with carotid and aortic distensibility in healthy men and subjects with $\mathrm{FH}{ }^{156}$. The difference between non-familial and familial hypercholesterolemia and the effect of 
duration of hypercholesterolemia could explain the inconsistent results.

Lately there is a lot of interest in the influence of lipid-lowering therapy on atherosclerotic lesions. This effect seems to be rather small ${ }^{161}$. Most of these studies focused on the reversal of atherosclerotic plaques. There are only few studies about the effect of lipid-lowering drugs on vessel wall properties. Eight weeks of treatment with a HMG-coA reductase inhibitor did not improve large artery properties of the carotid, brachial and femoral arteries in mildly hypercholesterolemic patients ${ }^{151}$. Since animal experiments have shown that reversal of changes in distensibility in atherosclerosis occur slowly, the duration of this therapy could have been too short to show an effect. A 6 month-treatment with another HMG-coA reductase inhibitor did also not improve vessel wall properties of the radial artery in hypercholesterolemic patients ${ }^{155}$, however after 24 months of therapy radial artery compliance was improved. This was also described for aortic stiffness after 13 months of therapy with a diet and a HMGcoA reductase inhibitor ${ }^{157}$.

\subsubsection{Smoking}

Cigarette smoking is a major risk factor for cardiovascular morbidity and mortality, independent of other risk factors ${ }^{162}$. It is also the most preventable cause of cardiovascular mortality and morbidity. The long term risks of smoking are dose-related, the more one smokes, the greater the risk ${ }^{163}$. The effect of smoking however appears to be reversible; the risk for cardiac death in smokers was comparable to that in non-smokers within 1 year after stopping 162. This was not true for the risk of peripheral arterial disease, which was not completely reversed after cessation of smoking ${ }^{162}$. Smoking has acute (sympathetic) effects on the systemic and coronary circulation: increase in heart rate, blood pressure and myocardial contractility ${ }^{163}$. Besides this, smoking has an effect on the endothelium, platelet function, hemostasis and lipid metabolism ${ }^{163}$. The relation between smoking and large artery stiffness is unclear. Impaired compliance of the arterial system of the lower leg has been described in a group of heavy smokers ${ }^{164}$. On the other hand similar vessel wall properties of the elastic aorta and muscular brachial artery in smokers and non-smokers have been reported ${ }^{165}$. The same result was described for total arterial compliance ${ }^{166}$. In addition, in a population study there was also no relation between smoking and aortic stiffness ${ }^{57}$.

Besides these cross-sectional studies concerning the chronic effect of smoking, there are also some studies about the acute effect of smoking on arterial wall properties. All of these studies reported increased arterial stiffness and decreased compliance of several different arteries after smoking a cigarette ${ }^{165,167-171}$. In some studies the effect was maintained for at least 20 minutes ${ }^{170}$. The decrease in distensibility was probably the resultant of the increase in blood pressure and an active stiffening, due to elevated muscular tone, which might be partially the result of activation of the sympathetic nervous sytem ${ }^{170}$. The increase in heart rate could also be an explanation. This means that after each cigarette the load on the arterial wall increases, which can lead to plaque rupture, an important feature in atherosclerotic disease.

In addition to the hazard of smoking for the smoker him/herself, passive smoking also seems to give an acute deterioration of aortic distensibility ${ }^{172}$.

\subsubsection{Diabetes mellitus}

Diabetes mellitus is a well known risk factor for atherosclerotic diseases such as coronary 
heart disease and peripheral vascular disease ${ }^{173}$. In diabetic patients mortality from heart disease is three times more common than in the normal population and that from peripheral vascular disease five times more common ${ }^{174}$. Several groups studied large artery properties in diabetic patients (Table 3 ).

Table 3 Large artery properties in diabetic patients

\begin{tabular}{|c|c|c|c|c|c|c|c|}
\hline Type & Author & Artery & Technique & D & $\mathrm{DC}$ & $\mathrm{CC}$ & \\
\hline $\begin{array}{c}\text { IDDM } \\
+ \\
\text { NIDDM }\end{array}$ & $\begin{array}{l}\text { Woolam }{ }^{175} \\
\text { Scarpello }\end{array}$ & $\begin{array}{l}\text { BA } \\
\text { BA } \\
\text { TA }\end{array}$ & $\begin{array}{l}\text { PWV } \\
\text { PWV }\end{array}$ & & $\begin{array}{l}\downarrow \\
= \\
= \\
\downarrow\end{array}$ & & $\begin{array}{l}\text { footulcer - } \\
\text { footulcer + }\end{array}$ \\
\hline IDDM & $\begin{array}{c}\text { Oxlund }{ }^{177} \\
\text { Pillsbury } \\
\\
\text { Thordarson } \\
{ }^{179} \\
\text { Lehmann }^{180} \\
\text { Kool }^{181} \\
\text { Christensen } \\
\text { Berry }^{184}{ }^{182-183} \\
\text { Rydén Ahlgren }{ }^{185,186} \\
\text { Lambert }^{187} \\
\text { Zenere }^{188} \\
\text { Giannattasio }\end{array}$ & $\begin{array}{c}\text { aorta } \\
\text { BA } \\
\text { aorta } \\
\text { aorta } \\
\text { aorta } \\
\text { aorta } \\
\text { CCA } \\
\text { FA } \\
\text { BA } \\
\text { FA } \\
\text { total } \\
\text { aorta } \\
\text { CCA } \\
\text { CCA } \\
\text { FA } \\
\text { aorta } \\
\text { CCA } \\
\text { RA }\end{array}$ & $\begin{array}{l}\text { in vitro } \\
\text { PWV } \\
\text { ultrasound } \\
\text { PWV } \\
\text { ultrasound } \\
\\
\text { ultrasound } \\
\text { SV/PP } \\
\text { ultrasound } \\
\text { ultrasound } \\
\text { ultrasound } \\
\text { ultrasound }\end{array}$ & $\begin{array}{l}= \\
= \\
= \\
=\end{array}$ & $\begin{array}{l}1 \\
1 \\
1 \\
1 \\
1 \\
= \\
= \\
1 \\
= \\
1 \\
1 /= \\
1 /= \\
1 \\
= \\
= \\
1 \\
1 \\
= \\
1\end{array}$ & $\begin{array}{l}= \\
= \\
=\end{array}$ & $\begin{array}{c}\text { F/M } \\
\text { F/M } \\
\text { microalb. } \\
\text { normoalb. } \\
\\
\text { compl. } \\
\text { no compl. }\end{array}$ \\
\hline NIDDM & $\begin{array}{l}\text { Lehmann }^{180} \\
\quad{ }^{190}{ }^{190} \\
\text { Wahlquist }{ }^{191} \\
\text { McVeigh }{ }^{192}\end{array}$ & $\begin{array}{l}\text { aorta } \\
\text { aorta } \\
\text { aorta } \\
\text { total }\end{array}$ & $\begin{array}{c}\text { PWV } \\
\text { PWV } \\
\text { PWV } \\
\text { waveform }\end{array}$ & & $\begin{array}{l}\downarrow \\
\downarrow \\
\downarrow\end{array}$ & & $=$ \\
\hline
\end{tabular}

$\uparrow$, increase; $\downarrow$, decrease; =, no change compared with control subjects; BA, brachial artery; CCA, common carotid artery; FA, femoral artery; RA, radial artery; TA anterior tibial artery; Total, total arterial compliance; PWV, pulse wave velocity; SV/PP, stroke volume divided by pulse pressure; D, diameter; DC, distensibility coefficient; CC, cross-sectional compliance; IDDM, insulin-dependent diabetes mellitus; NIDDM, non-insulin-dependent diabetes mellitus; F, female; M, male; alb. albuminuria; compl., complications 


\section{Introduction}

Table 3 shows contradictory results. Some authors describe a lower arterial distensibility in diabetic patients $175,178,179,182,190,191$, while other authors only found a lower distensibility of lower leg arteries in diabetic subjects with peripheral neuropathy and healed or ulcerated feet ${ }^{176}$, or did not find a difference in arterial distensibility between diabetic patients and control subjects ${ }^{181}$. Lehmann and coworkers even described a more distensible aorta in uncomplicated type 1 diabetic patients compared to controls. This was particularly the case in type 1 diabetics, who were measured in the first year after diagnosis. This could be comparable to the increase in distensibility seen in young familial hypercholesterolemic patients ${ }^{153}$. In this study diabetics and controls were however not matched for blood pressure, which could have influenced the results ${ }^{153,180}$. Some authors also described a decrease in arterial compliance in diabetic patients ${ }^{184}$, while others found not ${ }^{181,192}$. A possible cause for the inconsistency in the results of studies about the effect of diabetes on large artery properties could be caused by the fact that most results are based on heterogeneous groups of patients with insulin and noninsulin dependent patients, with or without complications, with variable duration of disease, different types of medication and differences in regulation of the disease. Some authors namely found relations between arterial distensibility and glycemic control ${ }^{190}$ or duration of disease ${ }^{177,179,182,185}$. On the other hand this is disputed by others ${ }^{184,192}$. The presence of complications, like microalbuminuria can also make a difference in the results ${ }^{187,188}$. Besides this there also might be a gender-difference ${ }^{185,186}$. It is not only unclear whether diabetic patients have altered vessel wall properties, the mechanism by which the disease contributes to the atherosclerotic process and the possible increased arterial stiffness is also not fully understood. Several mechanisms have been proposed: hemostatic abnormalities ${ }^{266}$, hyperinsulinemia ${ }^{193}$, non-enzymatic glycosylation ${ }^{194,195}$, changes in the autonomic nervous system ${ }^{196}$ and clustering of other risk factors ${ }^{173}$.

\subsubsection{Neuroendocrine and metabolic factors \\ Estrogens}

Vessel wall properties differ between men and women. In addition, stiffness of the aorta ${ }^{197}$ and carotid artery ${ }^{197,198}$ is described to be higher in postmenopausal compared to age-matched premenopausal women. With these results in mind, several groups studied the effects of female hormones, like estrogen and progesterone.

There does not seem to be a relation between the menstrual cycle and arterial wall properties of the carotid and femoral arteries ${ }^{199}$. Three months use of a third generation oral contraceptive also does not seem to influence these vessel wall properties ${ }^{200}$.

Several groups investigated the effect of estrogen replacement therapy with contradictory results. Some describe a positive effect of estrogens on distensibility of the aorta ${ }^{201}$ and CCA ${ }^{202,203}$, while others found no relation between estrogen replacement and distensibility of the aorta ${ }^{204}$, carotid ${ }^{205,206}$ or brachial arteries ${ }^{204}$. Several authors describe a positive effect of estrogen replacement therapy on systemic compliance ${ }^{201,202,204,206}$. Since estrogens have a vasodilatory capacity ${ }^{207}$, the increase in compliance might be caused by vasodilation. Another evidence for this is the fact that the effect of estrogens on systemic compliance can be established in 4 weeks and also disappears after 4 weeks withdrawal ${ }^{201,208}$. Estrogens, however, also have direct effects on the arterial wall: estrogens decrease collagen production and decrease the elastin/collagen ratio ${ }^{209}$. In one study it is suggested estrogens may protect against endothelial injury ${ }^{210}$. 
Since most hormone replacement therapy contains estrogens and progestins, the latter to prevent the risk of uterine cancer, the combination was also tested. One study found no difference in carotid artery distensibility between estrogens alone and the combination ${ }^{203}$, while other studies described an attenuation of the estrogen effect on carotid artery distensibility and total arterial compliance with concomitant progestins ${ }^{202,206}$.

\section{Insulin}

Insulin is a growth promotor that can mediate structural changes of vascular wall tissue ${ }^{147}$. Recent data suggest a role for insulin in vascular changes. Some studies showed an inverse relation between insulin and aortic compliance ${ }^{147}$ and distensibility ${ }^{57}$, which was also found for distensibility of the common carotid artery ${ }^{148}$. On the contrary, a recent study described an increase in compliance of large arteries, caused by a vasodilation or increase in distensibility ${ }^{211}$. The relation between insulin and large artery properties might also be gender-dependent: Giltay et al showed a negative relation between insulin and femoral artery wall properties in women, which was not found in men ${ }^{212}$. Since no relation between insulin and carotid artery wall properties were found, neither in men nor women, the relation might also depend on the arterial territory ${ }^{212}$. In conclusion, the exact relation between insulin and vessel wall properties has to be further elucidated.

\section{Hormones of the renin-angiotensin system and sympathetic nervous system}

Effector hormones of the sympathetic nervous system and renin-angiotensin system have been implicated as growth promotors that can lead to structural changes of vascular wall tissue ${ }^{147}$. Dimensions of large muscular arteries are influenced by vasoactive substances like angiotensin, noradrenaline and atrial natriuretic peptide ${ }^{213-216}$, which could lead to altered vessel wall properties. In addition, Neutel and coworkers found a negative relation between noradrenaline and proximal arterial compliance, in normal subjects ${ }^{147}$.

Higher aldosterone plasma levels also tended to be associated with reduced total arterial compliance in normal subjects ${ }^{147}$, hypertensive subjects ${ }^{217}$, treated patients with congestive heart failure ${ }^{218}$ and subjects with primary hyperaldosteronism ${ }^{219}$. In the last study, compliance did not return to normal after treatment. The authors hypothesized two mechanisms which could be responsible: increased collagen deposition in the vessel wall or an increased responsiveness to adrenergic stimulation.

\section{Hypopituitarism, Growth hormone, Thyroid hormone}

Hypopituitary subjects, on routine hormone replacement have a higher mortality rate, caused by vascular disorders ${ }^{220}$. Symptom-free hypopituitary women, but not men, also seem to have a lower carotid artery distensibility and compliance ${ }^{221}$. The subjects in the latter study were all growth-hormone deficient and had replacement of thyroxine, cortisol and sex-steroids. The cause of the altered wall properties in this study is not clear.

One explanation could be growth hormone deficiency, which is related to an increased cardiovascular risk ${ }^{222}$. It has been shown that symptom-free growth hormone deficient adults have less distensible arteries than controls. In addition they have higher cholesterol levels ${ }^{153}$. It is not clear whether the growth hormone deficiency per se, the hypercholesterolemia or the combination is the cause of the alteration in large artery properties.

Arterial distensibility of the carotid and radial artery also seems to be decreased in hypothy- 
roid patients compared to age-matched controls ${ }^{223}$. After replacement therapy with thyroid hormones distensibility returned to normal. The latter suggests more functional than structural changes, although structural changes, for instance accumulation of mucopolysaccharoid substances cannot be excluded.

\section{Homocysteine}

In the last decade, hyperhomocysteinemia has been recognized as a cardiovascular risk factor ${ }^{224}$. Homocysteine for instance enhances smooth muscle proliferation ${ }^{225}$. One study reported a link between homocysteine and PWV of the lower limb in subjects with end-stage renal disease ${ }^{226}$. This was also reported for aortic stiffness in hypertensive patients ${ }^{227}$. However, in a study by Smilde et al, in subjects with a genetically disordered homocysteine metabolism, the effect of homocysteine on arterial stiffness was only marginal ${ }^{228}$ : Homocysteine explained only a minor proportion of the variability in carotid artery distensibility and femoral artery compliance. This discrepancy could be explained by different arteries studied and different populations.

\subsubsection{Exercise}

Physical fitness and physical activity are associated with a decreased risk of cardiovascular disease and lower incidence of hypertension ${ }^{229}$. Is this obtained by preservation of arterial distensibility and compliance? Cross-sectional studies comparing athletes and untrained subjects have found a higher aortic and brachial artery compliance in athletes ${ }^{56,230}$ and trained cyclists ${ }^{231}$ respectively. In this latter study, cyclists had a larger diameter of the femoral artery compared to sedentary controls, but similar vessel wall properties. In hammer-throwers, diameter and compliance of the radial artery of the dominant arm were found to be increased compared to sedentary subjects, while this was not the case for the non-dominant arm ${ }^{232}$. This suggests training can increase local arterial diameter and compliance. Stiffness of the aorta and carotid artery is also described to be lower in trained postmenopausal women compared to sedentary women, with a similar blood pressure ${ }^{197}$. Not only very trained subjects seem to have less stiff arteries, also subjects with moderate activity (for instance dancing with sufficient activity to cause sweating) have a less stiff aorta compared to sedentary subjects ${ }^{233}$. The increase of arterial distensibility with training might be due to a reduction of overall blood pressure, a decrease in smooth muscle tone, a reduced production of renin and angiotensin and/or a reduction in sympathetic effects. In addition it could also be a flow-dependent mechanism ${ }^{232}$. Besides this it could also be that athletes have a high arterial compliance for constitutional reasons rather than as a result of physical training. The study of the hammerthrowers does not support this, since the changes were only found in the dominant, trained $\operatorname{arm}^{232}$.

A study with a 4-week exercise programme showed an increase in arterial compliance, which decreased to baseline values after a 8 -week sedentary period ${ }^{234}$. In this study blood pressure was lowered, which could explain the results. Studies on the acute effects of exercise have shown an increase in aortic compliance in hypertensive subjects ${ }^{235}$. In normotensives and mildly hypertensive subjects a decrease in aortic compliance has been shown ${ }^{236,237}$. An acute bout of exercise led to an increase in total arterial compliance and a decrease in aortic and femoral artery stiffness, which returned to normal after 1 hour ${ }^{238}$. This suggests a change in vascular smooth muscle tone, leading to vasodilation. Another study however, showed no 
effect of 6 weeks of moderate exercise training on blood pressure and vessel wall properties of the common carotid, brachial and femoral arteries ${ }^{231}$.

On the contrary, a population study showed a positive relation between stiffness of the thoracic aorta and leisure-time physical activity, meaning that the thoracic aorta gets more stiff with physical activity ${ }^{57}$. A recent study by Bertovic et al also reported a stiffer proximal aorta and leg arteries in strength-trained individuals compared to sedentary controls ${ }^{230}$. The authors of both studies suggest this might be explained by arterial fatigue, caused by repeated periods of increase in blood pressure during exercise ${ }^{57,230}$.

\subsubsection{Diet}

Eating of fish can improve or preserve large artery vessel wall properties ${ }^{239}$. Pulse wave velocity of the aorta was smaller in subjects from fishing villages compared to farming villages, which means a lower arterial distensibility in the subjects from the farming villages. These effects of fish eating can be caused by fish oils, which might affect the arterioslerotic process in a favourable way. ${ }^{240}$.

Another dietary factor that might be important is the intake of salt. Compared to subjects with a high salt-intake, subjects with a low salt-intake have a better arterial distensibility ${ }^{241}$. A low salt diet in normotensive adult subjects can result in a higher arterial distensibility, independently of the effect on blood pressure ${ }^{241}$. As mentioned in the hypertension section, compared to sodium-resistant subjects, sodium-sensitive borderline hypertensive subjects have a lower compliance and distensibility of the carotid, brachial and femoral arteries ${ }^{121}$. The mechanisms underlying these findings are not clear ${ }^{121}$. Possible explanations are an increased activity of the sympathetic system or renin-angiotensin system or a decreased concentration of atrial natriuretic peptide ${ }^{122}$.

Recently 2 reports described a positive effect of isoflavones (in soybeans and red clover) on systemic arterial compliance in menopausal and perimenopausal women ${ }^{242,243}$. The explanation might be that isoflavonoids have weak estrogenic activity.

\subsubsection{Kidney diseases}

Patients with end-stage renal failure have an increased cardiovascular risk. Several studies showed a larger diameter and decreased distensibility of elastic and muscular large arteries in patients on hemodialysis compared to control subjects, independently of blood pressure ${ }^{244-246}$. These altered vessel wall properties might be due to the long-existence of hypertension, lipid disorders, electrolyte disturbances, toxic effects of the uremia, the hypercalcemia after dialysis 244,247 or the kidney disease per se ${ }^{246}$.

Subjects on long-treatment-time dialysis have less hypertension and cardiovascular complications as compared to the more usual short-treatment-time dialysis. However, even in this patients femoral artery distensibility and compliance, but not carotid artery distensibility and compliance were found to be reduced ${ }^{248}$. Three months after renal transplantation distensibility of the carotid artery is also, still, decreased. These patients were however on immunosuppressive therapy, which might have influenced the large artery properties ${ }^{249}$.

Another explanation could be hyperparathyroidism, which is often found in end-stage renal failure. Barenbrock et al described a significant negative relation between plasma parathyroid levels and carotid artery distensibility in renal transplant patients ${ }^{250}$. Since the effects were not related to calcium, blood pressure or arterial diameter, the authors suggest structural modifica- 
tions of the wall ${ }^{250}$.

\subsubsection{Connective tissue disorders}

Patients with elastic tissue disorders like Marfan have a decreased aortic distensibility ${ }_{153,251,252}$. This might be caused by an altered structure of the tunica media ${ }^{251}$. Patients with osteogenesis imperfecta also have a lower aortic distensibility ${ }^{253}$. In subjects with EhlersDanlos syndrome, a condition associated with a collagen type III deficiency, arterial distensibility is improved, however at the expense of a weakened wall, leading to ruptures at an early age ${ }^{254}$.

\subsection{RELATION BETWEEN LARGE ARTERY WALL PROPERTIES AND ATHEROSCLEROSIS}

Conflicting results have been reported regarding the arterial wall stiffness in atherosclerosis. Subjects with coronary artery disease have an abnormally rigid aorta ${ }^{255-257}$. A decrease in arterial distensibility has also been reported in patients with arteriosclerosis obliterans (an atherosclerotic disease of the lower limbs) ${ }^{258}$. One study described a close correlation between carotid artery stiffness in vivo and postmortem degree of atherosclerosis in this artery ${ }^{259}$. These results suggest a decrease in arterial distensibility with atherosclerosis. Distensibility and compliance of the radial artery are, however, increased in subjects with peripheral vascular disease ${ }^{260}$. This might be explained by 1) different structure of the artery, 2) some kind of compensation for the loss in central artery compliance.

How would atherosclerosis affect the wall ? Atherosclerosis is a pleomorphic disorder, characterised by accumulation of lipid, thrombus, collagen and cellular components in the intima of the arterial wall ${ }^{4}$. In experimental atherosclerosis in rhesus monkeys, Farrar et al showed a loss of aortic distensibility with the development of atherosclerosis, which was reversible with the regression of the atherosclerosis ${ }^{159}$. Surprisingly, during the induction of atheroma, the aorta firstly became more distensible, and then as focal lesions were formed, began to stiffen, ultimately becoming less distensible ${ }^{159}$. This result was confirmed by others ${ }^{261}$. The early phase of the atherosclerotic disease (atherosis) is due to the infiltration of LDL cholesterol into the intima and formation of foam cells ${ }^{161,262}$. This may lead to an increased distensibility. In older plaques, later sclerosis develops, due to laying down of collagen in the vessel wall ${ }^{161,262}$ and arteries become stiffer ${ }^{153}$. Increased distensibility has thus been related to early stages of atherosclerosis. This means that the increased aortic distensibility found in early life (age 10-20) may be an early stage of atherosclerosis leading to stiffer arteries in later life ${ }^{22}$. Consequently an increase and a decrease in distensibility can be an indication of atherosclerosis ${ }^{22}$.

Avolio and coworkers were, however, unable to find a correlation between the degree of atherosclerosis and degree of arterial stiffening in two populations with a high and low incidence of atherosclerosis ${ }^{41}$. The method used was, however, not able to detect early atherosclerotic lesions.

The possible stiffening of arteries in the development of atherosclerosis might not be a homogeneous process. Increased stiffness of the carotid artery was found at identifiable atherosclerotic lesions compared to places of the carotid walls nearby, where no lesion was visible ${ }^{44}$. In 
a study on atherosclerotic lesions in the carotid artery bifurcation, distensibility was reduced at the site of the lesion, even when it was not associated with an intraluminal process ${ }^{263}$. In conclusion, there is controversy about the effect of atherosclerosis on vessel wall properties. In a recent study by Blacher et al, arterial stiffness of the aorta in patients with end-stage renal failure, requiring hemodialysis, was a major predictor of all cause mortality and morbidity ${ }^{264}$. The same author described a similar relation for hypertensive patients: a strong relation between aortic PWV and atherosclerotic alterations and a strong predictor of cardiovascular risk ${ }^{265}$. A PWV $>13 \mathrm{~m} / \mathrm{s}$ even appeared a strong predictor of cardiovascular mortality ${ }^{265}$. It is still not clear whether increased arterial stiffness is a risk factor contributing to the development of cardiovascular disease or is a marker of arterial disease. However, arterial stiffness measurements seem to be able to serve as tools for identifying patients at risk for cardiovascular disease. To further investigate this relation, longitudinal studies in unselected populations are necessary.

\section{$1.5 \quad$ THIS THESIS}

This introduction section shows that for most cardiovascular risk factors, results from studies on the relation between arterial wall properties and the risk factors are inconsistent. Explanations for this could be: different methods applied, small number of subjects and heterogeneous groups. In addition, vascular territories may behave differently.

To clarify the relation between vessel wall properties and different cardiovascular risk factors, the present thesis studies this relation in a random relatively large population sample and at different vascular territories.

The population sample and methods used in the studies of the present thesis are described in chapter 2.

Chapter 3 and 4 describe the relation between age and gender and large artery properties of the aorta, carotid, brachial and femoral arteries. Since one of the explanations for the observed gender-differences could be the influence of estrogen, in chapter 5 the relation between menopause and large artery wall properties is studied.

Besides the influence of age and gender, we focused on the relation of vessel wall properties with metabolic risk factors, like obesity, insulin resistance and type 1 diabetes mellitus.

In chapter 6, the relation between obesity and large artery wall properties is described. Part of the results might have been caused by insulin resistance. In chapter 7, the relation between insulin resistance and vessel wall properties is studied.

Since the incidence of type I diabetes is 1:300, the number of subjects with type I diabetes in the study population was too small to study the effect of diabetes on vessel wall properties. This was studied in a different group of subjects. In chapter 8 , vessel wall properties in different groups of IDDM patients were studied.

Finally chapter 9 discusses the results of the studies published in this thesis and gives recommendations for future resarch. 


\section{References}

1. Ross R: Atherosclerosis - an inflammatory disease. N Engl J Med 1999;340:115-126

2. Campbell JH, Campbell GR: Pathogenesis of atheroma, in Swales JD (ed): Textbook of hypertension, 1st ed. Oxford, Blackwell Scientific Publications, 1994, pp. 670-681.

3. Rubba P, Riccardi G, Pauciullo P, Vaccaro O, Carbone L, Mancini M: Different localization of early arterial lesions in insulin-dependent diabetes mellitus and in familial hypercholesterolemia. Metabolism 1989;38:962-966.

4. $\quad$ Ross R: The pathogenesis of atherosclerosis-an update. N Engl J Med 1986;314:488-500.

5. Katz FH, Romph P, Smith JA: Diurnal variation of plasma aldosterone, cortisol and renin activity in supine man. J Clin Endocrinol Metab 1975;40:125-134.

6. O'Rourke M: Mechanical principles in arterial disease. Hypertension 1995;26:2-9.

7. Nichols WW, O'Rourke MF: Properties of the arterial wall: Theory and Practice, in Nichols WW, O'Rourke.MF (eds): Mc Donald's Blood Flow in Arteries. Theoretic, experimental and clinical principles, 4th ed. London, E. Arnold, 1999, pp. 54-98.

8. O'Rourke: Function of arteries as vascular conduits, in O'Rourke MF (ed): Arterial function in health and disease., Churchill Livingstone, Edinburgh London Melbourne and New York, 1982, pp. 53-64.

9. Hoeks APG, Brands PJ, Reneman RS: Assessment of the arterial distension waveform using Doppler signal processing. J Hypertens 1992;10(Suppl. 6):s19-s22.

10. O'Rourke MF: Arterial stiffness, systolic blood pressure, and logical treatment of arterial hypertension. Hypertension 1990;15:339-347.

11. Levy BI, Safar M: Ventricular afterload and aortic impedance, in Swyngedauw B (ed): Cardiac hypertrophy and failure. London, UK, J Libbey INSERM, 1990, pp. 521-530.

12. Ferguson JJ, Randall O: Hemodynamic correlates of arterial compliance. Cathet Cardiovasc Diagn 1986;12:376-380.

13. Safar ME, London GM: The arterial system in human hypertension, in Swales JD (ed): Textbook of hypertension, 1st ed. Oxford, Blackwell Scientific Publications, 1994, pp. 85-102.

14. Langewouters GJ, Wesseling KH, Goedhard WJA: The static elastic properties of 45 human thoracic and 20 abdominal aortas in vitro and the parameters of a new model. J Biomech 1984;17:425-435.

15. Darne B, Girerd X, Safar M, Cambien F, Guize L: Pulsatile versus steady component of blood pressure: a cross-sectional analysis and a prospective analysis on cardiovascular mortality. Hypertension 1989;13:392-400.

16. Pannier BM, London GM, Safar ME: The possible impact of arterial compliance on cardiac hypertrophy in arterial hypertension. Scand J Clin Lab Invest 1989;196:22-27.

17. Safar ME, Toto-Moukouo JJ, Bouthier JA, Asmar RE, Levenson JA, Simon AC, London GM: Arterial dynamics, cardiac hypertrophy, and antihypertensive treatment. Circulation 1987;75(Suppl. I):I156-I161.

18. O'Rourke: Basic concepts for the understanding of large arteries in hypertension. $J$ Cardiovasc Pharmacol 1985; 7:s14-s21.

19. Fuster V, Badimon L, Badimon JJ, Chesebro JH: The pathogenesis of coronary artery disease and the acute coronary syndromes. $N$ Engl J Med 1992;326:242-250.

20. Van Bortel LM, Kool MJ, Struijker Boudier HA: Effects of antihypertensive agents on local arterial distensibility and compliance. Hypertension 1995;26:531-534.

21. Roach MR, Burton AC: The reason for the shape of the distensibility curve of arteries. Can J Biochem Physiol 1957;35:681-690.

22. Laogun AA, Gosling RG: In vivo arterial compliance in man. Clin Phys Physiol Meas 1982;3:201212 .

23. Nichols WW, O'Rourke MF: Aging. Hypertension. Atherosclerosis, in Nichols WW, O'Rourke MF (eds): Mc Donald's Blood Flow in Arteries. Theoretic, experimental and clinical principles, 4th ed. London, E. Arnold, 1999, pp. 347-402.

24. Benetos A, Laurent S, Hoeks AP, Boutouyrie PH, Safar ME: Arterial alterations with ageing and high blood pressure. A noninvasive study of carotid and femoral arteries. Arterioscler Thromb 1993;13:9097.

25. Dobrin PD: Vascular mechanics, in Sheperd T, Abboud M (eds): Handbook of Physiology. Section 2: 
The cardiovascular system. Bethesda, Maryland, American Physiological Society, 1983, vol III: Peripheral circulation and organ blood flow, Part I, pp. 65-102.

26. Simon A, Levenson J: Use of arterial compliance for evaluation of hypertension. Am J Hypertens 1991;4:97-105.

27. Gow BS: The influence of vascular smooth muscle on the viscoelastic properties of blood vessels, in Bergel DH (ed): Cardiovascular fluid dynamics. London, Bergel,DH, 1972, pp. 65-110.

28. Nichols WW, O'Rourke MF: Pulsatile pressure/flow relations, in Nichols WW, O'Rourke MF (eds): Mc Donald's Blood Flow in Arteries. Theoretic, experimental and clinical principles, 4th ed. London, E. Arnold, 1999, pp. 98-114.

29. Achimastos A, Simon AC, Girerd X, Pithois-Merli I, Levenson J: The efficacy of a transdermal formulation of clonidine in mild to moderate hypertension and its effects on the arterial and venous vasculature of the forearm. Eur J Clin Pharmacol 1987;33:111-114.

30. Christensen KL, Mulvany MJ, Jespersen LT: Can mean arterial pressure be estimated from measurements of systolic and diastolic blood pressure, and vice versa? J Hypertens 1990;8:321-326.

31. Altura BT, Altura BM: Pentobarbital and contraction of vascular smooth muscle. Am J Physiol 1975;229:1635-1640.

32. Nakayama R, Azuma T: Noninvasive measurements of digital pressure and compliance in man. Am $J$ Physiol 1977;233:168-179.

33. Liu Z, Ting CT, Zhu S, Yin FCP: Aortic compliance in human hypertension. Hypertension 1989;14:129-136.

34. Finkelstein SM, Collins VR, Cohn JN: Arterial vascular compliance response to vasodilators by Fourier and pulse contour analysis. Hypertension 1988;12:380-387.

35. Simon AC, Safar ME, Levenson JA, London M, Levy BI, Chau NP: An evaluation of large arteries compliance in man. Am J Physiol 1979;237:h550-h556.

36. Yin FCP, Liu Z: Arterial compliance-physiological viewpoint, in Westerhof N, Gross DR (eds): Vascular dynamics: physiological perspectives. New York and London, Plenum, 1989, pp. 9-22.

37. Hoeks APG: Non-invasive study of local mechanical arterial characteristics in humans, in Safar ME (ed): The arterial system in hypertension. Dordrecht, The Netherlands, Kluwer Academic Publisher, 1993, pp. 119-134.

38. Moens E: Die Pulscurve. Leiden, EJ Brill, 1878.

39. Safar ME: Pulse Pressure in essential hypertension: clinical and therapeutical implications. $J$ Hypertens 1989;7:769-776.

40. Hoeks APG, Brands PJ, Smeets FAM, Reneman RS: Assessment of the distensibility of superficial arteries. Ultrasound Med Biol 1990;16:121-128.

41. Avolio AP, Chen S, Wang R, Zhang C, Li M, O'Rourke MF: Effects of ageing on changing arterial compliance and left ventricular load in a northern Chinese urban community. Circulation 1983;68:5058 .

42. Arndt JO, Klauske J, Mersch F: The diameter of the intact carotid artery in man and its change with pulse pressure. Pflugers Arch 1968;301:230-240.

43. Barth JD, Blankenhorn DH, Wickham E, Lai JY, Chin HP, Selzer RH: Qualitative ultrasound pulsation study in human carotid artery disease. Arteriosclerosis 1988;8:778-781.

44. Blankenhorn DH, Chin HP, Conover DJ, Nessim SA: Ultrasound observation on pulsation in human carotid artery lesions. Ultrasound Med Biol 1988;14:583-587.

45. Roman MJ, Pini R, Pickering TG, Devereux RB: Non-invasive measurements of arterial compliance in hypertensive compared with normotensive adults. J Hypertens 1992;10(suppl 6):S115-S118.

46. Olsen CF: Doppler ultrasound: A technique for obtaining arterial wall motion parameters. IEEE Trans Biomed Eng 1977;SU-24:354-358.

47. Wildi E, Knutti JW, Allen HV, Meindl JD: Dynamics and limitations of blood/muscle interface detection using Doppler power returns. IEEE Trans Biomed Eng 1980;27:565-573.

48. Levenson JA, Peronneau PA, Simon A, Safar ME: Pulsed Doppler: determination of diameter, blood flow velocity, and volume flow of brachial artery in man. Cardiovasc Res 1981;15:164-170.

49. Reneman RS, Van Merode T, Hick P, Muytjens AMM, Hoeks APG: Age related changes in carotid artery wall properties in men. Ultrasound Med Biol 1986;12:465-471.

50. Hoeks APG, Ruissen CJ, Hick P, Reneman RS: Transcutaneous detection of relative changes in 
artery diameter. Ultrasound Med Biol 1985;11:51-59.

51. Mozersky DJ, Sumner DS, Hokanson DE, Strandness DE: Transcutaneous measurement of the elastic properties of the human femoral artery. Circulation 1972;46:948-955.

52. Hokanson DE, Mozersky DJ, Sumner DS, Strandness DE: A phase-locked echo tracking system for recording arterial diameter changes in vivo. J Appl Physiol 1972;32:728-733.

53. Tardy Y, Meister JJ, Perret F, Brunner HR, Arditi M: Non-invasive estimate of the mechanical properties of peripheral arteries from ultrasonic and photoplethysmographic measurements. Clin Phys Physiol Meas 1991;12:39-54.

54. Siche J, De Gaudemaris R, Riachi M, Mallion J: Relationship between low-frequency oscillations of blood pressure and changes in arterial diameter. J Hypertens 1992;10(Suppl. 6):s45-s48.

55. Hayoz D, Tardy Y, Rutschmann B, Waeber B, Meister J, Brunner HR: Effect of mental stress on the tone of a medium-sized muscular artery. J Hypertens 1992;10(Suppl. 6):s57-s59.

56. Mohiaddin RH, Underwood SR, Bogren HG, Firmin DN, Klipstein RH, Rees RSO, Longmore DB: Regional aortic compliance studied by magnetic resonance imaging: the effects of age, training and coronary artery disease. $\mathrm{Br}$ Heart $J$ 1989;62:90-96.

57. Kupari M, Hekali P, Keto P, Poutanen V, Tikkanen MJ, Standertskjold-Nordenstam C: Relation of aortic stiffness to factors modifying the risk of atherosclerosis in healthy people. Arterioscler Thromb 1994;14:386-394.

58. Borow KM, Newburger JW: Noninvasive estimation of central aortic pressure using the oscillometric method for analyzing systemic artery pulsatile blood flow: comparative study of indirect systolic, diastolic, and mean brachial artery pressure with simultaneous direct ascending aortic pressure measurements. Am Heart J 1982;103:879-886.

59. Reneman RS, van Merode T, Brands PJ, Hoeks APG: Inhomogeneities in arterial wall properties under normal and pathological conditions. J Hypertens 1992;10(Suppl. 6):s35-s39.

60. Benetos A, Tsoucaris-Kupfer D, Favereau X, Corcos T, Safar M: Carotid artery tonometry: an accurate non-invasive method for central aortic pulse pressure evaluation. J Hypertens 1991;9(Suppl. 6):s144-s145.

61. Kelly R, Hayward C, Ganis J, Daley J, Avolio A, O'Rourke M: Noninvasive registration of the arterial pressure pulse waveform using high-fidelity applanation tonometry. $J$ Vasc Med Biol 1989;1:142-149.

62. Karamanoglu M, O'Rourke MF, Avolio AP, Kelly RP: An analysis of the relationship between central aortic and peripheral upper limb pressure waves in man. Eur Heart J 1993;14:160-167.

63. Millar-Craig MW, Bishop CN, Raftery EB: Circadian variation of blood-pressure. Lancet 1978;i:795797.

64. Kool MJ, Wijnen JA, Hoeks AP, Struyker-Boudier HA, Van Bortel LM: Diurnal pattern of vesselwall properties of large arteries in healthy men. J Hypertens 1991;9(Suppl. 6):s108-s109.

65. Hofstra L, Willigers JM, Huvers FC, Schaper NC, Kester ADM, Kitslaar PJEHM, Hoeks APG: Short-term variation in the elastic properties of a muscular artery in humans. Clin Sci 1994;86:567574.

66. Hayoz D, Bernardi L, Noll G, Weber R, Porret C, Passino C, Wenzel R, Stergiopulos N: Flowdiameter phase shift. A potential indicator of conduit artery function. Hypertension 1995;26:20-25.

67. Joannides R, Richard V, Moore N, Godin M, Thuillez C: Influence of sympathetic tone on mechanical properties of muscular arteries in humans. Am J Physiol 1995;286:H794-H801.

68. Boutouyrie P, Lacolley P, Girerd X, Beck L, Safar M, Laurent S: Sympathetic activation decreases medium-sized arterial compliance in humans. Am J Physiol 1994;267:H1368-H1376.

69. Barenbrock M, Spieker C, Witta J, Evers S, Hoeks APG, Rahn KH, Zidek W: Reduced distensibility of the common carotid artery in patients treated with ergotamine. Hypertension 1996;28:115-119.

70. Bank AJ, Kaiser DR: Smooth muscle relaxation. Effects on arterial compliance, distensibility, elastic modulus, and pulse wave velocity. Hypertension 1998;32:356-359.

71. Giannattasio C, Failla M, Mangoni AA, Scandalo L, Fraschini N, Mancia G: Evaluation of arterial compliance in humans. Clin Exp Hypertens 1996;18:347-362.

72. $\quad$ Roy CS: The elastic properties of the arterial wall. J Physiol 1880;3:125-159.

73. Bader H: Dependence of wall stress in the human thoracic aorta on age and pressure. Circ Res 
1967;20:354-361.

74. Newman DC, Lallemand RC: The effect of age on the distensibility of the abdominal aorta of man. Surg Gynecol Obstet 1978;147:211-214.

75. Learoyd MB, Taylor MG: Alterations with age in the viscoelastic properties of human arterial walls. Circ Res 1966;18:278-292.

76. Avolio AP, Deng FQ, Li WQ, Luo YF, Huang ZD, Xing LF, O'Rourke MF: Effects of ageing on arterial distensibility in populations with high and low prevalence of hypertension: a comparison between urban and rural communities in China. Circulation 1985;71:202-210.

77. Boutouyrie P, Laurent S, Benetos A, Girerd XJ, Hoeks APG, Safar ME: Opposing effects of ageing on distal and proximal large arteries in hypertensives. J Hypertens 1992;10(Suppl. 6):s87-s91.

78. Sonesson B, Hansen F, Stale H, Länne T: Compliance and diameter in the human abdominal aortathe influence of age and sex. Eur J Vasc Surg 1993;7:690-697.

79. Länne T, Sonesson B, Bergqvist D, Bengtsson H, Gustafsson D: Diameter and compliance in the male human abdominal aorta: influence of age and aortic aneurysm. Eur J Vasc Surg 1992;6:178-184.

80. Kawasaki T, Sasayama S, Yagi S, Asakawa T, Hirai T: Non-invasive assessment of the age related changes in stiffness of major branches of the human arteries. Cardiovasc Res 1987;21:678-687.

81. Blacher J, London GM, Safar ME, Mourad J: Influence of age and end-stage renal disease on the stiffness of carotid wall material in hypertension. J Hypertens 1999;17:237-244.

82. Schmidt-Trucksass A, Grathwoll D, Schmid A, Boragk R, Upmeier C, Keul J, Huonker M: Structural, functional, and hemodynamic changes in the common carotid artery with age in male subjects. Arterioscler Thromb Vasc Biol 1999;19:1091-1097.

83. Bortolotto LA, Franconi G, Boutouyrie P, Legrain S, Girerd X: The aging process modifies the distensibility of elastic but not muscular arteries. Hypertension 1999;34:889-892.

84. Safar M: Aging and its effects on the cardiovascular system. Drugs 1990;39(Suppl. 1):1-8.

85. Virmani R, Avolio AP, Mergner WJ, Robinowitz M, Herderick EE, Cornhill JF, Guo S, Liu T, Ou D, O'Rourke M: Effect of ageing on aortic morphology in populations with high and low prevalence of hypertension and atherosclerosis. Comparison between occidental and chinese communities. Am J Physiol 1991;139:1119-1129.

86. Kelly R, Hayward C, Avolio A, O'Rourke M: Noninvasive determination of age-related changes in the human arterial pulse. Circulation 1989;80:1652-1659.

87. Hickler RB: Aortic and large artery stiffness: current methodology and clinical correlations. Clin Cardiol 1990;13:317-322.

88. Hofstra L, Ermers EJM, Langeveldt APM, Hoeks APG, Kitslaar PJEHM: Vessel Wall Doppler Tracking: A new technique to assess vessel wall compliance. $J$ Vasc Tech 1993;17:65-68.

89. Castelli WP: Epidemiology of coronary heart disease. The Framingham study. Am J Med 1984;76:412.

90. Hansen F, Mangell P, Sonesson B, Länne T: Diameter and compliance in the human carotid arteryvariations with age and sex. Ultrasound Med Biol 1995;21:1-9.

91. Milnor WR: Normal hemodynamic state, in Milnor WR (ed): Hemodynamics. Baltimore, Williams and Wilkins, 1982, pp. 135-156.

92. van Merode T, Hick PJJ, Hoeks APG, Smeets FAM, Reneman RS: Differences in carotid artery wall properties between presumed-healthy men and women. Ultrasound Med Biol 1988;14:571-574.

93. Burt V, Whelton P, Roccella EJ, Brown C, Cutler JA, Higgins M: Prevalence of hypertension in the US adult population: results from the Third National Health and Nutrition Examination Survey. Hypertension 1995;25:305-313.

94. Lehmann ED, Hopkins KD, Gosling RG: In vivo determinants of arterial stiffness. Athero-sclerosis 1996; 125:139-144.

95. Ferreira AVL, Viana MC, Mill JG, Asmar RG, Cunha RS: Racial differences in aortic stiffness in normotensive and hypertensive subjects. J Hypertens 1999;17:631-637.

96. Guidelines subcommittee: 1999-World Health Organization-International Society of Hypertension guidelines for the management of hypertension. J Hypertens 1999;17:151-183.

97. Kannel WB, Stokes J: Hypertension as a cardiovascular risk factor, in Bulpitt CJ (ed): Handbook of hypertension, volume 6: Epidemiology of hypertension. Amsterdam, Elsevier Science Publishing Co. Inc., 1985, pp. 15-34. 


\section{Introduction}

98. Rutan GH, Kuller LH, Neaton JD, Wnthworth DN, McDonald RH, McFate Smith W: Mortality associated with diastolic hypertension and isolated systolic hypertension among men screened for the multiple risk factor intervention trial. Circulation 1988;77:504-514.

99. Frank O: Der puls in den arterien. $Z$ Biol 1905;46:441-553.

100. Frank O: Die elastizität der blutegefasse. Z Biol 1920;71:255-272.

101. Laurent S, Caviezel B, Beck L, Girerd X, Billaud E, Boutouyrie P, Hoeks A, Safar M: Carotid artery distensibility and distending pressure in hypertensive humans. Hypertension 1994;23:878-883.

102. Isnard RN, Pannier BM, Laurent S, London GM, Diebold B, Safar ME: Pulsatile diameter and elastic modulus of the aortic arch in essential hypertension: a noninvasive study. J Am Coll Cardiol 1989;13:399-405.

103. Messerli FH, Frohlich ED, Ventura HO: Arterial compliance in essential hypertension. $J$ Cardiovasc Pharmacol 1985;7:S33-S35.

104. Bouthier J, Benetos A, Simon A, Levenson J, Safar M: Pulsed Doppler evaluation of diameter, blood velocity and blood flow of common carotid artery in sustained essential hypertension. $J$ Cardiovasc Pharmacol 1985;7(Suppl. 21):s99-s104.

105. Eiskjaer H, Christensen T, Pedersen EB: Abnormal structure and increased stiffness of the femoral arterial wall in young patients with sustained hypertension. J Intern Med 1989;226:235-240.

106. Armentano R, Megnien J, Simon A, Bellenfant F, Barra J, Levenson J: Effects of hypertension on viscoelasticity of carotid and femoral arteries in humans. Hypertension 1995;26:48-54.

107. Safar ME, Peronneau PA, Levenson JA, Toto-Moukouo JA, Simon AC: Pulsed doppler: diameter, blood flow velocity and volumic flow of the brachial artery in sustained essential hypertension. Circulation 1981;63:393-400.

108. Hayoz D, Rutschmann B, Perret F, Niederberger M, Tardy Y, Mooser V, Nussberger J, Waeber B, Brunner HR: Conduit artery compliance and distensibility are not necessarily reduced in hypertension. Hypertension 1992;20:1-6.

109. Gribbin B, Pickering TG, Sleight P: Arterial distensibility in normal and hypertensive man. Clin Sci 1979;56:413-417.

110. Smulyan H, Vardan S, Griffiths A, Gribbin B: Forearm arterial distensibility in systolic hypertension. J Am Coll Cardiol 1984;3:387-393.

111. Laurent S, Hayoz D, Trazzi S, Boutouyrie P, Waeber B, Omboni S, Brunner HR, Mancia G, Safar M: Isobaric compliance of the radial artery is increased in patients with essential hypertension. $J$ Hypertens 1993;11:89-98.

112. Mourad JJ, Girerd X, Boutouyrie P, Safar M, Laurent S: Opposite effects of remodeling and hypertrophy on arterial compliance in hypertension. Hypertension 1998;31, part 2:529-533.

113. Safar ME, Levy BI, Laurent S, London GM: Hypertension and the arterial system: clinical and therapeutic aspects. J Hypertens 1990;8(Suppl. 7):S113-S119.

114. Stella ML, Failla M, Mangoni AA, Carugo S, Giannattasio C, Mancia G: Effects of isolated systolic hypertension and essential hypertension on large and middle-sized artery com-pliance. Blood Press 1998;7:96-102.

115. Liao D, Arnett DK, Tyroler HA, Riley WA, Chambless LE, Szklo M, Heiss G: Arterial stiffness and the development of hypertension. The ARIC study. Hypertension 1999;34:201-206.

116. Simon A, Levenson J, Bouthier J, Maarek B: Haemodynamic basis of early modifications of the large arteries in borderline hypertension. J Hypertens 1987;5:179-184.

117. Ventura H, Messerli FH, Oigman W, Suarez DH, Dreslinski GR, Dunn FG, Reisin E, Frohlich ED: Impaired systemic arterial compliance in borderline hypertension. Am Heart J 1984;108:132-135.

118. van Merode T, Brands PJ, Hoeks APG, Reneman RS: Faster aging of the carotid artery bifurcation in borderline hypertensive subjects. J Hypertens 1993;11:171-176.

119. van Merode T, Hick PJJ, Hoeks APG, Rahn KH, Reneman RS: Vessel wall properties of the carotid artery in normotensive and borderline hypertensive young male volunteers. J Hypertens 1987;5(Supp1. 5):s471-s473.

120. van Merode T, Hick PJJ, Hoeks APG, Rahn KH, Reneman RS: Carotid artery wall properties in normotensive and borderline hypertensive subjects of various ages. Ultrasound Med Biol 1988; 14:563-569.

121. Draaijer P, Kool MJ, Maessen JM, Van Bortel LM, de Leeuw PW, van Hooff JP, Leunissen KM: 
Vascular distensibility and compliance in salt-sensitive and salt-resistant borderline hypertension. $J$ Hypertens 1993;11:1199-1207.

122. Draaijer P, de Leeuw P, Maessen J, van Hooff J, Leunissen K: Salt-sensitivity testing in patients with borderline hypertension: reproducibility and potential mechanisms. J Hum Hypertens 1995;9:263269.

123. Weber MA, Smith DHG, Neutel JM, Graettinger WF: Arterial properties of early hypertension. $J$ Hum Hypertens 1991;5:417-423.

124. Giannattasio C, Cattaneo BM, Mangoni AA, Carugo S, Stella ML, Failla M, Trazzi S, Sega R, Grassi G, Mancia G: Cardiac and vascular structural changes in normotensive subjects with parental hypertension. J Hypertens 1995;13:259-264.

125. Benetos A, Topouchian J, Ricard S, Gautier S, Bonnardeaux A, Asmar R, Poirier O,

Soubrier F, Safar M, Cambie F: Influence of Angiotensin II type 1 receptor polymorphism on aortic stiffness in never-treated hypertensive patients. Hypertension 1995;26:44-47.

126. Van Bortel LM, Spek JJ: Influence of aging on arterial compliance. J Hum Hypertens 1998;12:583586.

127. Van Bortel LMAB, Kool MJF: Vessel wall properties of large arteries in hypertension and effect of antihypertensive treatment. Can J Cardiol 1994;10(Suppl. D):37D-40D.

128. Kool MJ, Lustermans FA, Breed JG, Struijker Boudier HA, Hoeks AP, Reneman RS, Van Bortel LM: The influence of perindopril and the diuretic combination amiloride + hydrochlorothiazide on the vessel wall properties of large arteries in hypertensive patients. $J$ Hypertens 1995;13:839-848.

129. Dyer AR, Persky V, Stamler J, Paul O, Shekell RB, Berkson DM: Heart rate as a prognostic factor for coronary heart disease and mortality: findings in three Chicago epidemiologic studies. Am J Epidemiol 1980;112:736-749.-

130. Sa Cunha R, Pannier B, Benetos A, Siché J, London G, Mallion J, Safar ME: Associations between high heart rate and arterial rigidity in normotensive and hypertensive subjects. $J$ Hypertens 1997; 15:1423-1430.

131. Liang Y, Gatzka CD, Du X, Cameron JD, Kingwell BA, Dart AM: Effects of heart rate on arterial compliance in men. Clin Exp Pharmacol Physiol 1999;26:342-346.

132. Soma J, Aakhus S, Angelsen BAJ, Skjaerpe T: Influence of body size and left ventricular ejection dynamics on total arterial compliance determined using Doppler echocardiography and subclavian artery pulse tracings in healthy humans. Blood Press 1998;7:239-246.

133. Gordon T, Kannel WB: Obesity and cardiovascular disease: the Framingham Study, in Burland WL, Samuel PD, Yudkin J (eds): Obesity symposium. Proceedings of a Servier research institute symposium. Edinburgh, Churchill Livingstone, 1974, pp. 367-374.

134. Hubert HB, Feinleib M, McNamara PM, Castelli WP: Obesity as an independent risk factor for cardiovascular disease: a 26-year follow - up of participants in the Framingham Heart Study. Circulation 1983;67:968-976.

135. Garrison RJ, Castelli WP: Weight and thirty-year mortality of men in the Framingham study. Ann Intern Med 1985;103:1006-1009.

136. Messerli FH, Christie B, Decarvalho JGR, Aristimuno GG, Suarez DH, Dreslinski GR, Frohlich ED: Obesity and essential hypertension. Hemodynamics, intravascular volume sodium excretion, and plasma renin activity. Arch Intern Med 1981;141:81-85.

137. Rocchini AP, Moorehead C, Katch V, Key J, Finta KM: Forearm resistance vessel abnormalities and insulin resistance in obese adolescents. Hypertension 1992;19:615-620.

138. Stepniakowski K, Egan BM: Additive effects of obesity and hypertension to limit venous volume. Am J Physiol 1995;268:R562-R568.

139. Mujais SK, Tarazi RC, Dustan HP, Fouad FM, Bravo EL: Hypertension in obese patients: hemodynamic and volume studies. Hypertension 1982;4:84-92.

140. Toto-Moukouo JJ, Achomastos RG, Asmar RG, Hugues CJ, Safar ME: Pulse wave velocity in patients with obesity and hypertension. Am Heart J 1986;112:136-140.

141. Mangoni AA, Giannattasio C, Brunani A, Failla M, Colombo M, Bolla G, Cavagnini F, Grassi G, Mancia G: Radial artery compliance in young, obese, normotensive subjects. Hypertension 1995;26:984-988.

142. Oren S, Grossman E, Frohlich ED: Arterial and venous compliance in obese and nonobese subjects. 
Am J Cardiol 1996;77:665-667.

143. Resnick LM, Militianu D, Cunnings AJ, Pipe JG, Evelhoch JL, Soulen R: Direct magnetic resonance determination of aortic distensibility in essential hypertension: relation to age, abdominal visceral fat, and in situ intracellular free calcium. Hypertension 1997;30:654-659.

144. Balkestein EJ, van Aggel-Leijssen DP, van Baak MA, Struijker-Boudier HA, Van Bortel LM: The effect of weight loss with or without exercise training on large artery compliance in healthy obese men. J Hypertens 1999;17:1831-1835.

145. Yamashita T, Sasahara T, Pomeroy SE, Collier G, Nestel PJ: Arterial compliance, blood pressure, plasma leptin, and plasma lipids in women are improved with weight reduction equally with a meat based diet and a plant-based diet. Metabolism 1998;47:1308-1314.

146. DeFronzo RA, Ferrannini E: Insulin resistance: a mulifaceted syndrome responsible for NIDDM, obesity, hypertension, dyslipidemia, and atherosclerotic cardiovascular disease. Diabetes Care 1991;14:173-194.

147. Neutel JM, Smith DHG, Graettinger WF, Weber MA: Dependency of arterial compliance on circulating neuroendocrine and metabolic factors in normal subjects. Am J Cardiol 1992;69:1340-1344.

148. Salooma V, Riley W, Kark JD, Nardo C, Folsom AR: Non-insulin-dependent diabetes mellitus and fasting glucose and insulin concentrations are associated with arterial stiffness indexes; The ARIC study. Circulation 1995;91:1432-1443.

149. Kannel WB, Castelli WP, Gordon T, McNamara PM: Serum cholesterol, lipoproteins, and the risk of coronary heart disease: the Framingham study. Ann Intern Med 1971;74:1-12.

150. Hayoz D, Weber R, Rutschman B, Darioli R, Burnier M, Waeber B, Brunner HR: Postischemic blood flow response in hypercholesterolemic patients. Hypertension 1995;26:497-502.

151. Kool M, Lustermans F, Kragten H, Struijker Boudier H, Hoeks A, Reneman R, Rila H, Hoogendam I, Van Bortel L: Does lowering of cholesterol levels influence functional properties of large arteries. Eur J Clin Pharmacol 1995;48:217-223.

152. Giannattasio C, Mangoni AA, Carugo S, Bombelli M, Stefanoni P, Failla M, Stella M, Sega R, Grassi G, Vergani C, Mancia G: Arterial compliance in familial hypercholesterolaemia; a preliminary report. J Hypertens 1993;11(Suppl. 5):s82-s83.

153. Lehmann ED, Hopkins KD, Gosling RG: Aortic compliance measurements using doppler ultrasound: in vivo biochemical correlates. Ultrasound Med Biol 1993;19:683-710.

154. Iannuzzi A, Rubba P, Pauciullo P, Celentano E, Capano G, Sartorio R, Mercuri M, Gene Bond M: Stiffness of the aortic wall in hypercholesterolemic children. Metabolism 1999;48:55-59.

155. Giannattasio C, Mangoni AA, Failla M, Carugo S, Stella ML, Stefanoni P, Grassi G, Vergani C, Mancia G: Impaired radial artery compliance in normotensive subjects with familial hypercholesterolemia. Atherosclerosis 1996;124:249-260.

156. Toikka JO, Niemi P, Ahotupa M, Niinikoski H, Viikari JSA, Rönnemaa T, Hartiali JJ, Raitakari OT: Large-artery elastic properties in young men. Relationships to serum lipoproteins and oxidized lowdensity lipoproteins. Arterioscler Thromb Vasc Biol 1999;19:436-441.

157. Tomochika Y, Okuda F, Tanaka N, Wasaki Y, Tokisawa I, Aoyagi S, Morikuni C, Ono S, Okada K, Matsuzaki M: Improvement of atherosclerosis and stiffness of the thoracic descending aorta with cholesterol-lowering therapies in familial hypercholesterolemia. Arterio-scler Thromb Vasc Biol 1996;16:955-962.

158. Pitsavos C, Toutouzas K, Dernellis J, Skoumas J, Skoumbourdis E, Stefanadis C, Toutouzas P: Aortic stiffness in young patients with heterozygous familial hypercholesterolemia. Am Heart $J$ 1998;135:604-608.

159. Farrar DJ, Bond MG, Riley WA, Sawyer JK: Anatomic correlates of aortic pulse wave velocity and carotid artery elasticity during atherosclerosis progression and regression in monkeys. Circulation 1991;83:1754-1763.

160. de Simone G, Roman MJ, Daniels SR, Mureddu G, Kimball TR, Greco R, Devereux RB: Age-related changes in total arterial capacitance from birth to maturity in a normotensive population. Circulation 1997;29:1213-1217.

161. Kramsch DM, Blankenhorn DH: Regression of atherosclerosis: which components regress and what influences their reversal. Wien Klin Wochenschr 1992;104:2-9.

162. Kannel WB, Higgins M: Smoking and hypertension as predictors of cardiovascular risk in population 
studies. J Hypertens 1990;8(Suppl. 5):s3-s8.

163. Winniford MD: Smoking and cardiovascular function. J Hypertens 1990;8(Suppl. 5):s17-s23.

164. Wollersheim H, Firestone G, Fronek A: Selective increase in popliteal artery wall stiffness in longterm smokers. J Hypertens 1993;11(Suppl. 5):s84-s85.

165. Kool MJF, Hoeks APG, Struijker Boudier HAJ, Reneman RS, Van Bortel LMAB: Short- and longterm effects of smoking on arterial wall properties in habitual smokers. J Am Coll Cardiol 1993;2:1881-1886.

166. McVeigh GE, Morgan DJ, Finkelstein SM, Lemay LA, Cohn JN: Vascular abnormalities associated with long-term cigarette smoking identified by arterial waveform analysis. Am J Med 1997;102:227231.

167. Berlin I, Cournot A, Renout P, Duchier J, Safar M: Peripheral haemodynamic effects of smoking in habitual smokers. A methodological study. Eur J Clin Pharmacol 1990;38:57-60.

168. Caro CG, Lever MJ, Parker KH, Fish PJ: Effect of cigarette smoking on the pattern of arterial blood flow: possible insight into mechanisms underlying the development of arterio-sclerosis. Lancet 1987;ii:11-13.

169. Faiila M, Grappiola A, Carugo S, Calchera A, Giannattasio C, Mancia G: Effects of cigarette smoking on carotid and radial artery distensibility. J Hypertens 1997; 15:1659-1664.

170. Stefanadis C, Tsiamis E, Vlachopulos C, Stratos C, Toutouzas K, Pitsavos C, Marakas S, Boudoulas $\mathrm{H}$, Toutouzas P: Unfavorable effect of smoking on the elastic properties of the human aorta. Circulation 1997;95:31-38.

171. Giannattasio C, Mangoni AA, Stella ML, Carugo S, Grassi G, Mancia G: Acute effects of smoking on radial artery compliance in humans. J Hypertens 1994;12:691-696.

172. Stefanadis C, Vlachopoulos C, Tsiamis E, Diamantopoulos L, Toutouzas K, Giatrakos N, Vaina S, Tsekoura D, Toutouzas P: Unfavorable effects of passive smoking on aortic function in men. Ann Intern Med 1998;128:426-434.

173. Kannel WB, McGee DL: Diabetes and cardiovascular disease, the Framingham study. JAMA 1979;241:2035-2038.

174. Stolar MW: Atherosclerosis in diabetes: the role of hyperinsulinemia. Metabolism 1988;37:1-9.

175. Woolam GL, Schnur PL, Vallbona C, Hoff H: The pulse wave velocity as an early indicator of atherosclerosis in diabetic subjects. Circulation 1962;25:533-539.

176. Scarpello JHB, Martin TRP, Ward JD: Ultrasound measurements of pulse-wave velocity in the peripheral arteries of diabetic subjects. Clin Sci 1980;58:53-57.

177. Oxlund H, Rasmussen LM, Andreassen TT, Heickendorff L: Increased aortic stiffness in patients with type 1 (insulin-dependent) diabetes mellitus. Diabetologia 1989; 32:748-752.

178. Pillsbury HC, Hung W, Kyle MC, Freis ED: Arterial pulse waves and velocity and systolic time intervals in diabetic children. Am Heart J 1974;87:783-790.

179. Thordarson $\mathbf{H}$, Thorgeirsson G, Helgason T: Aortic stiffness in insulin-dependent diabetics: an echocardiografic study. Diabetic Med 1986;3:449-454.

180. Lehmann ED, Gosling RG, Sönksen PH: Arterial wall compliance in diabetes. Diabetic Med 1992;9:114-119.

181. Kool MJ, Lambert J, Stehouwer CD, Hoeks AP, Struijker Boudier HA, Van Bortel LM: Vessel wall properties of large arteries in uncomplicated IDDM. Diabetes Care 1995;18:618-624.

182. Christensen T, Neubauer B: Arterial wall stiffness in insulin-dependent diabetes mellitus. Acta Radiol 1987;28:207-208.

183. Christensen T, Neubauer B: Internal diameter of the common femoral artery in patients with insulindependent diabetes mellitus. Acta Radiol 1988;29:423-425.

184. Berry KL, Skyrme-Jones RAP, Cameron JD, O'Brien RC, Meredith IT: Systemic arterial compliance is reduced in young patients with IDDM. Am J Physiol 1999;276:H1839-H1845.

185. Rydén Ahlgren Å, Sundkvist G, Wollmer P, Sonesson B, Länne P: Increased aortic stiffness in women with Type 1 diabetes mellitus is associated with diabetes duration and autonomic nerve function. Diabetic Med 1999;16:291-297.

186. Rydén Ahlgren Å, Länne T, Wollmer P, Sonesson B, Hansen F, Sundkvist G: Increased arterial stiffness in women, but not in men, with IDDM. Diabetologia 1995;38:1082-1089.

187. Lambert J, Smulders RA, Aarsen M, Donker AJM, Stehouwer CDA: Carotid artery stiffness is 
increased in microalbuminuric IDDM patients. Diabetes Care 1998;21:99-103.

188. Zenere BM, Arcaro G, Saggiani F, Rossi L, Muggeo M, Lechi A: Noninvasive detection of functional alterations of the arterial wall in IDDM patients with and without microalbuminuria. Diabetes Care 1995; 18:975-982.

189. Giannattasio C, Failla M, Piperno A, Grappiolo A, Gamba P, Paleari F, Manci G: Early impairment of large artery structure and function in type I diabetes mellitus. Diabetologia 1999;42:987-994.

190. Lo CS, Relf IRN, Myers KA, Wahlqvist ML: Doppler ultrasound recognition of preclinical changes in arterial wall in diabetic subjects: compliance and pulse-wave damping. Diabetes Care 1986;9:2731.

191. Wahlqvist ML, Sam C, Myers KA, Simpson RW, Simpson JM: Putative determinants of arterial wall compliance in NIDDM. Diabetes Care 1988;11:787-790.

192. McVeigh G, Brennan G, Hayes R, Cohn J, Finkelstein S: Vascular abnormalities in non-insulindependent diabetes mellitus identified by arterial waveform analysis. Am J Med 1993;95:424-430.

193. Stout RW: Insulin as a mitogenic factor: role in the pathogenesis of cardiovascular disease. Am J Med 1991;90:62s-65s.

194. Schnider SL, Kohn RR: Glycosylation of human collagen in aging and diabetes mellitus. J Clin Invest 1980;66:1179-1181.

195. Wolffenbuttel BHR, Boulanger CM, Crijns FRL, Huijberts MSP, Poitevin P, Swennen GNM, Vasan S, Egan JJ, Ulrich P, Cerami A, Levy BI: Breakers of advanced glycation end products restore large artery properties in experimental diabetes. Proc Natl Acad Sci USA 1998;95:4630-4634.

196. Jensen-Urstad K, Reichard P, Jensen-Urstad M: Decreased heart rate variability in patients with type 1 diabetes mellitus is related to arterial wall stiffness. J Intern Med 1999;245:57-61.

197. Tanaka H, DeSouza CA, Seals DR: Absence of age-related increase in central arterial stiffness in physically active women. Arterioscler Thromb Vasc Biol 1998;18:127-132.

198. Westendorp ICD, Bots ML, Grobbee DE, Reneman RS, Hoeks APG, Van Popele NM, Hofman A, Witteman JCM: Menopausal status and distensibility of the common carotid artery. Arterioscler Thromb Vasc Biol 1999;19:713-717.

199. Willekes C, Hoogland HJ, Keizer HA, Hoeks AP, Reneman RS: Female sex hormones do not influence arterial wall properties during the normal menstrual cycle. Clin Sci 1997;92:487-491.

200. Willekes C, Hoogland H, Keizer HA, Hoeks APG, Reneman RS: Three months of third generation oral contraceptives does not affect arterial wall properties. Ultrasound Med Biol 1999;25:723-728.

201. Rajkumar C, Kingwell BA, Cameron JD, Waddell T, Mehra R, Christophidis N, Komesaroff PA, McGrath B, Jennings GL, Sudhir K, Dart AM: Hormonal therapy increases arterial compliance in postmenopausal women. J Am Coll Cardiol 1997;30:350-356.

202. Liang Y, Teede H, Shiel LM, Thomas A, Craven R, Sachithanandan N, McNeil JJ, Cameron JD, Dart A, McGrath BP: Effects of oestrogen and progesterone on age-related changes in arteries of postmenopausal women. Clin Exp Pharmacol Physiol 1997;24:457-459.

203. Nagai Y, Early CJ, Kemper MK, Bacal CS, Metter EJ: Influence of age and postmenopausal estrogen replacement therapy on carotid artery stiffness in women. Cardiovasc Res 1999;41:307-311.

204. Hayward CS, Knight DC, Wren BG, Kelly RP: Effect of hormone replacement therapy on noninvasive cardiovascular haemodynamics. J Hypertens 1997;15:987-993.

205. Tanaka H, DeSouza CA, Seals DR: Arterial stiffness and hormone replacement use in healthy postmenopausal women. J Geront 1998;53a:M344-M346.

206. McGrath BP, Liang Y, Teede H, Shiel LM, Cameron JD, Dart A: Age-related deterioration in arterial structure and function in postmenopausal women. Impact of hormone replacement therapy. Arterioscler Thromb Vasc Biol 1998;18:1149-1156.-

207. Lieberman E, Gerhard M, Uehata A, Walsh B, Selwyn A, Ganz P: Estrogen improves endotheliumdependent flow-mediated vasodilation in postmenopausal women. Ann Intern Med 1994;121:936-941.

208. Waddell TK, Rajkumar C, Cameron JD, Jennings GL, Dart AM, Kingwell BA: Withdrawal of hormonal therapy for 4 weeks decreases arterial compliance in postmenopausal women. $J$ Hypertens 1999;17:413-418.

209. Riedel M, Rafflenbeul W, Lichtlen P: Ovarian sex steroids and atherosclerosis. Clin Invest 1993;71:406-412.

210. Celermajer DS, Sorensen KE, Spiegelhalter DJ, Georgakopoulos D, Robinson J, Deanfiled JE: Aging 
is associated with endothelial dysfunction in healthy men years before the age-related decline in women. J Am Coll Cardiol 1994;24:471-476.

211. Westerbacka J, Wilkinson I, Cockroft J, Utriainen T, Vehkavaraa S, Yki-Järvinen H: Diminished wave reflection in the aorta. A novel physiological action of insulin on large blood vessels. Hypertension 1999;33:1118-1122.

212. Giltay EJ, Lambert J, Elbers JMH, Gooren LJG, Asscheman H, Stehouwer CDA: Arterial compliance and distensibility are modulated by body composition in both men and women but by insulin sensitivity only in women. Diabetologia 1999;42:214-221.

213. Dzau VJ, Safar ME: Large conduit arteries in hypertension: role of the vascular renin-angiotensin system. Circulation 1988;77:947-954.

214. Laurent S, London GM, Safar ME: Increased response of the brachial artery diameter to norepinephrine in essential hypertension: preliminary report. J Hypertens 1986;4(Suppl. 6):237-239.

215. Levenson J, Simon AC, Bouthier JD, Benetos A, Safar ME: Post - synaptic alpha - blockade and brachial artery compliance in essential hypertension. J Hypertens 1984;2:37-41.

216. Simon AC, Levenson JA, Levy BY, Bouthier JE, Peronneau PP, Safar ME: Effect of nitroglycerin on peripheral large arteries in hypertension. Br J Clin Pharm 1982;14:241-246.

217. Blacher J, Amah G, Girerd X, Kheder A, Ben Mais H, Safar ME: Association between increased plasma levels of aldosterone and decreased systemic arterial compliance in subjects with essential hypertension. Am J Hypertens 1997;10:1326-1334.

218. Duprez DA, De Buyzere ML, Rietzschel ER, Taes Y, Clement DL, Morgan D, Cohn JN: Inverse relationship between aldosterone and large artery compliance in chronically treated heart failure patients. Eur Heart J 1998;19:1371-1376.

219. Veglio F, Molino P, Cat Genova G, Melhio R, Rabbia F, Grosso T, Martini G, Chiandussi L: Impaired baroreflex function and arterial compliance in primary aldosteronism. $J$ Hum Hypertens 1999;13:29-36.

220. Rosen T, Bengtsson B: Premature mortality due to cardiovascular disease in hypopituitarism. Lancet 1990;336:285-288.

221. Markussis V, Beshyah SA, Fisher C, Parker KH, Nicolaides AN, Johnston DG: Abnormal carotid arterial wall dynamics in symptom-free hypopituitary adults. Eur J Endocrinol 1997;136:157-164.

222. Merimee TJ, Fineberg SE, Hollander W: Vascular disease in the chronic HGH-deficient state Diabetes 1973;22:813-819.

223. Giannattasio C, Ricolta MR, Failla M, Mangoni AA, Stella ML, Mancia G: Large and medium size artery abnormalities in untreated and treated hypothyroidism. Eur Heart J 1997;18:1492-1498.

224. Boers G: Hyperhomocysteinemia as a risk factor for arterial and venous disease: a review of evidence and relevance. Thromb Haemost 1997;78:520-522.

225. Tsai JC, Perrella MA, Yoshizumi M: Promotion of vascular smooth muscle cell growth by homocysteine: a link to atherosclerosis. Proc Natl Acad Sci USA 1994;91:1519-1522.

226. Blacher J, Demuth K, Guerin AP, Safar ME, Moatti N, London GM: Influence of biochemical alterations on arterial stiffness in patients with end-stage renal disease. Arterioscler Thromb Vasc Biol 1998;18:535-541.

227. Bortolotto LA, Safar ME, Billaud E, Lacroix C, Asmar R, London GM, Blacher J: Plasma homocysteine, aortic stiffness, and renal function in hypertensive patients. Hypertension 1999;34:837-842.

228. Smilde TJ, van den Berkmortel FWPJ, Boers GHJ, Wollersheim H, de Boo T, van Langen H, Stalenhoef AFH: Carotid and femoral artery wall thickness and stiffness in patients at risk for cardiovascular disease, with special emphasis on hyperhomocysteinemia. Arterio-scler Thromb Vasc Biol 1998;18:1958-1963.

229. Wijnen JAG, Kool MJF, van Baak MA, Kuipers H, de Haan CHA, Verstappen FTJ: Effect of exercise training on ambulatory blood pressure. Int J Sports Med 1994;15:10-15.

230. Bertovic DA, Waddell TK, Gatzka CD, Cameron JD, Dart AM, Kingwell BA: Muscular strength training is associated with low arterial compliance and high pulse pressure. Hypertension 1999;33:1385-1391.

231. Wijnen JAG, Kuipers H, Kool MJF, Hoeks APG, van Baak MA, Struijker Boudier JAH, Verstappen FTJ, Van Bortel LMAB: Vessel wall properties of large arteries in trained and sedentary subjects. Basic Res Cardiol 1991;86(Suppl. 1):25-29. 


\section{Introduction}

232. Giannattasio C, Cattaneo BM, Mangoni AA, Carugo S, Sampieri L, Cuspidi C, Grassi G, Mancia G: Changes in arterial compliance induced by physical training in hammer-throwers. $J$ Hypertens 1992;10(Suppl. 6):s53-s55.

233. Kakiyama T, Matsuda M, Koseki S: Effect of physical activity on the distensibility of the aortic wall in healthy males. Angiology 1998:49:749-757.

234. Cameron JD, Dart AM: Exercise training increases total systemic arterial compliance in humans. Am J Physiol 1994;266:H693-701.

235. Feske W, Finkelstein SM, Francis G, Cohn JN: Arterial vascular compliance response to exercise in hypertension. ISA 1988;88:161-165.

236. Nichols WW, Pepine CJ, Feldman RL, Christie LG, Conti CR: Exercise induced changes in aortic input impedance in mild hypertension. Circulation 1980;62:III-258.

237. Murgo JP, Westerhof N, Giolma JP, Altobelli SA: Effects of exercise on aortic input impedance and pressure wave forms in normal humans. Circ Res 1981;48:334-343.

238. Kingwell BA, Berry KL, Cameron JD, Jennings GL, Dart AM: Arterial compliance increases after moderate-intensity cycling. Am J Physiol 1997;273:H2186-H2191.

239. Wahlqvist ML, Lo CS, Myers KA: Fish intake and arterial wall characteristics in healthy people and diabetic patients. Lancet 1989;21 oktober:944-946.

240. Hamazaki T, Urakaze M, Sawazaki S, Yamazaki K, Taki H, Yano S: Comparison of pulse wave velocity of the aorta between inhabitants of fishing and farming villages in Japan. Atherosclerosis 1988;73:157-160.

241. Avolio AP, Clyde KM, Beard TC, Cooke HM, Ho KKL, O'Rourke MF: Improved arterial distensibility in normotensive subjects on a low salt diet. Arteriosclerosis 1986;6:166-169.

242. Nestel PJ, Pomeroy S, Kay S, Komesaroff P, Behrsing J, Cameron JD, West L: Isoflavones from red clover improve systemic arterial compliance but not plasma lipids in menopausal women. $J$ Clin Endocrinol Metab 1999;84:895-898.

243. Nestel PJ, Yamashita T, Sasahara T, Pomeroy S, Dart A, Komesaroff P, Owen A, Abbey M: Soy Isoflavones improve systemic arterial compliance but not plasma lipids in menopausal and perimenopausal women. Arterioscler Thromb Vasc Biol 1997;17:3392-3398.

244. Barenbrock M, Spieker C, Laske V, Heidenrich S, Hohage H, Bachmann J, Hoeks APG, Rahn K: Studies of the vessel wall properties in hemodialysis patients. Kidney Int 1994;45:1397-1400.

245. London GM, Marchais SY, Safar ME, Genest AF, Guerin AP, Metivier F, Chedid K, London AM: Aortic and large artery compliance in end-stage renal failure. Kidney Int 1990;37:137-142.

246. Mourad J, Girerd X, Boutouyrie P, Laurent S, Safar M, London G: Increased stiffness of radial artery wall material in end-stage renal disease. Hypertension 1997;30:1425-1430.

247. Marchais S, Guerin A, Safar M, London G: Arterial compliance in uraemia. $J$ Hypertens 1989;7(suppl. 6):s84-s85.

248. Luik AJ, Spek JJ, Charra B, Van Bortel LMAB, Laurent G, Leunissen KML: Arterial compliance in patients on long-treatment-time dialysis. Nephrol Dial Transplant 1997;12:2629-2632.

249. Barenbrock M, Spieker C, Laske V, Baumgart P, Hoeks APG, Zidek W, Rahn KH: Effect of longterm hemodialysis on arterial compliance in end-stage renal failure. Nephron 1993;65:249-253.

250. Barenbrock M, Hausberg M, Kosch M, Kisters K, Hoeks APG, Rahn K: Effect of hyperparathyroidism on arterial distensibility in renal transplant recipients. Kidney Int 1998;54:210-215.

251. Yin FCP, Brin KP, Tin C, Pyeritz RE: Arterial hemodynamic indexes in Marfan's syndrome. Circulation 1989;79:854-862.

252. Hirata K, Triposkiadis F, Sparks E, Bowen J, Wooley CF, Boudoulas H: The Marfan syndrome: abnormal aortic elastic properties. J Am Coll Cardiol 1991;18:57-63.

253. Kalath S, Tsipouras P, Silver FH: Increased aortic root stiffness associated with Osteogenesis Imperfecta. Ann Biomed Eng 1987;15:91-99.

254. Francois B, de Paepe A, Clement D: Pusle wave velocity recordings in a family with ecchymotic Ehlers-Danlos syndrome. Int Angiol 1986;5:1-5.

255. Hirai T, Sasayama S, Kawasaki T, Yagi S: Stiffness of systemic arteries in patients with myocardial infarction. A noninvasive method to predict severity of coronary atherosclerosis. Circulation 1989;80:78-86.

256. Simonson E, Nakagawa K: Effect of age on pulse wave velocity and "aortic ejection time" in healthy 
Chapter 1

men and in men with coronary artery disease. Circulation 1960;22:126-129.

257. Stefanadis C, Wooley CF, Bush CA, Kolibash AJ, Boudoulas H: Aortic distensibility abnormalities in coronary artery disease. Am J Cardiol 1987;59:1300-1304.

258. Levenson JA, Simon AC, Maarek BE, Gitelman RJ, Fiessinger JN, Safar ME: Regional compliance of brachial artery and saline infusion in patients with arteriosclerosis obliterans. Arteriosclerosis 1985;5:80-87.

259. Wada T, Kodaira K, Fujishiro K, Maie K, Tsukiyama E, Fukumoto T, Uchida T, Yamazaki S: Correlation of ultrasound-measured common carotid artery stiffness with pathological findings. Arterioscler Thromb 1994;14:479-482.

260. Catalano M, Scandale G, Jun T, Minola M, Recchia M, Annoni M: Radial artery compliance in patients with peripheral vascular disease. Vasc Med 1997;2:8-12.

261. Newman DL, Gosling RG, Bowden NLR: Changes in aortic distensibility and area ratio with the development of atherosclerosis. Atherosclerosis 1971;14:231-240.

262. Blankenhorn DH, Kramsch DM: Reversal of atherosis and sclerosis. The two components of atherosclerosis. Circulation 1989;79:1-7.

263. Van Merode T, Lodder J, Smeets FAM, Hoeks APG, Reneman RS: An accurate non-invasive method to diagnose minor atherosclerotic lesions in the carotid artery bulb. Stroke 1989;20:1336-1340.

264. Blacher J, Guerin AP, Pannier B, Marchais SJ, Safar ME, London GM: Impact of aortic stiffness on survival in end-stage renal disease. Circulation 1999;99:2434-2439.

265. Blacher J, Asmar R, Djane S, London GM, Safar ME: Aortic pulse wave velocity as a marker of cardiovascular risk in hypertensive patients. Hypertension 1999;33:1111-1117.

266. Halushka PV, Rogers RC, Loadholt CB, Colwell JA: Increased platelet thromboxane synthesis in diabetes mellitus. J Lab Clin Med 1981;97:87-96. 



\section{CHAPTER 2}

Methods and Subjects 


\subsection{Population sample identification}

Except for the study described in chapter 8, all studies in this thesis were performed in a random population sample. This population sample was identified in a rural area of Belgium ${ }^{1}$. The population sample was stratified by sex and age (20-39, 40-59, $\geq 60$ years) in an attempt to recruit the same number of subjects in each stratum. From population registers a random sample of the households was drawn. All household members aged 20 years or older were eligible except if they were foreign nationals, or if the quota of their age-sex stratum had been fulfilled. At baseline (1985-1989), we invited 1419 subjects with a minimum age of 20 years, of whom $1107(78 \%)$ took part. After excluding subjects who had died $(\mathrm{n}=83)$ and those who were severely ill $(n=3)$ or had moved $(n=7), 1014$ subjects were eligible for a follow-up examination of whom, from 1991 to 1995,823 (81\%) participated. Of these participants, 209 subjects did not take part in the vascular measurements and 41 subjects were not actually examined because of technical and logistic problems. In the course of the present analysis a further 76 subjects were removed from the database, because vascular measurements were not available at all arteries studied: the common carotid, brachial and common femoral arteries. The number of subjects finally considered in the analysis totalled 250 men and 247 women.

Table 1. Characteristics of the study population

\begin{tabular}{llll}
\hline Item & Men & Women & $\mathrm{P}$ \\
\hline $\mathrm{N}$ & 250 & 247 & 0.72 \\
Age (years) & $50 \pm 13$ & $50 \pm 12$ & $<.001$ \\
Body height $(\mathrm{cm})$ & $173 \pm 7$ & $161 \pm 6$ & $<.001$ \\
Body weight $(\mathrm{kg})$ & $78 \pm 11$ & $65 \pm 11$ & .007 \\
Body mass index $\left(\mathrm{kg} / \mathrm{m}^{2}\right)$ & $26.0 \pm 3.3$ & $25.2 \pm 4.0$ & \\
Blood Pressure $(\mathrm{mmHg})^{\dagger}$ & & & .004 \\
$\quad$ Systolic & $132 \pm 15$ & $128 \pm 18$ & $<.001$ \\
$\quad$ Mean & $100 \pm 10$ & $96 \pm 10$ & $<.001$ \\
$\quad$ Diastolic & $84 \pm 10$ & $81 \pm 10$ & .001 \\
Heart rate (bpm) & $61 \pm 10$ & $64 \pm 10$ & 0.50 \\
Smokers & $84(33.6)$ & $76(30.6)$ & $<.001$ \\
Drinking alcohol & $85(34.0)$ & $28(11.3)$ & 0.87 \\
Antihypertensive treatment & $37(14.8)$ & $40(16.1)$ & $15\left(9.0^{\ddagger}\right)$ \\
Contraceptive pill & & & \\
\hline
\end{tabular}

Data are mean \pm SD or number of subjects with percentage in brackets. Mean blood pressure $=$ $(2 . \mathrm{DBP}+\mathrm{SBP}) / 3$. ${ }^{\dagger}$ Measured with a sphygmomanometer in sitting position. ${ }^{\ddagger}$ Percentage of women between $20-55$ years of age with oral contraception.

\subsection{Study design}

All participants were asked to refrain from smoking, drinking caffeine containing beverages and heavy excercise for at least 3 hours before being examined. Firstly the participants were seated and were asked to relax for five minutes. Then sitting blood pressure was measured. 
Afterwards the participants were interviewed about their current health status, smoking and drinking habits and intake of drugs.

After 15 minutes of supine rest in a quiet room vessel wall properties of the right elastic common carotid artery (CCA) and right muscular common femoral (CFA) and brachial (BA) arteries were measured. All measurements were made by the same observer, at an arterial segment which showed no echocardiographical signs of atherosclerosis in B-mode. Simultaneously with the assessment of the vessel wall properties blood pressure and pulse rate were recorded. PWV was calculated afterwards.

\subsection{Blood pressure and heart rate}

Sitting blood pressure was measured five times consecutively with a sphygmomanometer. Data of systolic and diastolic blood pressure are means of five measurements. This blood pressure was used for characterisation of the subjects. Mean blood pressure (MBP) was calculated as $(2 . \mathrm{DBP}+\mathrm{SBP}) / 3$. This mean blood pressure was used as a possible confounding factor in the analyses.

Simultaneously with the vessel wall measurements, supine blood pressure and heart rate were measured at the left arm, with a semiautomated oscillometric device (Dinamap; Critikon, Tampa, Florida). Every 3 minutes recordings were made. At least 15 recordings were averaged and taken as the patient's reading. Pulse pressure of the brachial artery was calculated as systolic (SBP) minus diastolic (DBP) blood pressure. This pulse pressure was used for calculation of the vessel wall properties.

\subsection{Vessel wall properties}

\subsubsection{Arterial compliance and distensibility}

Vessel wall properties - compliance and distensibility - can be measured locally with a vessel wall movement detector system ${ }^{2}$. This system consists of a conventional echo-imager system (Ultramark V; ATL, Bothell, Washington, USA), a data acquisition system, and a personal computer with an $\mathrm{AD}$-card. With a 7.5 Mhz transducer the vessel of interest is visualized in B-mode (Fig.1). A line of observation or M-line is positioned perpendicularly to the artery. The echo-system is switched to M-mode, after which, by pressing on a footpedal, data are stored. During 5-6 seconds radiofrequency (RF) signals are digitised and stored in an internal buffer memory. This process is triggered by the R-top of a simultaneously recorded ECG, for a constant time-relationship between the distension curve and the ECG. The first RF-line is displayed on the computer screen. It is used to identify the wall-lumen interfaces. Two calipers (boxes, fig.2) are placed on the anterior and posterior wall of the vessel. The distance between these calipers corresponds to the initial diameter of the vessel lumen. This is the minimum diameter, measured at end-diastole. After this procedure the next RF-lines are transferred to the computer and processed to retrieve the movement of the arterial walls. The sample volumes are not fixed, but move along the beam, according to the detected movement (tracking principle). 


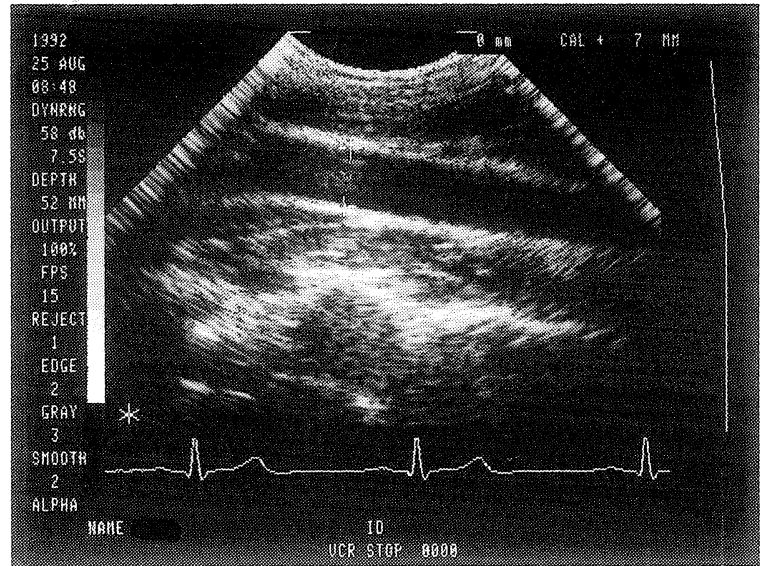

Fig. 1 B-mode image of the common carotid artery of a young healthy volunteer

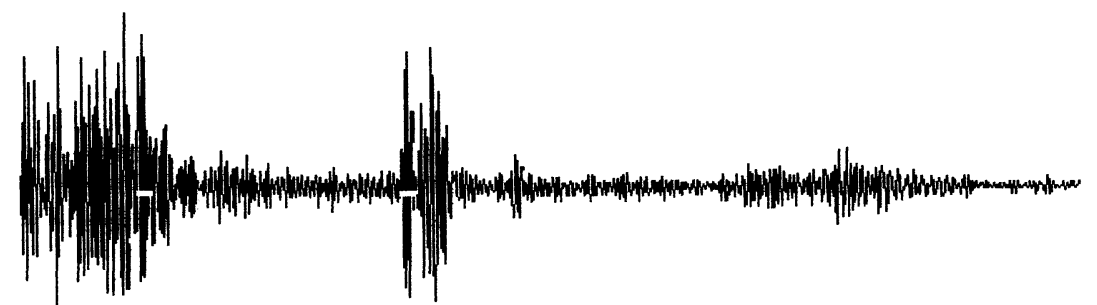

Fig. 2 An example of the digitized radiofrequency (RF) signal. The white boxes indicate the sample volumes and cover the anterior (left) and posterior (right) walls.

After processing of all RF-lines, the movement of the arterial walls during time is shown on the screen (Fig.3). The distension curve - the change in diameter during time - is obtained by the difference in movement between the anterior and posterior wall. From this distension curve, diameter $(\mathrm{D})$ and change in diameter $(\Delta \mathrm{D})$ during each heart cycle can be obtained. Simultaneously with the vessel wall measurements arm blood pressure and heart rate are measured with a Dinamap (see section 2.3). Pulse pressure at the common carotid and common femoral arteries were obtained from calibration of the distension waveform. 


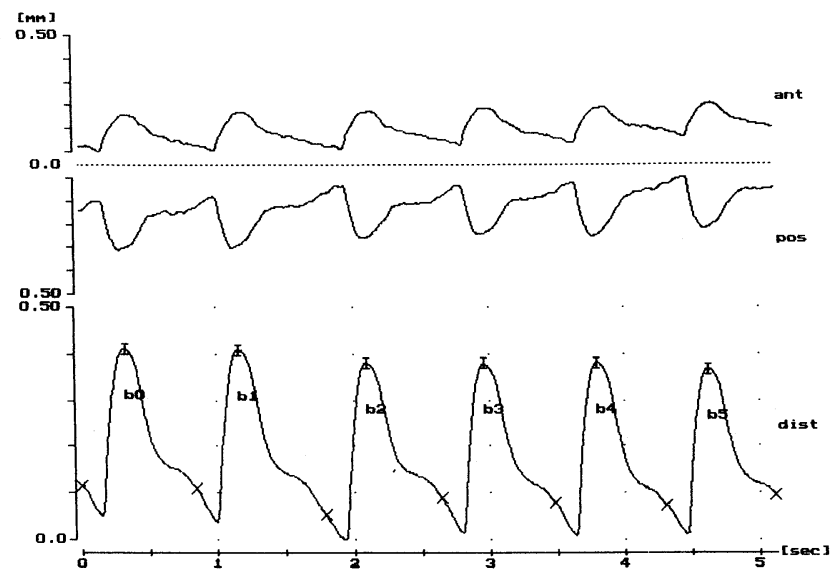

Fig. 3 Displacement waveforms of the anterior (top) and posterior (middle) wall of the common femoral artery. The difference between these two is the distension waveform (bottom). The cross indicates the occurence of the ECG trigger.

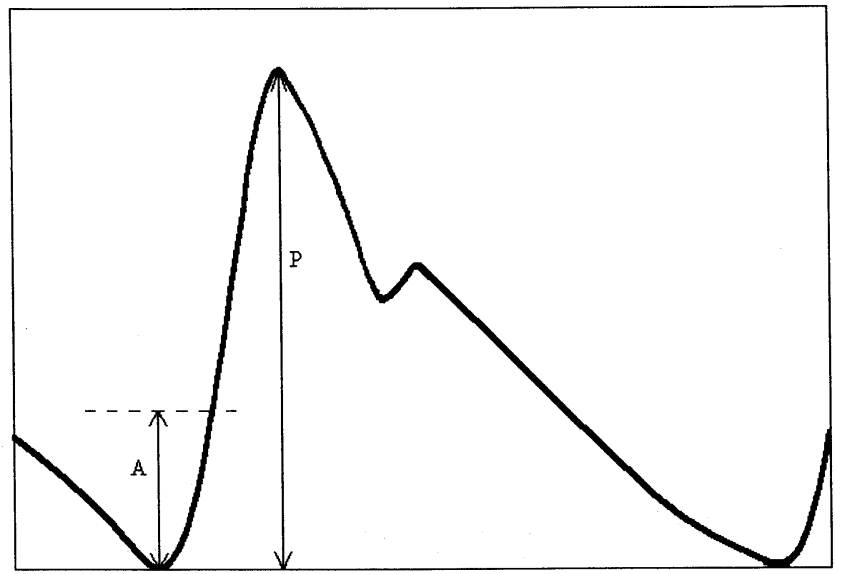

Fig. 4 Pressure wave. Y-axis: pressure, $\mathrm{X}$-axis: time; $\mathrm{P}$ represents pulse pressure, A represents MAPDBP.

\section{Calibration procedure:}

The calibration factor (CF) allows to calculate the pulse pressure at the target artery (PP tar) from the pulse pressure at the reference artery (PP ref) by the formula:

$\mathrm{PP}$ tar= CF x PP ref

The calibration factor can be calculated from the pressure waveforms at the target and reference artery. In the pressure wave shown in figure 4, ' $\mathrm{P}$ ' represents the pulse pressure and ' $\mathrm{A}$ ' MAP minus DBP (MAP-DBP) respectively. ' $\mathrm{P}$ ' and 'A' can be calculated from the pressure 
waveform in arbitrary units. 'A' is calculated by dividing the area under the pressure wave by time. This can be written by the formula:

$\mathrm{PP} /(\mathrm{MAP}-\mathrm{DBP})=\mathrm{P} / \mathrm{A}$, define $\mathrm{PA}=\mathrm{P} / \mathrm{A}$, then:

$(\mathrm{MAP}-\mathrm{DBP})=\mathrm{PP} / \mathrm{PA}$

As (MAP-DBP) is assumed constant through the large artery tree, this formula holds for

reference and target artery:

$\mathrm{PP} \operatorname{tar} / \mathrm{PA}$ tar $=\mathrm{PP}$ ref/PA ref $=(\mathrm{MAP}-\mathrm{DBP})$

$\mathrm{PP}$ tar $=\mathrm{PP}$ ref $\mathrm{x}$ PA tar/PA ref $=\mathrm{CF} \times \mathrm{PP}$ ref

The calibration factor $\mathrm{CF}=\mathrm{PA}$ tar $/ \mathrm{PA}$ ref

Likewise, instead of using the pressure waveform, in this thesis, the distension waveforms were used.

To calculate vessel wall properties - compliance and distensibility - , the assumption is made that an increase in arterial volume during systole is caused by an increase in cross-sectional area and not by a change in arterial length ${ }^{3,4}$. Cross-sectional compliance is defined as the compliance/unit of length; it is the change in cross-sectional area per unit of pressure. It reflects the buffering capacity of an artery. Likewise, distensibility is defined as the relative change in cross-sectional area per unit of pressure. It reflects the elasticity of the wall of the artery. From $\mathrm{D}, \Delta \mathrm{D}$ and $\Delta \mathrm{P}$ vessel wall properties can be calculated ${ }^{3}$ :

Compliance coefficient $(\mathrm{CC}) \quad=\Delta \mathrm{V} / \mathrm{L}) / \Delta \mathrm{P}=\Delta \mathrm{A} / \Delta \mathrm{P}=\pi\left(2 \mathrm{D} \cdot \Delta \mathrm{D}+\Delta \mathrm{D}^{2}\right) / 4 \Delta \mathrm{P}$

Distensibility coefficient $(\mathrm{DC})=(\Delta \mathrm{A} / \mathrm{A}) / \Delta \mathrm{P}=\left(2 \Delta \mathrm{D} \cdot \mathrm{D}+\Delta \mathrm{D}^{2}\right) /\left(\Delta \mathrm{P} . \mathrm{D}^{2}\right)$

This device can be used to measure vessel wall properties of different superficial large arteries. In the studies described in this thesis the elastic common carotid artery and the muscular brachial and femoral arteries were measured. A reproducibility study has shown that with this system diameter and change in diameter during the heart cycle can be measured reproducibly. Intraobserver variability at the common carotid artery was less than $5 \%$ for diameter and less than $10 \%$ for compliance and distensibility. The results for the muscular arteries were somewhat less, but still lower than $15 \%{ }^{5}$.

\subsubsection{Pulse wave velocity}

The vessel wall movement detector system also gives the delay time from the ECG-trigger (Rtop) to the $10 \%$ level of the distension waveform of the artery that is measured at that time. This estimates the transit time of the pulse wave between the heart and the site of measurement. The difference between the transit times of the pulse wave from the heart to the femoral and carotid artery was used as an estimate of the carotido-femoral transit time (T). The distances from the sternal notch to the site of measurement of the common carotid artery and femoral artery were measured with a tape measurer. The difference between these two distances was used as the length of the carotido-femoral segment $(\mathrm{L})^{6}$.

The average pulse wave velocity in this segment was calculated as:

$$
\mathrm{PWV}=\mathrm{L} / \mathrm{T}
$$


which is an estimate of the stiffness of mainly the aortic pathway ${ }^{7}$.

Pulse wave velocity is related to arterial distensibility (DC) by the formula:

$\mathrm{PWV}=\sqrt{1 / \rho \mathrm{DC}}$ (Moens Korteweg ${ }^{8,9}$ ) ( $\rho=$ blood density)

\subsection{Data analysis}

Database management and statistical analyses were performed with the SAS software (The SAS Institute Inc., Cary, North Carolina). The methods of data analysis are presented in the methods sections of each individual chapter. Data are mean \pm SE, except for demographic values (mean $\pm \mathrm{SD}$ ). A p-value $<0.05$ was considered as statistically significant. In the analyses, statistical adjustments were made for possible confounders: mean arterial pressure, pulse rate, body mass index, smoking, use of alcohol and antihypertensive treatment. 


\section{References}

1. Staessen JA, Roels H, Fagard R: Lead exposure and conventional and ambulatory blood pressure. A prospective population study. JAMA 1996;275:1563-1570.

2. Hoeks APG, Brands PJ, Smeets FAM, Reneman RS: Assessment of the distensibility of superficial arteries. Ultrasound Med Biol 1990;16:121-128.

3. Reneman RS, Van Merode T, Hick P, Muytjens AMM, Hoeks APG: Age related changes in carotid artery wall properties in men. Ultrasound Med Biol 1986;12:465-471.

4. Reneman RS, van Merode T, Hick P, Hoeks APG: Cardiovascular applications of multi-gate pulsed doppler systems. Ultrasound Med Biol 1986;12(no. 5):357-370.

5. Kool MJF, van Merode T, Reneman RS, Hoeks APG, Struijker Boudier HAJ, Van Bortel LMAB: Evaluation of reproducibility of a vessel wall movement detector system for assessment of large artery properties. Cardiovasc Res 1994;28:610-614.

6. Demolis PD, Asmar RG, Levy BI, Safar ME: Non-invasive evaluation of the conduit function and the buffering function of large arteries in man. Clin Physiol 1991;11:553-564.

7. O'Rourke MF: Function of arteries as vascular conduits, in O'Rourke MF (ed): Arterial function in health and disease. Edinburgh,London, Melbourne, New York, Churchill Livingstone, 1982, pp. 5364.

8. Moens E: Die Pulscurve. Leiden, EJ Brill, 1878.

9. Hoeks APG: Non-invasive study of local mechanical arterial characteristics in humans, in Safar ME (ed): The arterial system in hypertension. Dordrecht, The Netherlands, Kluwer Academic Publisher, 1993, pp. 119-134. 


\section{CHAPTER 3}

The effect of age on brachial artery wall properties differs from the aorta and is gender-dependent: a population study

J.J. van der Heijden-Spek, J.A. Staessen, R.H. Fagard, A.P. Hoeks, H.A. Struijker Boudier, L.M. Van Bortel

Hypertension 2000; 35:637-642 


\begin{abstract}
Compliance and distensibility are wall properties of large arteries, which may play a role in cardiovascular disease. The purpose of this study was to investigate whether the influence of age on these vessel wall properties differs between vascular territories and is gender-dependent.

In a population sample of 497 men and women, age between 20-79 years, diameter, distensibility and compliance coefficient of the muscular brachial artery were measured with an echo-tracking device. Distensibility of the aorta was measured using pulse wave velocity. The effects of age and gender were assessed, adjusted for confounding factors like mean blood pressure, pulse rate, body mass index, smoking, alcohol intake and antihypertensive treatment.

Covariance analysis showed no relation between gender and distensibility of the elastic aorta. Distensibility of the muscular brachial artery was lower in men, while men had a larger diameter and larger compliance of the brachial artery. With age distensibility of the aorta decreased in both sexes to the same extent, while distensibility of the brachial artery did not change significantly. With age brachial artery diameter increased; this increase was more pronounced in women. In men brachial artery compliance did not change with age, while in women compliance of the brachial artery increased with age.

This study (1) confirms that distensibility of the aorta, an elastic artery, decreases with age. (2) In contrast to the aorta, after adjustment for confounding factors, in both men and women no relation exists between age and distensibility of the muscular brachial artery. (3) Brachial artery diameter increase with age is more pronounced in women than in men. (4) In contrast to the well-known decrease in arterial compliance of elastic arteries with age, brachial artery compliance is not decreased with age and even increased in women. In conclusion, the effect of age on large artery wall properties is not uniform, but depends on gender and vascular territory.
\end{abstract}




\section{Introduction}

Compliance and distensibility are vessel wall properties of large arteries. Arterial compliance, defined as the absolute change in volume per unit of pressure $(\Delta \mathrm{V} / \Delta \mathrm{P})$, reflects the buffering capacity of an artery; a decrease in compliance increases cardiac afterload and the risk of cardiac hypertrophy ${ }^{1-3}$. Arterial distensibility, defined as the relative change in volume per unit of pressure $((\Delta \mathrm{V} / \mathrm{V}) / \Delta \mathrm{P})$, reflects mainly the elasticity of the wall, and is considered a determinant of strain on the vessel wall ${ }^{4}$. A local decrease in distensibility might be associated with an increased risk of arterial wall damage, an important feature in atherosclerotic disease ${ }^{5}$. Preservation of distensibility might be important in protecting the arterial wall against damage at a particular site ${ }^{6}$.

From 1880 on, several groups have investigated the effect of age on elastic properties of the arterial system ${ }^{7}$. The first studies were post mortem studies ${ }^{8-10}$, later followed by in vivo measurements of regional distensibility ${ }^{11,12}$. At the age of twenty the vascular system is considered to be mature but it is unclear from which age distensibility starts to decrease. Several studies reported the influence of age on wall properties of elastic large arteries. It has been suggested that aortic distensibility reaches its peak at about 10 years of age ${ }^{11}$, and starts to decrease in the 3rd age decade ${ }^{9,13}$. With advancing age elastic arteries, like the aorta and common carotid artery dilate, become stiffer and show an increase in wall thickness ${ }^{8,11-18}$. The arterial tree, however, not only comprises elastic, but also medium-sized muscular arteries, like the brachial artery. Whether the effect of age on arterial wall properties of these arteries is similar to the effect on elastic arteries is not known. In addition, no study investigated whether the effect of age is gender-dependent. The aim of the present study was to investigate the effects of age and gender on wall properties of the medium-sized muscular brachial artery compared to the elastic aorta in a general population.

\section{Methods}

A population sample of 250 men and 247 women were investigated ${ }^{19}$ (chapter 2).

Nurses who had previously visited the participants at home, measured sitting blood pressure conventionally with a sphygmomanometer and interviewed the participants about their current health status, smoking and drinking habits and intake of drugs.

After 15 minutes of supine rest in a quiet room aortic and brachial artery wall properties were measured. Vessel wall properties of the right brachial artery were measured with a vessel wall movement detector system ${ }^{20}$ as described in chapter 2 . Simultaneously with the vascular measurements, blood pressure was measured at the left arm, with a semiautomated device (Dinamap; Critikon, Tampa, Florida). Pulse pressure was calculated as SBP-DBP. $\triangle \mathrm{P}$ during the heart cycle equals pulse pressure. From diameter, change in diameter during the heart cycle and pulse pressure, cross-sectional compliance and distensibility were calculated with the equations mentioned in chapter 2 . This method has shown good reproducibility ${ }^{20}$.

Vessel wall properties of the aorta were measured using pulse wave velocity. The delay times to the femoral and carotid artery was used as an estimate of the carotido-femoral transit time (T). The difference between the distances from the sternal notch to the site of measurement of the common carotid artery and femoral artery was used as an estimate of the length of the carotido-femoral segment $\left(\mathrm{L}_{\mathrm{ao}}\right)^{21}$. From this transit time and length, the pulse wave velocity of the aorta was calculated ${ }^{22}$ (chapter 2). Pulse wave velocity is related to arterial distensibility (DC) by the formula: PWV $=\sqrt{ } 1 / \rho D C \quad$ (Moens Korteweg ${ }^{23,24}$ ) ( $\rho=$ blood density) 


\section{Effects of age: aorta and brachial artery}

Database management and statistical analyses were performed with the SAS software (The SAS Institute Inc., Cary, North Carolina). The methods of analysis included Mann-Whitney-U tests for continuous variables and Chi-square tests for the dichotomous parameters. To test the influence of gender, an analysis of covariance was used with factors for mean arterial pressure (measured by sphygmomanometer), pulse rate, body mass index, smoking, use of alcohol and antihypertensive treatment. Factors with a p-value $>0.10$ were dropped from the model. To get the relation between vessel wall properties and age, age was also added as a covariate. To investigate the difference of the age-effect among the sexes, the interaction of age and sex was also tested for. A p-value $<0.05$ was considered as statistically significant.

The study was approved by the ethics committee of Leuven University and all subjects gave their written informed consent.

\section{Results}

The subjects, 250 men and 247 women, were $50 \pm 13$ years old, with a range from $26-82$ years (chapter 2). The distribution of age was similar among men and women: $6.0 \%$ were from 20 through 29 years old, $16.1 \%$ from 30 through $39,31.5 \%$ from 40 through $49,23.1 \%$ from 50 through $59,16.3 \%$ from 60 through 69 , and $7.0 \%$ were 70 years or older. The conventionally measured systolic and diastolic blood pressure was slightly higher in men than in women. Current smoking was reported by 160 participants (median 15 cigarettes a day; range 1-70) and 113 subjects reported regular alcohol consumption (median $20 \mathrm{~g}$ a day; range 1-196). A total of 77 subjects were taking antihypertensive treatment either in monotherapy or in combination. Of these, $36.4 \%$ ( 8 men and 20 women) were on diuretics, $57.1 \%$ ( 22 men and 22 women) on beta-blockers, $7.8 \%$ (4 men and 2 women) on angiotensin-converting-enzyme inhibitors and $26.0 \%$ ( 13 men and 7 women) on calcium antagonists.

Differences in vessel wall properties between men and women are shown in Table 1.

Table 1. Vessel wall properties in a random population

\begin{tabular}{llllllll}
\hline & \multicolumn{2}{c}{ Unadjusted } & & \multicolumn{2}{c}{ Adjusted $^{\dagger}$} & \\
Artery & Men & Women & $\mathrm{p}$ & Men & Women & $\mathrm{p}$ \\
& $\mathrm{N}=250$ & $\mathrm{~N}=247$ & & $\mathrm{~N}=250$ & $\mathrm{~N}=247$ & \\
\hline Aorta & & & & & & & \\
$\quad$ PWV $(\mathrm{m} / \mathrm{s})$ & $7.0 \pm 1.9$ & $6.7 \pm 2.1$ & $* *$ & $7.4 \pm 2.4$ & $7.2 \pm 2.2$ & \\
Brachial artery & & & & & & \\
$\quad$ Diameter $(\mathrm{mm})$ & $4.55 \pm 0.60$ & $3.65 \pm 0.57$ & $* * *$ & $4.52 \pm 0.48$ & $3.68 \pm 0.48$ & $* * *$ \\
DC $\left(10^{-3} / \mathrm{kPa}\right)$ & $20.9 \pm 9.9$ & $24.4 \pm 12.0$ & $* * *$ & $21.2 \pm 10.1$ & $24.1 \pm 10.2$ & $* * *$ \\
$\mathrm{CC}\left(\mathrm{mm}^{2} / \mathrm{kPa}\right)$ & $0.33 \pm 0.13$ & $0.25 \pm 0.12$ & $* * *$ & $0.33 \pm 0.12$ & $0.25 \pm 0.12$ & $* * *$ \\
\hline
\end{tabular}

Results are mean $\pm \mathrm{SD} .{ }^{\dagger}$ Data adjusted for mean arterial pressure, pulse rate, body mass index, current smoking, current alcohol intake and use of antihypertensive treatment. ${ }^{\ddagger}$ Measurements available in 242 men and 243 women. PWV: pulse wave velocity, Diameter: diameter, DC: distensibility coefficient, CC: cross-sectional compliance ; Statistical significance: $* * \mathrm{p}<.01,{ }^{* * *} \mathrm{p}<.001$ 
Since vessel wall properties can be influenced by confounders, which might differ between men and women, values were calculated adjusted for confounders like mean arterial pressure, pulse rate, body mass index, smoking, use of alcohol and antihypertensive treatment. After adjustment, pulse wave velocity of the aorta, a measure of aortic distensibility, was not different between men and women. Distensibility of the brachial artery was larger in women $(p<.001)$. But diameter and cross-sectional compliance of the brachial artery were smaller $(\mathrm{p}<.001)$ in women compared to men.

Descriptive analysis of the effect of age on vessel wall properties in men and women is shown in Fig. 1 and 2. Figures 1 and 2 show on the left the mean \pm SEM of the vessel wall properties for each 10-year age class, before adjustment for confounders mentioned above.

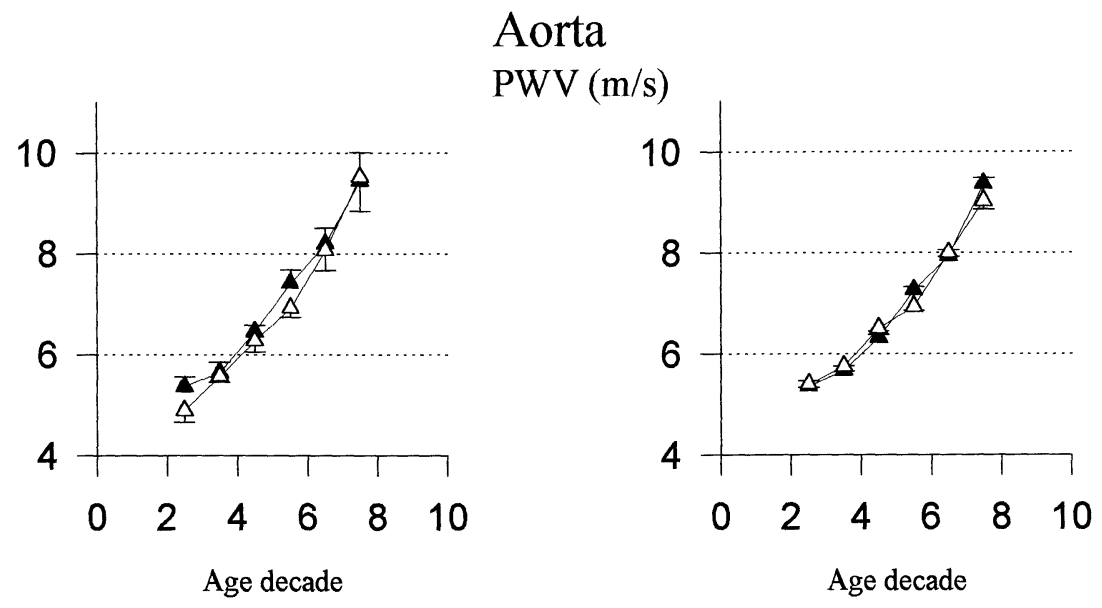

Fig. 1 Association between age and pulse wave velocity of the aorta in the whole population sample. Results before (left) and after (right) adjustment for mean arterial pressure, pulse rate, body mass index, current smoking, current alcohol intake and antihypertensive treatment. $\boldsymbol{\Delta}$ Men, $\Delta$ Women. Mean \pm SEM.

In a further step of the analysis a linear as well as a curvilinear (i.e. including both age and the quadratic term of age) model were fitted to the relationships between age and large artery wall properties for men and women separately. These analyses showed that a linear model (Table 2a, unadjusted values) was sufficient to fit all age relationships. The relationship was also analysed after adjusting for the confounders (Table $2 b$, adjusted values). All individual data were recalculated according to the adjusted linear regression model and are shown in Fig. 1-2 (on the right). 
Brachial Artery

$\mathrm{D}(\mathrm{mm})$
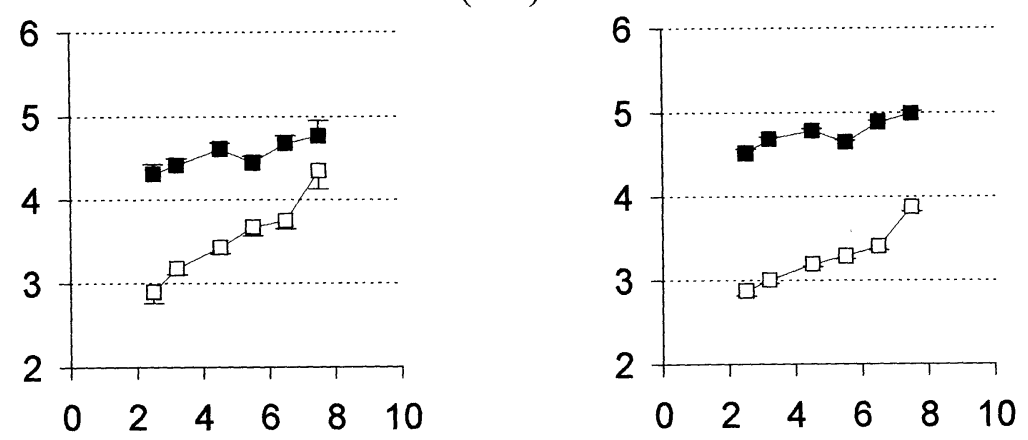

DC $(10-3 / \mathrm{kPa})$
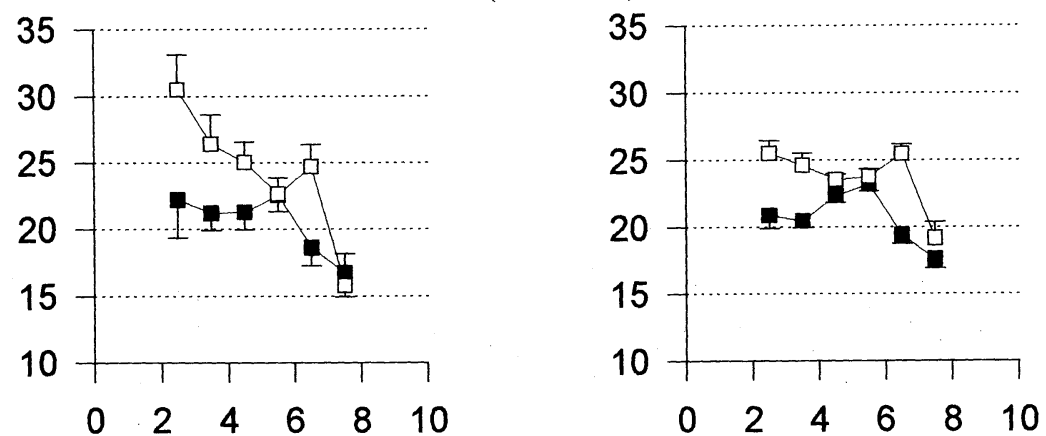

$\mathrm{CC}(\mathrm{mm} 2 / \mathrm{kPa})$
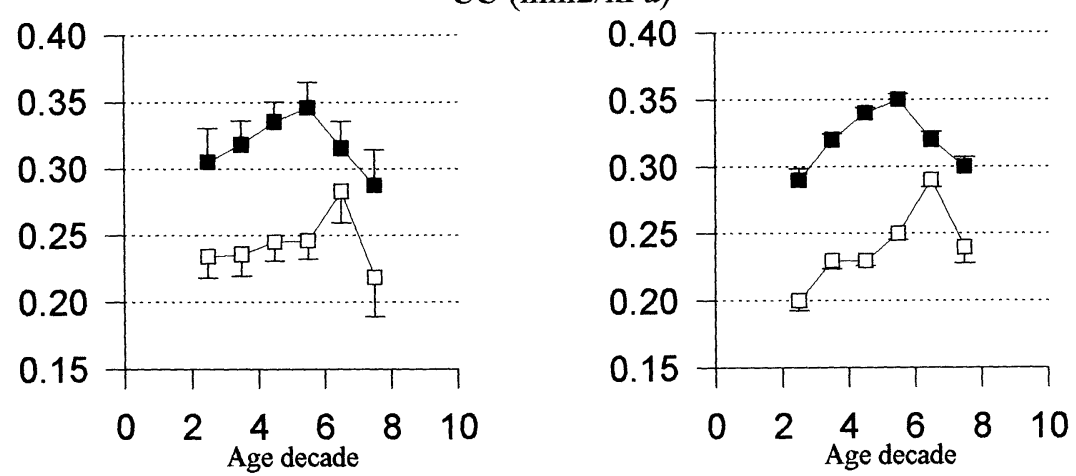

Fig. 2 Association between age and vessel wall properties of the brachial artery in the whole population sample. Results before (left) and after (right) adjustment for mean arterial pressure, pulse rate, body mass index, current smoking, current alcohol intake and antihypertensive treatment. $\mathbf{D e n}, \square$ Women. Mean \pm SEM. 
PWV of the aorta increased with age to the same extent in both sexes. Although visual inspection of adjusted data suggests a more pronounced decrease in brachial artery distensibility in women than in men, the linear regression model could neither in men nor in women show a statistically significant change in brachial artery distensibility with age (men: $p=0.76$; women: $\mathrm{p}=0.61$ ) after adjustment for confounders (Table $2 \mathrm{~b}$ ). Visual inspection of the relation between age and brachial artery diameter or cross-sectional compliance is in accordance with the linear regression model: after adjustment for confounders (Table $2 \mathrm{~b}$ ) with advancing age brachial artery diameter increased more in women $(\mathrm{p}=0.013)$ than in men. Brachial artery compliance increased in women $(\mathrm{p}=0.002)$, while it remained unchanged in men.

Table 2a. Relation between vessel wall properties and age. Unadjusted

\begin{tabular}{llll}
\hline Artery & $\begin{array}{l}\text { Men } \\
\text { slope } \\
(\text { age })^{-1} \cdot 10^{-3}\end{array}$ & $\begin{array}{l}\text { Women } \\
\text { slope } \\
(\text { age })^{-1} .10^{-3}\end{array}$ & $\begin{array}{l}\text { Gender difference } \\
\text { regarding slope }\end{array}$ \\
\hline $\begin{array}{l}\text { Aorta } \\
\text { PWV }(\mathrm{m} / \mathrm{s})\end{array}$ & $90.0 \pm 7.6^{* * *}$ & $95.3 \pm 9.4^{* * *}$ & n.s. \\
Brachial artery & $5.9 \pm 2.9 *$ & $19.8 \pm 2.6^{* * *}$ & $* * *$ \\
$\mathrm{D}(\mathrm{mm})$ & $-90.4 \pm 48.3^{*}$ & $-188.1 \pm 60.6^{* *}$ & n.s. \\
DC $\left(10^{-3} / \mathrm{kPa}\right)$ & n.s. & n.s. & n.s. \\
$\mathrm{CC}\left(\mathrm{mm}^{2} / \mathrm{kPa}\right)$ & & & \\
\hline
\end{tabular}

Regression coefficients \pm SE; ${ }^{\ddagger}$ Measurements available in 242 men and 243 women; PWV: pulse wave velocity, D: diameter, DC: distensibility coefficient, CC: cross-sectional compliance n.s. non-significant, $* \mathrm{p}<.05 ; * * \mathrm{p}<.01 ; * * * \mathrm{p}<.001$

Table 2b. Relation between vessel wall properties and age. Adjusted ${ }^{\dagger}$

\begin{tabular}{llll}
\hline Artery & $\begin{array}{l}\text { Men } \\
\text { slope } \\
(\text { age })^{-1} .10^{-3}\end{array}$ & $\begin{array}{l}\text { Women } \\
\text { slope } \\
(\text { age })^{-1} .10^{-3}\end{array}$ & $\begin{array}{l}\text { Gender difference } \\
\text { regarding slope }\end{array}$ \\
\hline $\begin{array}{l}\text { Aorta } \\
\text { PWV }(\mathrm{m} / \mathrm{s})\end{array}$ & $80.8 \pm 8.4^{* * *}$ & $76.9 \pm 9.4^{* * *}$ & n.s. \\
Brachial artery & $4.3 \pm 2.6+$ & $13.7 \pm 2.9 * * *$ & $*$ \\
D $(\mathrm{mm})$ & n.s. & n.s. & n.s. \\
DC $\left(10^{-3} / \mathrm{kPa}\right)$ & n.s. & $2.1 \pm 0.7 * *$ & $*$ \\
$\mathrm{CC}\left(\mathrm{mm}^{2} / \mathrm{kPa}\right)$ & & & \\
\hline
\end{tabular}

Regression coefficients $\pm \mathrm{SE} ;{ }^{\dagger}$ Adjusted for mean arterial pressure, pulse rate, body mass index, current smoking, current alcohol intake and use of antihypertensive treatment.

${ }^{\ddagger}$ Measurements available in 242 men and 243 women; PWV: pulse wave velocity, D: diameter, DC: distensibility coefficient, CC: cross-sectional compliance ; n.s. non-significant, $+\mathrm{p}<.1, * \mathrm{p}<$ $.05 ; * * \mathrm{p}<.01 ; * * * \mathrm{p}<.001$ 


\section{Discussion}

The present study investigated whether the well known decrease in aortic distensibility with age was also present in the muscular brachial artery and whether it was similar in men and women. Changes in vessel wall properties with age are not only the effect of ageing, but can also be the effect of other, interrelating factors that change with age. From previous studies blood pressure, body mass index and antihypertensive treatment have been identified ${ }^{25-27}$ as confounding factors. The effect of other factors, like smoking and pulse rate, is not always clear ${ }^{28-30}$. In the present study, to get the relation between vessel wall properties and age, values were adjusted for mean auscultatory blood pressure, pulse rate, antihypertensive treatment, body mass index, smoking and use of alcohol for each gender.

Gender differences in a random population In this population sample distensibility of the aorta did not differ between men and women. Kupari ${ }^{31}$, who investigated men and women aged 36 and 37 years old, also reported a gender independency of the aortic stiffness. Laogun et al however showed a higher aortic distensibility in women between $15-45$ years old compared to age-matched men ${ }^{11}$. This contradictory result could be due to the use of a smaller study population in the latter study. In addition, in this study no corrections were made for confounders, like mean arterial pressure and body mass index; which are important determinants of large artery properties and often differ between men and women. Also in the present study, the unadjusted data showed a higher aortic distensibility in women, compared to men. However, after adjustment there was no difference anymore. In contrast to the aorta, distensibility of the muscular brachial artery was larger in women compared to men. The reason of this gender difference is not quite clear. One reason could be a difference in smooth muscle tone and vessel wall structure (elastin/collagen) between men and women, possibly related to hormonal influences, for instance effects of estrogen. Constitutional differences between men and women might also play a role. Diameter of the brachial artery was larger in men, compared to women. Other authors also showed larger diameters of different arteries in men ${ }^{10,14,15}$. Since the caliber of vessels is related to body size (height and weight) ${ }^{16,32}$, and the size of women is smaller than of men, this could explain the smaller vessel diameter in women ${ }^{32}$. Because of the larger diameter in men, compliance of the brachial artery was higher in men than in women, despite the lower distensibility of the brachial artery.

Effect of age and gender Distensibility of the aorta decreased with age in both sexes to the same extent. These results confirm earlier studies ${ }^{11,18}$. Several studies showed that distensibility of another elastic artery, the carotid artery, also decreases with age ${ }^{13,18}$. In contrast the present study showed that distensibility of the muscular brachial artery was not related with age as already observed by Kawasaki and coworkers ${ }^{18}$. In addition the present study showed that this was the case for both men and women.

The mechanism by which ageing causes a decrease in distensibility of the aorta and common carotid artery is not fully clear. Several hypotheses have been proposed. Firstly the fatigueing effect of cyclic stress on the elastic fibers could play a role ${ }^{33,34}$. Ageing may lead to degeneration of the elastic fibers with stretching and remodeling of the arterial wall ${ }^{33,34}$, resulting in a loss of elasticity and a parallel increase in collagen and mucopolysaccharides. This hypothesis is supported by the observation that the decrease in distensibility with age is proportional to the increase in collagen with age ${ }^{34}$. Degeneration of elastin fibers may also explain arterial dilation with age. This dilation is greater in elastic than in muscular arteries, as would be predicted from theory. Secondly, with age vascular smooth muscle cells accumulate in the 
arterial wall. Thirdly, atherosclerosis could play a role ${ }^{34,35}$. The exact relation between atherosclerosis and arterial wall stiffness is still unclear. Besides, it has been shown that also in a population without atherosclerosis compliance decreased with age ${ }^{12}$. Fourthly, early and advanced wave reflections, seen with increasing age, could boost pulse pressure and decrease distensibility ${ }^{36}$.

In the present population sample, the diameter of the brachial artery increased with age. The results about changes in diameter of the brachial artery with age are not consistent in the literature. Some authors have found an increase in diameter ${ }^{18}$, while others have found no relation between age and arterial diameter ${ }^{14}$. There also seems to be a gender difference; in the present study the increase in diameter of the muscular brachial artery was more pronounced in women than in men.

Compliance of the BA was not related with age in men. Surprisingly, compliance of the BA increased with age. This increase was statistically significant in women but not in men. The increase in compliance of the BA is caused by a larger diameter, without a statistical change in distensibility. The increase in arterial diameter with age is also found in other arteries ${ }^{16-18}$. It has been suggested that the larger diameter with age is due to loss of elastic fibers in the arterial wall. Since brachial artery elasticity (reflected by distensibility) appears not significantly changed with age, an alternative explanation could be an adaptive remodeling of the brachial artery. If this latter hypothesis is true, than this adaptive remodeling of the brachial artery with age may be more pronounced in women than in men.

In conclusion, this study confirms that distensibility of the aorta, an elastic artery, decreases with age. This study shows that (1) in contrast to the aorta, after adjustment for confounding factors, in both men and women no relation exists between age and distensibility of the muscular brachial artery. (2) Brachial artery diameter increase with age is more pronounced in women than in men. (3) In contrast to the well-known decrease in arterial compliance of elastic arteries with age, brachial artery compliance is not decreased with age but even increased in women. (4) The effect of age on large artery wall properties is not uniform, but depends on gender and vascular territory.

\section{Acknowledgements}

The PheeCad study was supported by the municipality Hechtel-Eksel (Belgium), the National Fund for Medical Research Vlaanderen (Brussels, Belgium), the Ministry of the Flemish Community (Brussels, Belgium) and Schwarz Pharma GmbH (Monheim, Germany). The PheeCad study would not have been possible without the support of the General Practitioners. The field work was conducted with the assistance of O. Bomans, L. Gijsbers, A. Hermans, S. Van Hulle and M. Jehoul, Y. Toremans and R.Wolfs. The statistical analysis was conducted by B. Van Baelen. 


\section{References}

1. Langewouters GJ, Wesseling KH, Goedhard WJA: The static elastic properties of 45 human thoracic and 20 abdominal aortas in vitro and the parameters of a new model. J Biomech 1984;17:425-435.

2. Safar ME, London GM. The arterial system in human hypertension, in Swales JD (ed): Textbook of hypertension, 1st ed. Oxford, Blackwell Scientific Publications 1994, p 84-102.

3. Resnick LM, Militianu D, Cunnings AJ, Pipe JG, Evelhoch JL, Soulen RL. Direct magnetic resonance determination of aortic distensibility in essential hypertension. Hypertension 1997;30:654-659.

4. Hoeks APG, Brands PJ, Smeets FAM, Reneman RS: Assessment of the distensibility of superficial arteries. Ultrasound Med Biol 1990;16:121-128.

5. Fuster V, Badimon L, Badimon JJ, Chesebro JH: The pathogenesis of coronary artery disease and the acute coronary syndromes. N Engl J Med 1992;326:242-250.

6. Van Bortel LM, Kool MJ, Struijker Boudier HA: Effects of antihypertensive agents on local arterial distensibility and compliance. Hypertension 1995;26:531-534.

7. $\quad$ Roy CS: The elastic properties of the arterial wall. $J$ Physiol 1880;3:125-159.

8. Bader H: Dependence of wall stress in the human thoracic aorta on age and pressure. Circ Res 1967;20:354-361.

9. Newman DC, Lallemand RC: The effect of age on the distensibility of the abdominal aorta of man. Surg Gynecol Obstet 1978;147:211-214.

10. Learoyd MB, Taylor MG: Alterations with age in the viscoelastic properties of human arterial walls. Circ Res 1966;18:278-292.

11. Laogun AA, Gosling RG: In vivo arterial compliance in man. Clin Phys Physiol Meas 1982;3:201212.

12. Avolio AP, Chen S, Wang R, Zhang C, Li M, O'Rourke MF: Effects of aging on changing arterial compliance and left ventricular load in a northern Chinese urban community. Circulation 1983;68:5058.

13. Reneman RS, Van Merode T, Hick P, Muytjens AMM, Hoeks APG: Age related changes in carotid artery wall properties in men. Ultrasound Med Biol 1986;12:465-471.

14. Boutouyrie P, Laurent S, Benetos A, Girerd XJ, Hoeks APG, Safar ME: Opposing effects of ageing on distal and proximal large arteries in hypertensives. J Hypertens 1992;10(Suppl. 6):s87-s91.

15. Benetos A, Laurent S, Hoeks AP, Boutouyrie PH, Safar ME: Arterial alterations with ageing and high blood pressure. A noninvasive study of carotid and femoral arteries. Arterioscler Thromb 1993;13:9097.

16. Sonesson B, Hansen F, Stale H, Länne T: Compliance and diameter in the human abdominal aortathe influence of age and sex. Eur J Vasc Surg 1993;7:690-697.

17. Länne T, Sonesson B, Bergqvist D, Bengtsson H, Gustafsson D: Diameter and compliance in the male human abdominal aorta: influence of age and aortic aneurysm. Eur J Vasc Surg 1992;6:178-184.

18. Kawasaki T, Sasayama S, Yagi S, Asakawa T, Hirai T: Non-invasive assessment of the age related changes in stiffness of major branches of the human arteries. Cardiovasc Res 1987;21:678-687.

19. Staessen JA, Roels H, Fagard R: Lead exposure and conventional and ambulatory blood pressure. A prospective population study. JAMA 1996;275:1563-1570.

20. Kool MJF, van Merode T, Reneman RS, Hoeks APG, Struijker Boudier HAJ, Van Bortel LMAB: Evaluation of reproducibility of a vessel wall movement detector system for assess-ment of large artery properties. Cardiovasc Res 1994;28:610-614.

21. Demolis PD, Asmar RG, Levy BI, Safar ME: Non-invasive evaluation of the conduit function and the buffering function of large arteries in man. Clin Physiol 1991;11:553-564.

22. O'Rourke MF: Function of arteries as vascular conduits, in O'Rourke MF (ed): Arterial function in health and disease. Edinburgh,London, Melbourne, New York, Churchill Livingstone, 1982, pp. 5364.

23. Moens: Die Pulscurve. Leiden, EJ Brill, 1878.

24. Hoeks APG: Non-invasive study of local mechanical arterial characteristics in humans, in Safar ME (ed): The arterial system in hypertension., Kluwer Academic Publisher, 1993, pp. 119-134.

25. Spek JJ, Hoeks APG, Struijker Boudier HAJ, Van Bortel LMAB: Differences in vessel wall properties of large arteries between obese and lean subjects. Nier und Hochdruckkrank-heiten 1995;24:431- 
Chapter 3

$$
432 .
$$

26. Van Bortel LMAB, Kool MJF: Vessel wall properties of large arteries in hypertension and effect of antihypertensive treatment. Can J Cardiol 1994;10(Suppl. D):37D-40D.

27. Laurent S, Caviezel B, Beck L, Girerd X, Billaud E, Boutouyrie P, Hoeks A, Safar M: Carotid artery distensibility and distending pressure in hypertensive humans. Hypertension 1994;23:878-883.

28. Kool MJF, Hoeks APG, Struijker Boudier HAJ, Reneman RS, Van Bortel LMAB: Short- and longterm effects of smoking on arterial wall properties in habitual smokers. J Am Coll Cardiol 1993;2:1881-1886.

29. Stefanadis C, Vlachopoulos C, Tsiamis E, Diamantopoulos L, Toutouzas K, Giatrakos N, Vaina S, Tsekoura D, Toutouzas P: Unfavorable effects of passive smoking on aortic function in men. Ann Intern Med 1998;128:426-434.

30. Blacher J, Demuth K, Guerin AP, Safar ME, Moatti N, London GM: Influence of biochemical alterations on artarial stiffness in patients with end-stage renal disease. Arterioscler Thromb Vasc Biol 1998;18:535-541.

31. Kupari M, Hekali P, Keto P, Poutanen V, Tikkanen MJ, Standertskjold-Nordenstam C: Relation of aortic stiffness to factors modifying the risk of atherosclerosis in healthy people. Arterioscler Thromb 1994;14:386-394.

32. Milnor WR: Normal hemodynamic state, in Milnor WR (ed): Hemodynamics. Baltimore, Williams and Wilkins, 1982, pp. 135-156.

33. O'Rourke MF: Arterial stiffness, systolic blood pressure, and logical treatment of arterial hypertension. Hypertension 1990;15:339-347.

34. Safar M: Ageing and its effects on the cardiovascular system. Drugs 1990;39(Suppl. 1):1-8.

35. Virmani R, Avolio AP, Mergner WJ, Robinowitz M, Herderick EE, Cornhill JF, Guo S, Liu T, Ou D, O'Rourke M: Effect of ageing on aortic morphology in populations with high and low prevalence of hypertension and atherosclerosis. Comparison between occidental and chinese communities. Am J Physiol 1991;139:1119-1129.

36. Kelly R, Hayward C, Avolio A, O'Rourke M: Noninvasive determination of age-related changes in the human arterial pulse. Circulation 1989;80:1652-1659. 



\section{CHAPTER 4}

Disparate effects of age and gender on the wall properties of elastic and muscular large arteries: a population study 
Large artery wall properties: effects of age and gender

\begin{abstract}
Compliance and distensibility of large arteries may play a role in cardiovascular disease. The purpose of this study was to investigate how age and gender influence these vessel wall properties in different vascular territories.

In a population sample of 497 men $(M)$ and women $(F)$, ages 20-79 years, diameter, distensibility and cross-sectional compliance of the elastic common carotid artery (CCA), muscular brachial (BA) and femoral arteries (FA) were measured with an ultrasound device. The effects of age and gender were adjusted for confounding factors such as mean blood pressure, pulse rate, body mass index, smoking, alcohol intake and antihypertensive treatment.

With adjustment for confounders applied, in the 3 vascular territories men had a larger diameter and cross-sectional compliance of all arteries $(p<.001)$. Distensibility was similar in both sexes with the exception of the brachial artery, which in men showed lower distensibility $(p<.01)$. The diameter of the 3 arteries increased with age; for the muscular arteries $(B A$ and $F A)$ this increase was more pronounced $(p<.05)$ in women than in men. In men the CCA had the largest percentage increase (15\%) in diameter. Distensibility of the CCA and FA decreased with advancing age to a similar extent in both sexes. The percentage fall from the $3 r d$ to the 8th age decade was larger ( $p<.001)$ for the CCA $(M: 64 \%, F: 60 \%)$ than for the FA (M:29\%, F:38\%). Distensibility of the BA was not related to age. Cross-sectional compliance of the CCA decreased with age, more ( $p<.01)$ in men (50\%) than in women (40\%). Crosssectional compliance of the FA was not statistically related to age. In women, cross-sectional com-pliance of the BA increased (20\%) with age, in men there was no relation.

This study shows that the effect of age on large artery wall properties depends on (1) the vascular territory; with age arteries dilate and become stiffer, more in elastic than in muscular arteries. The effect of age on large artery wall properties also depends on (2) gender; the increase in diameter of muscular arteries is more pronounced in women.
\end{abstract}




\section{Introduction}

Arterial compliance (the buffering capacity of an artery, defined as the absolute change in volume per unit of pressure) and distensibility (reflecting largely the elasticity of the wall, defined as the relative change in volume per unit of pressure) can be indicative of early vascular changes and may play a role in atherosclerotic disease ${ }^{1-3}$.

Local distensibility and compliance can be assessed with ultrasonic wall-tracking techniques ${ }^{4}$. Studies using these techniques revealed that large conduit arteries do not react identically to disease states. For instance, in hypertension distensibility and compliance of elastic arteries decrease ${ }^{5}$, whereas compliance of the muscular radial artery does not ${ }^{6}$. Several authors studied the effect of aging on large artery wall properties. With advancing age elastic arteries, like the common carotid artery dilate, become stiffer and show an increase in wall thickness ${ }^{7}$ ${ }^{15}$. The influence of gender on these properties is inconsistent across the published reports $8,11,12,16,17$. The arterial tree, however, not only comprises elastic, but also (predominantly) muscular arteries, like the brachial and femoral arteries. Until now some smaller studies reported conflicting results on the effect of aging on muscular arteries ${ }^{10,11,14,18,19}$, whereas the effect of gender on these arteries also remains ill defined ${ }^{10,19}$.

The aim of the present study was to investigate the effects of age and gender on wall properties of three different vascular territories in a population sample: the common carotid artery, an elastic artery in which atherosclerosis is common, the common femoral artery, a muscular artery in which atherosclerosis is also common and the muscular brachial artery, an artery in which atherosclerosis is uncommon.

\section{Methods}

Vascular measurements were performed in 614 subjects from a random population sample ${ }^{20}$ (chapter 2). In the course of the present analysis a further 76 subjects were removed from the database, because vascular measurements were not available at all arteries studied. The number of subjects finally considered in the analysis totalled 250 men and 247 women.

All participants were asked to refrain from smoking, drinking caffeine containing beverages and heavy excercise for at least 3 hours before being examined. Firstly the sitting blood pressure was measured with a sphygmomanometer. Afterwards the participants were interviewed about their current health status, smoking and drinking habits and intake of drugs (chapter 2).

After 15 minutes of supine rest in a quiet room vessel wall properties of the right elastic common carotid artery (CCA) and right muscular common femoral (FA) and brachial (BA) arteries were measured with a vessel wall movement detector system ${ }^{4,21}$ (chapter 2).

Simultaneously with the assessment of the vessel wall properties blood pressure and pulse rate were recorded with a semiautomated device (Dinamap; Critikon, Tampa, Florida). Brachial artery pulse pressure was defined as systolic minus diastolic blood pressure. Pulse pressure at CCA and FA were calculated by calibration of the distension curves (chapter 2).

Database management and statistical analyses were performed with the SAS software (The SAS Institute Inc., Cary, North Carolina). The methods of analysis included Mann-Whitney-U tests for continuous variables and Chi-square tests for the dichotomous parameters. To test the influence of gender and age, analysis of covariance was used with mean arterial pressure (sphygmomanometer), pulse rate, body mass index, smoking, use of alcohol and antihypertensive treatment as covariates. Factors with a p-value $>0.10$ were dropped from the model. To 
Large artery wall properties: effects of age and gender

investigate the difference of the age-effect among the sexes, the interaction of age and sex was also tested for. In order to test the null hypothesis of no difference between the arteries regarding the effect of age on wall properties, a multivariate analysis of variance was performed for each sex separately on the percentage differences, calculated versus the wall properties in the 3 rd age decade. Data are mean \pm SD for demographic values and mean \pm SE for interactions. A p-value $<0.05$ was considered as statistically significant.

\section{Results}

Demographics of the subjects are described in chapter 2. Values of the vessel wall properties in men and women are shown in Table 1. After adjustment for mean arterial pressure, pulse rate, body mass index, smoking, use of alcohol and antihypertensive treatment, diameters of the CCA, BA and FA were larger $(\mathrm{p}<.001)$ in men compared to women. Distensibility of the elastic CCA and muscular FA did not differ statistically between men and women, whereas distensibility of the muscular BA was larger $(\mathrm{p}<.01)$ in women . Cross-sectional compliance of CCA, BA and FA were smaller $(\mathrm{p}<.001)$ in women.

Table 1. Vessel wall Properties in a random population

\begin{tabular}{lllllll}
\hline & \multicolumn{3}{c}{ Unadjusted } & \multicolumn{3}{c}{ Adjusted } \\
Artery & Men & Women & p & Men & Women & $\mathrm{p}$ \\
\hline Diameter & & & & & & \\
$\quad$ Carotid artery & $7.69 \pm 0.81$ & $6.90 \pm 0.80$ & $<.001$ & $7.38 \pm 0.96$ & $7.03 \pm 0.91$ & $<.001$ \\
Brachial artery & $4.55 \pm 0.60$ & $3.64 \pm 0.57$ & $<.001$ & $4.52 \pm 0.53$ & $3.68 \pm 0.53$ & $<.001$ \\
Femoral artery & $10.05 \pm 1.08$ & $8.53 \pm 1.02$ & $<.001$ & $9.92 \pm 1.06$ & $8.47 \pm 1.24$ & $<.001$ \\
DC $\left(10^{-3} / \mathrm{kPa}\right)$ & & & & & & \\
Carotid artery & $21.3 \pm 8.4$ & $21.8 \pm 8.6$ & .71 & $21.4 \pm 9.6$ & $21.3 \pm 10.5$ & .89 \\
Brachial artery & $20.8 \pm 9.9$ & $24.4 \pm 11.9$ & $<.001$ & $21.3 \pm 10.1$ & $23.9 \pm 10.1$ & .005 \\
Femoral artery & $7.9 \pm 4.1$ & $8.9 \pm 4.6$ & .02 & $8.1 \pm 4.9$ & $8.6 \pm 4.9$ & .14 \\
CC (mm $\left.{ }^{2} / \mathrm{kPa}\right)$ & & & & & & \\
Carotid artery & $0.97 \pm 0.37$ & $0.78 \pm 0.26$ & $<.001$ & $0.97 \pm 0.38$ & $0.78 \pm 0.41$ & $<.001$ \\
Brachial artery & $0.33 \pm 0.13$ & $0.25 \pm 0.12$ & $<.001$ & $0.33 \pm 0.12$ & $0.25 \pm 0.12$ & $<.001$ \\
Femoral artery & $0.61 \pm 0.30$ & $0.49 \pm 0.22$ & $<.001$ & $0.59 \pm 0.33$ & $0.44 \pm 0.35$ & $<.001$ \\
\hline
\end{tabular}

Results are mean $\pm \mathrm{SD} .{ }^{\dagger}$ Data adjusted for mean arterial pressure, pulse rate, body mass index, current smoking, current alcohol intake and use of antihypertensive treatment. DC: distensibility coefficient, CC: cross-sectional compliance

In a further step of the analysis a linear as well as a curvilinear (i.e. including both age and the quadratic term of age) model were fitted to the relationships between age and large artery properties for men and women separately (Table 2, unadjusted values). These analyses showed that a linear model was sufficient to fit all age relationships. These age-relationships were also analysed after adjusting for confounding factors (Table 2, adjusted values).

Results are shown in Fig. 1-2, as mean of each age decade and expressed as percentage difference compared to the 3 rd age decade. 


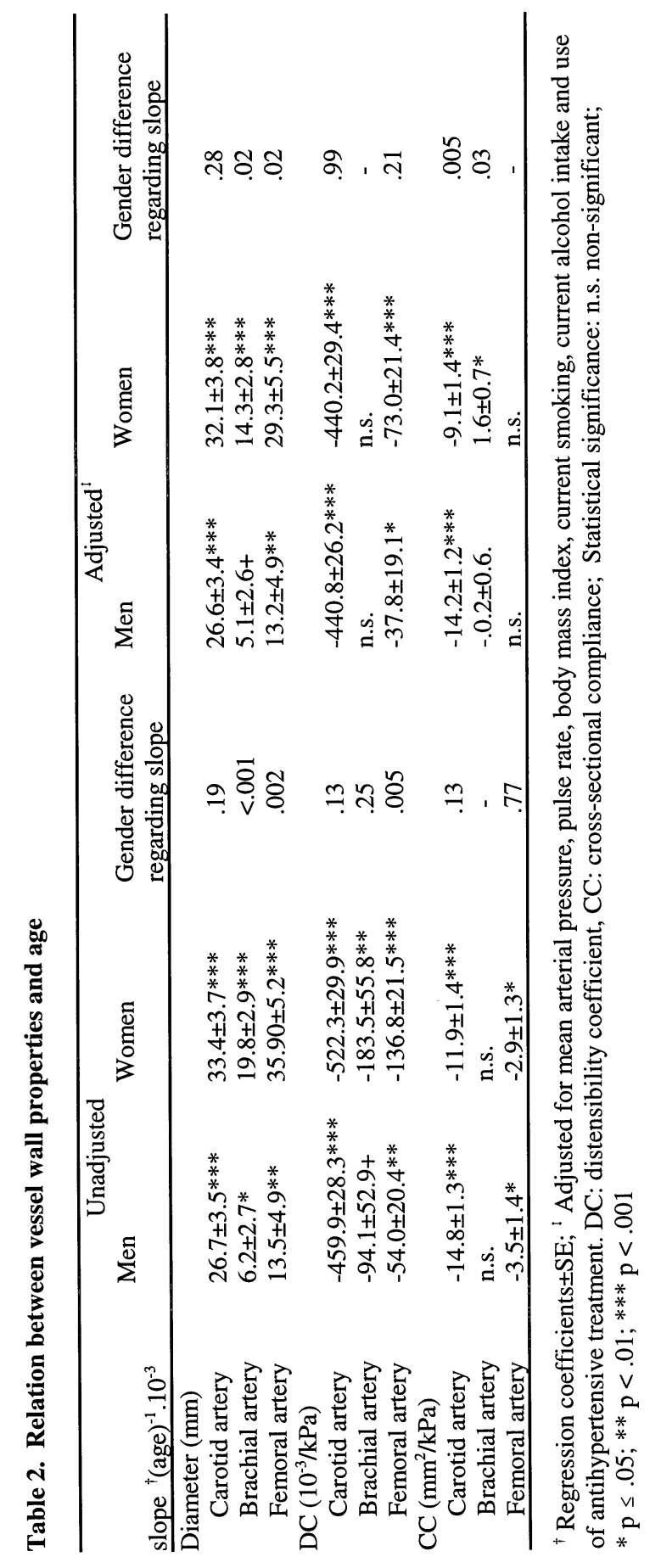


Large artery wall properties: effects of age and gender

Diameters of the CCA, BA and FA increased with advancing age in both men and women. The age-related increase in diameter of the muscular BA and FA was more pronounced $(\mathrm{p}<.05)$ in women than in men (Table 2). In men, after adjustment for confounders, the relative age-related dilatation of the CCA $(15 \%)$ was more pronounced than that of the FA $(3 \%, \mathrm{p}<.001)$ or BA $(10 \%, \mathrm{p}<.01)$ (Fig 1). Distensibility of the CCA and FA decreased equally in both men and women, while distensibility of the BA did not change statistically with age. In both men and women the percentage fall in distensibility from the 3rd to the 8th age decade was larger ( $\mathrm{p}<.001)$ in the CCA (M: 64\%, F:60\%) than in the FA (M:29\%, F:38\%) or BA (no relation with age) (Fig.1,2). In both men and women cross-sectional compliance of the CCA decreased with age, this phenomenon was more pronounced in men than in women $(\mathrm{p}<.01)$. Compliance of the FA was not statistically related to age. Compliance of the BA was also not correlated with age in men, but was positively correlated with age in women. In both sexes the percentage decrease in cross-sectional compliance of the CCA (M:50\%, F:40\%) was larger $(\mathrm{p}<.001)$ than in the FA (no significant relation with age) or BA (M:no relation, F: $20 \%$ increase with age).

\section{Discussion}

In the present population sample, in accordance with others ${ }^{10,11,17,22}$, arterial diameter of all arteries was larger in men than in women. This could be explained by constitutional differences between men and women or the relatively smaller size of women compared to men ${ }^{12,23}$. Distensibility of the CCA and FA did not differ between men and women, while distensibility of the muscular BA was larger in women compared to men. The reason of this gender difference and differences between arteries is not quite clear. Again constitutional differences might play a role. Another reason could be a difference in vessel wall structure (elastin/collagen) and smooth muscle tone between men and women. Hormones, like estrogen, could also play a role. Recent studies showed a lower CCA distensibility in postmenopausal women compared to premenopausal women of the same age ${ }^{24}$ and a reduction of carotid artery wall stiffness by administration of estrogens to postmenopausal women ${ }^{25}$. This suggests estrogens have a positive influence on arterial distensibility. Whether these effects are structural or more functional, for example by influencing arterial diameter has to be further elucidated.

Because of the larger diameter in men (and despite the lower distensibility of the BA), compliance of all three arteries was higher in men than in women, indicating men have a larger buffering capacity of large arteries.

One of the main findings of this study was that the effect of age depends on the vascular territory. In accordance to earlier studies ${ }^{11,12,14,26}$, diameter of all arteries increased with age in both sexes. It has been suggested that the larger diameter with age is due to the loss of elastic fibers in the arterial wall. Whether the arterial dilatation is a consequence of lifelong cyclic stress or is a physiological adaptation to an increased stiffness is not known.

The relatively largest percentage increase in diameter was seen for the elastic CCA. This is in line with the statement that with age proximal, elastic arteries predominantly dilate, whereas peripheral, muscular arteries are more prone to wall thickening ${ }^{27}$. On the other hand, percentage dilatation of the BA, a more muscular artery, was almost equal to that of the CCA. This suggests that at the BA, another vasodilatory mechanism than degeneration might be involved. In both men and women distensibility of the CCA and FA was negatively related with age, 
whereas distensibility of the BA was not related with age in both sexes. A decrease in carotid artery DC was described before ${ }^{8,13-15}$. Earlier studies describing the relation between age and femoral artery DC show some discrepancies: some found no relation ${ }^{11,14}$, while others only found a relation in women ${ }^{19}$. The mechanism by which aging causes a decrease in large artery distensibility is not fully clear. (1) Aging, meaning years of cyclic stress, may lead to degeneration of the elastin fibers with stretching and remodeling of the arterial wall ${ }^{28,29}$, resulting in a loss of elasticity and a parallel increase in collagen and mucopolysaccharide. This mainly occurs in the elastic arteries. (2) Vasodilatation per se can lead to a decrease in distensibility. (3) Another reason could be accumulation of vascular smooth muscle cells in the arterial wall. (4) Atherosclerosis could also play a role in the ageing process ${ }^{28,30}$. (5) Finally, early and advanced wave reflections, seen with increasing age, could boost pulse pressure and further decrease distensibility ${ }^{31}$, especially of central arteries like the aorta and carotid artery.

In accordance to previous reports, in the present study distensibility was lower towards the periphery ${ }^{8,11,27}$. This has been attributed to differences in histopathological structures: in the proximal aorta elastin is the dominant component, whereas towards the periphery collagen dominates ${ }^{8,11,22,32}$. As stated, the present study shows that with ageing the largest percentage decrease in distensibility was seen in the central elastic CCA. This means that with advancing age the difference in stiffness between central and more peripheral arteries decreases. In addition, Van Merode et all described that the inhomogeneous distribution of wall elasticity along the femoral artery bifurcation in young subjects becomes more homogeneous in the older age ${ }^{33}$. This supports the idea, that in old age the aorta and large arteries will behave like a branching tube of common stiffness ${ }^{34}$. It might also indicate that smaller, more muscular arteries are capable to adapt to the decreased elasticity of the larger arteries, possibly by changing arterial tone.

Compliance of the CCA decreased with age in both men and women. This is caused by the large decrease in distensibility with age, which was not completely counteracted by the increase in diameter. Compliance of the FA was however not related with age in both sexes. Only a small number of studies exist on the effect of age on arterial compliance, confirming the present results on the $\mathrm{CCA}{ }^{11,16}$ and $\mathrm{FA}^{11,19}$. Compliance of the BA in men was also not related with age, whereas in women compliance of the BA increased with age. The more pronounced increase in BA compliance in women may result in a smaller loss of systemic arterial compliance with aging.

This brings us to the second main finding of our study, namely that the effect of age also is gender-dependent. Distensibility of all arteries decreased in both sexes to the same extent. Compliance of the CCA decreased more in men, than in women. As mentioned before, compliance of the BA increased in women and did not change in men. This increase in compliance of the BA is caused by an increase in diameter, without a statistical change in distensibility. The increase in brachial artery diameter, with no significant change in brachial artery elasticity (reflected by distensibility), suggests the increase in diameter is not totally due to a degeneration of elastic fibers, but is rather an adaptive remodeling proces of the brachial artery. This vasodilation appears to be more pronounced in women, especially in the muscular BA and FA. This was not the case for the elastic CCA. Maybe estrogens also play a role in this process, since recent studies showed estrogens have a direct effect on the arterial wall, inducing vasodilation ${ }^{35}$. The increase in brachial artery compliance with age in women may limit the decrease in systemic arterial compliance. 


\section{Large artery wall properties: effects of age and gender}

In conclusion, this study shows that [1] the effect of age on large artery wall properties depends on the vascular territory; with age arteries dilate and become stiffer, more in elastic than muscular arteries. [2] The effect of age on large artery wall properties also depends on gender; the increase in diameter of muscular arteries is more pronounced in women. [3] The present study confirms that vessel wall properties differ between men and women; men have a larger arterial diameter and compliance than women.

\section{Acknowledgements}

The PheeCad study was supported by the municipality Hechtel-Eksel (Belgium), the National Fund for Medical Research Vlaanderen (Brussels, Belgium), the Ministry of the Flemish Community (Brussels, Belgium) and Schwarz Pharma GmbH (Monheim, Germany). The PheeCad study would not have been possible without the support of the General Practitioners. The field work was conducted with the assistance of O. Bomans, L. Gijsbers, A. Hermans, S. Van Hulle and M. Jehoul, Y. Toremans and R.Wolfs. The statistical analysis was conducted by B. Van Baelen. 


\section{Men}

$\mathrm{D}(\mathrm{mm})$
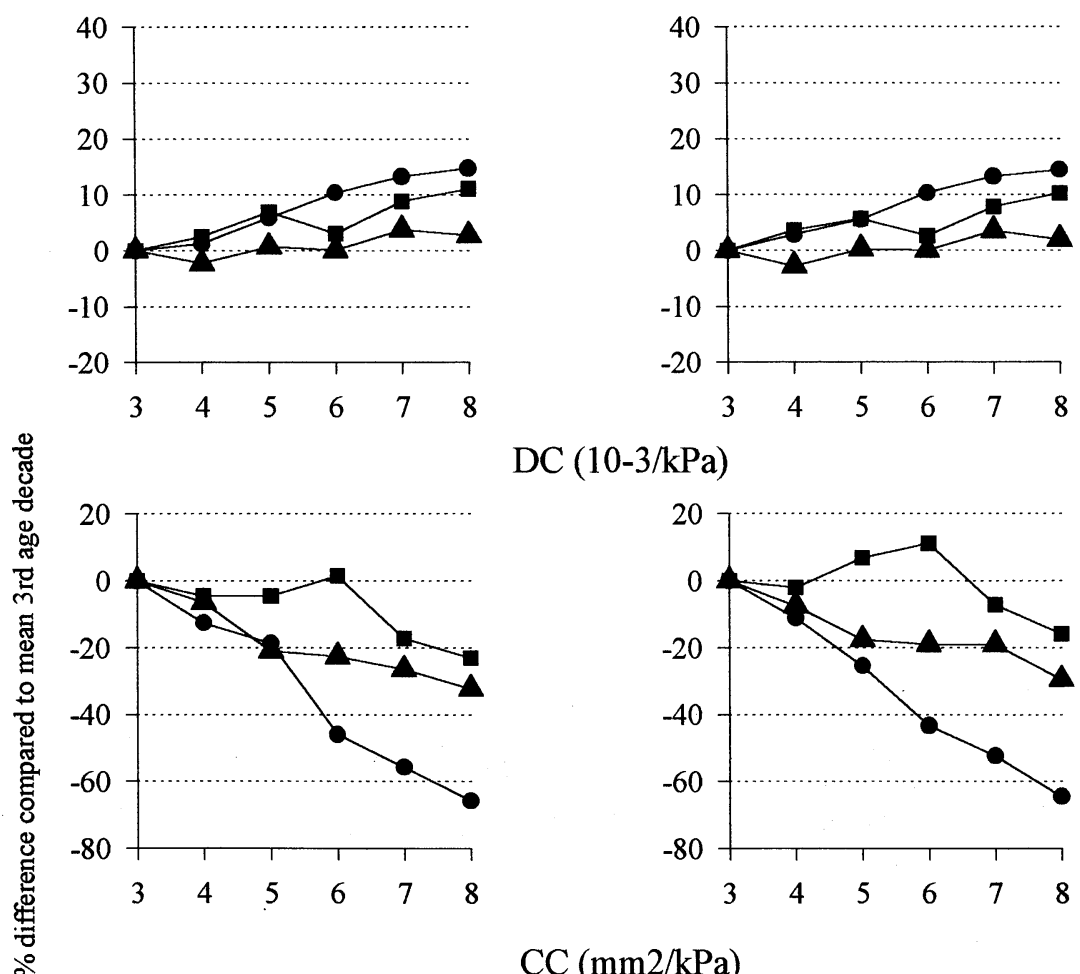

$\mathrm{DC}(10-3 / \mathrm{kPa})$
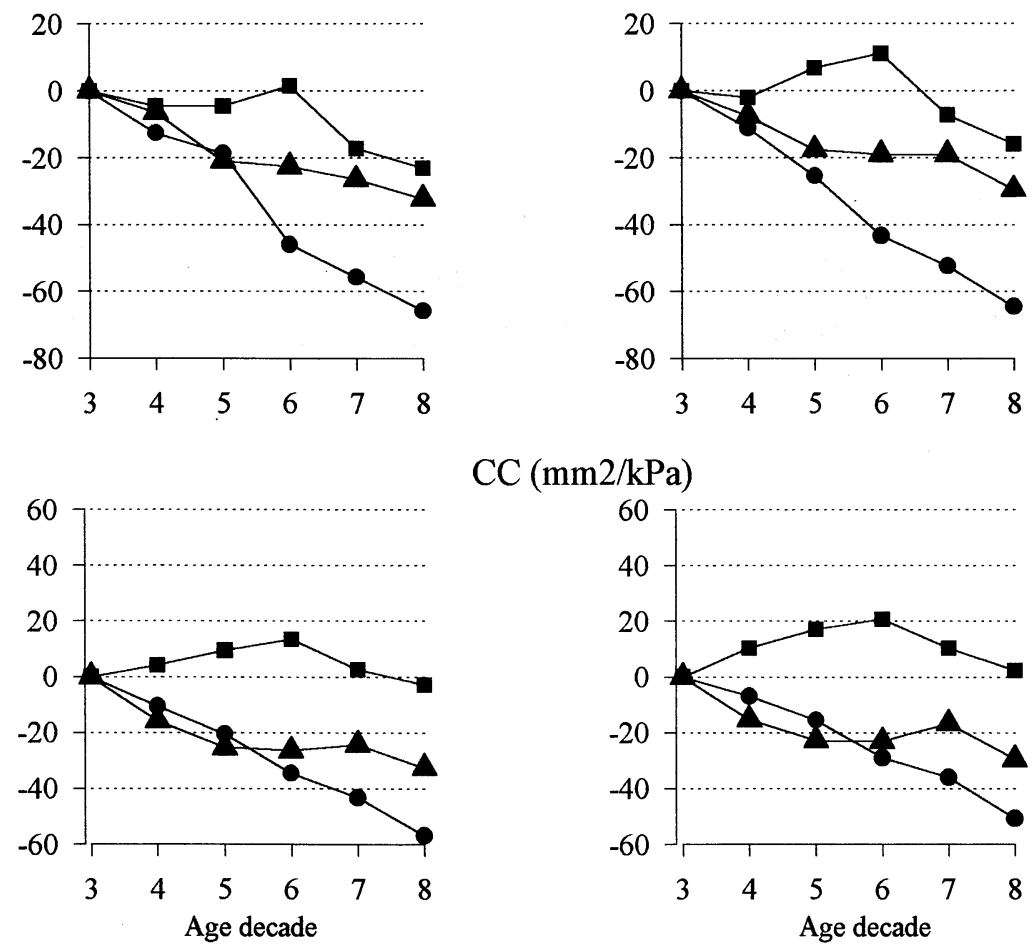

$\mathrm{CC}(\mathrm{mm} 2 / \mathrm{kPa})$

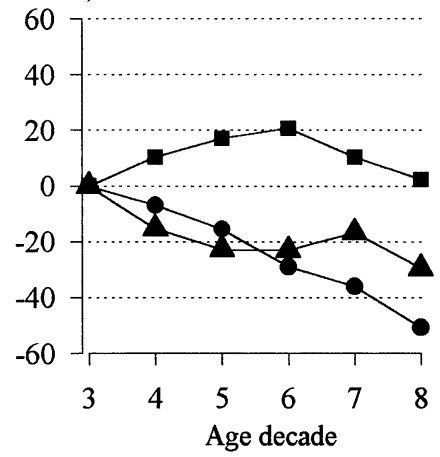

Fig. 1 Differences between arterial territories. Association between age and vessel wall properties of the common carotid artery (CCA), brachial artery (BA) and common femoral artery (FA) in men, before (left) and after (right) adjustment for mean arterial pressure, pulse rate, body mass index, current smoking, current alcohol intake and antihypertensive treatment. Data are shown as mean percentage difference compared to the mean of the third age decade. common carotid artery, $\Delta$ femoral artery, $\square$ brachial artery. 
Women

$\mathrm{D}(\mathrm{mm})$
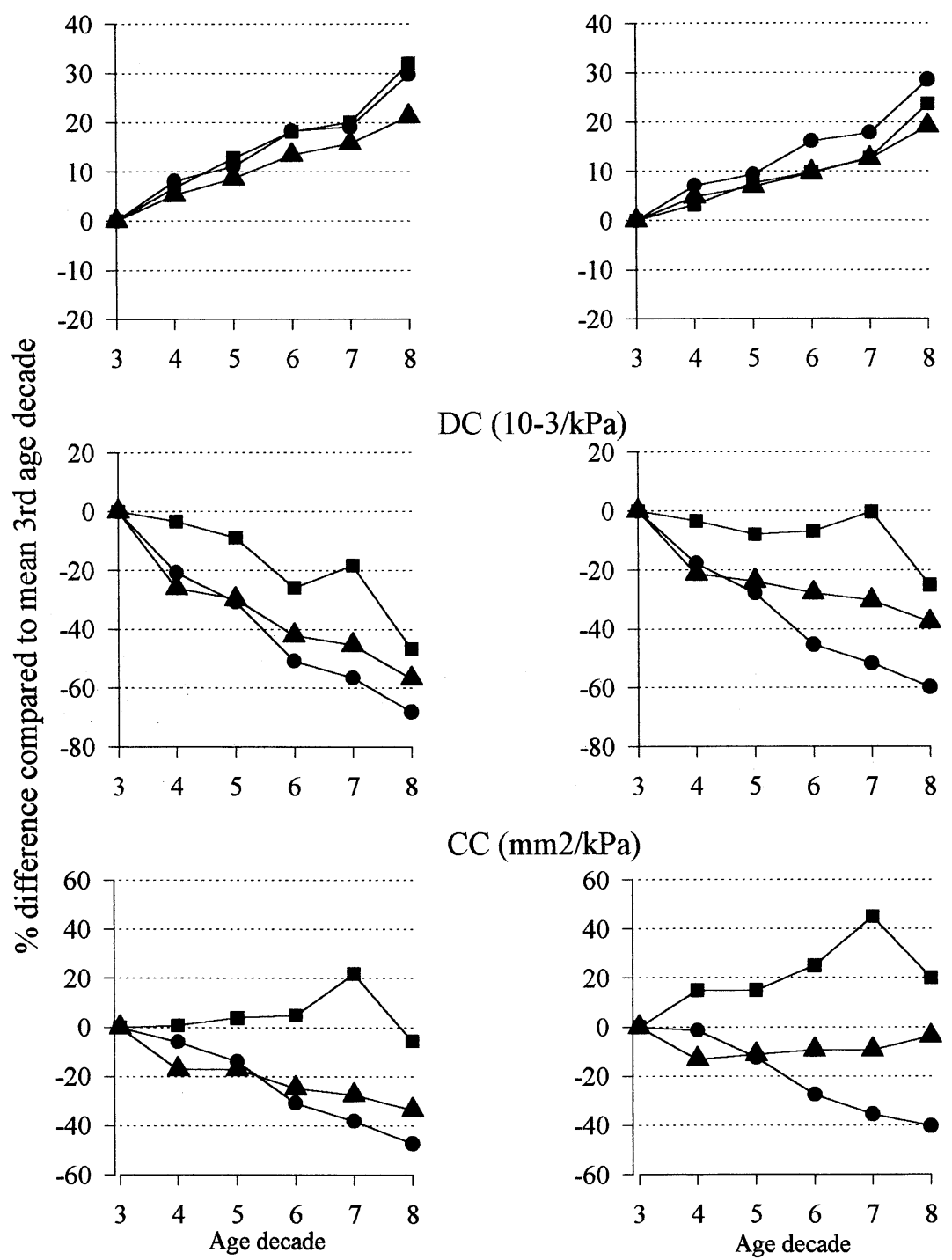

$\mathrm{DC}(10-3 / \mathrm{kPa})$

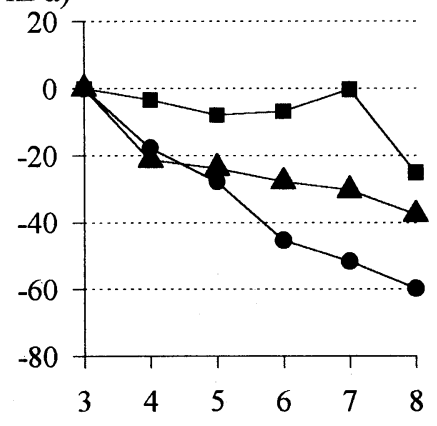

$\mathrm{CC}(\mathrm{mm} 2 / \mathrm{kPa})$

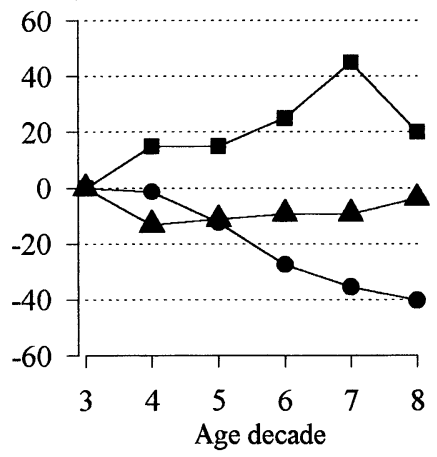

Fig. 2 Differences between arterial territories. Association between age and vessel wall properties of the common carotid artery (CCA), brachial artery (BA) and common femoral artery (FA) in women, before (left) and after (right) adjustment for mean arterial pressure, pulse rate, body mass index, current smoking, current alcohol intake and antihypertensive treatment. Data are shown as mean percentage difference compared to the mean of the third age decade. common carotid artery, $\Delta$ femoral artery, $\mathbf{b}$ brachial artery. 
Chapter 4

\section{References}

1. Safar ME, London GM: The arterial system in human hypertension, in Swales JD (ed): Textbook of hypertension, 1st ed. Oxford, Blackwell Scientific Publications, 1994, pp. 85-102.

2. Ferguson JJ, Randall O: Hemodynamic correlates of arterial compliance. Cathet Cardiovasc Diagn 1986;12:376-380.

3. Langewouters GJ, Wesseling KH, Goedhard WJA: The static elastic properties of 45 human thoracic and 20 abdominal aortas in vitro and the parameters of a new model. J Biomech 1984;17:425-435.

4. Hoeks APG, Brands PJ, Smeets FAM, Reneman RS: Assessment of the distensibility of superficial arteries. Ultrasound Med Biol 1990;16:121-128.

5. Safar ME, Simon AC, Levenson JA: Structural changes of large arteries in sustained essential hypertension. Hypertension 1984;6(III):III117-III121.

6. Laurent S, Hayoz D, Trazzi S, Boutouyrie P, Waeber B, Omboni S, Brunner HR, Mancia G, Safar M: Isobaric compliance of the radial artery is increased in patients with essential hypertension. $J$ Hypertens 1993;11:89-98.

7. Bader H: Dependence of wall stress in the human thoracic aorta on age and pressure. Circ Res 1967;20:354-361.

8. Laogun AA, Gosling RG: In vivo arterial compliance in man. Clin Phys Physiol Meas 1982;3:201212.

9. Avolio AP, Chen S, Wang R, Zhang C, Li M, O'Rourke MF: Effects of aging on changing arterial compliance and left ventricular load in a northern Chinese urban community. Circulation 1983;68:5058.

10. Boutouyrie P, Laurent S, Benetos A, Girerd XJ, Hoeks APG, Safar ME: Opposing effects of ageing on distal and proximal large arteries in hypertensives. J Hypertens 1992;10(Suppl. 6):s87-s91.

11. Benetos A, Laurent S, Hoeks AP, Boutouyrie PH, Safar ME: Arterial alterations with ageing and high blood pressure. A noninvasive study of carotid and femoral arteries. Arterioscler Thromb 1993;13:9097.

12. Sonesson B, Hansen F, Stale H, Länne T: Compliance and diameter in the human abdominal aortathe influence of age and sex. Eur J Vasc Surg 1993;7:690-697.

13. Reneman RS, Van Merode T, Hick P, Muytjens AM, Hoeks APG: Age related changes in carotid artery wall properties in men.Ultrasound Med Biol 1986;12:465-471.

14. Kawasaki T, Sasayama S, Yagi S, Asakawa T, Hirai T: Non-invasive assessment of the age related changes in stiffness of major branches of the human arteries. Cardiovasc Res 1987;21:678-687.

15. Blacher J, London GM, Safar ME, Mourad J: Influence of age and end-stage renal disease on the stiffness of carotid wall material in hypertension. J Hypertens 1999;17:237-244.

16. van Merode T, Hick PJJ, Hoeks APG, Smeets FAM, Reneman RS: Differences in carotid artery wall properties between presumed-healthy men and women. Ultrasound Med Biol 1988;14:571-574.

17. Hansen F, Mangell P, Sonesson B, Länne T: Diameter and compliance in the human carotid arteryvariations with age and sex. Ultrasound Med Biol 1995;21:1-9.

18. Mozersky DJ, Sumner DS, Hokanson DE, Strandness DE: Transcutaneous measurement of the elastic properties of the human femoral artery. Circulation 1972;46:948-955.

19. Hofstra L, Ermers EJM, Langeveldt APM, Hoeks APG, Kitslaar PJEHM: Vessel Wall Doppler Tracking: A new technique to assess vessel wall compliance. $J$ Vasc Tech 1993;17:65-68.

20. Staessen JA, Roels H, Fagard R: Lead exposure and conventional and ambulatory blood pressure. A prospective population study. JAMA 1996;275:1563-1570.

21. van der Heijden-Spek JJ, Staessen JA, Fagard RA, Hoeks AP, Struijker Boudier HA, Van Bortel LM: The effect of age on brachial artery wall properties differs from the aorta and is gender-dependent: a population study. Hypertension 2000;35:637-642.

22. Nichols WW, O'Rourke MF: Aging. Hypertension. Atherosclerosis, in Nichols WW, O'Rourke MF (eds): Mc Donald's Blood Flow in Arteries. Theoretic, experimental and clinical principles, 4th ed. London, E. Arnold, 1999, pp. 347-402.

23. Milnor WR: Normal hemodynamic state, in Milnor WR (ed): Hemodynamics. Baltimore, Williams and Wilkins, 1982, pp. 135-156

24. Westendorp ICD, Bots ML, Grobbee DE, Reneman RS, Hoeks APG, Van Popele NM, Hofman A, Witteman JCM: Menopausal status and distensibility of the common carotid artery. Arterioscler 
Thromb Vasc Biol 1999;19:713-717.

25. Liang Y, Teede H, Shiel LM, Thomas A, Craven R, Sachithanandan N, McNeil JJ, Cameron JD, Dart A, McGrath BP: Effects of oestrogen and progesterone on age-related changes in arteries of postmenopausal women. Clin Exp Pharmacol Physiol 1997;24:457-459.

26. Schmidt-Trucksass A, Grathwoll D, Schmid A, Boragk R, Upmeier C, Keul J, Huonker M: Structural, functional, and hemodynamic changes in the common carotid artery with age in male subjects. Arterioscler Thromb Vasc Biol 1999;19:1091-1097.

27. Learoyd MB, Taylor MG: Alterations with age in the viscoelastic properties of human arterial walls. Circ Res 1966;18:278-292.

28. Safar M: Ageing and its effects on the cardiovascular system. Drugs 1990;39(Suppl. 1):1-8.

29. O'Rourke MF: Arterial stiffness, systolic blood pressure, and logical treatment of arterial hypertension. Hypertension 1990;15:339-347.

30. Virmani R, Avolio AP, Mergner WJ, Robinowitz M, Herderick EE, Cornhill JF, Guo S, Liu T, Ou D, O'Rourke M: Effect of ageing on aortic morphology in populations with high and low prevalence of hypertension and atherosclerosis. Comparison between occidental and chinese communities. Am J Physiol 1991;139:1119-1129.

31. Kelly R, Hayward C, Avolio A, O'Rourke M: Noninvasive determination of age-related changes in the human arterial pulse. Circulation 1989;80:1652-1659.

32. Nichols WW, O'Rourke MF: Properties of the arterial wall: Theory and Practice, in Nichols WW, O'Rourke.MF (eds): Mc Donald's Blood Flow in Arteries. Theoretic, experimental and clinical principles, 4th ed. London, E. Arnold, 1999, pp. 54-98.

33. Van Merode T, Brands PJ, Hoeks APG, Reneman RS: Different effects of ageing on elastic and muscular arterial bifurcations in men. $J$ Vasc Res 1996;33:47-52.

34 Hickler RB: Aortic and large artery stiffness: current methodology and clinical correlations. Clin Cardiol 1990;13:317-322.

35. Lieberman E, Gerhard M, Uehata A, Walsh B, Selwyn A, Ganz P: Estrogen improves endotheliumdependent flow-mediated vasodilation in postmenopausal women. Ann Intern Med 1994;121:936941. 


\section{CHAPTER 5}

Menopause and the characteristics of the large arteries in a population study

J.A. Staessen, J.J. van der Heijden-Spek, M.E. Safar,

E. Den Hond, J. Gasowski, R.H. Fagard, H.A.J. Struijker Boudier, L.M.A.B. Van Bortel

submitted 
Menopause and large arteries

\begin{abstract}
In previous cross-sectional and longitudinal population studies, we found that the slope of systolic pressure on age was steeper in postmenopausal than in premenopausal women. We hypothesized that this observation could be due to a specific effect of menopause on the elasticity of the large arteries. We investigated 315 randomly selected women, ages 30 to 70 years. Based on 5.2 years of follow-up, 166 women were premenopausal and 149 menopausal (44 reaching menopause and 105 postmenopausal). These women were matched on age and body mass index with 315 men. We used a wall-tracking ultrasound system to measure the diameter, cross-sectional compliance and distensibility of the brachial and the common carotid and femoral arteries as well as carotid-femoral pulse wave velocity. Pulse pressure was determined from 24-hour blood pressure recordings. Both in menopausal women $(r=0.37 ; P<0.001)$ and in matching male controls $(r=0.16 ; P=0.04)$, pulse pressure widened with increasing age. The slope of the 24-hour pulse pressure on age was steeper in menopausal women than in their premenopausal counterparts $(0.428 \mathrm{vs}-0.066 \mathrm{~mm} \mathrm{Hg}$ per year; $P=0.003)$ and than in the male controls $(0.428 \mathrm{vs} 0.188 \mathrm{~mm} \mathrm{Hg}$ per year; $P=0.06)$. After adjustment for age, 24-hour mean pressure, body mass index, antihypertensive drug treatment, smoking and the use of oral contraceptives or hormonal replacement therapy, postmenopausal women showed a higher carotid-femoral pulse wave velocity $(7.77 \mathrm{vs} 6.71 \mathrm{~m} / \mathrm{s}$; $P=0.02)$ and had a slightly greater diameter of the common carotid artery $(7.09 \mathrm{vs} 6.79 \mathrm{~mm}$; $P=0.07)$ than their premenopausal counterparts. After similar adjustments, menopausal class was not significantly associated with other vascular measurements in women or with any vascular measurement in control men. In conclusion, menopause per se may increase aortic stiffness. This phenomenon may contribute to the rise in systolic pressure and pulse pressure in women beyond age 50 and, in turn, may lead to a slight dilatation of the common carotid artery.
\end{abstract}




\section{Introduction}

Systolic pressure rises with age at least until the eight decade of life ${ }^{1}$. However, until 50 to 60 years, systolic pressure is on average lower in women than in men, whereas the opposite is observed in older subjects ${ }^{1}$. Diastolic pressure on the other hand increases in both sexes only until middle age and thereafter levels off or even slightly declines. Thus, from 50 to 60 years onwards systolic pressure starts to rise and pulse pressure widens more rapidly in women than in men.

Whether menopause may accelerate the age-related increase in systolic pressure remains debated $^{2}$. Most longitudinal surveys found that menopause is not associated with hypertension, while cross-sectional studies reported an elevated or unchanged blood pressure after menopause (for review, see reference 2 ). In a previous cross-sectional population study ${ }^{3}$, we observed that systolic pressure rose $0.5 \mathrm{~mm} \mathrm{Hg}$ per year more in women with natural or surgical menopause than in their premenopausal counterparts. In a subsequent longitudinal study ${ }^{4}$, we found that over 5.2 years (median) of follow-up systolic pressure did not change in women who stayed premenopausal $(\mathrm{P}=0.71)$, but increased on average by $4 \mathrm{~mm} \mathrm{Hg}$ in perimenopausal $(\mathrm{P}=0.07)$ and postmenopausal $(\mathrm{P}=0.01)$ women. Because similar changes were not observed for systolic pressure in men or for diastolic pressure in both sexes ${ }^{4}$, we hypothesized that in older women the increase in systolic pressure and the widening of pulse pressure could be potentiated via a specific effect of menopause on the elasticity of the large arteries. We invited the subjects enrolled in our longitudinal study ${ }^{4}$ for an extensive evaluation of the structural and functional properties of their large arteries ${ }^{5}$. We report in this article our findings with regard to menopause.

\section{Methods}

\section{Study population}

We described the recruitment and follow-up of the participants in previous publications ${ }^{4}$. At baseline (1985-1989), we invited 1419 randomly selected subjects with a minimum age of 20 years, of whom $1107(78 \%)$ took part. After excluding subjects who had died $(n=83)$ and those who were severely ill $(n=3)$ or had moved $(n=7), 1014$ persons were eligible for a follow-up examination of whom, from 1991 to 1995, $823(81 \%)$ participated. From our previous analysis on menopause and blood pressure ${ }^{4}$, we excluded 76 subjects because of missing conventional or ambulatory blood pressure measurements and 117 because their age at follow-up was less than 30 years or exceeded 70 years. The 315 women included in the latter analysis ${ }^{4}$ were matched on age and rank of body mass index at baseline with 315 men. These 630 subjects constitute the study population for this article.

\section{Measurements at Follow-Up}

Trained nurses measured the participants' sitting blood pressure at home ${ }^{4}$. They determined systolic and phase $\mathrm{V}$ diastolic blood pressures 5 times consecutively to the nearest $2 \mathrm{~mm} \mathrm{Hg}$ after the subjects had rested for 5 minutes. Within 1 week of the home visit the participants had their 24-hour blood pressure measured with SpaceLabs 90202 monitors (Redmond, WA) ${ }^{6}$, programmed to obtain readings with an interval of 20 minutes from 8 AM until 10 PM and every 45 minutes from 10 PM to 8 AM. Standard cuffs had a $12 \times 24 \mathrm{~cm}$ inflatable portion, but if upper arm girth exceeded $31 \mathrm{~cm}$, larger cuffs with $15 \times 35 \mathrm{~cm}$ bladders were employed. The same cuff size was used for all blood pressure measurements. The oscillometric Space- 
Labs devices provided direct measurements of mean arterial pressure; pulse pressure was calculated as the difference between systolic and diastolic blood pressure.

A standardized questionnaire inquired into each person's medical and surgical history, smoking and drinking habits, intake of medications. We defined premenopause and postmenopause as an active menstrual cycle and continuous amenorrhea throughout follow-up. Women with periods at baseline but with amenorrhea at follow-up were classified as perimenopausal. Surgical menopause was diagnosed, if the menses had disappeared after bilateral oophorectomy. Follicle-stimulating hormone (FSH) was measured in the serum by an immunoradiometric assay.

After the participants had refrained from smoking and drinking alcohol or caffeine containing beverages for at least 3 hours, and after they had rested for 15 minutes in the supine position, the same observer (J.J.H.-S.) measured the vascular characteristics of the brachial and the common carotid and femoral arteries. A wall-tracking ultrasound system allowed to reproducibly ${ }^{7}$ determine the vessel diameter during diastole and its change during the cardiac cycle 7,8 . depending on the vascular territory, the intra-observer coefficients of variation varied from 2.1 to $3.3 \%$ for diameter and from 9.2 to $12.8 \%$ for the changes in diameter ${ }^{7}$. Simultaneously with the vascular measurements, blood pressure was recorded at 3-minute intervals at the left upper arm with a semi-automated device (Dinamap 845, Applied Medical Reseach Corporation, Tampa, FL). We extrapolated the local blood pressure in the common carotid and femoral arteries from the simulaneously measured brachial blood pressure by calibration of the arterial distension curves ${ }^{9,10}$. We then calculated the compliance and distensibility coefficients as the absolute and relative changes during the cardiac cycle in the cross-sectional area of the vessel per unit change in the local pulse pressure ${ }^{7}$. From the delay between the R-wave trigger of the electrocardiogram and the $10 \%$ level of the ascending limb of the distension waveform in the carotid and femoral arteries, the ultrasound system also computed the carotid-femoral transit time ${ }^{11,12}$. From this interval and from the distance between the sternal notch and the site of the femoral measurements ${ }^{11,12}$, the carotid-femoral pulse wave velocity was calculated as an estimate of aortic stiffness ${ }^{11,12}$. For statistical analysis, we averaged the vascular measurements over 15 cardiac cycles.

\section{Statistical analysis}

The FSH distribution was logarithmically transformed. For between-group comparisons we used Student's t-test, analysis of variance and the $\chi 2$-statistic. We compared menopausal groups only if the P-value in the analysis of variance was less than 0.15 . The statistical methods also included single and multiple linear regression. Regression slopes were compared across groups using the single model approach ${ }^{13}$. Although we hypothesized that menopause would be associated with increased vascular stiffness, we used only 2 -sided tests.

\section{Results}

Characteristics of the Subjects

The cohort had been followed for a median time of 5.2 years (range, 3.8-8.3 years) and included 166 premenopausal and 149 menopausal women. Of the latter group, 44 perimenopausal subjects had reached menopause during follow-up and 105 were postmenopausal since baseline. The serum FSH concentration (5th-95th percentile interval) in the premenopausal women was $5(0-41) \mathrm{U} / \mathrm{L}$; in the perimenopausal and postmenopausal groups, these levels 
were 64 (31-143) U/L and 57 (8-126) U/L, respectively $(\mathrm{P}<0.001$ versus premenopausal subjects). Peri- and postmenopausal women showed higher conventional and ambulatory blood pressures and were more obese and shorter than their premenopausal counterparts (Table 1); for blood pressure and body height comparable trends were observed in the male controls.

Table 1 Characteristics of 315 women and 315 control men at follow-up

\begin{tabular}{|c|c|c|c|c|}
\hline & $\begin{array}{l}\text { Pre } \\
(n=166)\end{array}$ & $\begin{array}{l}\text { Peri } \\
(\mathrm{n}=44)\end{array}$ & $\begin{array}{l}\begin{array}{l}\text { Post } \\
(n=105)\end{array} \\
\end{array}$ & $P$ \\
\hline \multicolumn{5}{|l|}{ Women } \\
\hline Follow-up (y) & $5.2 \pm 0.5$ & $5.3 \pm 0.7$ & $5.2 \pm 0.6$ & .43 \\
\hline Age $(y)$ & $41.0 \pm 5.6$ & $52.2 \pm 4.9$ & $61.2 \pm 6.3$ & $<.001$ \\
\hline Body height $(\mathrm{cm})$ & $161.8 \pm 6.3$ & $160.7 \pm 7.3$ & $158.3 \pm 6.7$ & $<.001$ \\
\hline Body mass index $\left(\mathrm{kg} / \mathrm{m}^{2}\right)$ & $24.7 \pm 4.7$ & $27.1 \pm 5.8$ & $28.4 \pm 6.2$ & $<.001$ \\
\hline \multicolumn{5}{|c|}{ Home blood pressure $(\mathrm{mm} \mathrm{Hg})$} \\
\hline SBP & $117.0 \pm 13.2$ & $125.8 \pm 16.3$ & $135.7 \pm 20.1$ & $<.001$ \\
\hline DBP & $75.8 \pm 9.2$ & $80.6 \pm 9.8$ & $81.8 \pm 10.6$ & $<.001$ \\
\hline \multicolumn{5}{|c|}{ 24-hour blood pressure monitoring $(\mathrm{mm} \mathrm{Hg})$} \\
\hline SBP & $113.0 \pm 9.1$ & $114.1 \pm 10.6$ & $121.3 \pm 12.4$ & $<.001$ \\
\hline DBP & $69.3 \pm 6.8$ & $70.0 \pm 8.9$ & $71.5 \pm 7.0$ & .06 \\
\hline MBP & $83.5 \pm 7.2$ & $84.8 \pm 8.7$ & $88.4 \pm 9.2$ & $<.001$ \\
\hline $\mathrm{PP}$ & $43.8 \pm 5.6$ & $44.1 \pm 7.1$ & $49.8 \pm 8.3$ & $<.001$ \\
\hline \multicolumn{5}{|l|}{ Men } \\
\hline Follow-up (y) & $5.3 \pm 0.6$ & $5.3 \pm 0.4$ & $5.2 \pm 0.5$ & .27 \\
\hline Age (y) & $40.8 \pm 6.5$ & $52.9 \pm 5.1$ & $62.2 \pm 6.6$ & $<.001$ \\
\hline Body height $(\mathrm{cm})$ & $175.2 \pm 6.7$ & $170.7 \pm 6.6$ & $170.2 \pm 7.0$ & $<.001$ \\
\hline Body mass index $\left(\mathrm{kg} / \mathrm{m}^{2}\right)$ & $26.2 \pm 3.8$ & $26.3 \pm 3.4$ & $26.4 \pm 3.2$ & .95 \\
\hline \multicolumn{5}{|c|}{ Home blood pressure $(\mathrm{mm} \mathrm{Hg})$} \\
\hline SBP & $126.2 \pm 14.2$ & $135.0 \pm 21.4$ & $132.5 \pm 17.8$ & $<.001$ \\
\hline DBP & $80.9 \pm 10.3$ & $84.2 \pm 11.3$ & $79.4 \pm 10.2$ & .04 \\
\hline \multicolumn{5}{|c|}{ 24-hour blood pressure monitoring $(\mathrm{mm} \mathrm{Hg})$} \\
\hline SBP & $119.7 \pm 8.9$ & $123.8 \pm 14.4$ & $120.9 \pm 11.8$ & .08 \\
\hline DBP & $73.2 \pm 7.3$ & $75.9 \pm 8.0$ & $72.4 \pm 7.7$ & .04 \\
\hline MBP & $87.7 \pm 7.5$ & $91.5 \pm 9.9$ & $87.7 \pm 8.2$ & .02 \\
\hline PP & $46.5 \pm 5.3$ & $47.9 \pm 8.4$ & $48.5 \pm 8.7$ & .08 \\
\hline
\end{tabular}

Values are means \pm SD. $\mathrm{P}$ values for the differences across 3 menopausal groups and 3 strata of male controls were derived by analysis of variance. SBP, systolic blood pressure; DBP, diastolic blood pressure; MBP, mean blood pressure; PP pulse pressure

Of the premenopausal women, $36(22 \%)$ were on oral contraceptives. Hormonal replacement therapy was used by $2(5 \%)$ perimenopausal and $6(6 \%)$ postmenopausal women. In the periand postmenopausal groups, menopause had been surgically induced in $5(11 \%)$ and $22(21 \%)$ subjects, respectively. Of the pre-, peri- and postmenopausal women $12(7.2 \%), 8(18.2 \%)$ and 
$41(39.0 \%)$ were on antihypertensive drug treatment; among the control men, these numbers were $12(7.2 \%), 9(20.5 \%)$ and $29(27.6 \%)$, respectively. Less than $1 \%$ of all participants were on nitrates or coronary vasodilators.

Among women, the pre-, peri- and postmenopausal groups included 75 (45.2\%), $12(27.3 \%)$ and $16(15.2 \%)$ smokers and $15(9.0 \%), 1(2.3 \%)$ and $9(8.6 \%)$ individuals who consumed alcohol. Among men, these numbers were $67(40.4 \%), 15(34.1 \%)$ and $38(36.2 \%)$ and 68 (41.0\%), $13(29.5 \%)$ and $24(22.9 \%)$, respectively. Female and male smokers smoked 15 (median) gram tobacco per day (5th-95th percentile interval, 5-30 g/day). Among drinkers, alcohol consumption was similar in both sexes, averaging 15 (5-60) g/day).

\section{Vascular Properties and Menopause}

In exploratory analyses we first plotted the mean 24-hour pulse pressure by menopausal class at follow-up and by fourths of the age distributions in women and men separately (Figure 1). Single regression analysis showed that in premenopausal women the 24-hour pulse pressure was not correlated with age $(\mathrm{r}=0.07 ; \mathrm{P}=0.40)$, whereas in the corresponding male controls the latter association was negative $(\mathrm{r}=0.30 ; \mathrm{P}<0.001)$ because of the age-related increase in the 24-hour diastolic pressure. 4 In menopausal women $(\mathrm{r}=0.37 ; \mathrm{P}<0.001)$ and matching male controls $(\mathrm{r}=0.16 ; \mathrm{P}=0.04)$ pulse pressure widened with increasing age. The slope of the 24-hour pulse pressure on age was steeper in the menopausal women than in their premenopausal counterparts $(0.428$ vs $(0.066 \mathrm{~mm} \mathrm{Hg}$ per year; $\mathrm{P}=0.003)$ and than in the male controls (0.428 vs $0.188 \mathrm{~mm} \mathrm{Hg}$ per year; $\mathrm{P}=0.06$ ).

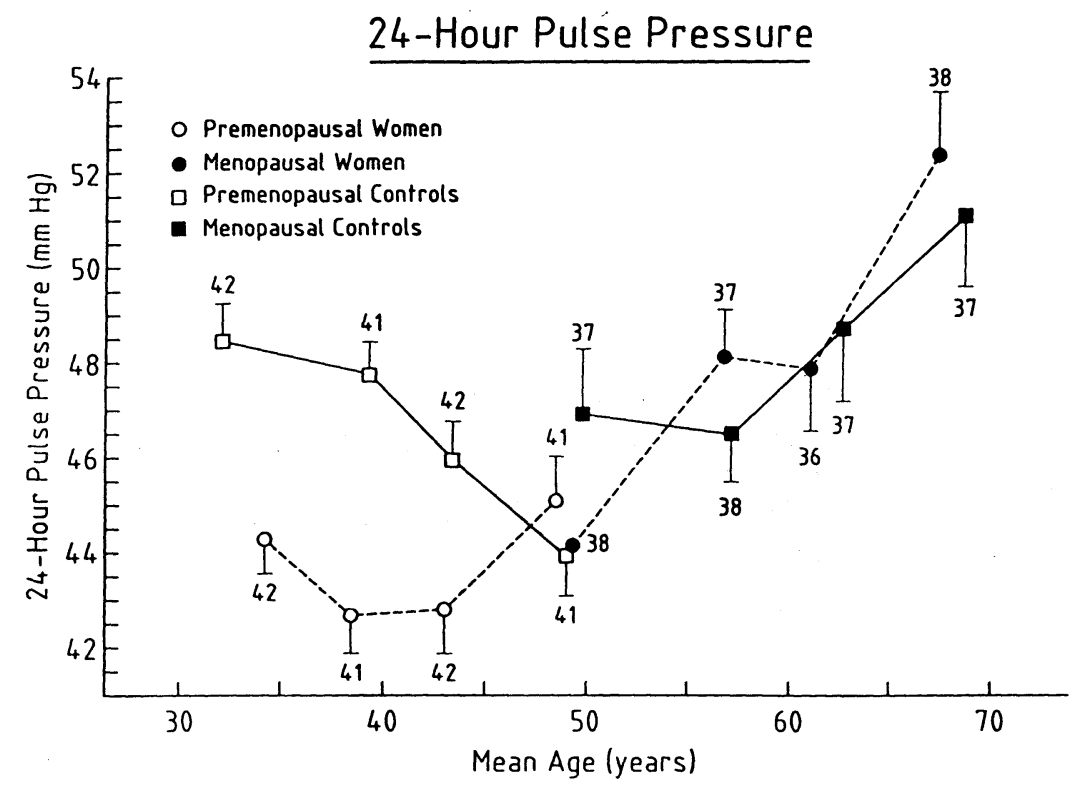

Figure 1. 24-hour pulse pressure determined by ambulatory monitoring. Values are unadjusted means \pm SE by fourths of the age distributions in 166 premenopausal and 149 peri- or postmenopausal women and in similar numbers of control men matched with the women on age and body mass index. 
Before any adjustment, the arterial diameters of the brachial and the common carotid and femoral arteries increased with menopause in women, while compliance and distensibility of the common carotid and femoral arteries decreased (Table 2). In male controls comparable differences were observed but only for the carotid artery (Table 2). In women and control men, the carotid-femoral pulse wave velocity rose across the menopausal strata.

After cumulative adjustment for age, 24-hour mean pressure, body mass index, antihypertensive drug treatment, smoking and the use of oral contraceptives or hormonal replacement therapy (Table 3 ), the carotid-femoral pulse wave velocity increased $(\mathrm{P}=0.03)$ with menopause in women. A similar trend was noted for the diameter of the common carotid artery $(\mathrm{P}=0.13)$. After adjustment for confounders (Figure 2), postmenopausal women showed a greater carotid-femoral pulse wave velocity $(7.77$ vs $6.71 \mathrm{~m} / \mathrm{s} ; \mathrm{P}=0.02)$ and had a slightly wider diameter of the common carotid artery $(7.09$ vs $6.79 \mathrm{~mm} ; \mathrm{P}=0.07)$ than their premenopausal counterparts. With similar adjustments, menopause was no longer significantly associated with the other vascular measurements (Table 3). In control men, after adjustment for age, mean 24-hour pressure, body mass index, antihypertensive drug treatment and smoking, there were no differences across the 3 control groups (Table 3 ).

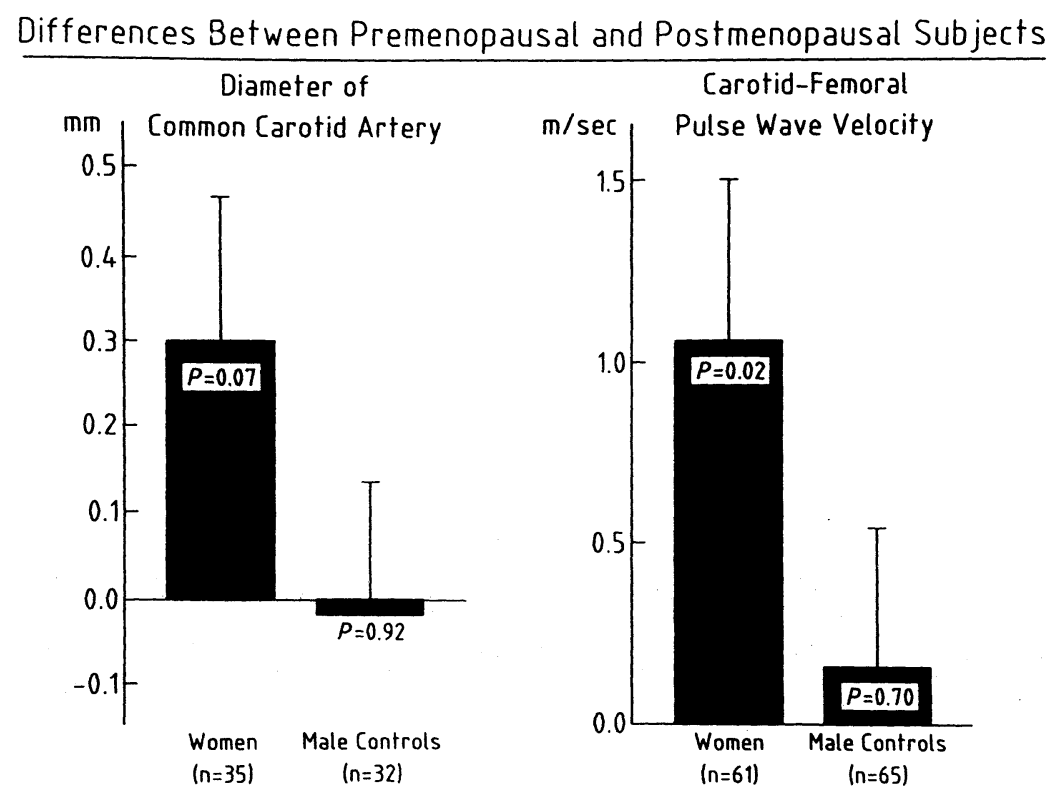

Figure 2. Mean differences (SE) in the diameter of the common carotid artery (left) and in carotid-femoral pulse wave velocity (right) between premenopausal and postmenopausal women and between corresponding male controls. The differences (P-values given) were adjusted for age, 24-hour mean pressure, body mass index, intake of antihypertensive drugs, smoking and in women also for the use of oral contraceptives or hormonal replacement therapy. 
Menopause and large arteries

Table 2 Vascular characteristics by menopausal class before adjustment for confounders

\begin{tabular}{|c|c|c|c|c|c|c|c|}
\hline & $\mathrm{n}$ & $\begin{array}{l}\text { Pre } \\
\text { mean } \pm S D\end{array}$ & $\mathrm{n}$ & $\begin{array}{l}\text { Peri } \\
\text { mean } \pm S D\end{array}$ & $\mathrm{n}$ & $\begin{array}{l}\text { Post } \\
\text { mean } \pm S D\end{array}$ & $\mathrm{P}$ \\
\hline \multicolumn{8}{|l|}{ Women } \\
\hline \multicolumn{8}{|l|}{ Brachial artery } \\
\hline $\mathrm{D} \quad(\mathrm{mm})$ & 125 & $3.52 \pm 0.44$ & 35 & $3.71 \pm 0.64$ & 76 & $3.87 \pm 0.55$ & $<.001$ \\
\hline$\left(\mathrm{mm}^{2} / \mathrm{kPa}\right)$ & 125 & $0.24 \pm 0.11$ & 35 & $0.22 \pm 0.11$ & 75 & $0.26 \pm 0.13$ & .28 \\
\hline DC $\quad\left(10^{-3} / \mathrm{kPa}\right)$ & 125 & $25.1 \pm 13.0$ & 35 & $21.4 \pm 10.9$ & 75 & $22.5 \pm 9.94$ & .15 \\
\hline \multicolumn{8}{|c|}{ Common carotid artery } \\
\hline $\mathrm{D} \quad(\mathrm{mm})$ & 132 & $6.61 \pm 0.63$ & 35 & $7.14 \pm 0.76$ & 78 & $7.31 \pm 0.85$ & $<.001$ \\
\hline$\left(\mathrm{mm}^{2} / \mathrm{kPa}\right)$ & 125 & $0.87 \pm 0.25$ & 35 & $0.73 \pm 0.27$ & 74 & $0.65 \pm 0.18$ & $<.001$ \\
\hline DC $\quad\left(10^{-3} / \mathrm{kPa}\right)$ & 125 & $25.1 \pm 6.7$ & 35 & $18.1 \pm 5.80$ & 74 & $15.7 \pm 5.0$ & $<.001$ \\
\hline \multicolumn{8}{|l|}{ Femoral artery } \\
\hline $\mathrm{D} \quad(\mathrm{mm})$ & 123 & $8.26 \pm 0.89$ & 31 & $8.66 \pm 0.94$ & 65 & $9.03 \pm 1.04$ & $<.001$ \\
\hline$\left(\mathrm{mm}^{2} / \mathrm{kPa}\right)$ & 116 & $0.51 \pm 0.22$ & 30 & $0.47 \pm 0.24$ & 63 & $0.44 \pm 0.22$ & .12 \\
\hline$\left(10^{-3} / \mathrm{kPa}\right)$ & 116 & $9.68 \pm 4.52$ & 30 & $8.07 \pm 4.02$ & 63 & $7.12 \pm 3.82$ & $<.001$ \\
\hline \multicolumn{8}{|l|}{ Aorta } \\
\hline PWV (m/s) & 122 & $6.00 \pm 1.25$ & 31 & $6.59 \pm 1.06$ & 61 & $8.13 \pm 2.81$ & $<.001$ \\
\hline
\end{tabular}

Men

Brachial artery

D

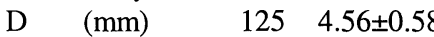

CC $\quad\left(\mathrm{mm}^{2} / \mathrm{kPa}\right) \quad 125 \quad 0.33 \pm 0.13$

DC $\quad\left(10^{-3} / \mathrm{kPa}\right) \quad 125 \quad 20.1 \pm 10.3$

$32-0.31 \pm 0.11$

$0.31 \pm 0.11$

$81 \quad 4.56 \pm 0.62$

$81 \quad 0.33 \pm 0.15$

Common carotid artery

$\begin{array}{lllllllll}\mathrm{D} \quad(\mathrm{mm}) & 125 & 7.48 \pm 0.63 & 32 & 7.95 \pm 0.88 & 82 & 8.00 \pm 0.78 & <.001 \\ \mathrm{CC} & \left(\mathrm{mm}^{2} / \mathrm{kPa}\right) & 125 & 1.08 \pm 0.33 & 32 & 0.93 \pm 0.37 & 80 & 0.80 \pm 0.32 & <.001 \\ \mathrm{DC} & \left(10^{-3} / \mathrm{kPa}\right) & 125 & 24.7 \pm 7.2 & 32 & 18.6 \pm 5.6 & 80 & 15.8 \pm 5.77 & <.001 \\ \text { emoral artery } & & & & & & & \\ \mathrm{D} \quad(\mathrm{mm}) & 121 & 9.97 \pm 0.97 & 28 & 9.93 \pm 0.93 & 70 & 10.26 \pm 1.32 & .16 \\ \mathrm{CC} \quad\left(\mathrm{mm}^{2} / \mathrm{kPa}\right) & 120 & 0.63 \pm 0.29 & 28 & 0.59 \pm 0.33 & 69 & 0.59 \pm 0.30 & .64 \\ \text { DC } \quad\left(10^{-3} / \mathrm{kPa}\right) & 120 & 8.39 \pm 4.09 & 28 & 7.75 \pm 4.25 & 69 & 7.24 \pm 3.72 & .16 \\ \text { orta } & & & & & & & \\ \text { PWV }(\mathrm{m} / \mathrm{s}) & 120 & 6.31 \pm 1.26 & 26 & 7.37 \pm 1.73 & 65 & 7.95 \pm 2.14 & <.001\end{array}$

$\mathrm{P}$ values for the differences across 3 menopausal groups and 3 strata of male controls were derived by analysis of variance; D, diameter; DC, distensibility coefficient; CC cross-sectional compliance; PWV, pulse wave velocity. 
Table 3 Vascular characteristics by menopausal class after adjustment for age and other confounders

\begin{tabular}{|c|c|c|c|c|}
\hline & Pre & Peri & Post & $\mathrm{P}$ \\
\hline \multicolumn{5}{|l|}{ Women } \\
\hline \multicolumn{5}{|l|}{ Brachial artery } \\
\hline $\mathrm{D} \quad(\mathrm{mm})$ & $3.63 \pm 0.07$ & $3.62 \pm 0.10$ & $3.65 \pm 0.09$ & .96 \\
\hline $\mathrm{CC} \quad\left(\mathrm{mm}^{2} / \mathrm{kPa}\right)$ & $0.26 \pm 0.02$ & $0.24 \pm 0.02$ & $0.26 \pm 0.02$ & .52 \\
\hline DC $\quad\left(10^{-3} / \mathrm{kPa}\right)$ & $24.6 \pm 1.7$ & $23.0 \pm 2.3$ & $25.8 \pm 2.2$ & .54 \\
\hline \multicolumn{5}{|l|}{ Common carotid artery } \\
\hline $\mathrm{D} \quad(\mathrm{mm})$ & $6.79 \pm 0.10$ & $7.10 \pm 0.14$ & $7.09 \pm 0.13$ & .13 \\
\hline $\mathrm{CC} \quad\left(\mathrm{mm}^{2} / \mathrm{kPa}\right)$ & $0.76 \pm 0.03$ & $0.78 \pm 0.04$ & $0.81 \pm 0.04$ & .71 \\
\hline DC $\quad\left(10^{-3} / \mathrm{kPa}\right)$ & $21.5 \pm 0.8$ & $19.9 \pm 1.1$ & $21.6 \pm 1.0$ & .25 \\
\hline \multicolumn{5}{|l|}{ Femoral artery } \\
\hline $\mathrm{D} \quad(\mathrm{mm})$ & $8.17 \pm 0.13$ & $8.19 \pm 0.19$ & $8.47 \pm 0.18$ & .37 \\
\hline$\left(\mathrm{mm}^{2} / \mathrm{kPa}\right)$ & $0.47 \pm 0.03$ & $0.45 \pm 0.05$ & $0.45 \pm 0.04$ & .92 \\
\hline$\left(10^{-3} / \mathrm{kPa}\right)$ & $9.10 \pm 0.63$ & $8.71 \pm 0.89$ & $8.52 \pm 0.84$ & .88 \\
\hline \multicolumn{5}{|l|}{ Aorta } \\
\hline $\mathrm{PWV}(\mathrm{m} / \mathrm{s})$ & $6.71 \pm 0.26$ & $6.73 \pm 0.37$ & $7.77 \pm 0.36$ & .03 \\
\hline \multicolumn{5}{|l|}{ Men } \\
\hline \multicolumn{5}{|l|}{ Brachial artery } \\
\hline $\mathrm{D} \quad(\mathrm{mm})$ & $4.57 \pm 0.08$ & $4.49 \pm 0.11$ & $4.44 \pm 0.10$ & .62 \\
\hline $\mathrm{CC} \quad\left(\mathrm{mm}^{2} / \mathrm{kPa}\right)$ & $0.32 \pm 0.02$ & $0.28 \pm 0.03$ & $0.29 \pm 0.02$ & .52 \\
\hline DC $\quad\left(10^{-3} / \mathrm{kPa}\right)$ & $19.7 \pm 1.4$ & $19.0 \pm 1.8$ & $19.7 \pm 1.7$ & .93 \\
\hline \multicolumn{5}{|l|}{ Common carotid artery } \\
\hline $\mathrm{D} \quad(\mathrm{mm})$ & $7.75 \pm 0.10$ & $7.88 \pm 0.13$ & $7.73 \pm 0.12$ & .56 \\
\hline$\left(\mathrm{mm}^{2} / \mathrm{kPa}\right)$ & $0.99 \pm 0.04$ & $1.01 \pm 0.06$ & $0.96 \pm 0.06$ & .77 \\
\hline DC $\quad\left(10^{-3} / \mathrm{kPa}\right)$ & $21.4 \pm 0.8$ & $20.7 \pm 1.1$ & $20.8 \pm 1.0$ & .86 \\
\hline \multicolumn{5}{|l|}{ Femoral artery } \\
\hline $\mathrm{D} \quad(\mathrm{mm})$ & $9.96 \pm 0.16$ & $9.77 \pm 0.23$ & $9.92 \pm 0.21$ & .75 \\
\hline $\mathrm{CC} \quad\left(\mathrm{mm}^{2} / \mathrm{kPa}\right)$ & $0.59 \pm 0.04$ & $0.57 \pm 0.06$ & $0.55 \pm 0.06$ & .85 \\
\hline DC $\quad\left(10^{-3} / \mathrm{kPa}\right)$ & $8.14 \pm 0.56$ & $7.80 \pm 0.81$ & $7.39 \pm 0.74$ & .74 \\
\hline \multicolumn{5}{|l|}{ Aorta } \\
\hline $\mathrm{PWV}(\mathrm{m} / \mathrm{s})$ & $7.19 \pm 0.23$ & $7.25 \pm 0.34$ & $7.34 \pm 0.32$ & .93 \\
\hline
\end{tabular}

Values are least square means $( \pm \mathrm{SE})$, adjusted for age, 24-hour mean pressure, body mass index, intake of antihypertensive drugs, smoking and in women also for the use of oral contraceptives or hormonal replacement therapy. $P$ values for the differences across 3 menopausal groups and 3 strata of male controls were derived by analysis of variance. For the number of subjects included in each statistic, see Table 2. D, diameter; DC, distensibility coefficient; CC cross-sectional compliance; PWV, pulse wave velocity. 


\section{Discussion}

In previous cross-sectional ${ }^{3}$ and longitudinal ${ }^{4}$ population studies, we found that the slope of systolic blood pressure on age was steeper in postmenopausal than in premenopausal women. The present article builds on this experience ${ }^{3,4}$ and shows that after adjustment for age and other confounding factors, aortic pulse wave velocity was greater in postmenopausal women than in their premenopausal counterparts, whereas this observation could not be reproduced in control men. It is plausible that menopause, by increasing the stiffness of the aorta, may contribute to the rise in systolic blood pressure and pulse pressure, which occurs in middle-aged and older women and which in turn may lead to a slight dilatation of the common carotid artery.

A limitation of our study was its observational nature and the relatively small sample size. On the other hand, its population-based design increased its external validity. To the best of our knowledge, our study was among the first to ascertain the presence of menopause in a prospective manner. The same investigator performed all vascular measurements. Women were matched on age and rank of body mass index at baseline with men drawn from the same community. We used a conservative statistical approach by limiting the number of comparisons between the menopausal groups based on the P-values in the analysis of variance and by using 2-sided tests. Our present findings suggest that in women menopause is associated with a loss of aortic elasticity, over and above the effects of aging. In an earlier hospital-based cross-sectional study, 14 women $(n=104)$ showed at the level of the common carotid artery increased and earlier arterial wave reflections than men $(n=119)$, because of their shorter body height and greater aortic tapering. In line with our findings, aortic pulse wave velocity rose with age in both sexes, but the increase was steeper in postmenopausal women than in age-matched men ${ }^{14}$. In premenopausal women greater distensibility of the brachial and femoral arteries partially compensated for the effects of shorter body height and enhanced aortic tapering, but after menopause this compensatory mechanism disappeared ${ }^{14}$. In the present population study, the analyses were adjusted for body mass index, hence for the inverse of body height (squared), but not for aortic tapering.

Several studies are in line with the present findings. Gangar et all ${ }^{5}$ found that the pulsatility index of the internal carotid artery was inversely correlated with the time elapsed since the last menstrual bleeding and that estrogen replacement therapy normalized the raised pulsatility index ${ }^{15}$. Westendorp et all found a decrease in distension of the common carotid artery in postmenopausal women compared to premenopausal women ${ }^{16}$. In the ascending aorta, Pines et al $1{ }^{17}$ demonstrated a gradual decline in Doppler- derived peak flow velocity, flow velocity integral and mean flow acceleration in women who went through menopause. In an earlier study ${ }^{18}$ the same authors had shown that hormonal replacement therapy produced a significant improvement in these aortic flow measurements. Karpanou et al ${ }^{19}$ noticed that in hypertensive women reaching natural menopause, compared with age-matched hypertensive controls, aortic root function abruptly deteriorated as evidenced by significant declines in the distensibility and the cross-sectional compliance and by a rise in the aortic stiffness index ${ }^{19}$. Other studies are in keeping with our findings, but did not correct for the level of blood pressure ${ }^{20-22}$ or reported that withdrawal of hormonal replacement therapy for 4 weeks resulted in a decrease of systemic arterial compliance and an increase in pulse wave velocity in the femoralis-dorsalis pedis region, but not in the aorto-femoral territory ${ }^{22}$.

Recent studies using ambulatory monitoring ${ }^{23-26}$ or automated blood pressure 
self-measurement ${ }^{27}$ are in agreement with the hypothesis that estrogen deprivation, either at the onset of menstruation ${ }^{27}$ or in non-substituted postmenopausal normotensive ${ }^{24-26}$ or hypertensive ${ }^{23}$ women, may increase blood pressure. Estrogens change the loading conditions on the elastin or collagen fibers or alter the structure of the vessel wall. Experiments in laboratory animals proved that estrogens dilate the large arteries ${ }^{28,29}$. In peri- and postmenopausal women ${ }^{30-32}$ they widen the smaller resistance vessels by mechanisms that include the protection of endothelial function ${ }^{31}$ the potentiation of nitric oxide release ${ }^{30,32}$ and the modulation of sympathetic reactivity ${ }^{25,33}$. Estrogens may also influence the visco-elastic properties of the arterial wall by changing the relative proportions of collagen and elastin ${ }^{34}$ by inhibition of smooth muscle cell proliferation, or by the prevention of atherosclerotic stiffening ${ }^{35}$. Menopause does not occur as a sudden event but as a continuous transition from a regular menstrual cycle to ovarian failure ${ }^{2}$. Thus, estrogen deficiency or hormonal replacement therapy may initially induce functional alterations, while structural vascular changes are more likely to contribute to long-term effects. For instance, Cohn et al ${ }^{36}$ found that in postmenopausal women with documented atherosclerosis, compared to healthy postmenopausal controls, oscillatory but not capacitive systemic arterial compliance was reduced.

In conclusion, menopause per se may affect the stiffness of the aorta and the diameter of the common carotid artery. Estrogen deficiency may therefore contribute to the rise in systolic blood pressure and pulse pressure in women beyond age 50 .

\section{Acknowledgements}

This study was supported by the municipality Hechtel-Eksel (Belgium), the Fonds voor Wetenschappelijk Onderzoek Vlaanderen (Brussels, Belgium), the Ministry of the Flemish Community (Brussels, Belgium) and Schwarz Pharma GmbH, Monheim, Germany. The survey would not have been possible without the support of the General Practitioners. The assistance of Rina Bollen, Lieve Gijsbers, Alida Hermans, Marie-Jeanne Jehoul, Sylvia Van Hulle and Marleen Vandermaesen is gratefully acknowledged. 


\section{References}

1. Staessen J, Amery A, Fagard R: Editorial review. Isolated systolic hypertension in the elderly. $J$ Hypertens 1990;8:393-405.

2. Staessen JA, Bieniaszewski L, Brosens I, Fagard R: The epidemiology of menopause and its association with cardiovascular disease. In Messerli FH, Aepfelbacher FC (eds): Hypertension in Postmenopausal Women. New York, Marcel Dekkers Inc, 1996, pp 43-78.

3. Staessen J, Bulpitt CJ, Fagard R, Lijnen P, Amery A: The influence of menopause on blood pressure. J Hum Hypertens 1989;3:427-433.

4. Staessen JA, Ginocchio G, Thijs L, Fagard R: Conventional and ambulatory blood pressure and menopause in a prospective population study. J Hum Hypertens 1997;11:507-514.

5. van der Heijden-Spek JJ, Staessen JA, Fagard RH, Hoeks AP, Struijker Boudier HAJ, Van Bortel LM: The effects of age on brachial artery wall properties differs from the aorta and is gender dependent: a population study. Hypertension 2000;35:637-642.

6. O'Brien E, Mee F, Atkins N, O'Malley K: Evaluation of the SpaceLabs 90202 non-invasive ambulatory recorder according to the AAMI Standard and BHS criteria. J Hum Hypertens 1991;5:223-226.

7. Kool MJF, van Merode T, Reneman RS, Hoeks APG, Struijker Boudier HAJ, Van Bortel LMAB: Evaluation of the reproducibility of a vessel wall movement detector system for assessment of large artery properties. Cardiovasc Res 1994;28:610-614.

8. Hoeks APG, Brands PJ, Smeets FAM, Reneman RS: Assessment of the distensibility of superficial arteries. Ultrasound Med Biol 1990;16:121-128.

9. Nichols WW, MF O'Rourke: McDonald's blood flow in arteries. Theoretical, experimental and clinical principles. New York, Oxford University Press Inc., 1998,

10. Takazawa K, Tanaka N, Takeda K, Kurosu F, Ibukiyama C: Underestimation of vasodilator effects of nitroglycerin by upper limb blood pressure. Hypertension 1995;26:520-523.

11. Demolis PD, Asmar RG, Levy BI, Safar ME: Non-invasive evaluation of the conduit function and the buffering function of large arteries in man. Clin Physiol 1991;11:553-564.

12. Asmar R, Benetos A, Topouchian J, Laurent P, Pannier B, Brisac AM, Target R, Levy BI: Assessment of arterial distensibility by automatic pulse wave velocity measurement. Hypertension $1995 ; 26: 485-490$.

13. Kleinbaum DG, LL Kupper, KE Muller: Applied Regression Analysis and Other Multivariate Methods. Boston, MA, PWS-Kent Publishing Company, 1988, pp 41-79.

14. London GM, Guerin AP, Pannier B, Marchais SJ, Stimpel M: Influence of sex on arterial hemodynamics and blood pressure. Role of body height. Hypertension 1995;26:514-519.

15. Gangar KF, Vyas S, Whitehead M, Crook D, Meire H, Campbell S: Pulsatility index in internal carotid artery in relation to transdermal oestradiol and time since menopause. Lancet 1991;338:839-842.

16. Westendorp ICD, Bots ML, Grobbee DE, Reneman RS, Hoeks APG, Van Popele NM, Hofman, A, Witteman JCM: Menopausal status and distensibility of the common carotid artery. Arterioscler Thromb Vasc Biol 1999;19:713-717.

17. Pines A, Fisman EZ, Drory Y, Levo Y, Shemesh J, Ben-Ari E, Ayalon D: Menopause-induced changes in Doppler-derived parameters of aortic flow in healthy women. Am J Cardiol 1992;69: 1104 $-1106$.

18. Pines A, Fisman EZ, Levo Y, Averbuch M, Lidor A, Drory Y, Finkelstein A, Hetman-Peri M, Moshkowitz M, Ben-Ari E, Ayalon D: The effects of hormone replacement therapy in normal postmenopausal women: measurements of Doppler-derived parameters of aortic flow. Am J Obstet Gynecol 1991;164:1104-1106.

19. Karpanou EA, Vyssoulis GP, Papakyriakou SA, Toutouza MG, Toutouzas PK: Effects of menopause on aortic root function in hypertensive women. J Am Coll Cardiol 1996;28:1562- 1566.

20. Rajkumar C, Kingwell BA, Cameron JD, Waddell T, Mehra R, Christophidis N, Kamesaroff PA, McGrath B, Jennings GL, Sudhir K, Dart AM: Hormonal therapy increases arterial compliance in postmenopausal women. J Am Coll Cardiol 1997;30:350-356.

21. Laogun AA, Gosling RG: In vivo arterial compliance in man. Clin Phys Physiol Meas 1982;3:201-212.

22. Waddell TK, Rajkumar C, Cameron JD, Jennings GL, Dart AM, Kingwell BA: Withdrawal of 
Chapter 5

hormonal therapy for 4 weeks decreases arterial compliance in postmenopausal women. $J$ Hypertens 1999;17:413-414.

23. Manhem K, Ahlm H, Milsom I, Svensson A: Transdermal oestrogen reduces daytime blood pressure in hypertensive women. J Hum Hypertens 1998;12:323-327.

24. van Ittersum FJ, van Baal WM, Kenemans P, Mijatovic V, Donker AJM, van der Mooren MJ, Stehouwer CDA: Ambulatory - not office - blood pressures decline during hormone replacement therapy in healthy postmenopausal women. Am J Hypertens 1998;11:1147-1152.

25. Harvey PJ, Wing LM, Savage J, Molloy D: The effects of different types and doses of oestrogen replacement therapy on clinic and ambulatory blood pressure and the renin-angiotensin system in normotensive postmenopausal women. J Hypertens 1999;17:405-411.

26. Seely EW, Walsh BW, Gerhard MD, Williams GH: Estradiol with or without progesterone and ambulatory blood pressure in postmenopausal women. Hypertension 1999;33:1190-1194.

27. Dunne FP, Barry DG, Ferriss JB, Grealy G, Murphy D: Changes in blood pressure during the normal menstrual cycle. Clin Sci 1991;81:515-518.

28. Andersson SG, Hacksaw BT, Still GJ, Greiss FC: Uterine blood flow and its distribution after chronic estrogen and progesterone administration. Am J Obstet Gynecol 1977;127:138-142.

29. Wolinsky H: Effects of estrogen and progestogen treatment on the response of the aorta of male rats to hypertension. Circulation 1972;30:341-349.

30. Sudhir K, Jennings GL, Funder JW, Komesaroff PA: Estrogen enhances basal nitric oxide release in the forearm vasculature in perimenopausal women. Hypertension 1996;28:330-334.

31. Taddei S, Virdis A, Ghiadoni L, Mattei P, Sudano I, Bernini G, Pinto S, Salvetti A: Menopause is associated with endothelial dysfunction in women. Hypertension 1996;28:576-582.

32. Lieberman EH, Gerhard MD, Ueheta A, Walsh BW, Selwyn AP, Ganz P, Yeung AC, Creager MA: Estrogen improves endothelium-dependent flow-mediated vasodilation in postmenopausal women. Ann Intern Med 1994;121:936-941.

33. Sung BH, Ching M, Izzo JL, Jr., Dandona P, Wilson MF: Estrogen improves abnormal norepinephrine-induced vasoconstriction in postmenopausal women. J Hypertens 1999;17:523-528.

34. Fisher G, Swain M: Effect of sex hormones on blood pressure and vascular connective tissue in castrated and noncastrated male rats. Am J Physiol 1977;232:H617-H621.

35. Witteman JCM, Grobbee DE, Kok FJ, Hofman A, Valkenburg HA: Increased risk of atherosclerosis in women after the menopause. Brit Med J 1989;298:642-644.

36. Cohn JN, Finkelstein S, McVeigh G, Morgan D, LeMay.L., Robinson J, Mock J: Noninvasive pulse wave analysis for the early detection of vascular disease. Hypertension 1995;26:503508. 



\section{CHAPTER 6}

Obesity, fat distribution and vessel wall properties

J.J. van der Heijden-Spek, J.A. Staessen, R.H. Fagard, H.A.J. Struijker Boudier, L.M.A.B. Van Bortel 


\begin{abstract}
Obesity is a well-known independent risk factor for the development of cardiovascular disease. Compliance $(C C)$ and distensibility $(D C)$ are wall properties of large arteries, which may play a role in cardiovascular disease. The purpose of this study was to investigate the relation between large artery wall properties and measures of obesity, such as body mass index (BMI), waist to hip ratio (W-H ratio) and thickness of skinfold. Since body height contributes to BMI, the effects of height were analysed separately.

In a population sample of 250 men $(M)$ and 243 women $(F)$, age between 20-79 years, diameter, DC and CC of the elastic aorta and common carotid artery (CCA) and muscular brachial $(B A)$ and femoral arteries (FA) were measured with an echo-tracking device. The effects of height, body mass index (BMI), waist-to-hip ratio (W-H ratio) and skinfold thickness were assessed, adjusted for confounding factors.

In both sexes height was positively $(p<.05)$ related to diameter of the CCA and FA. Also in both sexes height was positively related to carotid artery $C C(p<.05)$, whereas at the femoral artery this positive relation was present only in men $(p<.01)$. BMI was positively $(p<.01)$ related to diameter of the CCA, BA and $F A$. Obesity was not significantly related to aortic stiffness. Except for carotid artery $D C$ in women, BMI was negatively $(p<.05)$ related to $D C$ of $C C A, B A$ and FA. In men, BMI was also negatively related to $C C$ of the $B A(p<.05)$ and $F A$ $(p<.05)$. An increased waist-to-hip ratio, i.e. an android body habitus, does not seem to be of importance for $D C$ and $C C$ in women. In men, it was negatively related to femoral artery $D C$ and $C C(p<.01)$. Skinfold thickness was negatively related to brachial artery $D C$ in women $(p<.001)$.

In conclusion the present study confirmed that height is a determinant of the buffering capacity of large arteries. The main findings of the study are that associations between obesity and arterial wall properties depend on the index of obesity, gender and the vascular territory. The majority of assocations are found with BMI. BMI-based obese subjects have a larger arterial diameter and stiffer arteries in both sexes. Waist to hip ratio does not appear to be of importance in women, but in men it is associated with a lower femoral artery distensibility and compliance. Skinfold thickness is negatively associated with brachial artery distensibility in women, whereas it does not appear to be of importance in men.
\end{abstract}




\section{Introduction}

Obesity, generally defined as a body mass index greater than $27 \mathrm{~kg} / \mathrm{m}^{2}$ or a body weight greater than $120 \%$ of ideal, is common in Westernized societies with an overall prevalence of $30 \%{ }^{1}$. Obesity is a well-known independent risk factor for the development of cardiovascular disease ${ }^{2,3}$. One of the possible targets of obesity-related risk is a change in vascular function. Compliance and distensibility are vessel wall properties of large arteries, which might be important in the development of cardiovascular disease ${ }^{4}$. Compliance, defined as the absolute change in volume per unit of pressure $(\Delta \mathrm{V} / \Delta \mathrm{P})$, reflects the buffering capacity of the arterial system. Distensibility, defined as the relative change in volume per unit of pressure $((\Delta \mathrm{V} / \mathrm{V}) / \Delta \mathrm{P})$, reflects the elastic properties of the wall.

Little is known about the relation between obesity and vessel wall properties of large arteries. The few studies investigating the relation between obesity and large artery properties show different results ${ }^{5-10}$. This could be due to different techniques, small number of subjects, the involvement of different arteries and different definitions of obesity. Obesity can be expressed in different ways: body mass index (BMI), waist-to-hip ratio and thickness of skinfold. These indices do not describe the same entity. For example waist-to-hip ratio can differ substantially between two subjects with the same BMI, indicating a difference in fat distribution. The pattern of fat distribution itself also seems to add in the cardiovascular risk ${ }^{11,12}$. Skinfold thickness is a measure of subcutaneous fat.

The aim of the present study was to investigate the relation between indices of obesity (BMI, waist-to-hip ratio and thickness of skinfold) and large artery wall properties of the aorta, common carotid, brachial and femoral arteries in a population sample. Since body height contributes to body mass, the relation between height and large artery wall properties was also studied.

\section{Methods}

Six hundred and fourteen people from a random population sample ${ }^{13}$ took part in vascular measurements (chapter 2). Of these participants 121 subjects were not included in the final analysis, because the necessary data were not complete, so the number of subjects finally considered in the analysis totalled 493 subjects ( 250 men and 243 women).

The cardiovascular examinations took place at a locally organised clinic. All participants were asked to refrain from smoking, caffeine containing beverages and heavy excercise for at least 3 hours before being examined. Data of systolic (SBP) and diastolic blood pressure (DBP) are mean of five measurements, measured conventionally with a sphygmomanometer. Mean blood pressure (MBP) was calculated as $(2 x \mathrm{DBP}+\mathrm{SBP}) / 3$. A standardized questionnaire gave insight into their current health status, smoking and drinking habits and intake of drugs. Height and weight were measured. Body mass index (BMI) was calculated as weight/height ${ }^{2}$. Waist circumference was measured with a tape measurer midway between the lower rib and the iliac crest. Hip circumference was measured at the point yielding maximum circumference over the buttocks. Waist-to-hip ratio (W-H ratio) was used as an indicator of centrally localized body fat distribution. Skinfold thickness, a measure of subcutaneous fat, was measured on the left arm, halfway between the upper arm, with a skinfold caliper (British Indicators LTD). After 15 minutes of supine rest in a quiet room vessel wall properties of the right elastic common carotid artery (CCA) and right muscular femoral (FA) and brachial arteries (BA) were measured with a vessel wall movement detector system ${ }^{14}$. The procedure and formulae 


\section{Large artery properties: effect of obesity}

have been described earlier ${ }^{15}$ (chapter 2).

With the vessel wall movement detector system also carotido-femoral transit time of the pulse wave $(T)$ was recorded ${ }^{16}$. The length of the carotido-femoral segment $\left(\mathrm{L}_{\mathrm{ao}}\right)$ was measured with a tape measurer ${ }^{17}$. From length and transit time, the average pulse wave velocity (PWV) in this segment was calculated ${ }^{18}$. Pulse wave velocity is related to arterial distensibility (DC) by the formula: $\quad P W V=\sqrt{ } 1 / \rho D C \quad$ (Moens Korteweg ${ }^{19,20}$ ) ( $\rho=$ blood density) Database management and statistical analyses were performed with the SAS software (The SAS Institute Inc., Cary, North Carolina). The methods of analysis included Mann-Whitney-U tests for continuous variables and Chi-square tests for the dichotomous parameters. To test the influence of height, an analysis of covariance was used with factors for age, gender, mean arterial pressure, pulse rate, smoking, use of alcohol, total cholesterol and antihypertensive treatment. Factors with a p-value $>0.10$ were dropped from the model. In addition, the same analysis with height as an additional confounding factor was repeated to investigate the effect of BMI, waist-to-hip ratio and skinfold thickness. To investigate which index of obesity was best related to large artery wall properties, an analysis of covariance with all indices of obesity was done. $F$ values were used to show the importance of the factors to explain variance. Data are presented as mean \pm SD for demographic values and mean \pm SE for regression coefficients. A p-value $<0.05$ was considered as statistically significant. The study was approved by the ethics committee of Leuven University and all subjects gave their written informed consent.

\section{Results}

Table 1. Demographic characteristics of the study population

\begin{tabular}{llll}
\hline & male & female & $\mathrm{p}$ \\
\hline $\mathrm{n}$ & 250 & 243 & \\
Age (years) & $50.4 \pm 13.0$ & $49.8 \pm 12.3$ & .61 \\
Body mass index $\left(\mathrm{kg} / \mathrm{m}^{2}\right)$ & $26.0 \pm 3.3$ & $25.2 \pm 4.0$ & .005 \\
Waist/Hip ratio & $0.89 \pm 0.09$ & $0.83 \pm 0.12$ & $<.001$ \\
Skinfold & $1.24 \pm 0.47$ & $2.01 \pm 0.62$ & $<.001$ \\
Blood Pressure $(\mathrm{mmHg})^{\ddagger}$ & & & \\
$\quad$ Systolic & $132 \pm 15$ & $128 \pm 19$ & .003 \\
$\quad$ Diastolic & $84 \pm 10$ & $81 \pm 10$ & $<.001$ \\
Heart rate (bpm) & $61 \pm 10$ & $64 \pm 10$ & .001 \\
Smokers & $84(33.6 \%)$ & $75(30.9 \%)$ & .52 \\
Drinking alcohol & $85(34 \%)$ & $28(11.5 \%)$ & $<.001$ \\
Antihypertensive treatment & $38(15.2 \%)$ & $38(15.6 \%)$ & .89 \\
\hline
\end{tabular}

Results are mean \pm SD or number of subjects with percentage in brackets. ${ }^{\ddagger}$ Measured with a sphygmomanometer in sitting position. bpm, beats/minute

The 250 men and 243 women were between 26 and 79 years old (Table 1). Men had a larger body mass index, W-H ratio and blood pressure, while women had a larger skinfold thickness and heart rate. One hundred and fiftynine participants smoked a median of 15 cigarettes per 
day (range 1-70). One hundred and thirteen subjects drank a median of $20 \mathrm{~g}$ alcohol per day (range 1-196). A total of 76 subjects were taking antihypertensive treatment either in monotherapy or in combination. Vessel wall properties in this population are described in Table 2.

Table 2. Vessel wall properties in the study population

\begin{tabular}{llll}
\hline & male & female & p \\
\hline PWV Aorta & & & \\
Diameter $(\mathrm{mm})$ & $7.0 \pm 1.9$ & $6.5 \pm 1.7$ & \\
CCA & & & \\
BA & $7.71 \pm 0.79$ & $6.92 \pm 0.78$ & $<.001$ \\
FA & $4.64 \pm 0.63$ & $3.61 \pm 0.62$ & $<.001$ \\
Distensibility Coefficient $\left(10^{-3} / \mathrm{kPa}\right)$ & $10.06 \pm 1.11$ & $8.49 \pm 1.09$ & $<.001$ \\
CCA & $21.4 \pm 8.4$ & & \\
BA & $20.8 \pm 10.0$ & $21.9 \pm 8.6$ & .62 \\
FA & $7.9 \pm 4.1$ & $24.4 \pm 11.8$ & $<.001$ \\
Compliance Coefficient $\left(\mathrm{mm}^{2} / \mathrm{kPa}\right)$ & $9.0 \pm 4.7$ & .012 \\
CCA & $1.04 \pm 0.32$ & & \\
BA & $0.33 \pm 0.16$ & $0.78 \pm 0.31$ & $<.001$ \\
FA & $0.63 \pm 0.32$ & $0.21 \pm 0.16$ & $<.001$ \\
\hline
\end{tabular}

Results are mean \pm SD. ' Measurements available in 464 subjects. PWV: pulse wave velocity, CCA common carotid artery, FA common femoral artery, BA brachial artery

In both sexes, after adjustment for age, mean arterial pressure, pulse rate, smoking, use of alcohol, total cholesterol and antihypertensive treatment, height was positively related to carotid and femoral artery diameter and only in women to brachial artery diameter (Table 3).

Height was not related to arterial distensibility. In both sexes height was positively related to carotid artery CC, while only in men there was also a positive relation with femoral artery CC. In both sexes, after adjustment for the factors mentioned above, BMI was positively related to arterial diameter (Table 4). Except for carotid artery DC in women, BMI was negatively related to DC of all arteries. There was no relation with PWV of the aorta. Only in men, BMI was negatively related to $\mathrm{CC}$ of the FA and BA. W-H ratio was not related to vessel wall properties in women. In men W-H ratio was positively related to diameter of the CCA and BA, negatively related to DC of the BA and FA and to CC of the FA. Thickness of skinfold was in both sexes positively related to carotid artery diameter. In women skinfold thickness was negatively related to brachial artery DC. Skinfold thickness did not relate to arterial compliance in both sexes.

Table 5 shows the importance of the different indices of obesity as determinants of the large artery wall properties. W-H ratio was the more important determinant of FA compliance in men, whereas skinfold thickness was the most important determinant of BA distensibility in women. BMI was the most important determinant of all other arterial wall properties, which were related to obesity. 
Table 3. Relation between arterial wall properties and height, after adjustment ${ }^{1}$

\begin{tabular}{lll}
\hline $\begin{array}{l}\text { Slope } \\
\left.\text { (height }(\mathrm{cm})^{-1}\right) .10^{2}\end{array}$ & male & female \\
\hline PWV Aorta & & \\
Diameter $(\mathrm{mm})$ & n.s. & n.s \\
$\quad$ CCA & $1.6 \pm 0.7^{*}$ & $1.6 \pm 0.7^{*}$ \\
BA & n.s. & $1.2 \pm 0.5^{*}$ \\
FA & $4.1 \pm 1.0^{* * *}$ & $4.3 \pm 0.9^{* * *}$ \\
Distensibility Coefficient $\left(10^{-3} / \mathrm{kPa}\right)$ & & \\
CCA & n.s. & n.s. \\
BA & n.s. & n.s. \\
FA & n.s. & n.s. \\
Compliance Coefficient $\left(\mathrm{mm}^{2} / \mathrm{kPa}\right)$ & & \\
CCA & $0.9 \pm 0.3^{* * *}$ & $0.5 \pm 0.2^{*}$ \\
BA & n.s. & n.s. \\
FA & $0.8 \pm 0.3^{* *}$ & n.s. \\
\hline
\end{tabular}

${ }^{1}$ adjustment for age, mean arterial pressure, heart rate, smoking, use of alcohol, total cholesterol and antihypertensive treatment. ${ }^{2}$ Regression coefficients \pm SE ${ }^{3}$ Measurements available in 464 subjects. PWV pulse wave velocity, ${ }^{*} \mathrm{p}<0.05,{ }^{* *} \mathrm{p}<0.01,{ }^{* * *} \mathrm{p}<0.001$, n.s. not significant.

\section{Discussion}

This is the first study investigating the association between three indices of obesity and wall properties of different arterial territories. Since body height contributes to body mass, we also analysed the effects of height separately.

The present study showed taller subjects have a higher compliance of the carotid and femoral arteries. This larger arterial compliance may contribute to a smaller cardiac afterload in taller men. This could explain why short men are more prone to ischemic heart disease ${ }^{21}$. This larger compliance was the result of a larger diameter in taller subjects, which was also described by others ${ }^{22,23}$. This result could also partly explain the difference in arterial diameter between men and women, since most women are shorter than men.

Obesity can be defined in different ways. One of the most used indices is BMI. In the present study, the majority of associations between obesity and vessel wall properties were found for BMI.

In accordance with others ${ }^{8,9,24}$, in the present study, arterial diameter of all arteries studied was increased in subjects with a higher BMI. This can be the result of the hyperdynamic circulation in obese subjects; obese subjects have a higher cardiac output, stroke volume and circulating blood volume and lower peripheral resistance ${ }^{25-28}$. This hyperdynamic circulation may cause flow-dependent vasodilation, leading to a larger arterial diameter.

BMI was negatively related to brachial and femoral artery DC in both men and women and carotid artery DC in men. However, like previous studies ${ }^{5,7}$, the present study did not find a relation between BMI and aortic distensibility. The exact cause of this higher arterial stiffness is not known. Several explanations could be hypothesized: (1) It could be a passive phenomenon, namely a consequence of the larger diameter in obese subjects. (2) The increased stiff- 
ness could be caused by an increased size of adipocytes, which may affect the transmural pressure ${ }^{6}$. (3) The increased stiffness could also be due to early atherosclerotic disease. It's however not clear whether a direct relation between obesity and atherogenesis exists. A recent report described an association between adipose tissue and $\mathrm{C}$ reactive protein, an inflammatory mediator, which may be directly involved in atherogenesis ${ }^{29}$. (4) It could also be an indirect relation; other factors, which often coincide with obesity, like hyperinsulinemia might be involved ${ }^{7,30-32}$. A decrease in DC may increase wall stress, which may lead to atherogenesis and cardiovascular events ${ }^{33}$.

Arterial compliance is determined by arterial diameter and distensibility. The increase in diameter in BMI-based obese subjects was often accompanied by a decrease in arterial distensibility. The net result was no change in arterial compliance of all three arteries in women. In men it resulted in a smaller arterial compliance of the muscular brachial and femoral arteries.

The associations between arterial wall properties and obesity, discussed so far, were based on obesity defined as a higher BMI. BMI is however not only an estimate of fat, it also comprises musculoskeletal mass. This means subjects with a high BMI can also be very well trained, non-obese subjects. Other estimates of obesity are waist-to-hip ratio and thickness of skinfold. The waist-to-hip ratio discriminates between fat deposited in the upper (android) and lower trunk (gynaecoid). Lately several reports showed that subjects with an android fat distribution have an increased cardiovascular risk, independent of BMI ${ }^{11,12}$. In the present study, waist-tohip ratio was not significantly related to large artery wall properties in women. In men waistto-hip ratio was negatively related to femoral artery distensibility and compliance. This is in line with an earlier study describing a negative relation between distensibility of the abdominal aorta and visceral fat accumulation ${ }^{34}$. Of all three indices of obesity, waist-to-hip ratio was also the most important determinant of femoral artery DC and CC in men, independent of BMI. The reason for this lower distensibility and compliance of the abdominal aorta and femoral artery is not clear. It has been suggested that it could be caused by the pressure of fat, surrounding the artery ${ }^{34}$.

Another method to assess fat distribution is by measuring skinfold thickness. In women thickness of skinfold was negatively related to brachial artery DC. Of the three obesity-indices studied, skinfold thickness was also the most important determinant of brachial artery DC in women.The cause of this is not clear, like for waist-to-hip ratio local pressure of fat might be hypothesized. This parameter does not seem to be of importance in determining large artery distensibility and compliance in men.

In conclusion, the present study confirmed that height is a determinant of the buffering capacity of large arteries. The main findings of the study are that associations between obesity and arterial wall properties depend on the index of obesity, gender and the vascular territory. The majority of assocations are found with BMI. BMI-based obese subjects have a larger arterial diameter and stiffer arteries in both sexes. Fat distribution assessed by waist-to-hip ratio (an android body habitus) does not appear to be of importance in women, but in men it is associated with a lower femoral artery distensibility and compliance. Skinfold thickness is negatively associated with brachial artery distensibility in women, whereas it does not appear to be of importance in men. Whether the described effects are caused by obesity itself, i.e. local pressure of fat, or by concomitant factors like hyperinsulinemia and whether these changes are reversible remains to be further investigated. 


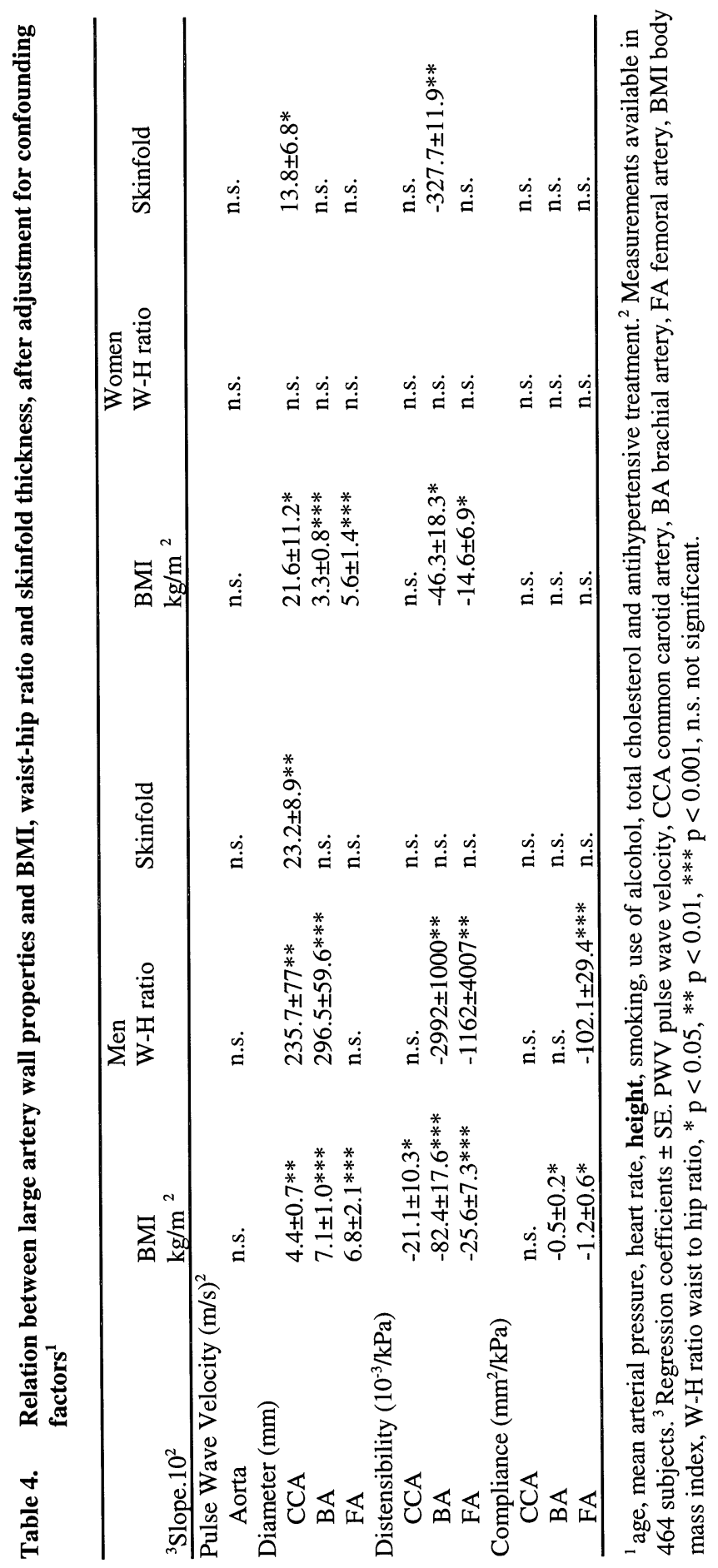




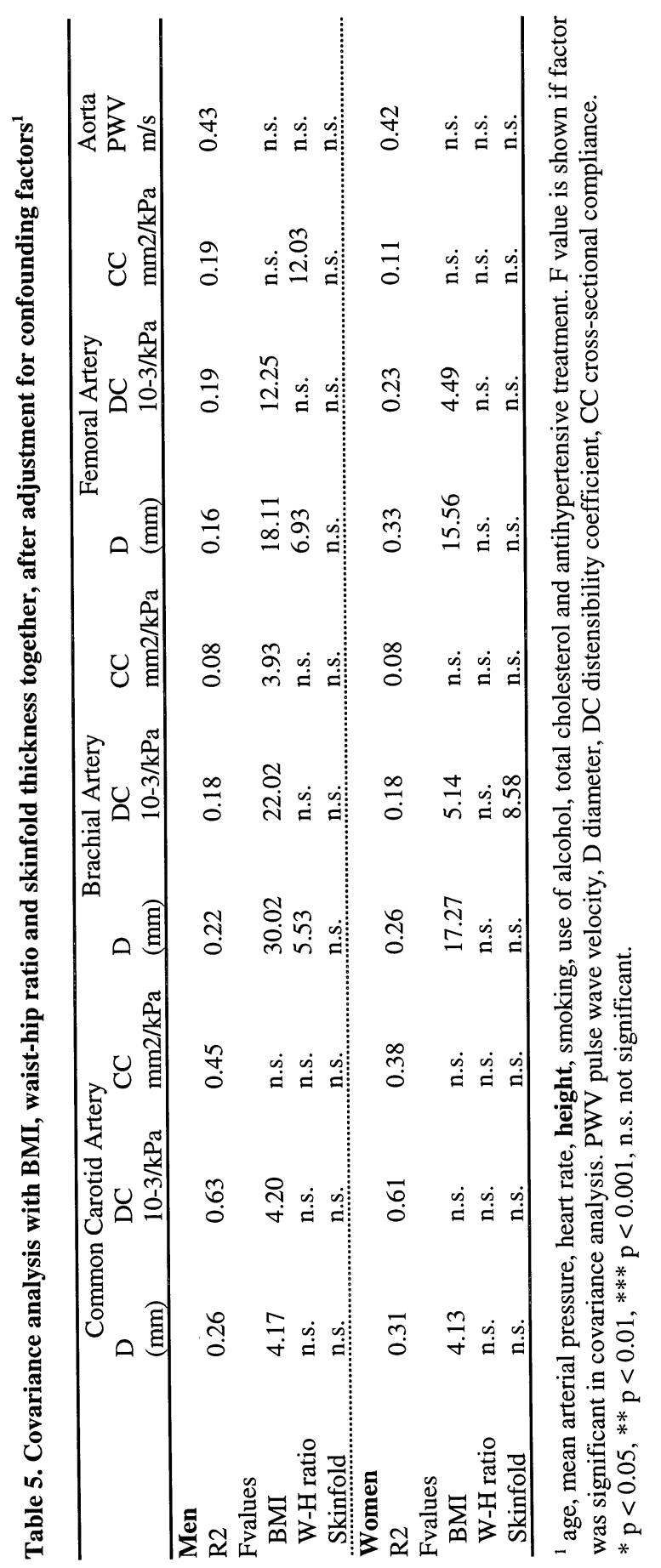




\section{References}

1. DeFronzo RA: Insulin resistance, hyperinsulinemia, and coronary artery disease: a complex metabolic web. J Cardiovasc Pharmacol 1992;20(Suppl. 11):s1-s16.

2. Gordon T, Kannel WB: Obesity and cardiovascular disease: the Framingham Study, in Burland WL, Samuel PD, Yudkin J (eds): Obesity symposium. Proceedings of a Servier research institute symposium. Edinburgh, Churchill Livingstone, 1974, pp. 367-374.

3. Hubert HB, Feinleib M, McNAMARA PM, Castelli WP: Obesity as an independent risk factor for cardiovascular disease: a 26-year follow - up of participants in the Framingham Heart Study. Circulation 1983;67:968-976.

4. Safar M: Arteries in clinical hypertension., Lippincott-Raven, 1996.

5. Mujais SK, Tarazi RC, Dustan HP, Fouad FM, Bravo EL: Hypertension in obese patients: hemodynamic and volume studies. Hypertension 1982;4:84-92.

6. Toto-Moukouo JJ, Achomastos RG, Asmar RG, Hugues CJ, Safar ME: Pulse wave velocity in patients with obesity and hypertension. Am Heart J 1986;112:136-140.

7. Kupari M, Hekali P, Keto P, Poutanen V, Tikkanen MJ, Standertskjold-Nordenstam C: Relation of aortic stiffness to factors modifying the risk of atherosclerosis in healthy people. Arterioscler Thromb 1994;14:386-394.

8. Giltay EJ, Lambert J, Elbers JMH, Gooren LJG, Asscheman H, Stehouwer CDA: Arterial compliance and distensibility are modulated by body composition in both men and women but by insulin sensitivity only in women. Diabetologia 1999;42:214-221.

9. Mangoni AA, Giannattasio C, Brunani A, Failla M, Colombo M, Bolla G, Cavagnini F, Grassi G, Mancia G: Radial artery compliance in young, obese, normotensive subjects. Hypertension 1995;26:984-988.

10. Oren S, Grossman E, Frohlich ED: Arterial and venous compliance in obese and nonobese subjects. Am J Cardiol 1996;77:665-667.

11. Williams SRP, Jones E, Bell W, Davies B, Bourne MW: Body habitus and coronary heart disease in men. A review with reference to methods of body habitus assessment. Eur Heart J 1997;18:376-393.

12. Solomon CG, Manson JE: Obesity and mortality: a review of the epidemiologic data. Am J Clin Nutr 1997;66 (suppl):1044s-1050s.

13. Staessen JA, Roels H, Fagard R: Lead exposure and conventional and ambulatory blood pressure. A prospective population study. JAMA 1996;275:1563-1570.

14. Hoeks APG, Brands PJ, Smeets FAM, Reneman RS: Assessment of the distensibility of superficial arteries. Ultrasound Med Biol 1990;16:121-128.

15. van der Heijden-Spek JJ, Staessen JA, Fagard RA, Hoeks AP, Struijker Boudier HA, Van Bortel LM: The effect of age on brachial artery wall properties differs from the aorta and is gender-dependent: a population study. Hypertension 2000;35:637-642.

16. Kool MJ, Lambert J, Stehouwer CD, Hoeks AP, Struijker Boudier HA, Van Bortel LM: Vessel wall properties of large arteries in uncomplicated IDDM. Diabetes Care 1995;18:618-624.

17. Demolis PD, Asmar RG, Levy BI, Safar ME: Non-invasive evaluation of the conduit function and the buffering function of large arteries in man. Clin Physiol 1991;11:553-564.

18. O'Rourke MF: Function of arteries as vascular conduits, in O'Rourke MF (ed): Arterial function in health and disease. Edinburgh,London, Melbourne, New York, Churchill Livingstone, 1982, pp. 53-64.

19. Moens E: Die Pulscurve. Leiden, EJ Brill, 1878.

20. Hoeks APG: Non-invasive study of local mechanical arterial characteristics in humans, in Safar ME (ed): The arterial system in hypertension. Dordrecht, The Netherlands, Kluwer Academic Publisher, 1993, pp. 119-134

21. Morris JN, Everitt MG, Pollard R, Chave SPW: Vigorous exercise in leisure-time: protection against coronary heart disease. Lancet 1980;ii:1207-1210.

22. Sonesson B, Hansen F, Stale H, Länne T: Compliance and diameter in the human abdominal aorta- the influence of age and sex. Eur J Vasc Surg 1993;7:690-697.

23. Milnor WR: Normal hemodynamic state, in Milnor WR (ed): Hemodynamics. Baltimore, Williams and Wilkins, 1982, pp. 135-156.

24. Spek JJ, Hoeks APG, Struijker Boudier HAJ, Van Bortel LMAB: Differences in vessel wall properties of large arteries between obese and lean subjects. Nier und Hochdrukkrankheiten 1995;8:431-432. 
25. Messerli FH, Christie B, Decarvalho JGR, Aristimuno GG, Suarez DH, Dreslinski GR,

Frohlich ED: Obesity and essential Hypertension. Hemodynamics, intravascular volume sodium excretion, and plasma renin activity. Arch Intern Med 1981;141:81-85.

26. Backman L, Freyschuss U, Hallberg D, Melcher A: Reversibility of cardiovascular changes in extreme obesity. Acta Med Scand 1979;205:367-373.

27. Rocchini AP, Moorehead C, Katch V, Key J, Finta KM: Forearm resistance vessel abnormalities and insulin resistance in obese adolescents. Hypertension 1992;19:615-620.

28. Stepniakowski K, Egan BM: Additive effects of obesity and hypertension to limit venous volume. Am J Physiol 1995;268:R562-R568.

29. Hak AE, Stehouwer CDA, Bots LM, Polderman KH, Schalkwijk CG, Westendorp ICD, Hofman A, Witteman JCM: Associations of C-reactive protein with measures of obesity, insulin resistance, and subclinical atherosclerosis in healthy, middle-aged women. Arterioscler Thromb Vasc Biol 1999;19:1986-1991.

30. DeFronzo RA, Ferrannini E: Insulin resistance: a mulifaceted syndrome responsible for NIDDM, obesity, hypertension, dyslipidemia, and atherosclerotic cardiovascular disease. Diabetes Care 1991;14:173-194.

31. Neutel JM, Smith DHG, Graettinger WF, Weber MA: Dependency of arterial compliance on circulating neuroendocrine and metabolic factors in normal subjects. Am J Cardiol 1992;69:1340-1344.

32. Salooma V, Riley W, Kark JD, Nardo C, Folsom AR: Non-insulin-dependent diabetes mellitus and fasting glucose and insulin concentrations are associated with arterial stiffness indexes; The ARIC study. Circulation 1995;91:1432-1443.

33. O'Rourke MF: Basic concepts for the understanding of large arteries in hypertension. J Cardiovasc Pharmacol 1985; 7:S14-S21.

34. Resnick LM, Militianu D, Cunnings AJ, Pipe JG, Evelhoch JL, Soulen R: Direct magnetic resonance determination of aortic distensibility in essential hypertension: relation to age, abdominal visceral fat, and in situ intracellular free calcium. Hypertension 1997;30:654-659. 



\section{CHAPTER 7}

Relation between insulin resistance and large artery properties

J.J. van der Heijden-Spek, J.A. Staessen, R.H. Fagard, H.A.J. Struijker Boudier, L.M.A.B. Van Bortel 
Large artery properties: effect of insulin resistance

\begin{abstract}
Changes in arterial wall properties, compliance and distensibility, can be related to cardiovascular disease. There is also evidence for a link between insulin resistance, hyperinsulinemia and macrovascular disease. Data on the relation between insulin resistance and large artery wall properties are scarce.

In a population sample of 463 men and women, age between 20-79 years and fasting glucose below $6.0 \mathrm{mmol} / \mathrm{l}$, diameter, distensibility coefficient and cross-sectional compliance of the elastic common carotid artery and muscular brachial and femoral arteries were measured with an echo-tracking device. Distensibility of the aorta was measured using pulse wave velocity. The effects of insulin resistance, insulin and glucose were assessed, adjusted for mean blood pressure, pulse rate, body mass index, total cholesterol, smoking, alcohol intake and antihypertensive treatment.

In women insulin resistance, insulin (except for femoral artery diameter) and glucose were not related to large artery wall properties. In men, without adjustment for body mass index, insulin resistance was positively related to carotid $(p<.001)$ and brachial artery $(p<.01)$ diameter, and negatively related to brachial $(p<.05)$ and femoral artery $(p<.01)$ distensibility and femoral artery compliance $(p<.01)$. After adjustment for BMI, insulin resistance was positively related to carotid artery diameter $(p<.001)$ and negatively $(p<.01)$ related to femoral artery compliance. The effects of insulin were comparable to the effects of insulin resistance. Glucose was negatively $(p<.05)$ related to brachial artery compliance. BMI affected more arterial wall properties than insulin resistance.

In conclusion, the relation between insulin resistance and large artery wall properties is gender-dependent. In women, insulin resistance is not related to any of the large artery wall properties. The relation between insulin resistance and large artery wall properties in men depends on the vascular territory: compliance of the femoral artery was most affected by insulin resistance. Alteration of large artery properties in subjects with insulin resistance is probably due to increased insulin levels. Altered arterial wall properties in BMI-based obese subjects can only in part be attributed to an increase in insulin resistance.
\end{abstract}




\section{Introduction}

Changes in vessel wall properties of large arteries (compliance and distensibility) might play a role in the development of cardiovascular disease ${ }^{1}$. A decrease in compliance (change in volume per unit of pressure) increases cardiac afterload and the risk of cardiac hypertrophy ${ }^{2-4}$. A decrease in distensibility (relative change in volume per unit of pressure) is associated with an increased risk of arterial wall damage, an important feature in atherosclerotic disease ${ }^{5}$.

Vascular disease is more frequently seen in patients with non-insulin dependent diabetes mellitus and even in prediabetic and insulin resistant subjects ${ }^{6-9}$.

Insulin resistance is defined as a subnormal biological response to a given concentration of insulin. Insulin resistance can lead to (non-insulin dependent) diabetes mellitus, but is also found in apparently healthy subjects who maintain normal glucose levels by marked elevations of insulin secretion ${ }^{10}$, causing hyperinsulinemia.

The relation between insulin and large artery wall properties has been studied ${ }^{11-14}$, showing no

${ }^{14}$ or a positive relation ${ }^{11,13,15,16}$ between insulin and arterial stiffness. It is not yet clear whether a relationship exists between insulin resistance and altered vessel wall properties. Until now, only one relatively small study described the relation between arterial stiffness of the carotid and femoral artery and insulin sensitivity in healthy subjects ${ }^{16}$. There is however no study reporting the relation between insulin resistance and arterial wall properties at different arterial sites in a population.

The aim of the present study was to investigate the influence of insulin resistance (InsR) on large artery wall properties of different large arteries in a population sample of presumed healthy subjects with a normal fasting serum glucose level. In addition, we tried to reveal whether the effect was caused by insulin resistance per se or could be related to the influence of other factors like insulin, glucose or obesity. Since the relation between insulin and arterial stiffness seems to be gender-dependent ${ }^{11,16}$, men and women were analysed separately.

\section{Methods}

This study is also part of the population study ${ }^{17}$. Of the participating subjects, 614 took part in the vascular measurements. One hundred and fifty one subjects were removed from the data base, because fasting glucose was equal or higher than $6 \mathrm{mmol} / \mathrm{l}(\mathrm{n}=14)$ or insulin resistance was not estimated $(n=17)$ or vascular measurements were not available at each of the three arteries studied. The number of subjects finally considered in the analysis totalled 232 men and 231 women.

Vessel wall properties of the right elastic common carotid artery (CCA) and right muscular femoral (FA) and brachial arteries (BA) were measured with a vessel wall movement detector system ${ }^{18}$ according to a previously described protocol ${ }^{19}$ (chapter 2). During these measurements blood pressure and pulse rate were recorded every 3 minutes with an appropriate sized cuff at the left arm with a semiautomated device (Dinamap; Critikon, Tampa, Florida). The mean of these recordings (at least 10) was taken as the subject's reading. Brachial artery pulse pressure was defined as systolic minus diastolic blood pressure. Pulse pressure at CCA and FA were calculated by calibration of the distension curves (chapter 2). With the vessel wall movement detector system it is also possible to measure carotido-femoral transit time of the pulse wave $(T)^{20}$. The length of the carotido-femoral segment $\left(\mathrm{L}_{\mathrm{ao}}\right)$ was measured with a tape measurer. From length and transit time, pulse wave velocity (PWV) of the aorta was calculated. Pulse wave velocity is related to arterial distensibility (DC) by the formula: 
PWV $=\sqrt{ } 1 / \rho D C \quad$ (Moens Korteweg $\left.{ }^{21,22}\right) \quad(\rho=$ blood density)

Subjects were visited at home after an overnight fast for venous blood sampling for glucose and insulin. Glucose was measured by a glucose oxidase method, plasma insulin levels were measured by RIA. Insulin resistance (InsR) was assessed by calculating the insulin resistance index 23,24 .

$$
\text { InsR }=[\text { Insulin }] / 22.5 \times \mathrm{e}^{-\ln [\text { Glucose }]}
$$

For database management and statistical analyses the SAS software package (The SAS institute Inc., Cary, North Carolina) was used. The statistical models of the raw data of insulin resistance fitted better than the logarithmic transformed data. The methods of analysis included Mann-Whitney-U tests for continuous variables and Chi-square tests for the dichotomous parameters. To test the relation between insulin, glucose, insulin resistance and vessel wall properties, analyses of covariance were used. From the literature it is known that vessel wall properties are influenced by different factors like age, blood pressure and antihypertensive treatment ${ }^{25-27}$. Thus when studying the relation between InsR and large artery properties it is important to adjust for these factors. Adjustment was done for age, blood pressure, heart rate, antihypertensive treatment, total cholesterol, smoking and use of alcohol. Factors with a pvalue $>0.10$ were dropped from the model. Data are presented as mean \pm SD for demographic values and mean $\pm \mathrm{SE}$ for regression coefficients. A $\mathrm{p}$-value $<0.05$ was considered as statistically significant. The study was approved by the ethics committee of Leuven University and all subjects gave their written informed consent.

\section{Results}

Table 1. Characteristics of the study population

\begin{tabular}{llll}
\hline & Men & Women & $\mathrm{p}$ \\
\hline $\mathrm{n}$ & 232 & 231 & \\
Age (years) & $50.5 \pm 11$ & $49.7 \pm 12.3$ & .55 \\
Body mass index $\left(\mathrm{kg} / \mathrm{m}^{2}\right)$ & $25.9 \pm 3.4$ & $25.1 \pm 4.0$ & .005 \\
Blood Pressure $(\mathrm{mmHg})$ & & & \\
$\quad$ Systolic & $131 \pm 14$ & $128 \pm 19$ & .001 \\
$\quad$ Diastolic & $84 \pm 11$ & $80 \pm 10$ & $<.001$ \\
Pulse rate (bpm) & $61 \pm 9$ & $64 \pm 9$ & .001 \\
& & & \\
Smokers & $82(35.3 \%)$ & $72(31.2 \%)$ & .34 \\
Drinking alcohol & $82(35.3 \%)$ & $24(10.4 \%)$ & $<.001$ \\
Antihypertensive treatment & $34(14.7 \%)$ & $35(15.2 \%)$ & 0.88 \\
& & & \\
Glucose (mmol/l) & $4.9 \pm 0.5$ & $4.8 \pm 0.5$ & $<.001$ \\
Insulin (u/l) & $8.2 \pm 4.4$ & $8.2 \pm 4$ & .69 \\
Total cholesterol(mmol/l) & $5.7 \pm 1.0$ & $5.7 \pm 0.8$ & .68 \\
Insulin resistance & $1.8 \pm 1.1$ & $1.8 \pm 0.9$ & .65 \\
\hline
\end{tabular}

Results are mean \pm SD or number of subjects with percentage within brackets. \# Measured with a sphygmomanometer in sitting position. bpm beats/minute 
Population Characteristics

Age ranged from 26 to 79 years (Table 1). One hundred and fifty four subjects currently smoked a median of 14 cigarettes a day (range 1-62). Alcohol drinkers consumed a median of $14 \mathrm{~g}$ a day (range 1-196). Fasting glucose ranged from 3.8 to $5.9 \mathrm{mmol} / \mathrm{l}$, fasting insulin from 2.2 to $26.9 \mathrm{u} / \mathrm{l}$. Vessel wall properties in this population are described in Table 2 .

Table 2. Vessel wall properties in the population

\begin{tabular}{clll}
\hline & Men & Women & p \\
\hline $\begin{array}{l}\text { PWV aorta }(\mathrm{m} / \mathrm{s})^{1} \\
\text { Diameter }(\mathrm{mm})\end{array}$ & $7.0 \pm 2.0$ & $6.6 \pm 1.8$ & .002 \\
CCA & $7.69 \pm 0.82$ & $6.88 \pm 0.81$ & $<.001$ \\
BA & $4.57 \pm 0.60$ & $3.64 \pm 0.55$ & $<.001$ \\
FA & $10.05 \pm 1.09$ & $8.53 \pm 1.01$ & $<.001$ \\
Distensibility Coefficient $\left(10^{-3} / \mathrm{kPa}\right)$ & $21.3 \pm 8.2$ & $22.2 \pm 8.6$ & \\
CCA & $20.8 \pm 10.0$ & $24.6 \pm 12.0$ & .35 \\
BA & $8.0 \pm 4.2$ & $8.9 \pm 4.6$ & $<.001$ \\
FA & $0.97 \pm 0.35$ & & .02 \\
Compliance Coefficient $\left(\mathrm{mm}^{2} / \mathrm{kPa}\right)$ & $0.80 \pm 0.26$ & $<.001$ \\
CCA & $0.33 \pm 0.13$ & $0.25 \pm 0.11$ & $<.001$ \\
BA & $0.62 \pm 0.31$ & $0.49 \pm 0.22$ & $<.001$ \\
FA & & &
\end{tabular}

Results are mean \pm SD. ${ }^{1}$ Measurements available in 447 subjects. PWV pulse wave velocity, CCA common carotid artery, BA brachial artery, FA femoral artery.

\section{Insulin resistance}

Unadjusted data are shown in Table $3 a$ for men and Table $3 b$ for women. InsR did not relate to arterial diameter in women, while in men there was a positive relation between InsR and carotid $(\mathrm{p}<.001)$ and brachial artery $(\mathrm{p}<.01)$ diameter (Table 3$)$. In both sexes a positive relation was found between InsR and PWV of the aorta $(\mathrm{p}<.01)$ and a negative relation with brachial $(\mathrm{p}<.01)$ and femoral $(\mathrm{p}<.01)$ artery DC. The same was found for carotid artery DC in men $(\mathrm{p}<.05)$. InsR was negatively related $(\mathrm{p}<.01)$ to femoral artery $\mathrm{CC}$ in both sexes and brachial artery $\mathrm{CC}$ in women $(\mathrm{p}<.05)$.

InsR often appears in obese subjects. Also in the present study, InsR was related to BMI (correlation $0.40, \mathrm{p}<.001$ ). By adjusting for BMI, we might underestimate the relation between InsR and large artery properties. We therefore performed two analyses: one adjusting for all confounding factors except for BMI and one with adjustment for all factors including BMI.

Without adjustment for BMI, in women, there were no significant relations between InsR and large artery wall properties. In men InsR was positively related to carotid $(\mathrm{p}<.001)$ and brachial artery $(\mathrm{p}<.01)$ diameter. InsR was or tended to be negatively related to distensibility of the aorta $(\mathrm{p}=.06), \mathrm{BA}(\mathrm{p}<.01)$ and FA $(\mathrm{p}<.05)$. There was also an inverse relation $(\mathrm{p}<.01)$ between InsR and femoral artery compliance and a trend for a negative relation with brachial artery compliance $(\mathrm{p}=.07)$. 
Large artery properties: effect of insulin resistance

Table 3a Men: relation with Insulin Resistance, before and after adjustment ${ }^{1}$.

\begin{tabular}{|c|c|c|c|c|}
\hline Slope ${ }^{2}$ & $\begin{array}{l}\text { InsR } \\
\text { Unadjusted }\end{array}$ & $\begin{array}{l}\text { InsR } \\
\text { Adjusted, } \\
\text { without BMI }\end{array}$ & $\begin{array}{l}\text { InsR } \\
\text { Adjusted, } \\
\text { with BMI }\end{array}$ & $\begin{array}{l}\text { BMI }\left(\mathrm{kg} / \mathrm{m}^{2}\right) \\
\text { Adjusted }\end{array}$ \\
\hline \multicolumn{5}{|l|}{ PWV (m/s) } \\
\hline Aorta $^{3}$ & $0.34 \pm 0.12 * *$ & $0.18 \pm 0.10+$ & $0.18 \pm 0.10+$ & n.s. \\
\hline \multicolumn{5}{|l|}{ Diameter (mm) } \\
\hline Carotid artery & $0.18 \pm 0.05 * * *$ & $0.17 \pm 0.05 * * *$ & $0.17 \pm 0.05 * * *$ & $0.041 \pm 0.014 * *$ \\
\hline Brachial artery & $0.10 \pm 0.04 * *$ & $0.10 \pm 0.04 * *$ & n.s. & $0.067 \pm 0.011 * * *$ \\
\hline Femoral artery & n.s. & n.s. & n.s. & $0.061 \pm 0.021 * *$ \\
\hline \multicolumn{5}{|l|}{$\mathrm{DC}\left(10^{-3} / \mathrm{kPa}\right)$} \\
\hline Carotid artery & $-1.10 \pm 0.51 *$ & n.s. & n.s. & $-0.23 \pm 0.10 *$ \\
\hline Brachial artery & $-1.83 \pm 0.61 * *$ & $-1.69 \pm 0.58 * *$ & n.s. & $-0.79 \pm 0.18 * * *$ \\
\hline Femoral artery & $-0.69 * *$ & $-0.51 \pm 0.24 *$ & n.s. & $-0.25 \pm 0.08 * *$ \\
\hline \multicolumn{5}{|l|}{$\mathrm{CC}\left(\mathrm{mm}^{2} / \mathrm{kPa}\right)$} \\
\hline Carotid artery & n.s. & n.s. & n.s. & n.s. \\
\hline Brachial artery & $-0.015 \pm 0.008+$ & $-0.013 \pm 0.008+$ & n.s. & $-0.0043 \pm 0.0016 *$ \\
\hline Femoral artery & $-0.05 \pm 0.019 * *$ & $-0.051 \pm 0.018 * *$ & $-0.051 \pm 0.018 * *$ & $-0.013 \pm 0.0014 *$ \\
\hline
\end{tabular}

Table 3b Women: relation with Insulin Resistance, before and after adjustment ${ }^{1}$.

\begin{tabular}{|c|c|c|c|c|}
\hline Slope $^{2}$ & $\begin{array}{l}\text { InsR } \\
\text { Unadjusted }\end{array}$ & $\begin{array}{l}\text { InsR } \\
\text { Adjusted, } \\
\text { without BMI }\end{array}$ & $\begin{array}{l}\text { InsR } \\
\text { Adjusted, } \\
\text { with BMI }\end{array}$ & $\begin{array}{l}\text { BMI }\left(\mathrm{kg} / \mathrm{m}^{2}\right) \\
\text { Adjusted }\end{array}$ \\
\hline \multicolumn{5}{|l|}{$\overline{P W V}(\mathrm{~m} / \mathrm{s})$} \\
\hline Aorta $^{3}$ & $0.36 \pm 0.13 * *$ & n.s. & n.s. & n.s. \\
\hline \multicolumn{5}{|l|}{ Diameter (mm) } \\
\hline Carotid artery & n.s. & n.s. & n.s. & $0.20 \pm 0.10 *$ \\
\hline Brachial artery & $0.072 \pm 0.039+$ & n.s. & n.s. & $0.038 \pm 0.009 * * *$ \\
\hline Femoral artery & n.s. & n.s. & n.s. & $0.064 \pm 0.015 * * *$ \\
\hline \multicolumn{5}{|l|}{$\mathrm{DC}\left(10^{-3} / \mathrm{kPa}\right)$} \\
\hline Carotid artery & n.s. & n.s. & n.s. & n.s. \\
\hline Brachial artery & $-2.54 \pm .83 * *$ & n.s. & n.s. & $-0.49 \pm 0.20 *$ \\
\hline Femoral artery & $-0.87 \pm 0.32 * *$ & n.s. & n.s. & $-0.18 \pm 0.07 *$ \\
\hline \multicolumn{5}{|l|}{$\mathrm{CC}\left(\mathrm{mm}^{2} / \mathrm{kPa}\right)$} \\
\hline Carotid artery & n.s. & n.s. & n.s. & n.s. \\
\hline Brachial artery & $-0.016 \pm 0.008 *$ & n.s. & n.s. & n.s. \\
\hline Femoral artery & $-0.45 \pm 0.015 * *$ & n.s. & n.s. & n.s. \\
\hline
\end{tabular}

${ }^{1}$ adjustment was done for age, sex, mean blood pressure, BMI, heart rate, total cholesterol, smoking, use of alcohol and treatment of hypertension. ${ }^{2}$ Regression coefficients \pm SE. ${ }^{3}$ Measurements available in 223 men, 224 women. PWV pulse wave velocity, DC distensibility coefficient, CC crosssectional compliance. ${ }^{*} \mathrm{p}<0.05,{ }^{* *} \mathrm{p}<0.01,{ }^{* * *} \mathrm{p}<0.001$. 
The results of the analysis with adjustment for BMI was similar for women. In men InsR was no longer related to brachial artery diameter, while there was still a positive relation with carotid artery diameter $(\mathrm{p}<.001)$. InsR was, except for a trend for the aorta, no longer significantly related to arterial distensibility. The (negative) relation between InsR and femoral artery compliance remained significant $(\mathrm{p}<.01)$.

BMI was associated with more arterial wall properties than insulin resistance (Table 3a-3b).

Insulin and Glucose

Insulin resistance is accompanied by increased serum levels of insulin and glucose. To investigate whether the relation between InsR and vessel wall properties in men can be explained by the increased serum insulin or glucose levels, two additional analyses were made, investigating the association between large artery wall properties and insulin and glucose respectively, again before and after adjustment for the possible confounding factors (Table 4a-b). In men, after adjustment, glucose tended to be inversely related to brachial artery DC $(\mathrm{p}=.06)$ and was inversely related to brachial artery $\mathrm{CC}(\mathrm{p}<.05)$. The results for insulin were largely in accordance with the results for InsR. In women, insulin was only negatively related to femoral artery diameter $(\mathrm{p}<.05)$, while glucose was not related to any of the measured wall properties.

Table 4a Men: relation between insulin and glucose and large artery properties, before and after adjustment ${ }^{1}$.

\begin{tabular}{lllll}
\hline Slope $^{2}$ & $\begin{array}{l}\text { Insulin } \\
\text { Unadjusted } \\
(\mathrm{U} / \mathrm{l})\end{array}$ & $\begin{array}{l}\text { Insulin } \\
\text { Adjusted } \\
(\mathrm{U} / \mathrm{l})\end{array}$ & $\begin{array}{l}\text { Glucose } \\
\text { Unadjusted } \\
(\mathrm{mmol} / \mathrm{l})\end{array}$ & $\begin{array}{l}\text { Glucose } \\
\text { Adjusted } \\
\text { (mmol/l) }\end{array}$ \\
\hline $\begin{array}{l}\text { PWV aorta } \\
\text { Diameter }(\mathrm{mm})\end{array}$ & $0.068 \pm 0.028^{*}$ & $0.044 \pm 0.023^{*}$ & $1.10 \pm 0.28^{* * *}$ & n.s. \\
$\quad$ CCA & $0.040 \pm 0.04 * * *$ & $0.041 \pm 0.011^{* * *}$ & $0.39 \pm 0.13^{* *}$ & n.s. \\
BA & $0.02 \pm 0.009^{* *}$ & n.s. & n.s. & n.s. \\
FA & n.s. & n.s. & n.s. & n.s. \\
DC $\left(10^{-3} / \mathrm{kPa}\right)$ & & & & \\
CCA & n.s. & n.s. & $-4.72 \pm 1.27^{* * *}$ & n.s. \\
BA & $-0.40 \pm 0.1^{* *}$ & n.s. & $-4.67 \pm 1.57^{* *}$ & $-2.75 \pm 1.50+$ \\
FA & $-0.17 \pm 0.06^{* *}$ & n.s. & $-1.38 \pm 0.66^{*}$ & n.s. \\
CC $\left(\mathrm{mm}{ }^{2} / \mathrm{kPa}\right)$ & & & & n.s. \\
CCA & n.s. & n.s. & $-0.13 \pm 0.056^{*}$ & n.s. \\
BA & n.s. & n.s. & $-0.051 \pm 0.020^{*}$ & $-0.040 \pm 0.020^{*}$ \\
FA & $-0.014 \pm 0.004^{* *}$ & $-0.012 \pm 0.004^{* *}$ & $-0.094 \pm 0.049+$ & n.s. \\
\hline
\end{tabular}

\footnotetext{
${ }^{1}$ adjustment was done for age, sex, mean blood pressure, BMI, heart rate, total cholesterol, smoking, use of alcohol and treatment of hypertension. ${ }^{2}$ Regression coefficients \pm SE. ${ }^{3}$ Measurements available in 223 men, 224 women. PWV pulse wave velocity, CCA common carotid artery, BA brachial artery, FA femoral artery. DC distensibility coefficient, CC cross-sectional compliance . $* \mathrm{p}<0.05$, ** $\mathrm{p}<0.01,{ }^{* * *} \mathrm{p}<0.001$, n.s. not significant.
} 
Table 4b Women: relation between insulin and glucose and large artery properties, before and after adjustment ${ }^{1}$.

\begin{tabular}{|c|c|c|c|c|}
\hline Slope $^{2}$ & $\begin{array}{l}\text { Insulin } \\
\text { Unadjusted } \\
\text { (U/l) }\end{array}$ & $\begin{array}{l}\text { Insulin } \\
\text { Adjusted } \\
\text { (U/l) }\end{array}$ & $\begin{array}{l}\text { Glucose } \\
\text { Unadjusted } \\
\text { (mmol/l) }\end{array}$ & $\begin{array}{l}\begin{array}{l}\text { Glucose } \\
\text { Adjusted } \\
\text { (mmol/l) }\end{array} \\
\end{array}$ \\
\hline PWV aorta ${ }^{2}$ & $0.080 \pm 0.030 * *$ & n.s. & $0.66 \pm 0.30 *$ & n.s. \\
\hline \multicolumn{5}{|l|}{ Diameter (mm) } \\
\hline $\mathrm{CCA}$ & n.s. & n.s. & $-2.74 \pm 1.41+$ & n.s. \\
\hline $\mathrm{BA}$ & n.s. & n.s. & n.s. & n.s. \\
\hline FA & n.s. & $-0.032 \pm 0.016^{*}$ & $0.33 \pm 0.17 *$ & n.s. \\
\hline \multicolumn{5}{|l|}{ DC $\left(10^{-3} / \mathrm{kPa}\right)$} \\
\hline CCA & n.s. & n.s. & n.s. & n.s. \\
\hline BA & $-0.61 \pm 0.20 * *$ & n.s. & n.s. & n.s. \\
\hline FA & $-0.19 \pm 0.08 *$ & n.s. & n.s. & n.s. \\
\hline \multicolumn{5}{|l|}{$\mathrm{CC}\left(\mathrm{mm}^{2} / \mathrm{kPa}\right)$} \\
\hline $\mathrm{CCA}$ & n.s. & n.s. & n.s. & n.s. \\
\hline BA & $-0.004 \pm 0.002 *$ & n.s. & n.s. & n.s. \\
\hline FA & $-0.010 \pm 0.004 * *$ & n.s. & $-1.57 \pm 0.75^{*}$ & n.s. \\
\hline
\end{tabular}

${ }^{1}$ adjustment was done for age, sex, mean blood pressure, BMI, heart rate, total cholesterol, smoking, use of alcohol and treatment of hypertension. ${ }^{2}$ Regression coefficients \pm SE. ${ }^{3}$ Measurements available in 223 men, 224 women. PWV pulse wave velocity, CCA common carotid artery, BA brachial artery, FA femoral artery. DC distensibility coefficient, CC cross-sectional compliance . ${ }^{*} \mathrm{p}<0.05,{ }^{* *} \mathrm{p}<$ $0.01, * * * \mathrm{p}<0.001, \mathrm{n} . \mathrm{s}$. not significant.

\section{Discussion}

In the present study, the effects of insulin resistance, fasting insulin and fasting glucose on large artery wall properties of different arterial territories were studied in a random population with a normal fasting glucose. Since insulin resistance is often found in obese subjects, adjusting for BMI, the relation between the syndrome Insulin Resistance and large artery properties might be underestimated. To investigate this, an additional analysis without adjustment for BMI was done.

The main finding of the present study was the gender-related differences of the results. In women InsR was not related to any of the large artery wall properties. The same was true for glucose and, except for femoral artery diameter, also for insulin.

In men insulin resistance was negatively related to femoral artery compliance, meaning insulin resistant men have a lower femoral artery compliance. As in insulin resistant and diabetic patients early atherosclerosis occurs in the femoral artery and arteries of the lower limbs ${ }^{28}$, this altered femoral artery compliance might be an early feature or an indicator of an increased risk for atherosclerotic disease. A similar result was recently described in a clamp study ${ }^{16}$. However in contrast to the present study, this negative relation between insulin resistance and femoral artery compliance relation was found only in women and not in men ${ }^{16}$. Explanations could be: small number of subjects (17 men, 17 women) and a very different study population (young, non-obese subjects). Cross-sectional compliance is the resultant of diameter and 
distensibility. InsR was also negatively related to distensibility of the femoral artery. Since diameter was not significantly changed, this suggests a really stiffer artery in insulin resistant men.

InsR was also negatively related to distensibility of the muscular brachial artery. This lower distensibility could be a passive phenomenon, due to vasodilation. Brachial artery diameter was namely also positively related to insulin resistance, but neither to insulin nor glucose serum levels. The relation disappeared after correction for BMI. This suggests that the larger BA diameter in insulin resistant subjects is related to the higher BMI. It has been shown that BMI-based obese subjects have a larger BA diameter (chapter 6). As obese subjects have a hyperdynamic relation, the increase in $\mathrm{BA}$ diameter might be due to flow-dependent vasodilation.

In men InsR was also positively related to carotid artery diameter. After adjustment for BMI, insulin resistant men still had a larger carotid artery diameter. This could be related to a higher blood pressure. Indications for this are a positive relation between InsR and heart rate and blood pressure, after adjustment for BMI (data not shown). As the larger diameter of CCA was also present for insulin alone, it could be due to insulin-induced vasodilation ${ }^{29}$. Since carotid artery distensibility was not changed in InsR subjects, the larger diameter might also be caused by remodeling.

In a further step of the analysis the relation between glucose and insulin and vessel wall properties was investigated to see if the found relations were caused by insulin resistance per se.

The results for insulin were in accordance with the results for InsR. This similarity suggests most of the observed relations between InsR and large artery properties might be mainly the effect of insulin. As already mentioned, the literature concerning the relation between insulin and large artery wall properties is not clear. A recent study described an increase in compliance of large arteries after insulin infusion, caused by a vasodilation or increase in distensibility ${ }^{30}$. Some studies showed a negative relation between insulin and distensibility of the aorta ${ }^{12,13}$ and common carotid artery ${ }^{11}$, while others found no relation between aortic distensibility and insulin in healthy people ${ }^{14}$. An explanation for these discrepancies could be the fact that some studies presented results that were not adjusted for age and blood pressure. This is supported by a recent study by van Popele et all, which showed that the found relation between insulin and carotid artery distensibility disappears after adjustment for mean arterial pressure ${ }^{31}$.

The exact effect of insulin on the arterial wall is not fully elucidated. The direct action of insulin on arteries is vasodilation. Indirectly by increasing SNS activity, it causes vasoconstriction ${ }^{29}$. The net effect of a chronic hyperinsulinemic state on arterial diameter depends on the weight of both mechanisms. Insulin is also assumed to be an atherogenic hormone: it increases the formation and decreases the regression of lipid plaques, it enhances proliferation of smooth muscle cells, it stimulates synthesis of connective tissue, it stimulates growth factors and it enhances cholesterol synthesis and increases low density lipoprotein activity ${ }^{32}$.

The fact that in women there was no relation between insulin and InsR and large artery properties may contribute to the findings of Modan et al, that hyperinsulinemia was associated with an increased cardiovascular risk in men, but not in women ${ }^{33}$.

In men, there were no relations between glucose and carotid and femoral artery wall properties. These results are in accordance with a recent study, showing that in healthy men carotid artery wall properties are not influenced by acute systemic hyperglycemia ${ }^{34}$. On the other 
hand some studies suggest an increased stiffening of large arteries in hyperglycemic states, which might be caused by non-enzymatic glycosylation of collagen fibrils in the arterial wall ${ }^{35}$. In the present study serum glucose was limited to $6 \mathrm{mmol} / \mathrm{l}$.

BMI appears to affect more arterial wall properties than insulin resistance, indicating that the effects of obesity on large artery wall properties are only in part due to an increased insulin resistance.

In conclusion, [1] the relation between insulin resistance and large artery wall properties are gender-dependent. Insulin resistance, glucose and insulin are not related to large artery wall properties in non-diabetic women. [2] The relation between insulin resistance and large artery wall properties in men depends on the vascular territory. In men, compliance of the femoral artery was the most affected by insulin resistance. This altered femoral artery compliance might be an early feature or sign of an increased risk for atherosclerotic disease. [3] Alterations of large artery wall properties in subjects with an increased insulin resistance is probably due to the increased insulin levels. [4] As BMI affects more arterial wall properties than insulin resistance, altered arterial wall properties in obese subjects can only in part be attributed to an increased insulin resistance.

\section{Acknowledgements}

The PheeCad study was supported by the municipality Hechtel-Eksel (Belgium), the National Fund for Medical Research Vlaanderen (Brussels, Belgium), the Ministry of the Flemish Community (Brussels, Belgium) and Schwarz Pharma GmbH (Monheim, Germany). The PheeCad study would not have been possible without the support of the General Practitioners. The field work was conducted with the assistance of O. Bomans, L. Gijsbers, A. Hermans, S. Van Hulle and M. Jehoul, Y. Toremans and R.Wolfs. The statistical analysis was conducted by B. Van Baelen. 


\section{References}

1. Safar M: Arteries in clinical hypertension., Lippincott-Raven, 1996.

2. Safar ME, London GM: The arterial system in human hypertension, in Swales JD (ed): Textbook of hypertension, 1st ed. Oxford, Blackwell Scientific Publications, 1994, pp. 85-102.

3. Ferguson JJ, Randall O: Hemodynamic correlates of arterial compliance. Cathet Cardiovasc Diagn 1986;12:376-380.

4. Langewouters GJ, Wesseling $\mathrm{KH}$, Goedhard WJA: The static elastic properties of 45 human thoracic and 20 abdominal aortas in vitro and the parameters of a new model. J Biomech 1984;17:425-435.

5. Fuster V, Badimon L, Badimon JJ, Chesebro JH: The pathogenesis of coronary artery disease and the acute coronary syndromes. N Engl J Med 1992;326:242-250.

6. Stolar MW: Atherosclerosis in diabetes: the role of hyperinsulinemia. Metabolism 1988;37:1-9.

7. Welborn TA, Knuiman MW, Ward N, Whittal DE: Serum insulin is a risk marker for coronary heart disease mortality in men but not in women. Diabetes Res Clin Pract 1994;26:51-59.

8. Folsom AR, Szklo M, Stevens J, Liao F, Smith R, Eckfeldt JH: A prospective study of coronary heart disease in relation to fasting insulin, glucose, and diabetes: the Athersoclerosis Risk in Communities (ARIC) study. Diabetes Care 1997;20:935-942.

9. Laakso M, Sarlund H, Salonen R, Suhonen M, Pyorala K, Salonen JT, Karhapaa P: Asymptomatic atherosclerosis and insulin resistance. Arterioscler Thromb 1991;11:1068-1076.

10. Moller DE, Flier JS: Insulin resistance - mechanisms, syndromes, and implications. $N$ Engl J Med 1991;325(no. 13):938-948.

11. Salooma V, Riley W, Kark JD, Nardo C, Folsom AR: Non-insulin-dependent diabetes mellitus and fasting glucose and insulin concentrations are associated with arterial stiffness indexes; The ARIC study. Circulation 1995;91:1432-1443.

12. Neutel JM, Smith DHG, Graettinger WF, Weber MA: Dependency of arterial compliance on circulating neuroendocrine and metabolic factors in normal subjects. Am J Cardiol 1992;69:1340-1344.

13. Kupari M, Hekali P, Keto P, Poutanen V, Tikkanen MJ, Standertskjold-Nordenstam C: Relation of aortic stiffness to factors modifying the risk of atherosclerosis in healthy people. Arterioscler Thromb 1994;14:386-394.

14. Hopkins KD, Lehmann ED, Gosling RG, Parker JR, Sonksen PH: Biochemical correlates of aortic distensibility in vivo in normal subjects. Clin Sci 1993;84:593-597.

15. Buntin $\mathrm{CH}$, Silver $\mathrm{FH}$ : Noninvasive assessment of mechanical properties of peripheral arteries. Ann Biomed Eng 1990;18:549-566.

16. Giltay EJ, Lambert J, Elbers JMH, Gooren LJG, Asscheman H, Stehouwer CDA: Arterial compliance and distensibility are modulated by body composition in both men and women but by insulin sensitivity only in women. Diabetologia 1999;42:214-221.

17. Staessen JA, Roels H, Fagard R: Lead exposure and conventional and ambulatory blood pressure. A prospective population study. JAMA 1996;275:1563-1570.

18. Hoeks APG, Brands PJ, Smeets FAM, Reneman RS: Assessment of the distensibility of superficial arteries. Ultrasound Med Biol 1990;16:121-128.

19. van der Heijden-Spek JJ, Staessen JA, Fagard RA, Hoeks AP, Struijker Boudier HA, Van Bortel LM: The effect of age on brachial artery wall properties differs from the aorta and is gender-dependent: a population study. Hypertension 2000;35:637-642.

20. Kool MJ, Lambert J, Stehouwer CD, Hoeks AP, Struijker Boudier HA, Van Bortel LM: Vessel wall properties of large arteries in uncomplicated IDDM. Diabetes Care 1995;18:618-624.

21. Moens E: Die Pulscurve. Leiden, EJ Brill, 1878.

22. Hoeks APG: Non-invasive study of local mechanical arterial characteristics in humans, in Safar ME (ed): The arterial system in hypertension. Dordrecht, The Netherlands, Kluwer Academic Publisher, 1993, pp. 119-134.

23. Turner RC, Holman RR, Matthews D, Hockaday TDR, Peto J: Insulin deficiency and insulin resistance interaction in diabetes: estimation of their relative contribution by feedback analysis from basal plasma insulin and glucose concentrations. Metabolism 1979;28(no. 11):1086-1096.

24. Matthews DR, Hosker JP, Rudenski AS, Naylor BA, Treacher DF, Turner RC: Homeostasis model assessment: insulin resistance and B-cell function from fasting plasma glucose and insulin concentrations in man. Diabetologia 1985;28:412-419. 


\section{Large artery properties: effect of insulin resistance}

25. Hansen F, Mangell P, Sonesson B, Länne T: Diameter and compliance in the human carotid arteryvariations with age and sex. Ultrasound Med Biol 1995;21:1-9.

26. Van Bortel LMAB, Kool MJF: Vessel wall properties of large arteries in hypertension and effect of antihypertensive treatment. Can J Cardiol 1994;10(Suppl. D):37D-40D.

27. Laurent S, Caviezel B, Beck L, Girerd X, Billaud E, Boutouyrie P, Hoeks A, Safar M: Carotid artery distensibility and distending pressure in hypertensive humans. Hypertension 1994;23:878-883.

28. Rubba P, Riccardi G, Pauciullo P, Vaccaro O, Carbone L, Mancini M: Different localization of early arterial lesions in insulin-dependent diabetes mellitus and in familial hypercholesterolemia. Metabolism 1989;38:962-966.

29. Anderson EA, Hoffman RP, Balon TW, Sinkey CA, Mark AL: Hyperinsulinemia produces both sympathetic neural activation and vasodilation in normal humans. J Clin Invest 1991;87:2246-2252.

30. Westerbacka J, Wilkinson I, Cockroft J, Utriainen T, Vehkavaraa S, Yki-Järvinen H: Diminished wave reflection in the aorta. A novel physiological action of insulin on large blood vessels. Hypertension 1999;33:1118-1122.

31. Van Popele NM, Westendorp ICD, Bots ML, Reneman RS, Hoeks APG, Hofman A, Grobbee DE, Witteman JCM: Variables of the insulin resistance syndrome are associated with reduced arterial distensibility in healthy non-diabetic middle-aged women. Diabetologia 2000;43:665-672.

32. Stout RW: Insulin as a mitogenic factor: role in the pathogenesis of cardiovascular disease. Am J Med 1991;90:62s-65s.

33. Modan M, Or J, Karasik A, Drory Y, Fuchs Z, Lusky A, Chetrit A, Halkin H: Hyperinsulinemia, sex, and risk of atherosclerotic disease. Circulation 1991;84, no.3:1165-1175.

34. Lambert J, Smulders RA, Aarsen M, Gallay FP, Stehouwer CDA: The acute effect of hyperglycaemia on vessel wall properties. Scand J Clin Lab Invest 1997;57:409-414.

35. Wolffenbuttel BHR, Boulanger CM, Crijns FRL, Huijberts MSP, Poitevin P, Swennen GNM, Vasan S, Egan JJ, Ulrich P, Cerami A, Levy BI: Breakers of advanced glycation end products restore large artery properties in experimental diabetes. Proc Natl Acad Sci USA 1998;95:4630-4634. 


\section{CHAPTER 8}

The effect of insulin-dependent diabetes mellitus on large artery wall properties

J.J. van der Heijden-Spek, F.J. van Ittersum, C.D.A. Stehouwer, A.C. Nieuwenhuijzen Kruseman, P. Biemond, J.W.F. Elte,

H.R.A. Fischer, H.A.J. Struijker Boudier, L.M.A.B. Van Bortel 


\begin{abstract}
Subjects with insulin-dependent diabetes mellitus (IDDM) have an increased cardiovascular risk. Large artery wall properties (compliance $(C C)$ and distensibility $(D C)$ ) may play a role in this process. In the present study diameter, DC and CC of the elastic common carotid artery (CCA) and muscular femoral (FA) and brachial (BA) arteries were measured with a vessel wall movement detector system in IDDM patients with different duration of disease and with $\left(I D D M^{C+}\right)$ and without complications $\left(I D D M^{C-}\right)$. In addition aortic pulse wave velocity, an estimate of aortic stiffness, was measured.

Brachial artery wall properties were not affected by diabetes mellitus. DC of the aorta was lower $(p<.001)$ in IDDM patients than in control subjects. DC of the elastic CCA was lower in IDDM ${ }^{C+}$ compared to IDDM $M^{C-}$ and controls $(P<.01)$. CC of the CCA was lower $(P<.01)$ in the IDDM ${ }^{C+}$ group compared to IDDM $M^{C-}$ patients. In IDDM ${ }^{C-}$ compliance was even higher $(P<.01)$ than in control subjects.

Duration of disease was negatively related to aortic and FA DC $(p<.001)$, not to carotid artery $D C$. HbAlc was not related to any of the vessel wall properties measured.

In conclusion, diabetes affects wall properties of central arteries (aorta, CCA, FA), but not of the medium-sized BA. Large artery wall properties differ between complicated and uncomplicated IDDM patients. Distensibility and/or compliance of the aorta and carotid artery are lower in complicated IDDM. Compliance of the carotid artery of uncomplicated IDDM patients is even increased, suggesting that in an early phase of the disease arterial compliance may increase. Regulation of diabetes, expressed by HbAlc, does not influence arterial wall properties.
\end{abstract}




\section{Introduction}

Diabetes mellitus is a well known cardiovascular risk factor; it doubles the risk of cardiovascular disease in men and almost triples it in women ${ }^{1}$. This increase in risk is mainly caused by atherosclerosis. The mechanism by which the disease contributes to the atherosclerotic process is not fully understood. Compliance, the buffering capacity of an artery ${ }^{2}$, and distensibility, a determinant of strain on the vessel wall ${ }^{3}$, are wall properties of large arteries, which can be involved in atherosclerotic disease. Large artery wall properties can be influenced by different disease states like hypertension and possibly also diabetes mellitus ${ }^{4,5}$. However, reports concerning large artery wall properties in diabetic patients show some discrepancies. Some studies found an increase in arterial stiffness ${ }^{6-14}$, while others found no difference $12,15,16$ or even a decrease in stiffness ${ }^{15,16}$. This could be explained by the fact that most reports concern heterogeneous patient groups with regard to type of diabetes mellitus, duration of disease, medication, existence of complications and glycemic control. In a study by Kool and coworkers, except for the femoral artery, no obvious differences were found in vessel wall properties of elastic and muscular large arteries between uncomplicated insulin dependent diabetic patients (IDDM) and matched control subjects ${ }^{5}$. Distensibility of the femoral artery, an artery in which early atherosclerotic changes occur, was lower in the diabetic subjects ${ }^{5}$. This suggests the presence of early (possibly atherosclerotic) changes in this artery, reflected by a decrease in distensibility. This study was however limited to uncomplicated IDDM and the number of patients was too small to detect a possible relation between arterial stiffness and duration of disease.

The aim of the present study was to investigate large artery wall properties in insulin-dependent diabetic patients with different duration of disease and with and without complications. Since different arteries may behave differently ${ }^{5,17}$, we studied two predominantly elastic arteries (common carotid artery and aorta, both prone for the development of atherosclerosis) and two muscular arteries (the femoral artery, also an artery in which atherosclerosis develops and the brachial artery, an artery in which atherosclerosis is less pronounced).

\section{Methods}

\section{Subjects}

One hundred and four insulin-dependent diabetic (IDDM) patients (68 men, 36 women) were recruited from four outpatient clinics. IDDM was defined as onset of disease before 30 years of age in combination with insulin dependence from diagnosis. Two groups of IDDM patients were selected: 56 subjects with uncomplicated IDDM, with different duration of disease $\left(\right.$ IDDM $\left.^{\mathrm{C}-}\right)$ and 26 subjects with IDDM with complications (IDDM $\left.{ }^{\mathrm{C}+}\right)$. Uncomplicated IDDM was defined as diabetes without retinopathy, (micro)albuminuria, or clinical signs of neuropathy. Complicated IDDM was characterized by microalbuminuria / nephropathy, retinopathy or both. Retinopathy was determined by an ophthalmologist using direct and indirect ophthalmoscopy and fundus photography within six months before or three months after the measurements. Microalbuminuria was determined in three 24 hour urine samples, collected within 3 months before or after the vascular measurements. Subjects were classified as having microalbuminuria if 2 out of 3 samples contained $>3 \mathrm{mg}$ albumin $/ \mathrm{mmol}$ creatinine but $<25 \mathrm{mg}$ albumin/mmol creatinine, while macroalbuminuria was defined as $\geq 25 \mathrm{mg}$ albumin $/ \mathrm{mmol}$ creatinine. The control group included 82 apparently healthy volunteers ( 44 men, 38 women).Subjects were matched for age, gender, body mass index and mean arterial pressure. 
Exclusion criteria for all subjects were: intake of any medication other than insulin or oral contraceptives (17 female diabetic subjects and 6 control subjects), pregnancy, ankle/arm index (Doppler) $<0.95$, hypertension (defined as $>160 / 95 \mathrm{mmHg}$ ) at the time of the study, hyperlipidemia (cholesterol $\geq 8 \mathrm{mmol} / 1$, mean of 2 values, measured within 6 months prior to the study), any cardiovascular event 6 months prior to the study and atherosclerotic plaques in the arteries of interest, as detected by ultrasound during the examination. All patients received appropriate insulin treatment. In addition, all patients regularly controlled their own blood glucose. The study was performed in accordance with the principles of the Declaration of Helsinki (revised 1983) and was approved by the local Ethics Committees of the participating clinics. Informed consent was obtained from all subjects.

\section{Study design}

Subjects did not take a meal or inject insulin within 3 hours before the examination. In addition subjects refrained from smoking, taking caffeine and heavy excercise for at least 3 hours before examination. At the start of the study the actual blood glucose was determined (One Touch 2; Lifescan, Tilburg, The Netherlands). Measurements were performed if blood glucose levels were within acceptable limits $(\geq 4 \mathrm{mmol} / \mathrm{l}$ and $\leq 11 \mathrm{mmol} / \mathrm{l})$. If a subject suffered from symptomatic hypoglycemia or blood glucose was below $3 \mathrm{mmol} / \mathrm{l}$ or above $15 \mathrm{mmol} / \mathrm{l}$, the measurements were postponed. If blood glucose was between 3 and $4 \mathrm{mmol} / \mathrm{l}$, subjects were given $10 \mathrm{ml}$ glucose 50\% intravenously and if blood glucose was between 10 and $15 \mathrm{mmol} / \mathrm{l}$, subjects were given insulin (Actrapid ${ }^{\mathrm{R}}, 1 \mathrm{Unit} / 20 \mathrm{~kg}$ weight) intravenously. Fifteen minutes after injection of glucose or insulin, a second measurement of blood glucose was done. If the subject still had a blood glucose below $4 \mathrm{mmol} / \mathrm{l}$ or above $11 \mathrm{mmol} / \mathrm{l}$, mea-surements were postponed. Before and after the measurements blood was drawn to measure glucose. Blood glucose data reported are the mean of these two samples.

\section{Vascular measurements}

Blood pressure and pulse rate were recorded every 3 minutes at the left arm with a semiautomated device (Dinamap; Critikon, Tampa, Florida). The mean of these recordings $( \pm 15)$ was taken as the subject's reading. Brachial artery pulse pressure was defined as systolic minus diastolic blood pressure. Pulse pressure at the common carotid and femoral arteries were calculated by calibration of the distension curves (chapter 2 ).

After 15 minutes of supine rest in a quiet room vessel wall properties, i.e. diameter (D), distensibility coefficient (DC) and compliance coefficient (CC) of the right elastic common carotid artery (CCA) and right muscular common femoral (CFA) and brachial (BA) arteries were measured with a vessel wall movement detector system ${ }^{18,19}$. All measurements were made by the same observer. With the vessel wall movement detector system it is also possible to measure carotido-femoral transit time $(\mathrm{T}){ }^{19}$. Carotido-femoral length was measured with a tape measurer $\left(\mathrm{L}_{\mathrm{ao}}\right)^{20}$. The average pulse wave velocity $(\mathrm{PWV})$ in this segment was calculated as: $\quad \mathrm{PWV}=\mathrm{L}_{\mathrm{ao}} / \mathrm{T}$

which is an estimate of the stiffness of mainly the aortic pathway ${ }^{21}$. Pulse wave velocity is related to arterial distensibility (DC) by the formula:
$\mathrm{PWV}=\sqrt{ } 1 / \rho \mathrm{DC}$
(Moens Korteweg ${ }^{22,23}$ )
( $\rho=$ blood density) 


\section{Laboratory tests}

HbA1c was measured by high-performance liquid chromatography (Diamat, Biorad Laboratories, Richmond, Ca, USA) and obtained within 6 weeks before the start of the measurements. Urinary albumin excretion was measured by an immunoturbidimetric method. Glucose was measured by a glucoseoxydase method.

\section{Statistical analysis}

For database management and statistical analysis the SAS software package (The SAS institute Inc., Cary, North Carolina) was used. Study groups and patient characteristics were analysed by means of chi-square tests for categorical data. For continuous data the Kruskal-Wallis test for overall comparisons and the Mann-Whitney test for parewise comparisons were used. To investigate the relation between arterial wall properties and duration of diabetes, HbAlc, blood glucose level and complications, a covariance analysis was used. Adjustments were made for possible confounding factors: age, sex, body mass index, mean arterial pressure, heart rate, smoking and total cholesterol. Factors with a p-value $>0.10$ were dropped from the model. From this analysis also the estimated large artery properties after adjustment were calculated. Data are presented as mean \pm SD for demographic values or as mean \pm SE for other data. A p-value $<0.05$ was considered as statistically significant.

\section{Results}

\section{Characteristics of the IDDM patients and control subjects}

IDDM patients with complications were older and had a higher MAP and heart rate compared to IDDM patients without complications and to control subjects (Table 1). Glycaemic control did not differ between the two IDDM groups. HbAlc ranged from 3.7 through $13.2 \%$. Mean blood glucose levels during the measurements were between 3.9 and $10.9 \mathrm{mmol} / \mathrm{l}$ and were also comparable in both IDDM groups. Of the diabetic patients with complications, 12 had retinopathy, 6 microalbuminuria, 4 both retinopathy and microalbuminuria and 4 both retinopathy and macroalbuminuria. Mean 24 hour albumin excretion was $33 \pm 42 \mathrm{mg} / \mathrm{mmol}$ creatinine.

\section{Vessel wall properties of the IDDM patients and control subjects}

Data before adjustment for confounding factors are shown in Table 2. Data after adjustment are shown in Table 3. After adjustment, diameter of the CCA was larger in IDDM than in control subjects. In contrast, diameter of the FA tended to be smaller in IDDM patients. Diameter of the carotid and femoral arteries did not differ significantly between $\mathrm{IDDM}^{\mathrm{C}+}$ and $\mathrm{IDDM}^{\mathrm{C}-}$. Brachial artery diameter did not differ significantly between the 3 groups. PWV of the aorta was higher in IDDM patients than in controls, indicating a lower DC. DC of the elastic CCA was lower in $\mathrm{IDDM}^{\mathrm{C}+}$ compared to $\mathrm{IDDM}^{\mathrm{C}-}$ and controls. DC of the muscular BA and FA did not differ significantly between the groups. CC of the CCA was lower in the $\mathrm{IDDM}^{\mathrm{C}+}$ group compared to $\mathrm{IDDM}^{\mathrm{C}-}$ patients, but in $\mathrm{IDDM}^{\mathrm{C}-}$ compliance was higher than in control subjects. CC of the BA and FA did not differ significantly between the three groups. 


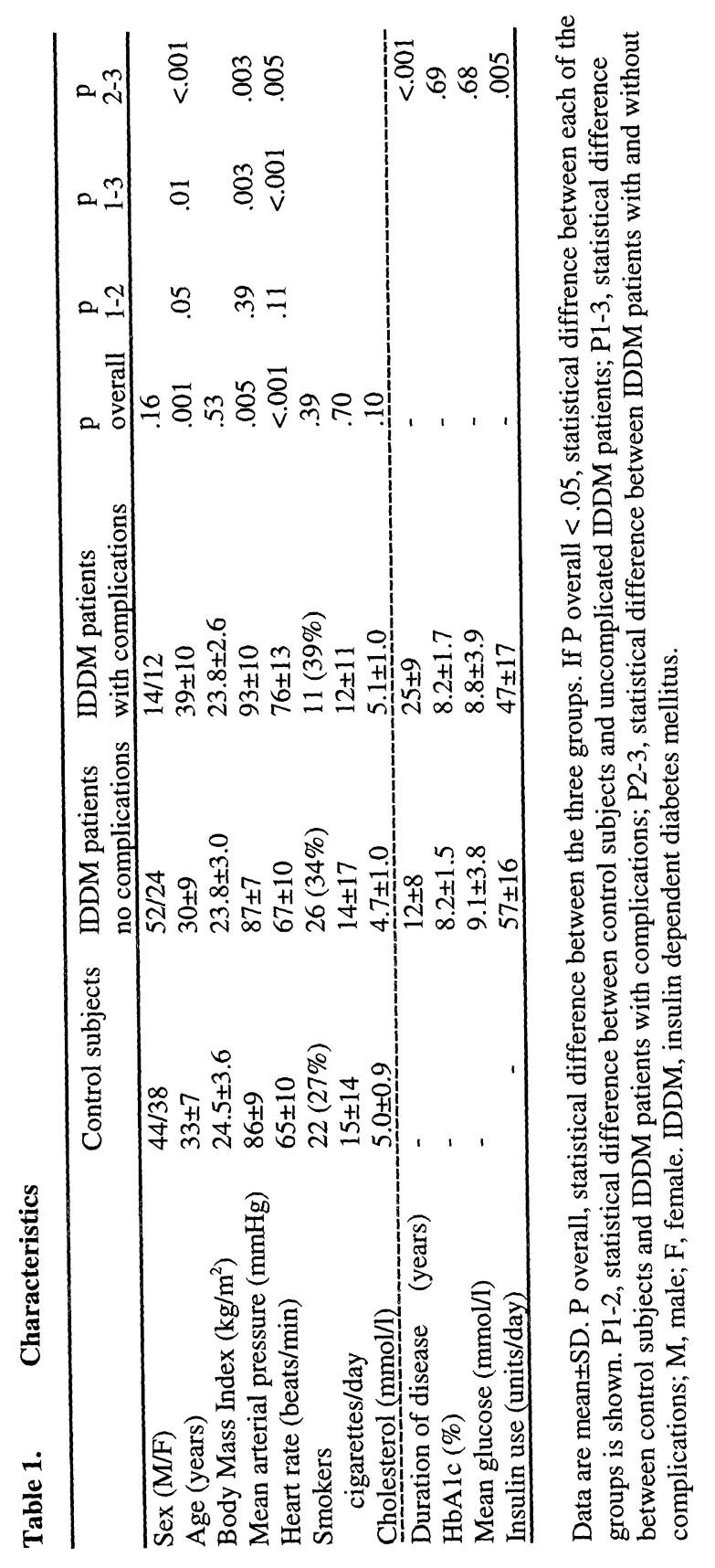




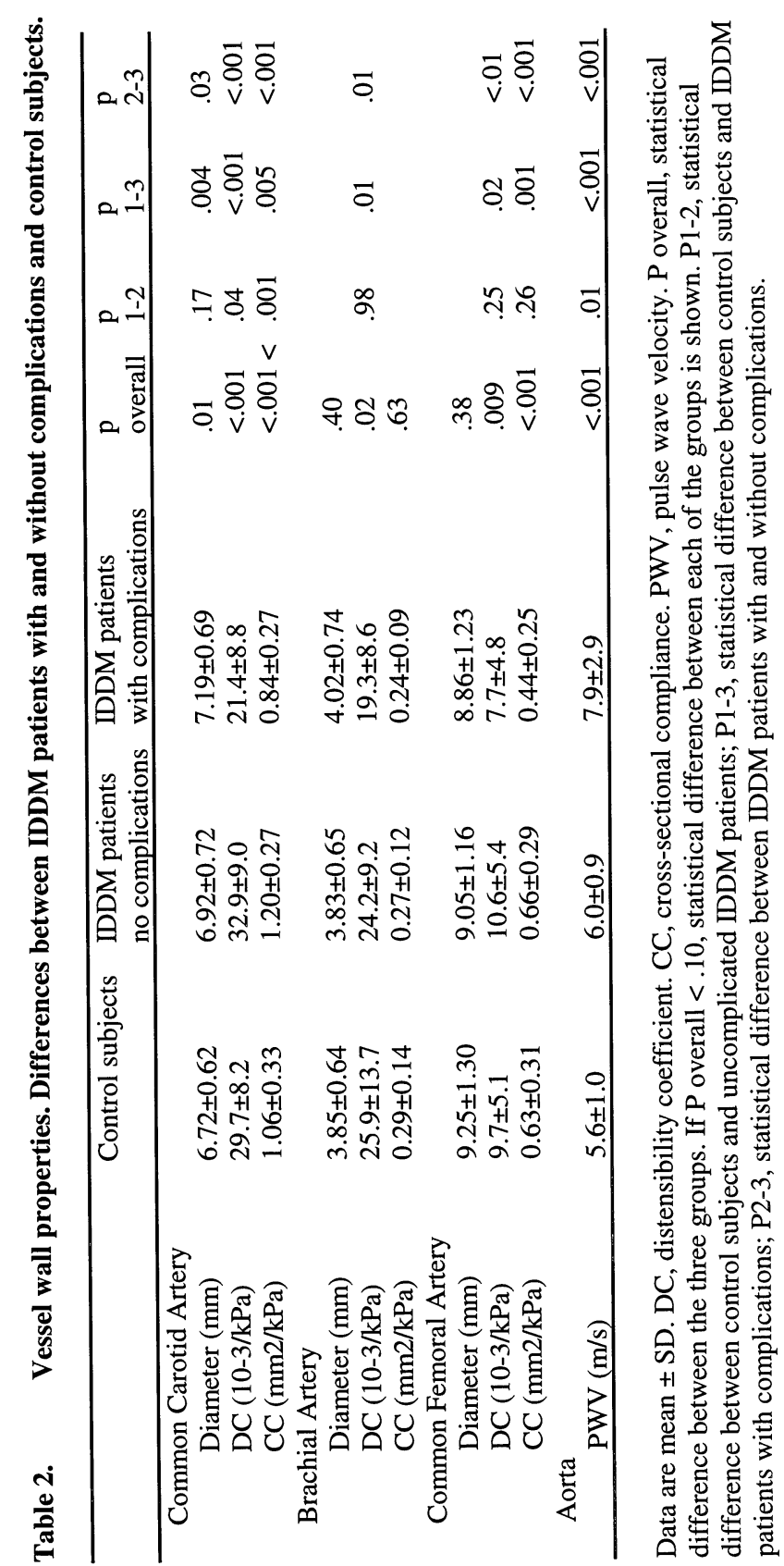




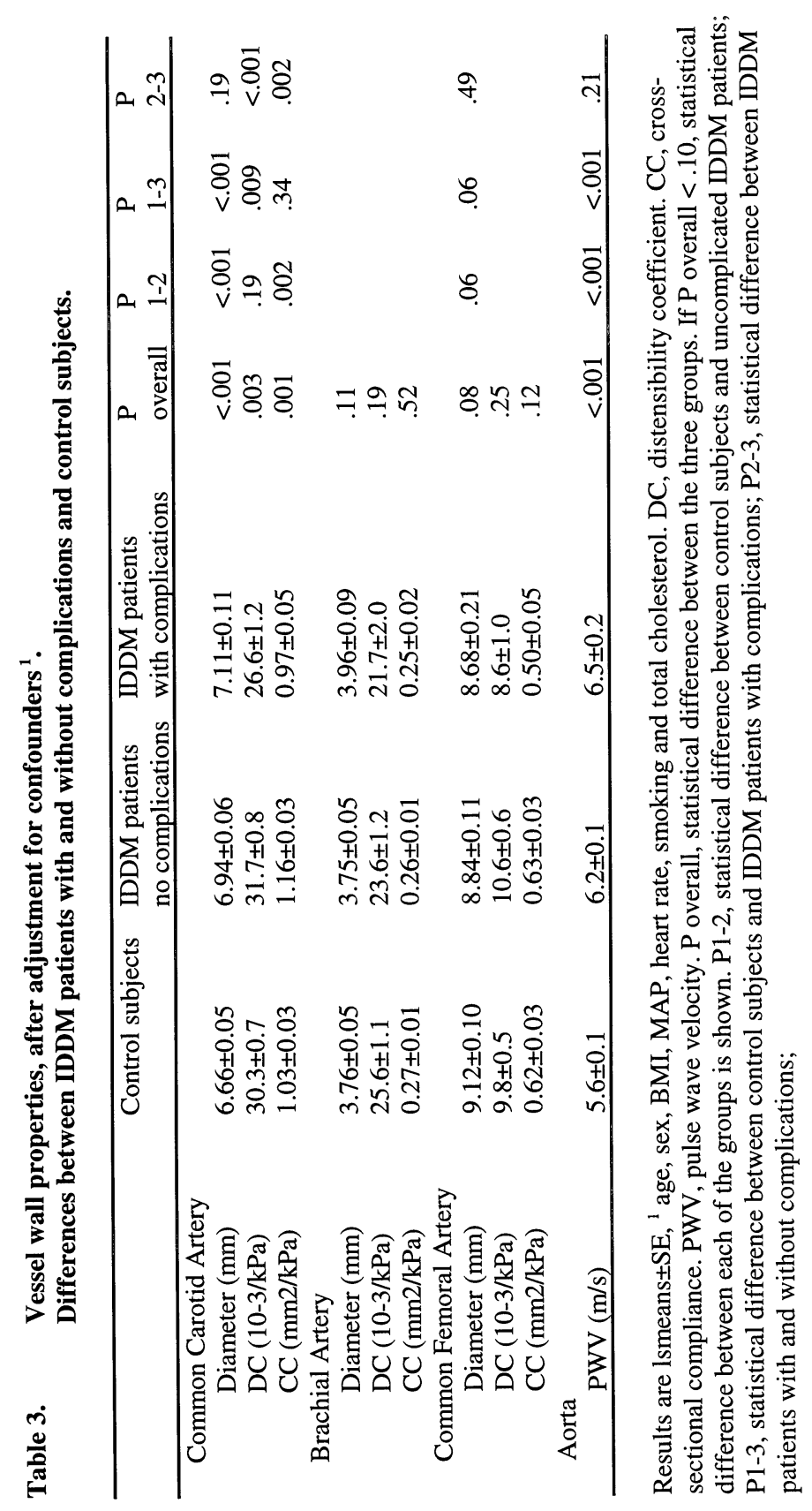


IDDM-patients: Relation between vessel wall properties and 'markers' of disease

To investigate the relation between large artery properties and 'markers of disease', like HbA1c, analysis of covariance was used with the following explanatory variables: age, sex , body mass index, mean blood pressure, total cholesterol, smoking, duration of disease, HbA1c, blood glucose (mean of two values, before and after the measurements), normal use of insulin, complications, extra infused glucose and extra infused insulin. As there were no relations between brachial artery wall properties and any of the markers of disease, data of the brachial artery are not shown in Table 4. HbAlc was not related to any of the vessel wall properties measured. Duration of disease was not related to arterial diameter. There was a negative relation between duration of disease and DC of the FA and aorta $(\mathrm{p}<.001)$. Duration of disease was negatively related to $\mathrm{CC}$ of the FA $(\mathrm{p}=.008)$. Blood glucose was positively related $(\mathrm{p}=.02)$ to femoral artery diameter. It was negatively related to DC of the FA $(\mathrm{p}=.01)$ and DC and CC of the CCA $(\mathrm{P}=.009, \mathrm{p}=.04$ resp.). There was a negative relation between the daily dose of insulin and $\mathrm{DC}(\mathrm{p}=.01)$ and $\mathrm{CC}$ of the FA $(\mathrm{p}=.009)$. There was a negative relation between the presence of complications and DC and $\mathrm{CC}$ of the CCA ( $\mathrm{p}=.002, \mathrm{p}=.04$ resp.). This was probably caused by the subjects with retinopathy, since in a further analysis the same results were found for subjects with retinopathy. Microalbuminuria was not related to arterial stiffness.

Table 4. IDDM patients. Relation between vessel wall properties and 'markers' of disease, after correction for confounders ${ }^{1}$

\begin{tabular}{|c|c|c|c|c|c|}
\hline slope $^{2}$ & Duration & HbA1c & Glucose & Insulin & Complications \\
\hline \multicolumn{6}{|l|}{$\mathrm{PWV}(\mathrm{m} / \mathrm{s})$} \\
\hline Aorta & $.15 \pm .04 * * *$ & n.s. & n.s. & n.s. & n.s. \\
\hline \multicolumn{6}{|l|}{ Diameter (mm) } \\
\hline Carotid artery & n.s. & n.s. & n.s. & n.s. & n.s. \\
\hline Femoral artery & n.s. & n.s. & $.048 \pm .021 *$ & n.s. & n.s. \\
\hline \multicolumn{6}{|l|}{$\mathrm{DC}\left(10^{-3} / \mathrm{kPa}\right)$} \\
\hline Carotid artery & n.s. & n.s. & $-.41 \pm .15 * *$ & n.s. & $-4.84 \pm 1.48 * *$ \\
\hline Femoral artery & $-.23 \pm .06 * * *$ & n.s. & $-.28 \pm .11^{*}$ & $-.077 \pm .031^{*}$ & n.s. \\
\hline \multicolumn{6}{|l|}{$\mathrm{CC}\left(\mathrm{mm}^{2} / \mathrm{kPa}\right)$} \\
\hline Carotid artery & n.s. & n.s. & $-.012 \pm .006 *$ & n.s. & $-.12 \pm .06 *$ \\
\hline Femoral artery & $-.009 \pm .003 * *$ & n.s. & n.s. & $-.004 \pm .002 * *$ & n.s. \\
\hline
\end{tabular}

1 age, sex, BMI, MAP, heart rate, smoking, total cholesterol, extra infused glucose, extra infused insulin. ${ }^{2}$ Regression coefficients \pm SE. CCA, common carotid artery; D diameter, DC, distensibility coefficient. CC, cross-sectional compliance. PWV, pulse wave velocity. n.s. not significant. ${ }^{*} \mathrm{p}<$ $0.05, * * \mathrm{p}<0.01, * * * \mathrm{p}<0.001$.

\section{Discussion}

The present study showed that the effect of diabetes on large artery properties depends on the vascular territory. In contrast to the central aorta, carotid and femoral arteries, vessel wall properties of the medium sized brachial artery were not influenced by diabetes mellitus.

In accordance with an in vitro study ${ }^{14,24}$, stiffness of the aorta was higher in both diabetic 
groups. Stiffness of the carotid artery was only higher in complicated, but not uncomplicated IDDM. This is in agreement by a recent study of Giannattasio et al. ${ }^{14}$.

In accordance to Kool and Lambert ${ }^{5,25}$, the present study showed a larger carotid artery diameter in diabetic compared to control subjects, whereas, also confirming earlier studies ${ }^{5,26}$, femoral artery diameter tended to be lower in diabetics compared to controls. Since during the early stages of atherosclerosis, arterial diameter may become increased ${ }^{27}$, this larger carotid artery diameter could be an expression of atherosclerosis. Further in the atherosclerotic process, probably because of increasing intima-media thickness of the wall, diameter decreases. This could explain the decrease in femoral artery diameter in diabetic subjects. This confirms the hypothesis that in diabetics atherosclerosis occurs earlier in the femoral artery than carotid artery ${ }^{28}$. Another explanation for the decrease in femoral artery diameter could be an increased tone, caused by an increase in noradrenaline content ${ }^{29}$. This was not confirmed by the results of the brachial artery. In addition, a recent study by Vervoort et all showed a decrease in sympathetic drive in noncomplicated type 1 diabetic patients ${ }^{30}$.

Compliance of the carotid artery was lower in complicated compared to uncomplicated IDDM patients. Carotid artery compliance of uncomplicated diabetics was even higher compared to control subjects, suggesting that in an early phase of the disease arterial compliance may increase. Lehmann et al reported a similar finding for the aorta in diabetic subjects in the first year after diagnosis ${ }^{15}$. The difference in carotid artery compliance between uncomplicated and complicated IDDM can explain why some authors did find a difference in arterial compliance between IDDM patients and control subjects ${ }^{13}$ and others did not ${ }^{5,25}$.

The observed difference in vessel wall properties between uncomplicated and complicated diabetic subjects could be caused by a different duration of disease, which was twice as high in the complicated IDDM. In this study, duration of disease was related to aortic stiffness. However, in accordance with other studies ${ }^{5,13}$, there was no relation between carotid artery diameter and distensibility and duration of disease. This suggests that other factors also might play a role.

The exact pathogenesis of macrovascular disease in diabetes is unknown. One of the hypotheses is that hyperglycemia causes formation of advanced glycosylation end-products ${ }^{31,32}$, leading to stiffer arteries. This might imply a relation between arterial wall properties and glycemic control. In accordance with several other studies ${ }^{5,6,13,25,33}$, HbAlc, an estimate of regulation during the last 6 weeks, was not significantly related with any of the measured vessel wall properties. Blood glucose during the investigation was positively related to femoral artery diameter and negatively related to distensibility of the carotid and femoral arteries and compliance of the carotid artery. Since no relation with HbAlc was found, this suggests a more (sub) acute effect of hyperglycemia. This is in contradiction with a recent clamp study, showing that in healthy men carotid artery wall properties were not influenced by acute, artificially induced systemic hyperglycemia ${ }^{34}$.

Another hypothesis explaining the relation between diabetes and macrovascular disease concerns hyperinsulinemia ${ }^{35}$. In the present study, daily dose of insulin was negatively related to femoral artery distensibility and compliance. One explanation could be a vasoconstrictive effect of insulin ${ }^{36}$, although this was not observed at the other muscular artery, the brachial artery. Another explanation could be more structural changes caused by insulin.

Presence of complications was a determinant of carotid and aortic stiffness (negative relation) and carotid artery compliance. In a sub-analysis in the subjects with complications, for all 
these three vessel wall properties (DC aorta, DC and CC of the CCA), retinopathy appeared to be the complication explaining the relation. In other words, subjects with retinopathy have stiffer elastic arteries. In contrast to Zenere ${ }^{33}$ and in agreement with Lambert ${ }^{11}$, no relation between arterial stiffness and microalbuminuria was found. However, for definite conclusions the number of subjects (six) was too small and a study in a larger patient group is necessary. This might be very difficult, since nowadays in an early stage, all patients with microalbuminuria are treated with ACE-inhibitors, which also have effects on large artery wall properties.

In conclusion, the main findings of this study are [1] the effect of diabetes depends on the vascular territory; diabetes affects wall properties of central arteries (aorta, CCA, FA), but not of the medium-sized brachial artery. [2] Large artery wall properties differ between complicated and uncomplicated IDDM patients. Distensibility and/or compliance of the elastic aorta and common carotid artery are lower in complicated IDDM. [3] Compliance of the carotid artery is increased in uncomplicated IDDM patients, suggesting that in an early phase of the disease arterial compliance may increase.

In addition the present study confirms that regulation of diabetes, expressed by $\mathrm{HbA1c}$, does not influence arterial wall properties.

\section{Acknowledgements}

This study would not have been possible without the collaboration of I.J.A. Praet, R. G. IJzerman, Free University Hospital, Amsterdam, dr. J.Th.P. Janssen and A. Noordzij, St. Franciscus Hospital, Roosendaal, dr. R. Nikkels, Atrium Hospital Heerlen and dr. C. Schop, IJsselland Hospital, Capelle a/d IJssel, The Netherlands. 


\section{Large artery properties: effect of IDDM}

\section{References}

1. Kannel WB, McGee DL: Diabetes and cardiovascular disease, the Framingham study. JAMA 1979;241:2035-2038.

2. Levy BI, Safar M: Ventricular afterload and aortic impedance, in Swyngedauw B (ed): Cardiac hypertrophy and failure. London, UK, J Libbey INSERM, 1990, pp. 521-530.

3. Hoeks APG, Brands PJ, Reneman RS: Assessment of the arterial distension waveform using Doppler signal processing. J Hypertens 1992;10(Suppl. 6):s19-s22.

4. Van Bortel LMAB, Kool MJF: Vessel wall properties of large arteries in hypertension and effect of antihypertensive treatment. Can J Cardiol 1994;10(Suppl. D):37D-40D.

5. Kool MJ, Lambert J, Stehouwer CD, Hoeks AP, Struijker Boudier HA, Van Bortel LM: Vessel wall properties of large arteries in uncomplicated IDDM. Diabetes Care 1995;18:618-624.

6. Thordarson H, Thorgeirsson G, Helgason $\mathrm{T}$ : Aortic stiffness in insulin-dependent diabetics: an echocardiografic study. Diabetic Med 1986;3:449-454.

7. Pillsbury HC, Hung W, Kyle MC, Freis ED: Arterial pulse waves and velocity and systolic time intervals in diabetic children. Am Heart $J$ 1974;87:783-790.

8. Lo CS, Relf IRN, Myers KA, Wahlqvist ML: Doppler ultrasound recognition of preclinical changes in arterial wall in diabetic subjects: compliance and pulse-wave damping. Diabetes Care 1986;9:2731.

9. Wahlqvist ML, Sam C, Myers KA, Simpson RW, Simpson JM: Putative determinants of arterial wall compliance in NIDDM. Diabetes Care 1988;11:787-790.

10. Woolam GL, Schnur PL, Vallbona C, Hoff H: The pulse wave velocity as an early indicator of atherosclerosis in diabetic subjects. Circulation 1962;25:533-539.

11. Lambert J, Smulders RA, Aarsen M, Donker AJM, Stehouwer CDA: Carotid artery stiffness is increased in microalbuminuric IDDM patients. Diabetes Care 1998;21:99-103.

12. Lambert J, Pijpers R, van Ittersum FJ, Comans EFI, Aarsen M, Pieper EJ, Donker AJM, Stehouwer CDA: Sodium, Blood Pressure, and Arterial Distensibility in Insulin-Dependent Diabetes Mellitus. Hypertension 1997;30:1162-1168.

13. Berry KL, Skyrme-Jones RAP, Cameron JD, O'Brien RC, Meredith IT: Systemic arterial compliance is reduced in young patients with IDDM. Am J Physiol 1999;276:H1839-H1845.

14. Giannattasio C, Failla M, Piperno A, Grappiolo A, Gamba P, Paleari F, Mancia G: Early impairment of large artery structure and function in type 1 diabetes mellitus. Diabetologia 1999;42:987-994.

15. Lehmann ED, Gosling RG, Sönksen PH: Arterial wall compliance in diabetes. Diabetic Med 1992;9:114-119.

16. Lehmann ED, Hopkins KD, Gosling RG: Aortic compliance measurements using doppler ultrasound: in vivo biochemical correlates. Ultrasound Med Biol 1993;19:683-710.

17. Benetos A, Laurent S, Hoeks AP, Boutouyrie PH, Safar ME: Arterial alterations with ageing and high blood pressure. A noninvasive study of carotid and femoral arteries. Arterioscler Thromb 1993;13:9097.

18. Hoeks APG, Brands PJ, Smeets FAM, Reneman RS: Assessment of the distensibility of superficial arteries. Ultrasound Med Biol 1990;16:121-128.

19. van der Heijden-Spek JJ, Staessen JA, Fagard RA, Hoeks AP, Struijker Boudier HA, Van Bortel LM: The effect of age on brachial artery wall properties differs from the aorta and is gender-dependent: a population study. Hypertension 2000;35:637-642.

20. Demolis PD, Asmar RG, Levy BI, Safar ME: Non-invasive evaluation of the conduit function and the buffering function of large arteries in man. Clin Physiol 1991;11:553-564.

21. O'Rourke MF: Function of arteries as vascular conduits, in O'Rourke MF (ed): Arterial function in health and disease. Edinburgh,London, Melbourne, New York, Churchill Livingstone, 1982, pp. 5364.

22. Moens E: Die Pulscurve. Leiden, EJ Brill, 1878.

23. Hoeks APG: Non-invasive study of local mechanical arterial characteristics in humans, in Safar ME (ed): The arterial system in hypertension. Dordrecht, The Netherlands, Kluwer Academic Publisher, 1993, pp. 119-134.

24. Oxlund H, Rasmussen LM, Andreassen TT, Heickendorff L: Increased aortic stiffness in patients with type 1 (insulin-dependent) diabetes mellitus. Diabetologia 1989;32:748-752. 
25. Lambert J, Aarsen M, Donker AJM, Stehouwer CDA: Endothelium-dependent and -independent vasodilation of large arteries in normoalbuminuric Insulin-Dependent Diabetes Mellitus. Arterioscler Thromb Vasc Biol 1996;16:705-711.

26. Christensen T, Neubauer B: Internal diameter of the common femoral artery in patients with insulindependent diabetes mellitus. Acta Radiol 1988;29:423-425.

27. Wikstrand J, Wiklund O: Frontiers in cardiovascular science. Quantitative measurements of atherosclerotic manifestations in humans. Arterioscler Thromb 1992;12:114-119.

28. Rubba P, Riccardi G, Pauciullo P, Vaccaro O, Carbone L, Mancini M: Different localization of early arterial lesions in insulin-dependent diabetes mellitus and in familial hypercholesterolemia. Metabolism 1989;38:962-966.

29. Neubauer B, Christensen NJ, Aarhus MD: Norepinephrine, epinephrine, and dopamine contents of the cardiovascular system in long-term diabetics. Diabetes 1976;25:6-10.

30. Vervoort G, Wetzels JF, Lutterman JA, van Doorn LG, Berden JH, Smits P: Elevated skeletal muscle blood flow in noncomplicated type 1 diabetes mellitus. Role of nitric oxide and sympathetic tone. Hypertension 1999;34:1080-1085.

31. Vlassara $\mathrm{H}$, Brownlee $\mathrm{M}$, Cerami A: Nonenzymatic glycosylation: role in the pathogenesis of diabetic complications. Clin Chem 1986;32(no. 10(B)):B37-B41.

32. Brownlee M, Cerami A, Vlassara H: Advanced glycosylation end products in tissue and the biochemical basis of diabetic complications. N Engl J Med 1988;318:1315-1321.

33. Zenere BM, Arcaro G, Saggiani F, Rossi L, Muggeo M, Lechi A: Noninvasive detection of funtional alterations of the arterial wall in IDDM patients with and without microalbuminuria. Diabetes Care 1995;18:975-982.

34. Lambert J, Smulders RA, Aarsen M, Gallay FP, Stehouwer CDA: The acute effect of hyperglycaemia on vessel wall properties. Scand J Clin Lab Invest 1997;57:409-414.

35. Bierman EL: Atherogenesis in diabetes. Arterioscler Thromb 1992;12(no. 6):647-656.

36. Anderson EA, Hoffman RP, Balon TW, Sinkey CA, Mark AL: Hyperinsulinemia produces both sympathetic neural activation and vasodilation in normal humans. J Clin Invest 1991;87:2246-2252. 



\section{CHAPTER 9}

\section{General discussion}




\subsection{Introduction}

In the last two decades there has been a lot of interest in large artery wall properties and their relation with cardiovascular disease and risk. Several new techniques to measure these wall properties have been developed. A number of studies focussed on the relation between cardiovascular risk factors and large artery wall properties, for instance studies on hypertension ${ }^{1,2}$ and smoking ${ }^{3-5}$. With the rise in number of studies, also discrepancies are seen (chapter 1 ). Several explanations for these inconsistencies can be given. [1] Different methods have been used, measuring different entities. [2] There is still indistinctness in the terminology used. [3] Small number of subjects, because of which there is sometimes not enough power. [4] Some studies, like those on diabetes mellitus, concern heterogeneous groups. [5] In addition, associations may differ between arterial territories. For instance two studies by Kool et al showed an influence of hypercholesterolemia and diabetes mellitus on the femoral, but not on the carotid and brachial arteries ${ }^{6,7}$. Taking this into account, in the present thesis investigations were done in a population sample of more than 500 subjects. Different vascular territories were studied: elastic and muscular arteries, in which atherosclerosis is or is not common.

\subsection{Associations between large artery wall properties and cardiovascular risk factors}

\subsubsection{Associations in a random population sample}

In addition to the factors mentioned in 9.1, most large artery studies reported, combine men and women or concern only men or only women. However, females have a lower risk of cardiovascular disease compared to males ${ }^{8}$. Large artery wall properties also seem to differ between men and women. In addition also the influence of cardiovascular risk factors might be gender-dependent. In the population studies described in the present thesis, we therefore chose to analyse men and women separately.

\subsubsection{Associations in men}

As can be seen from Table 1, the relation between cardiovascular risk factors and large artery properties differs between the vascular territories.

Aging has a negative effect on the distensibility of the aorta, common carotid and femoral arteries, while this is not the case for the brachial artery (chapter 3 and 4). At young age, the central arteries have the largest distensibility. Since with aging the largest decrease in distensibility is seen in the aorta and common carotid artery, this means that with age, the difference in stiffness between central and more peripheral arteries decreases and the arterial tree will behave as a branching tube of common stiffness. With age arteries also dilate, although more pronounced in elastic than muscular arteries. This dilatation is suggested to be caused by repetitive strain causing fragmentation of elastin ${ }^{9}$. From a completely different point of view it also could be suggested that it is a physiological adaptation (remodeling) to an increased stiffness of the central arteries. Evidence for the latter is the fact that the increase in diameter of the brachial artery from the 3rd to the 8th age decade is $10 \%$ in men and $24 \%$ in women, whereas for the carotid artery the percentages are respectively $15 \%$ and $28 \%$. This increase in diameter for the brachial artery is more than expected on the basis of degeneration. This 
suggests a vasodilatory mechanism to maintain the buffering capacity of the arterial tree.

Table 1 Relation between cardiovascular risk factors and large artery properties in men

\begin{tabular}{|c|c|c|c|c|c|c|c|c|c|c|}
\hline & \multicolumn{3}{|c|}{ Diameter (mm) } & \multicolumn{4}{|c|}{$\mathrm{DC}\left(10^{-3} / \mathrm{kPa}\right)$} & \multicolumn{3}{|c|}{$\mathrm{CC}\left(\mathrm{mm}^{2} / \mathrm{kPa}\right)$} \\
\hline & $\mathrm{CCA}$ & FA & $\mathrm{BA}$ & aorta & $\mathrm{CCA}$ & FA & BA & $\mathrm{CCA}$ & FA & $\mathrm{BA}$ \\
\hline Age & 11 & $\uparrow$ & $\uparrow$ & $\downarrow \downarrow$ & $\downarrow \downarrow$ & $\downarrow$ & $=$ & $\downarrow$ & $=$ & $=$ \\
\hline InsR & 1 & $=$ & $=$ & $(\downarrow)$ & $=$ & $=$ & $=$ & $=$ & $\downarrow$ & $=$ \\
\hline InsR-BMI & 1 & $=$ & $\uparrow$ & ( 1$)$ & $=$ & $\downarrow$ & $\downarrow \downarrow$ & $=$ & $\downarrow$ & ( 1$)$ \\
\hline Insulin & $\uparrow$ & $=$ & $=$ & $\downarrow$ & $=$ & $=$ & $=$ & $=$ & $\downarrow$ & $=$ \\
\hline Glucose & $=$ & $=$ & $=$ & $=$ & $=$ & $=$ & (1) & $=$ & $=$ & $\downarrow$ \\
\hline Height & $\uparrow$ & $\uparrow$ & $=$ & $=$ & $=$ & $=$ & $=$ & $\uparrow$ & $\uparrow$ & $=$ \\
\hline BMI & $\uparrow$ & 1 & $\uparrow$ & $=$ & $\downarrow$ & $\downarrow$ & $1 \downarrow$ & $=$ & $\downarrow$ & $\downarrow$ \\
\hline $\mathrm{W}-\mathrm{H}$ ratio & $\uparrow$ & $=$ & $\uparrow$ & $=$ & $=$ & $\downarrow$ & $\downarrow \downarrow$ & $=$ & $\downarrow$ & $=$ \\
\hline Skinfold & $\uparrow$ & $=$ & $=$ & $=$ & $=$ & $=$ & $=$ & $=$ & $=$ & $=$ \\
\hline
\end{tabular}

DC distensibility coefficient, CC cross sectional compliance, CCA common carotid artery, FA femoral artery, BA brachial artery, InsR insulin resistance, InsR-BMI relation with insulin resistance, not corrected for body mass index, BMI body mass index, W-H ratio waist to hip ratio, 1 positive relation, $\downarrow$ negative relation, $=$ not related,$(\downarrow)$ tended to be negatively related

Obesity is a cardiovascular risk factor and lately it has become clear that especially the distribution of fat (waist-hip ratio) seems to be important. In the present population sample we analysed the relation between different measures of obesity and large artery wall properties (chapter 6). BMI-based obese subjects have a larger arterial diameter and stiffer arteries. This, however, does not hold for the aorta. In men an android body habitus, reflected by an increased waist to hip ratio, was associated with lower femoral artery distensibility and compliance. Why is obesity related to larger and stiffer arteries ? Hypotheses are: [1] hyperdynamic circulation, leading to a flow-dependent vasodilation and as a result stiffer arteries, [2] atherosclerosis, [3] the effect of other coïnciding factors like hyperinsulinemia, [4] transmural pressure of adipocytes. The latter could also explain why there is especially a relation between an android body habitus and lower femoral artery distensibility and compliance. The consequence of this relation and the question whether these changes are reversible have to be further investigated. A recent study showed that loss of weight increased carotid artery distensibility at operating pressures, but not under isobaric conditions. This suggests that the decrease in distensibility with weight loss is probably due to the decrease in blood pressure ${ }^{10}$.

Since one of our hypotheses was that the relation between obesity and large artery properties could be explained by other factors, like insulin resistance, this was investigated in a study described in chapter 7. The study showed that altered wall properties in obese subjects can only partly be attributed to insulin resistance. This means that further research is necessary to fully explain the increase in arterial stiffness in obese subjects is necessary. It was also shown that alterations in large artery wall properties in insulin resistant men are probably due to insulin. The present results suggest insulin itself, and not only glucose, has to be further 
investigated for its role in cardiovascular disease.

\subsubsection{Associations in women}

As can be seen from Table 2, compared to Table 1, the results of the studies confirmed the hypothesis that the influence of risk factors on large artery properties is gender-dependent.

Table 2 Relation between cardiovascular risk factors and large artery properties in women

\begin{tabular}{|c|c|c|c|c|c|c|c|c|c|c|}
\hline & \multicolumn{3}{|c|}{ Diameter (mm) } & \multicolumn{4}{|c|}{$\mathrm{DC}\left(10^{-3} / \mathrm{kPa}\right)$} & \multicolumn{3}{|c|}{$\mathrm{CC}\left(\mathrm{mm}^{2} / \mathrm{kPa}\right)$} \\
\hline & $\mathrm{CCA}$ & FA & $\mathrm{BA}$ & aorta & CCA & $\mathrm{FA}$ & $\mathrm{BA}$ & $\mathrm{CCA}$ & FA & $\mathrm{BA}$ \\
\hline Age & $\uparrow$ & $\uparrow$ & $\uparrow$ & $\downarrow \downarrow$ & $\downarrow \downarrow$ & $\downarrow$ & $=$ & $\downarrow$ & $=$ & $\uparrow$ \\
\hline Menop. & $(\dagger)$ & $=$ & $=$ & $\downarrow$ & $=$ & $=$ & $=$ & $=$ & $=$ & $=$ \\
\hline InsR & $=$ & $=$ & $=$ & $=$ & $=$ & $=$ & $=$ & $=$ & $=$ & $=$ \\
\hline InsR-BMI & $=$ & $=$ & $=$ & $=$ & $=$ & $=$ & $=$ & $=$ & $=$ & $=$ \\
\hline Insulin & $=$ & $\downarrow$ & $=$ & $=$ & $=$ & $=$ & $=$ & $=$ & $=$ & $=$ \\
\hline Glucose & $=$ & $=$ & $=$ & $=$ & $=$ & $=$ & $=$ & $=$ & $=$ & $=$ \\
\hline Height & $\uparrow$ & $\uparrow \uparrow$ & $\uparrow$ & $=$ & $=$ & $=$ & $=$ & $\uparrow$ & $=$ & $=$ \\
\hline BMI & $\uparrow \uparrow$ & $\uparrow$ & $\uparrow$ & $=$ & $=$ & $\downarrow$ & $\downarrow \downarrow$ & $=$ & $=$ & $=$ \\
\hline W-H ratio & $\uparrow$ & $=$ & $=$ & $=$ & $=$ & $=$ & $=$ & $=$ & $=$ & $=$ \\
\hline Skinfold & $=$ & $=$ & $=$ & $=$ & $=$ & $=$ & $\downarrow$ & $=$ & $=$ & $=$ \\
\hline
\end{tabular}

DC distensibility coefficient, CC cross sectional compliance, CCA common carotid artery, FA femoral artery, BA brachial artery, InsR insulin resistance, InsR-BMI relation with insulin resistance, not corrected for body mass index, BMI body mass index, W-H ratio waist to hip ratio, $\uparrow$ positive relation, $\downarrow$ negative relation, $=$ not related

The effect of age differs between men and women. The most catching result is an increase in brachial artery compliance with age in women, but not in men. This increase in compliance is the result of a larger increase in diameter of the brachial artery, which also accounts for the femoral artery, both muscular arteries. This increase in diameter is much larger in women compared to men, while the decrease in distensibility is about equal in men and women. This could also point to an active, remodeling mechanism, and suggests that women more than men can compensate for the loss in compliance in the more central arteries.

One explanation for the gender difference could be the influence of hormones, mainly estrogens, of which it is believed that they provide protection against cardiovascular disease ${ }^{11}$. Estrogens are described to have direct effects on the vessel wall, for instance inducing vasodilation ${ }^{12}$ and changing the elastin-collagen ratio ${ }^{13}$. In the present thesis, to elucidate more about the role of estrogens in women, the effect of menopause was studied (chapter 5). Menopause was negatively related to aortic stiffness, but not related to stiffness of the other arteries. This difference between arteries could be one of the explanations for the discrepancy in the reports on the effects of estrogens on arterial distensibility : some describe a positive effect of estrogens on distensibility of the aorta ${ }^{14}$, while others found no relation between 
estrogen replacement and distensibility of the aorta ${ }^{15}$ (chapter 1). A similar contradiction was found by two studies on the relation between large artery properties and the menstrual cycle. One study described no relation between the menstrual cycle and carotid and femoral artery stiffness ${ }^{16}$, while another study described fluctuations of radial artery distensibility throughout the menstrual cycle ${ }^{17}$. The role of sex hormones on large artery wall properties has to be further investigated. If there is a clear positive relation, it could be an additional argument for supplementation of estrogens to (post)menopausal women.

In women obesity is also related to arterial diameter and distensibility; however, the influence seems to be much larger in men. In women, there was no relation between an android body habitus and large artery wall properties.

Insulin resistance, of which it is suggested to be linked to abdominal obesity, was not significantly related to large artery wall properties in women, whereas it was in men. Insulin and glucose itself were also not related to large artery wall properties. This is in accordance with a study showing no relation between insulin and cardiovascular risk in women ${ }^{18}$. This genderdifference and the meaning of it in relation with non-insulin dependent diabetes mellitus has to be further investigated.

\subsubsection{Associations in insulin-dependent diabetes mellitus}

Since the number of patients with insulin-dependent diabetes mellitus was too small in the random population sample, IDDM patients from different clinics were selected. Several previous studies investigated the effect of diabetes on large artery wall properties, with contradictory results. One of the main explanations of this is probably the fact that heterogeneous patient groups were used (chapter 1). In addition to an earlier study by Kool et al ${ }^{7}$, who investigated young, uncomplicated IDDM patients, we conducted a study in IDDM patients with and without complications (chapter 8). Unfortunately, because of the number of patients, it was not possible to analyse men and women separately.

Table 3 Relation between diabetes mellitus and large artery wall properties

\begin{tabular}{|c|ccc|cccc|ccc|}
\hline & \multicolumn{3}{|c|}{ Diameter (mm) } & \multicolumn{4}{|c|}{ DC $\left(10^{-3} / \mathrm{kPa}\right)$} & \multicolumn{3}{c|}{ CC $\left(\mathrm{mm}^{2} / \mathrm{kPa}\right)$} \\
& CCA & FA & BA & aorta & CCA & FA & BA & CCA & FA & BA \\
\hline $\begin{array}{c}\text { IDDM } \\
\text { no compl. }\end{array}$ & 1 & $(\downarrow)=$ & $\downarrow$ & $=$ & $=$ & $=$ & 1 & $=$ \\
\hline $\begin{array}{c}\text { IDDM } \\
\text { compl. }\end{array}$ & $1 \uparrow$ & $(\downarrow)=$ & $\downarrow \downarrow$ & $\downarrow$ & $=$ & $=$ & $=$ & $=$ \\
\hline
\end{tabular}

DC distensibility coefficient, CC cross sectional compliance, CCA common carotid artery, FA femoral artery, BA brachial artery, IDDM insulin-dependent diabetes mellitus, compl. complications, $\uparrow$ positive relation, $\downarrow$ negative relation, $=$ not related, $(\uparrow)$ tended to be positive related

Insulin-dependent diabetes mellitus affects central arteries (aorta, CCA, FA), but not the brachial artery. This is in accordance with other studies, showing that alterations in vessel 
wall properties can be heterogeneous along the arterial tree. In uncomplicated IDDM patients carotid artery compliance was even increased, suggesting an increase in arterial compliance in the early phase of the disease. Something similar has also been described by other authors in IDDM patients ${ }^{19}$ and in subjects with familial hypercholesterolemia ${ }^{20}$. These results suggest that early in the disease large artery properties already change. An hypothesis for this increase could be the development of atherosclerosis. In experimental atherosclerosis in rhesus monkeys, Farrar et al showed that during the induction of atheroma, the aorta firstly became more distensible, and then as focal lesions were formed, began to stiffen ${ }^{21}$.

Vessel wall properties also differ between complicated and uncomplicated IDDM. Part of this, but not all can be explained by different duration of disease. Similar results were described in a recent study by Giannattasio et al ${ }^{22}$. There are many hypotheses about the underlying mechanisms. Regulation of diabetes, estimated by HbA1c did not appear to be of importance. This is in contrast to what was expected, since many studies put emphasis on the importance of a good (meaning: low) HbA1c. A recent experimental study showed an increase in arterial distensibility with breakers of advanced glycation products ${ }^{23}$. Unfortunately these products are still not available for humans. Further research is necessary to reveal the underlying mechanisms and to investigate whether the process can be delayed.

\subsubsection{Most important conclusions from the present studies}

In the present population sample, in accordance with all other studies, men have a larger diameter and larger arterial compliance (chapter 3 and 4). Distensibility of the aorta, carotid and femoral arteries did not differ between the genders, while brachial artery distensibility was larger in women compared to men. The results of the studies in this thesis show that vessel wall properties not only differ between men and women, but also the influence of physiological and pathological influences seems to differ. This is in accordance to two earlier studies, which described a clear difference between men and women; one study concerning the relation between IDDM and arterial stiffness ${ }^{24}$, the other between insulin sensitivity and arterial stiffness ${ }^{25}$. This implies that in future, where possible, men and women should be analysed separately.

Another important finding from our studies is that the influence of physiological and pathological influences is dependent on the vascular territory. The effect of age, gender, obesity, insulin resistance and diabetes mellitus differs between arteries (this thesis). For age, hypertension and diabetes mellitus, this was also suggested in earlier papers ${ }^{7,22,26,27}$. Explanations for these differences can be: [1] different composition of the wall (elastic vs. muscular), [2] amplification of pulse pressure, due to pulse wave reflections, [3] standing position, because of which the pressure in the lower limbs is higher. In conclusion, when studying the influence between cardiovascular risk factors and vessel wall properties, it is important to be aware of the fact that large arteries may behave differently. This means that multiple sites have to be measured for characterisation of large artery wall properties .

\subsection{Large artery wall properties as a marker for cardiovascular risk}

[1] From the studies in this thesis and others (chapter 1), it can be concluded that most cardiovascular risk factors are related to arterial stiffness. These relations can be determined by structural or functional factors. An example of a structural relation is the effect of age ${ }^{28}$. 
The acute effect of smoking on large artery properties is an example of a functional relationship ${ }^{29}$. These relations are dependent on gender and vascular territory.

[2] Most associations found between large artery wall properties and cardiovascular risk factors are found for the aorta, common carotid and femoral arteries. These are also the arteries most prone for atherosclerosis.

[3] Several cardiovascular risk factors, for instance insulin resistance, seem to affect large artery wall properties in men, but not in women. This is in accordance with the finding that females have a lower cardiovascular risk compared to males ${ }^{8}$.

The above three points are arguments for an association between large artery wall properties and cardiovascular risk. Recently two studies agreed with this hypothesis. They showed that aortic stiffness was a major predictor of cardiovascular morbidity and mortality in patients with end-stage renal failure, requiring hemodialysis ${ }^{30}$ and hypertensive patients ${ }^{31}$. This means that measurements of large artery wall properties probably can serve to identify patients at risk for cardiovascular disease. However which arteries have to be measured and whether increased arterial stiffness is a risk factor contributing to the development of cardiovascular disease or is a marker of arterial disease is still not clear. However, in both condi-tions it can be used as a marker for cardiovascular risk.

\subsection{Future research}

\subsubsection{Assessment of local pulse pressure}

Lately there is more and more interest in pulse pressure as an independent cardiovascular risk factor ${ }^{32}$. This widening of pulse pressure is caused by arterial stiffness. Especially after the age of 50-60 years, pulse pressure, and thereby cardiovascular risk, increases.

In large arteries mean arterial pressure is constant, whereas pulse pressure varies ${ }^{33}$. As a consequence, the use of pulse pressure in one artery as a surrogate for pulse pressure in the target artery might be erroneous. Ideally, vessel wall movement should be related to pulse pressure measurements obtained simultaneously and at the same site. Unfortunately this is not always possible. If a good relation between pulse pressures in target and surrogate arteries exists, the error may be proportional. Consequently if pulse pressures in target and surrogate arteries behave similarly, results of comparative studies may demonstrate quite accurately changes in vessel wall properties, despite the fact that absolute values of vessel wall properties may be incorrect ${ }^{34}$.

Several studies described a good relation between carotid and brachial artery pulse pressures ${ }^{35,36}$. It is, however, known that pulse wave reflections may boost pulse pressure in the carotid artery, but not in the brachial artery ${ }^{37}$. This may disturb the relation between brachial and carotid artery pulse pressures.

In the last decade, a new non-invasive technique to measure local pulse pressure has been proposed: applanation tonometry ${ }^{38,39}$. Benetos and coworkers found a good correlation between brachial artery and femoral artery pulse pressure recorded with this technique ${ }^{40}$. However, several authors have found the magnitude of the pulse pressure obtained by applanation tonometry to be unreliable ${ }^{41,42}$. A new promising method might be assessment of local pulse pressure by calibration of the tonometer pressure wave. This is based on the observation that mean blood pressure is constant through the large artery tree and that diastolic pressure does not change substantially ${ }^{42,43}$. Applanation tonometry cannot be applied to all subjects 
and all arterial sites ${ }^{43}$. It requires a solid background (bone) to flatten the arterial wall and lean skin, to avoid cushioning of the pressure pulse. For instance, in obese subjects applanation tonometry is often inaccurate at a majority of arterial sites. In addition, performing measurements simultaneously with vessel wall movement detection, measurements have to be done at the contralateral site. In older subjects with atherosclerotic plaques this can introduce errors. In addition, for the carotid artery this is not possible. Thus measurements are done consecutively, which might also introduce errors.

Alternatively, pulse pressure based on calibration of arterial distension waves can be used and show good accuracy (chapter 2). This latter method was used in the studies described in this thesis. Comparing the data and analyses before and after calibration of the pulse pressure showed comparable trends. As could be expected for the relations between age and distensibility of the carotid artery, the slope was steeper after calibration (unpublished data).

This calibration however, does not mean the final solution. Future research must focus on techniques to measure pulse pressure locally and simultaneously with vessel wall movement detection.

\subsubsection{Associations with other cardiovascular risk factors}

Besides the risk factors studied in this thesis, there are also other risk factors that have to be (further) investigated: physical activity, mental stress, heart rate variability. There are also risk factors which have already been investigated, however with contradictory results, or only in one vascular territory. These factors, for instance smoking and hyperlipidemia, also have to be examined more thoroughly. In addition attention should focus on newly recognized risk factors that are currently under investigation, such as hyperhomocysteinemia. Until now, three studies investigated the relation with large artery properties with different results ${ }^{44-46}$. Again this could be explained by different arteries studied and different populations. This means further investigation is necessary.

Besides studying risk factors separately, also the effect of interactions between risk factors, for instance obesity, insulin resistance and hypertension, on large artery properties needs to be studied.

Future studies should also focus on genetic factors. There is already evidence for a relation between AT1 receptor polymorphism and aortic stiffness ${ }^{47}$. A recent study by Hanon et al found a relation between apolipoprotein E polymorphism and carotid artery wall hypertrophy, but no relation with carotid and radial artery wall properties ${ }^{48}$. This field of genetics should be further explored. This should be done for example in family studies. May be in future it is possible to link genotype with phenotype.

\subsubsection{Use of vessel wall properties as a marker for cardiovascular risk}

Besides the cross-sectional study, also longitudinal studies are necessary, to try to elucidate if measurement of vessel wall properties can be used as a marker of cardiovascular risk. First the risk has to be established. Early detection of increased arterial stiffness can possibly be used to identify subjects at risk for the development of cardiovascular disease.

Secondly, to identify subjects at risk, normal values for large artery wall properties should be agreed upon. To achieve this, more population studies should be conducted, or data from several groups, using the same technique, pooled to achieve large numbers of subjects. 
Knowing the normal values, subjects with stiffer arteries than their age-matched counterparts can be identified.

\subsubsection{New approaches for the treatment of high pulse pressure}

As stated in the introduction, vessel wall properties can probably be influenced by drugs. In future, research should focus on the development of new drugs which act more specifically upon large artery properties. For instance drugs, which decrease arterial stiffness without a substantial effect on resistance vessels. An example of such a drug is sinitrodil ${ }^{49}$. This is a new NO donor, with a higher selectivity for large arteries than for resistance vessels. This means a decrease in pulse pressure, without a substantial decrease in mean and diastolic blood pressure. This is very promising, especially for subjects with coronary artery disease, in which we want a decrease of the pulse pressure, however with maintenance of the diastolic pressure for coronary perfusion. 


\section{References}

1. Safar ME, London GM: The arterial system in human hypertension, in Swales JD (ed): Textbook of hypertension, 1st ed. Oxford, Blackwell Scientific Publications, 1994, pp. 85-102.

2. Nichols WW, O'Rourke MF: Aging. Hypertension. Atherosclerosis, in Nichols WW, O'Rourke MF (eds): Mc Donald's Blood Flow in Arteries. Theoretic, experimental and clinical principles, 4th ed. London, E. Arnold, 1999, pp. 347-402.

3. Kool MJF, Hoeks APG, Struijker Boudier HAJ, Reneman RS, Van Bortel LMAB: Short- and longterm effects of smoking on arterial wall properties in habitual smokers. $J$ Am Coll Cardiol 1993;2:1881-1886.

4. Giannattasio C, Mangoni AA, Stella ML, Carugo S, Grassi G, Mancia G: Acute effects of smoking on radial artery compliance in humans. J Hypertens 1994;12:691-696.

5. Stefanadis C, Vlachopoulos C, Tsiamis E, Diamantopoulos L, Toutouzas K, Giatrakos N, Vaina S, Tsekoura D, Toutouzas P: Unfavorable effects of passive smoking on aortic function in men. Ann Intern Med 1998;128:426-434.

6. Kool M, Lustermans F, Kragten H, Struijker Boudier H, Hoeks A, Reneman R, Rila H, Hoogendam I, Van Bortel L: Does lowering of cholesterol levels influence functional properties of large arteries. Eur J Clin Pharmacol 1995;48:217-223.

7. Kool MJ, Lambert J, Stehouwer CD, Hoeks AP, Struijker Boudier HA, Van Bortel LM: Vessel wall properties of large arteries in uncomplicated IDDM. Diabetes Care 1995;18:618-624.

8. Castelli WP: Epidemiology of coronary heart disease. The Framingham study. Am J Med 1984;76:412 .

9. O'Rourke M: Mechanical principles in arterial disease. Hypertension 1995;26:2-9.

10. Balkestein EJ, van Aggel-Leijssen DP, van Baak MA, Struijker-Boudier HA, Van Bortel LM: The effect of weight loss with or without exercise training on large artery compliance in healthy obese men. J Hypertens 1999;17:1831-1835.

11. Kannel WB, Hjortland M, McNamara PM, Gordon T: Menopause and the risk of cardiovascular disease: the Framingham study. Ann Intern Med 1976;85:447-452.

12. Lieberman E, Gerhard M, Uehata A, Walsh B, Selwyn A, Ganz P: Estrogen improves endotheliumdependent flow-mediated vasodilation in postmenopausal women. Ann Intern Med 1994;121:936941.

13. Riedel M, Rafflenbeul W, Lichtlen P: Ovarian sex steroids and atherosclerosis. Clin Invest 1993;71:406-412.

14. Rajkumar C, Kingwell BA, Cameron JD, Waddell T, Mehra R, Christophidis N, Komesaroff PA, McGrath B, Jennings GL, Sudhir K, Dart AM: Hormonal therapy increases arterial compliance in postmenopausal women. J Am Coll Cardiol 1997;30:350-356.

15. Hayward CS, Knight DC, Wren BG, Kelly RP: Effect of hormone replacement therapy on noninvasive cardiovascular haemodynamics. J Hypertens 1997;15:987-993.

16. Willekes C, Hoogland HJ, Keizer HA, Hoeks AP, Reneman RS: Female sex hormones do not influence arterial wall properties during the normal menstrual cycle. Clin Sci 1997;92:487-491.

17. Giannattassio C, Failla M, Grappiolo A, Stella ML, Del Bo A, Colombo M, Mancia G: Fluctuations of radial artery distensibility throughout the menstrual cycle. Arterioscler Thromb Vasc Biol 1999;19:1925-1929.

18. Welborn TA, Knuiman MW, Ward N, Whittal DE: Serum insulin is a risk marker for coronary heart disease mortality in men but not in women. Diabetes Res Clin Pract 1994;26:51-59.

19. Lehmann ED, Gosling RG, Sönksen PH: Arterial wall compliance in diabetes. Diabetic Med 1992;9:114-119.

20. Lehmann ED, Hopkins KD, Gosling RG: In vivo determinants of arterial stiffness. Atherosclerosis 1996;125:139-144.

21. Farrar DJ, Bond MG, Riley WA, Sawyer JK: Anatomic correlates of aortic pulse wave velocity and carotid artery elasticity during atherosclerosis progression and regression in monkeys. Circulation 1991;83:1754-1763.

22. Giannattasio C, Failla M, Piperno A, Grappiolo A, Gamba P, Paleari F, Mancia G: Early impairment of large artery structure and function in type 1 diabetes mellitus. Diabetologia 1999;42:987-994.

23. Wolffenbuttel BHR, Boulanger CM, Crijns FRL, Huijberts MSP, Poitevin P, Swennen GNM, Vasan 
S, Egan JJ, Ulrich P, Cerami A, Levy BI: Breakers of advanced glycation end products restore large artery properties in experimental diabetes. Proc Natl Acad Sci USA 1998;95:4630-4634.

24. Rydén Ahlgren Å, Länne T, Wollmer P, Sonesson B, Hansen F, Sundkvist G: Increased arterial stiffness in women, but not in men, with IDDM. Diabetologia 1995;38:1082-1089.

25. Giltay EJ, Lambert J, Elbers JMH, Gooren LJG, Asscheman H, Stehouwer CDA: Arterial compliance and distensibility are modulated by body composition in both men and women but by insulin sensitivity only in women. Diabetologia 1999;42:214-221.

26. Boutouyrie P, Laurent S, Benetos A, Girerd XJ, Hoeks APG, Safar ME: Opposing effects of ageing on distal and proximal large arteries in hypertensives. J Hypertens 1992;10(Suppl. 6):s87-s91.

27. Bortolotto LA, Franconi G, Boutouyrie P, Legrain S, Girerd X: The aging process modifies the distensibility of elastic but not muscular arteries. Hypertension 1999;34:889-892.

28. van der Heijden-Spek JJ, Staessen JA, Fagard RA, Hoeks AP, Struijker Boudier HA, Van Bortel LM: The effect of age on brachial artery wall properties differs from the aorta and is gender-dependent: a population study. Hypertension 2000;35:637-642.

29. Kool MJ, Hoeks AP, Struijker Boudier HAJ, Reneman RS, Van Bortel LMAB: Short- and long-term effects of smoking on arterial wall properties in habitual smokers. J Am Coll Cardiol 1993;22:18811886.

30. Blacher J, Guerin AP, Pannier B, Marchais SJ, Safar ME, London GM: Impact of aortic stiffness on survival in end-stage renal disease. Circulation 1999;99:2434-2439.

31. Blacher J, Asmar R, Djane S, London GM, Safar ME: Aortic pulse wave velocity as a marker of cardiovascular risk in hypertensive patients. Hypertension 1999;33:1111-1117.

32. Millar JA, Lever AF, Burke V: Pulse pressure as a risk factor for cardiovascular events in the MRC mild hypertension trial. J Hypertens 1999;17:1065-1077.

33. Safar ME: Pulse Pressure in essential hypertension: clinical and therapeutical implications. J Hypertens 1989;7:769-776.

34. Van Bortel LM, Kool MJ, Struijker Boudier HA: Effects of antihypertensive agents on local arterial distensibility and compliance. Hypertension 1995;26:531-534.

35. Borow KM, Newburger JW: Noninvasive estimation of central aortic pressure using the oscillometric method for analyzing systemic artery pulsatile blood flow: comparative study of indirect systolic, diastolic, and mean brachial artery pressure with simultaneous direct ascending aortic pressure measurements. Am Heart J 1982;103:879-886.

36. Reneman RS, van Merode T, Brands PJ, Hoeks APG: Inhomogeneities in arterial wall properties under normal and pathological conditions. J Hypertens 1992;10(Suppl. 6):s35-s39.

37. O'Rourke MF: Arterial stiffness, systolic blood pressure, and logical treatment of arterial hypertension. Hypertension 1990;15:339-347.

38. Benetos A, Tsoucaris-Kupfer D, Favereau X, Corcos T, Safar M: Carotid artery tonometry: an accurate non-invasive method for central aortic pulse pressure evaluation. J Hypertens 1991;9(Suppl. 6):s144-s145.

39. Kelly R, Hayward C, Ganis J, Daley J, Avolio A, O'Rourke M: Noninvasive registration of the arterial pressure pulse waveform using high-fidelity applanation tonometry. J Vasc Med Biol 1989;1:142-149.

40. Benetos A, Laurent S, Hoeks AP, Boutouyrie PH, Safar ME: Arterial alterations with ageing and high blood pressure. A noninvasive study of carotid and femoral arteries. Arterioscler Thromb 1993;13:90-97.

41. Chen CH, Ting CT, Nussbacher A, Nevo E, Kass DA, Pak P, Wang SP, Chang MS, Yin FCP: Validation of carotid artery tonometry as a means of estimating augmentation index of ascending aortic pressure. Hypertension 1996;27:168-175.

42. Van Bortel LM, Balkestein EJ, van der Heijden-Spek JJ, Vanmolkot FH, Staessen JA, Kragten JA, Vredeveld JW, Safar ME, Struijker Boudier HA, Hoeks AP: Non-invasive assessment of local arterial pulse pressure. submitted 2000.

43. Nichols WW, O'Rourke MF:, in Nichols WW, O'Rourke MF (eds): McDonald's blood flow in arteries. Theoretical, experimental and clinical principles, 4th ed. London, E.Arnold, 1999, pp. 453476.

44. Blacher J, Demuth K, Guerin AP, Safar ME, Moatti N, London GM: Influence of biochemical 


\section{General Discussion}

alterations on arterial stiffness in patients with end-stage renal disease. Arterioscler Thromb Vasc Biol 1998; 18:535-541.

45. Bortolotto LA, Safar ME, Billaud E, Lacroix C, Asmar R, London GM, Blacher J: Plasma homocysteine, aortic stiffness, and renal function in hypertensive patients. Hypertension 1999;34:837-842.

46. Smilde TJ, van den Berkmortel FWPJ, Boers GHJ, Wollersheim $\mathrm{H}$, de Boo $\mathrm{T}$, van Langen $\mathrm{H}$, Stalenhoef AFH: Carotid and femoral artery wall thickness and stiffness in patients at risk for cardiovascular disease, with special emphasis on hyperhomocysteinemia. Arterio-scler Thromb Vasc Biol 1998;18:1958-1963.

47. Benetos A, Topouchian J, Ricard S, Gautier S, Bonnardeaux A, Asmar R, Poirier O, Soubrier F, Safar M, Cambie F: Influence of Angiotensin II type 1 receptor polymorphism on aortic stiffness in never-treated hypertensive patients. Hypertension 1995;26:44-47.

48. Hanon O, Girerd X, Luong V, Jeunemaitre X, Laurent S, Safar ME: Association between the apolipoprotein $\mathrm{E}$ polymorphism and arterial wall thickness in asymptomatic adults. J Hypertens 2000;18:431-436.

49. Van Bortel LM, Spek JJ, Balkestein EJ, Sardina M, Struijker Boudier HA: Is it possible to develop drugs that act more selectively on large arteries? J Hypertens 1999;17:701-705. 


\section{CHAPTER 10}

Summary 
Compliance and distensibility are vessel wall properties of large arteries which may play a role in cardiovascular disease. Arterial compliance reflects the buffering capacity of an artery; a decrease in compliance increases cardiac afterload and the risk of cardiac hypertrophy. Arterial distensibility reflects mainly the elasticity of the wall. A local decrease in distensibility might be associated with an increased risk of arterial wall damage, an important feature in atherosclerotic disease.

In chapter 1 the definitions and determinants of these vessel wall properties are described. This chapter also reviews the relations between cardiovascular risk factors and large artery wall properties. From this review it can be concluded that for most cardiovascular risk factors results from studies on the relation between arterial wall properties and these risk factors are inconsistent. Explanations could be: different methods applied, small number of subjects, heterogeneous groups and possible differences between vascular territories.

To clarify the relation between vessel wall properties and different cardiovascular risk factors, in the present thesis the relation between cardiovascular risk factors and arterial diameter, distensibility and compliance coefficient of different vascular territories (the elastic aorta and common carotid artery and the muscular brachial and femoral arteries) was studied in a population sample of 497 men and women, age between $20-79$ years.

Chapter 2 describes the population sample and methods used in the different studies.

In chapter 3 and 4 , the influence of age and gender on the vessel wall properties of different vascular territories was investigated. After adjustment for possible confounding factors, i.e. mean blood pressure, pulse rate, body mass index, smoking, alcohol intake and antihypertensive treatment, covariance analysis showed that men had a larger diameter and compliance of all arteries. Distensibility was similar in both sexes with the exception of the brachial artery, which in men showed lower distensibility. The effect of age on large artery wall properties is not uniform, but depends on the vascular territory; with age arteries dilate and become stiffer, more in elastic than in muscular arteries. The effect of age on large artery wall properties also depends on gender; the increase in diameter of muscular arteries is more pronounced in women. In contrast to the well-known decrease in arterial compliance of elastic arteries with age, brachial artery compliance is not decreased with age and even increased in women.

The relation between menopause and large artery properties was investigated in a group of pre- and postmenopausal women and compared with men (chapter 5). Menopause per se was positively related to aortic stiffness. This may contribute to the rise in pulse pressure in women beyond age 50. Menopause was not related to stiffness of the other arteries.

Associations between obesity and arterial wall properties depend on the index of obesity, gender and the vascular territory (chapter 6 ). The majority of assocations are found with body mass index (BMI). BMI-based obese subjects have a larger arterial diameter and stiffer arteries in both sexes. An android body habitus, i.e. an increased waist to hip ratio, does not appear to be of importance in women, but in men it is associated with a lower femoral artery distensibility and compliance. Skinfold thickness is negatively associated with brachial artery distensibility in women, whereas it does not appear to be of importance in men.

Altered arterial wall properties in BMI-based obese subjects can only in part be attributed to an increase in insulin resistance (chapter 7). The relation between insulin resistance and large artery wall properties is also gender-dependent. In women, insulin resistance is not related to any of the large artery wall properties. The relation between insulin resistance and 
large artery wall properties in men depends on the vascular territory: compliance of the femoral artery was most affected by insulin resistance. Alteration of large artery properties in subjects with insulin resistance is probably due to increased insulin levels.

Insulin-dependent diabetes mellitus affects wall properties of central arteries (aorta, common carotid artery and femoral artery), but not of the medium-sized brachial artery (chapter 8). Large artery wall properties differ between complicated and uncomplicated IDDM patients. Distensibility and/or compliance of the aorta and carotid artery are lower in complicated IDDM. Compliance of the carotid artery of uncomplicated IDDM patients is even increased, suggesting that in an early phase of the disease arterial compliance may increase. Part of these results could be explained by a longer duration of disease. Regulation of diabetes, expressed by $\mathrm{HbAlc}$, does not influence arterial wall properties.

In chapter 9 the main conclusions from the studies are discussed. An important finding from our studies is that the influence of physiologic and pathologic influences is dependent on gender and vascular territory. In addition arguments are given for the use of large artery wall properties as a marker of cardiovascular disease. In this chapter also suggestions for future research are given. 



\section{CHAPTER 11}

Samenvatting 
Compliantie en distensibiliteit zijn vaatwandeigenschappen van grote slagaders (arteriën). Arteriële compliantie bepaalt het bufferend vermogen van een arterie, d.w.z in welke mate de arterie het slagvolume van het hart kan opvangen en geleidelijk kan afgeven aan de perifere weefsels. Een verminderde compliantie leidt tot een toename in nabelasting van het hart en verhoogt het risico op hypertrofie van het hart. Arteriële distensibiliteit is een maat voor de elasticiteit van de vaatwand. Een locale afname van de distensibiliteit geeft een toename van de stress op de vaatwand en is geassocieerd met een verhoogd risico op vaatwandschade. Een vermindering van compliantie en distensibiliteit zijn geassocieerd met een verhoogd cardiovasculair risico.

In hoofdstuk 1 worden de definities van de vaatwandeigenschappen beschreven en factoren die deze vaatwandeigenschappen bepalen/beïnvloeden. In dit hoofdstuk wordt er ook een overzicht gegeven van de relaties tussen bekende cardiovasculaire risicofactoren en de vaatwandeigenschappen. Uit dit overzicht blijkt dat er voor de meeste risicofactoren discrepanties bestaan tussen de resultaten van de verschillende studies. Verklaringen hiervoor kunnen zijn: [1] verschillende onderzoeksmethoden, [2] kleine aantallen personen per studie, [3] heterogene groepen en [4] mogelijk bestaan er ook verschillen tussen de arteriën onderling.

In dit proefschrift wordt gekeken naar de relaties tussen cardiovasculaire risicofactoren en diameter, compliantie en distensibiliteit van respectievelijk de grote buikslagader (aorta), de halsslagader (arteria carotis), de liesslagader (arteria femoralis) en de armslagader (arteria brachialis) in een populatiestudie.

Hoofdstuk 2 beschrijft de opzet van het onderzoek, de methoden die gebruikt zijn voor de metingen en de opbouw van de populatie, die bestaat uit een groep van 497 mannen en vrouwen, in de leeftijd van 20-79 jaar.

Hoofdstuk 3 en 4 beschrijven de invloed van leeftijd en geslacht op de arteriële vaatwandeigenschappen. Er werd gecorrigeerd voor mogelijk beïnvloedende factoren, zoals gemiddelde bloeddruk, hartfrequentie, gewicht (body mass index), roken, alcoholgebruik en gebruik van bloeddrukverlagende middelen. Covariantie analyse liet zien, dat mannen in vergelijking met vrouwen een grotere diameter en compliantie hebben van alle bestudeerde arteriën. De distensibiliteit was gelijk, met uitzondering van de arteria brachialis, waarvan de distensibiliteit bij mannen lager is dan bij vrouwen. Het effect van leeftijd op de vaatwandeigenschappen is niet eenduidig, maar hangt af van de arterie; met de leeftijd dilateren arteriën en worden stijver, meer in elastische dan in musculaire arteriën. Het effect van de leeftijd hangt ook af van het geslacht; de toename in diameter van musuclaire arteriën is groter bij vrouwen dan bij mannen. In tegenstelling tot de bekende afname in arteriële compliantie van elastische arteriën met de leeftijd, neemt de compliantie van de arteria brachialis bij mannen niet af met de leeftijd en bij vrouwen zelfs toe.

De relatie tussen menopauze en vaatwandeigenschappen is onderzocht in een groep postmenopauzale vrouwen en vergeleken met een groep premenopauzale vrouwen en een groep mannen (chapter 5). Er was een positief verband tussen menopauze zelf en de stijfheid van de aorta. Dit zou (mede) een verklaring kunnen zijn voor de toename in polsdruk die gezien wordt bij vrouwen na de leeftijd van 50 jaar. Menopauze was niet gerelateerd aan de stijfheid van één van de andere arteriën.

Overgewicht, ofwel obesitas, kan op verschillende manieren gedefinieerd worden. o.a. d.m.v. de body mass index (BMI), huidplooidikte en taille-heup ratio. Het verband tussen obesitas en vaatwandeigenschappen is afhankelijk van de bepaling van de obesitas, het 
geslacht en de arterie die gemeten is (chapter 6). De meeste associaties worden gevonden met de body mass index. Mensen met overgewicht, gebaseerd op een te hoge BMI, hebben arteriën met een grotere diameter en een lagere distensibiliteit. Dit geldt zowel voor mannen als voor vrouwen. Een androïde (mannelijke) lichaamsbouw, dat wil zeggen een hoge taille-heup ratio, lijkt bij vrouwen niet van belang te zijn. Bij mannen is het geassocieerd met een lagere distensibiliteit en compliantie van de arteria femoralis. Bij vrouwen is er een negatief verband tussen huidplooidikte en distensibiliteit van de arteria brachialis, terwijl dit bij mannen niet van invloed lijkt.

Personen met een hoge BMI zijn vaak ook ongevoeliger voor insuline: insuline-resistent. De verandering in arteriële vaatwandeigenschappen bij personen met een hoge BMI kan slechts voor een deel verklaard worden door insuline-resistentie (chapter 7). De relatie tussen insuline-resistentie en vaatwandeigenschappen is geslachtsafhankelijk. Bij vrouwen is er geen relatie tussen insuline-resistentie en vaatwandeigenschappen, terwijl er bij mannen wel een relatie is. Deze relatie is echter 'arterie-afhankelijk': de compliantie van de arteria femoralis wordt het meest beïnvloed door insuline-resistentie. De verandering in vaatwandeigenschappen als gevolg van insuline-resistentie wordt waarschijnlijk bepaald door de hyperinsulinemie.

Insuline-afhankelijke diabetes mellitus (IDDM) heeft een invloed op de centrale arteriën (aorta, arteria carotis, arteria femoralis), maar niet op de middelgrote arteria brachialis (chapter 8). Er bestaat een verschil in vaatwandeigenschappen tussen IDDM-patiënten met en zonder complicaties. Distensibiliteit en/of compliantie van de aorta en arteria carotis zijn lager bij IDDM patiënten met complicaties. De compliantie van de arteria carotis bij IDDM patienten zonder complicaties is juist toegenomen. Dit suggereert dat in een vroege fase van de ziekte arteriële compliantie kan toenemen. Een deel van deze resultaten kan verklaard worden door een langere ziekteduur bij patiënten met complicaties. De regulatie van de diabetes, weerspiegeld door een laag HbA1c, heeft geen invloed op de arteriële vaatwandeigenschappen.

In hoofdstuk 9 worden de belangrijkste conclusies uit dit proefschrift besproken. Een belangrijke conclusie is, dat de invloed van fysiologische en pathologische invloeden verschilt tussen mannen en vrouwen en ook tussen de verschillende arteriën. Daarnaast worden in dit hoofdstuk ook argumenten gegeven voor het gebruik van vaatwandeigenschappen als risicofactor voor of juist als uiting van cardiovasculaire ziekte. In dit hoofdstuk worden tenslotte ook suggesties gegeven voor vervolgonderzoek. 

Dankwoord 


\section{Dankwoord}

Promoveren doe je niet alleen. Het klinkt als een cliché, maar het is echt waar! Daarom wil ik een aantal mensen bedanken.

Allereerst wil ik de proefpersonen en patiënten bedanken: inwoners uit Hechtel-Eksel en Lommel en insuline-afhankelijke diabeten uit verschillende delen van Nederland, in totaal meer dan 750 personen. Zonder deze mensen, die vrijwillig 3 uur van hun tijd opofferden, was dit onderzoek niet mogelijk geweest.

Prof. dr. H. Struijker Boudier, mijn promotor. Beste Harry, jij was de stabiele factor op de achtergrond. In beginsel zouden het farmacologische studies worden, echter naarmate het proefschrift vorderde, werd het steeds meer epidemiologisch getint. Ondanks dit, bleef jij actief betrokken. Jouw suggesties waren altijd waardevol. Na een bespreking met jou, begon ik er zelf ook weer in te geloven.

Prof. dr. L. Van Bortel, mijn directe begeleider. Beste Luc, je bent begonnen als co-promotor en op de valreep mijn promotor geworden. Gefeliciteerd. Als iemand mij vraagt waarom het allemaal zo lang geduurd heeft, kan ik nu antwoorden dat ik gewacht heb totdat jij mijn promotor zou zijn. Ik wil je bedanken voor de mogelijkheden die jij mij hebt gegeven. Samen hebben wij, met en zonder apparatuur heel wat afgereisd. Je hebt vele werkzaamheden, toch vond jij nog altijd tijd, om mij, ook in de laatste (lange) fase, met raad en daad terzijde te staan.

Dr. J. Staessen, mijn co-promotor. Beste Jan, bedankt dat ik deel mocht uitmaken van het Pheecad team. Een groots opgezette studie, die al veel publicaties heeft opgeleverd en nog veel zal opleveren. Ons contact, vaak via brieven en fax (soms tot zeer laat in de avond), heb ik altijd plezierig en leerzaam gevonden. Ik ben verheugd dat jij mijn co-promotor wilt zijn.

De beginselen van het echoën werden mij bijgebracht door Mirian Kool (nu Starmans). Beste Mirian, je bent een echte duizendpoot. Onvermoeibaar. Wat mij vooral bijstaat, is dat jij er altijd was, hoe vroeg ik ook kwam of hoe laat ik ook wegging. Bedankt voor je steun, maar vooral ook voor de gezelligheid.

Voor ik met mijn metingen kon beginnen, moest ik eerst de techniek leren. Vele mensen zijn hiervoor proefpersoon geweest. Een speciaal woord van dank voor de mensen van de spoelkeuken en het magazijn.

Tijdens mijn metingen heb ik veel hulp gehad. Odette Bomans, Lieve Gijsbers en Alida Hermans ('OLA' is meer dan ijs alleen!) vormden het team in Lommel en Hechtel-Eksel. Jullie hulp was geweldig. Hele dagen hebben wij samen doorgebracht. Lief en leed gedeeld. Hierbij staat mij vooral de gezelligheid bij. Bestaat de 'Kruimel' nog? Dames bedankt!!!! Elk jaar op 21 juli denk ik speciaal aan jullie. Nu moet ik natuurlijk Sylvia Van Hulle ook niet vergeten, jullie stuwende kracht uit Leuven. Sylvia, ook jij bedankt voor alle hulp.

Een aantal studenten hebben mij tijdens mijn metingen geholpen: Floris Vanmolkot, Ingrid Praet en Richard IJzerman, bedankt voor jullie hulp.

Het onderzoek werd niet alleen verricht in België. De diabeten waren afkomstig van verschillende centra in Nederland: Dr. H. Fischer (IJssellandziekenhuis, Capelle a/d IJssel), Dr. J. Elte (Sint Franciscus Gasthuis, Rotterdam), Dr. R. Nikkels (Atrium Heerlen) en mijn zwager, Dr. P. Biemond (Sint Franciscus Ziekenhuis, Roosendaal) wil ik bedanken voor hun medewerking en gastvrijheid.

Tijdens de metingen ging ook weleens wat fout. Peter Brands en Jean Willigers van de 
afdeling Biofysica, jullie waren nooit te beroerd om te komen helpen, ook al was het in Lommel of Heerlen. Bedankt. Prof. Dr. A. Hoeks, Beste Arnold, soms had ik het idee, dat wij een verschillende taal spraken. Toch was jij altijd bereid technische principes uit te leggen en mee te denken bij problemen. Hiervoor mijn dank.

Een van de problemen betrof de calibratie van de polsdruk. Mede dankzij de metingen in Heerlen, die mogelijk waren door de gastvrijheid van Dr. J. Kragten en de metingen door mijn 'opvolgster' Liesje Balkestein, hebben wij hiervoor een oplossing gevonden. Bedankt voor jullie hulp.

Bart van Baelen, de statistiek is jouw verdienste. Toen ik door de bomen het bos niet meer zag, heb jij mij weer op het goede pad gebracht. Bedankt.

Op de afdeling Farmacologie heb ik een plezierige tijd gehad. Ook al was ik veel uithuizig, ik heb me altijd thuis gevoeld. De 'dinerclub' en de 'zwemclub' hebben mijn verblijf in het zuiden zeer aangenaam gemaakt.

De leden van de beoordelingscommissie; Prof. dr. J. van Ree, Prof. dr. K. Leunissen, Prof. dr. R. Reneman en Dr. C. Stehouwer wil ik danken voor hun kritische beoordeling van het manuscript en de waardevolle suggesties. The willingness of Prof. dr. M. Safar to review the manuscript is greatfully acknowledged.

Mijn ouders wil ik bedanken voor de mogelijkheden die zij mij gaven. Welke keuze ik ook makte, zij hebben mij altijd gesteund.

Tot slot de 2 belangrijkste mensen in mijn leven: Harry en Floris. Lieve Floris, gelukkig snap jij er nog niet veel van. Ik weet tenminste niet hoe ik had moeten uitleggen dat het schrijven van dit 'boekje' belangrijker was dan het bouwen van torens samen met jou.

Harry, grote lieverd van mij. Zolang je mij kent, ben ik bezig met mijn onderzoek. Zonder jouw steun en optimisme was dit nooit afgekomen. Eindelijk is het dan zover !! 

Curriculum Vitae 



\title{
Curriculum Vitae
}

Janneke van der Heijden-Spek

\author{
21-07-1967 geboren te Schoonhoven \\ 1979-1985 ongedeeld VWO, RSG "De Drie Waarden", Schoonhoven \\ 1985-1992 studie geneeskunde, Erasmus Universiteit, Rotterdam \\ 1989 doctoraal examen (cum laude) \\ 1992 artsexamen \\ 1992-1996 assistent in opleiding, vakgroep Farmacologie, divisie Klinische \\ Farmacologie, Universiteit Maastricht \\ 1996-1998 assistent geneeskundige in opleiding tot internist, Atrium ziekenhuis, Heerlen \\ 1998-heden huisarts in opleiding, Huisartsenopleiding, Universiteit Maastricht
}



Publications 


\section{List of publications}

\section{Full papers}

Kool MJF, Spek JJ, Struijker Boudier HAJ, Hoeks APG, Reneman RS, van Herwaarden RS, Van Bortel LMAB. Acute and subacute effects of nicorandil and isosorbide dinitrate (ISDN) on vessel wall properties of large arteries and hemodynamics in healthy volunteers. Cardiovasc Drugs Ther, 9, 331-337, 1995

Molijn GJ, Spek JJ, van Uffelen C, de Jong FH, Brinkman AO, Bruining HA, Lamberts SWJ, Koper JW. Differential adaptation of glucocorticoid sensitivity of peripheral mononuclear leucocytes in patients with sepsis or septic shock. J Clin Endocrinol Metab, 80 (6), 1799-1803, 1995

Van Bortel LMAB, Kool MJF, Spek JJ. Disparate effects of antihypertensive drugs on large artery distensibility and compliance in hypertension. Am J Cardiol, 76, 46E-49E, 1995

Spek JJ, Hoeks APG, Struijker Boudier HAJ, Van Bortel LMAB. Differences in vessel wall properties of large arteries between obese and lean subjects. Nieren und Hochdruckkrankheiten, 24, 431-432, 1995

Luik, AJ, Spek JJ, Charra B, Van Bortel LMAB, Laurent G, Leunissen, KML. Arterial compliance in patients on long-treatment-time dialysis. Nephrol Dial Transplant, 12, 2629-2632, 1997

Luik AJ, van Kuijk WHM, Spek J, de Heer F, Van Bortel LMAB, Schiffers PHM, Leunissen, KML. The effects of hypervolemia on inter-dialytic hemodynamics and blood pressure control in hemodialysis patients. Am J Kidney Dis, 30, 466-474, 1997

Van Bortel LM, Spek JJ. Influence of aging on arterial compliance. J Hum Hypertens, 12, 583-586, 1998

van Ittersum FJ, Spek JJ, Praet IJ, Lambert J, IJzerman RG, Fischer HR, Nikkels RE, Van Bortel LM. Donker $\mathrm{AJ}$, Stehouwer CD, Ambulatory blood pressures and autonomic nervous function in normoalbuminuric type I diabetic patients. Nephrol Dial Transplant, 13(2): 326-32, 1998

Van Bortel LM, Spek JJ, Balkestein LM, Sardina A, Struijker Boudier HA. Is it possible to develop drugs that act more selectively on large arteries? J Hypertens, 17, 701-705, 1999

van der Heijden-Spek JJ, Staessen JA, Fagard RH, Hoeks APG, Struijker Boudier HAJ, Van Bortel LMAB. Effect of age on brachial artery wall properties differs from the aorta and is gender- dependent. A population study. Hypertens, 35, 637-642, 2000

Staessen JA, van der Heijden-Spek JJ, Safar ME, Den Hond E, Gasowski J, Fagard RH, Struijker Boudier HAJ, Van Bortel LMAB, Menopause and the characteristics of the large arteries in a population study. submitted

van der Heijden-Spek JJ, Staessen JA, Fagard RH, Hoeks APG, Struijker Boudier HAJ, Van Bortel LMAB. Disparate effects of age and gender on the wall properties of elastic and muscular large arteries: a population study. submitted

Van Bortel LM, Vanmolkot FH, van der Heijden-Spek JJ, Bregu M, Staessen JA, Hoeks AP. Common carotid artery intima-media thickness: comparison of two different ultrasound-techniques. submitted

Van Bortel LM, Balkestein EJ, van der Heijden-Spek JJ, Vanmolkot FH, Staessen JA, Kragten JA, Vredeveld JW, Safar ME, Struijker Boudier HA, Hoeks AP. Non-invasive assessment of local arterial pulse pressure, comparison of applanation tonometry and echo-tracking. submitted

van der Heijden-Spek JJ, Staessen JA, Fagard RH, Struijker Boudier HAJ, Van Bortel LMAB. Obesity, fat distribution and vessel wall properties. in preparation 
van der Heijden-Spek JJ, Staessen JA, Fagard RH, Struijker Boudier HAJ, Van Bortel LMAB. Relation between insulin resistance and large artery properties. in preparation

van der Heijden-Spek JJ, van Ittersum FJ, Stehouwer CDA, Nieuwenhuijzen Kruseman AC, Biemond P, Elte JWF, Fischer HRA, Struijker Boudier HAJ, Van Bortel LMAB. The effect of insulin-dependent diabetes mellitus on large artery wall properties. in preparation

\begin{abstract}
s
Spek JJ, Hoeks APG, Struijker Boudier HAJ, Van Bortel LMAB. Subacute effects of Nicorandil and ISDN on vessel wall properties of large arteries and cardiac function. Pharmac Wkbl Sci Ed, 15 (suppl L), L5, 1993

Spek JJ, Hoeks APG, Struijker Boudier HAJ, Van Bortel LMAB. Differences in vessel wall properties of large arteries in obese and lean subjects. J Hypertens, vol 12 (suppl 3), S210, 1994
\end{abstract}

Spek JJ, Hoeks APG, Struijker Boudier HAJ, Van Bortel LMAB. Differences in vessel wall properties of large arteries in obese and lean subjects. Neth J Med, 44, A85, 1994

Spek JJ, Kool MJF, Hoeks APG, Struijker Boudier HAJ, van Herwaarden RS, Van Bortel LMAB. Subacute effects of nicorandil and ISDN on hemodynamics and large artery properties. Neth J Med, 44, A85, 1994

Spek JJ, Hoeks APG, Struijker Boudier HAJ, Van Bortel LMAB. Differences in vessel wall properties of large arteries between obese and lean subjects. Abstracts of Joint Meeting of the German and the Dutch Hypertension Society, november, P 106, 1994

Spek JJ, Staessen JA, Hoeks APG, Struijker Boudier HAJ, Van Bortel LMAB. The effect of obesity on large artery properties is gender-dependent. Abstractbook of second Workshop "Structure and function of large arteries", Paris, january 20-21, 1995

Spek JJ, Staessen JA, Hoeks APG, Struijker Boudier HAJ, Van Bortel LMAB. Disparate effects of ageing on wall properties of different large arteries. Abstracts of the seventh European Meeting on Hypertension, Milan, Italy, 9-12 june, 1995, pp 181 A795

Spek JJ, Staessen JA, Hoeks APG, Struijker Boudier HAJ, Van Bortel LMAB. Influence of insulin resistance on large artery properties. Abstracts of the seventh European Meeting on Hypertension, Milan, Italy, 9-12 june, 1995, pp 181 A796

Spek JJ, Staessen JA, Hoeks APG, Struijker Boudier HAJ, Van Bortel LMAB. The effect of ageing on wall properties is artery dependent. Eur Heart J, 1995, 16 (Abstract suppl), P493.

Spek JJ, Staessen JA, Hoeks APG, Struijker Boudier HAJ, Van Bortel LMAB. Large artery properties differ between dippers and non-dippers. Eur Heart J, 1995, 16 (Abstract suppl), P1986

Spek JJ, Staessen JA, Hoeks APG, Struijker Boudier HAJ, Van Bortel LMAB. Insulin-resistant subjects have stiffer femoral arteries. Eur Heart J, 1995, 16 (Abstract suppl), P852

Spek JJ, Staessen JA, Hoeks APG, Struijker Boudier HAJ, Van Bortel LMAB. Effects of ageing on wall properties of different large arteries. Neth J Med, 48, A95, 1996

Spek JJ, Staessen JA, Hoeks APG, Struijker Boudier HAJ, Van Bortel LMAB. Influence of insulin resistance on vessel wall properties of large arteries. Neth J Med, 48, A96, 1996

Spek JJ, Staessen JA, Hoeks APG, Struijker Boudier HAJ, Van Bortel LMAB. Effect of ageing on intimamedia thickness of the common carotid artery in men and women. J Hypertens, vol 14 (suppl 1), S103, 1996 
Spek JJ, Staessen JA, Hoeks APG, Struijker Boudier HAJ, Van Bortel LMAB. Is insulin resistance associated with intima-media thickness of the common carotid artery?, J Hypertens, vol 14 (suppl 1), S183, 1996

Spek JJ, Staessen JA, Hoeks APG, Struijker Boudier HAJ, Van Bortel LMAB. Does ageing affect intima-media thickness of the common carotid artery in men and women. Eur Heart J, 17 (Abstract suppl), P2346, 1996

Spek JJ, Staessen JA, Hoeks APG, Struijker Boudier HAJ, Van Bortel LMAB. The effects of age on large artery wall properties differ between men and women. Neth J Med, 50, A33, 1997

Spek JJ, Staessen JA, Hoeks APG, Struijker Boudier HAJ, Van Bortel LMAB. The effect of age on large artery wall properties is gender-dependent. J Hypertens, vol 15 (suppl 4), S44, 1997

van der Heijden-Spek JJ, Staessen JA, Hoeks APG, Struijker Boudier HAJ, Van Bortel LMAB. Obesity is a more important determinant of large artery stiffness than insulin resistance. J. Hypertens, vol 16 (suppl 2), S19, 1998

van der Heijden-Spek JJ, Staessen JA, Hoeks APG, Struijker Boudier HAJ, Van Bortel LMAB. Effect of age and duration of insulin-dependent diabetes on arterial elasticity of different vascular territories. J Hypertens, vol 16 (suppl 2), S163, 1998

van der Heijden-Spek JJ, Staessen JA, Hoeks APG, Struijker Boudier HAJ, Van Bortel LMAB. The effects of stimulants on large artery wall properties. J Hypertens, vol 17 (suppl 3), S82, 1999 



